\title{
REVISION AND PHYLOGENY OF THE FERN-INHABITING GENUS FELISACUS DISTANT (INSECTA: HETEROPTERA: MIRIDAE: BRYOCORINAE)
}

\author{
ANNA A. NAMYATOVA \\ AND GERASIMOS CASSIS
}

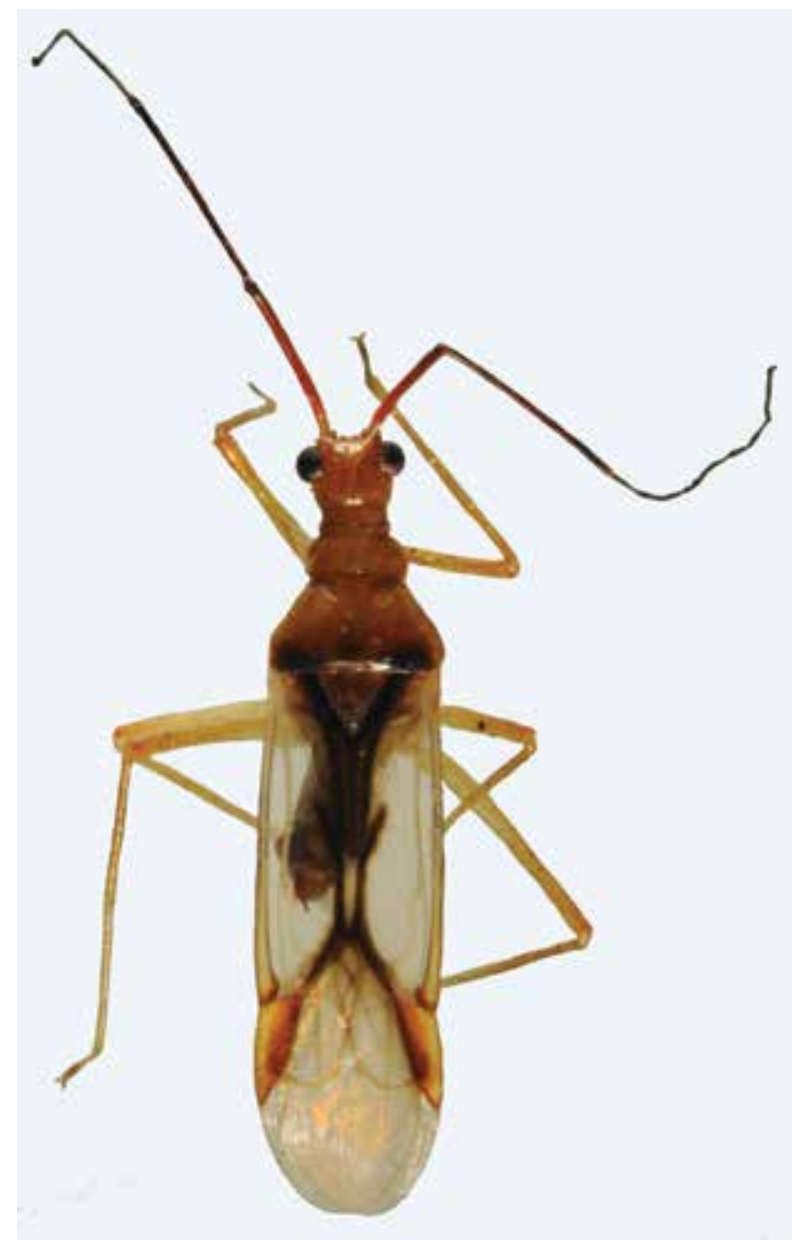

BULLETIN OF THE AMERICAN MUSEUM OF NATURAL HISTORY 


\title{
REVISION AND PHYLOGENY OF THE FERN-INHABITING GENUS FELISACUS DISTANT (INSECTA: HETEROPTERA: MIRIDAE: BRYOCORINAE)
}

\author{
ANNA A. NAMYATOVA AND GERASIMOS CASSIS \\ Evolution and Ecology Research Centre, \\ School of Biological, Earth and Environmental Sciences, \\ University of New South Wales
}

BULLETIN OF THE AMERICAN MUSEUM OF NATURAL HISTORY

Number 403, 168 pp., 22 figures, 1 table

Issued June 22, 2016 


\section{CONTENTS}

Abstract. ..................................................

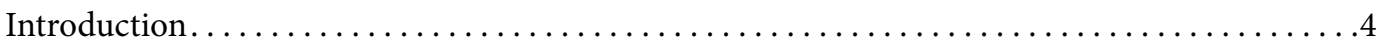

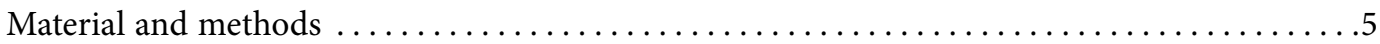

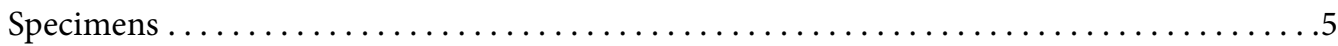

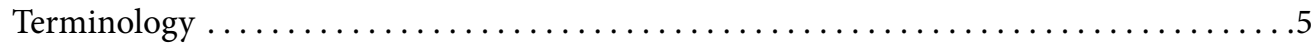

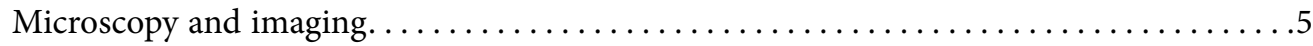

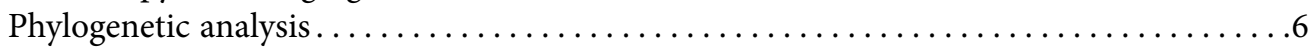

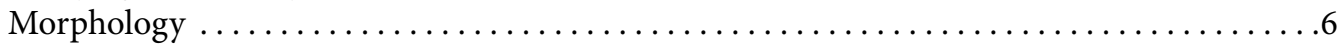

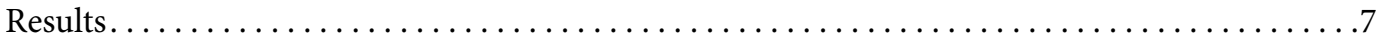

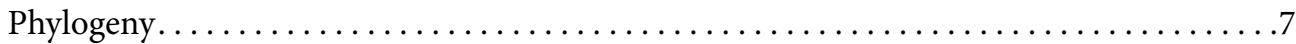

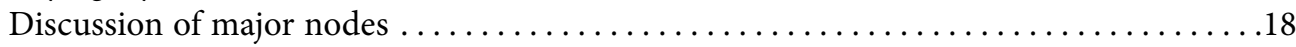

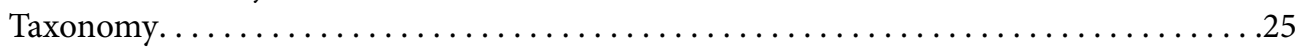

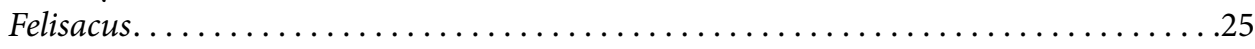

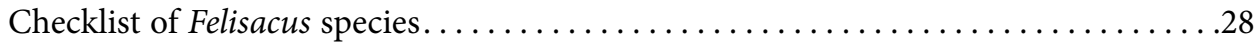

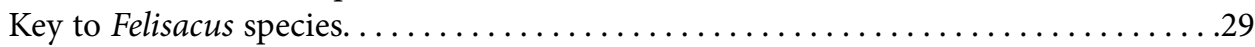

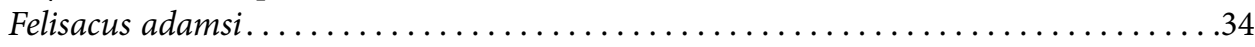

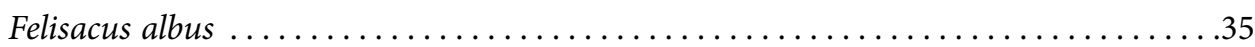

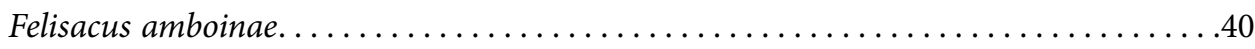

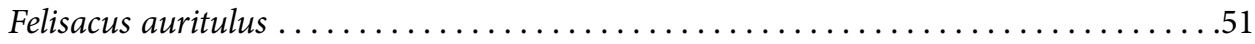

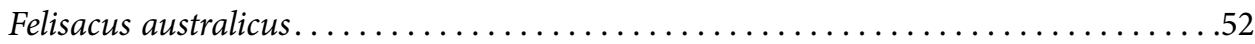

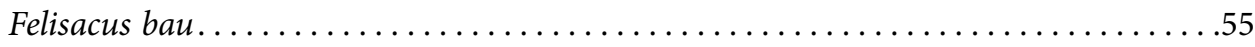

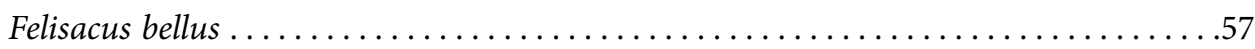

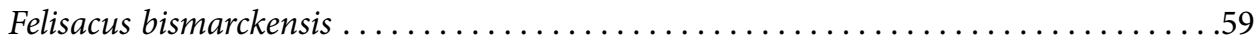

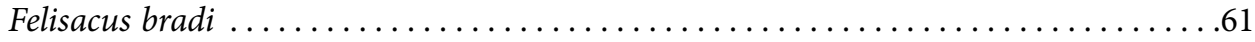

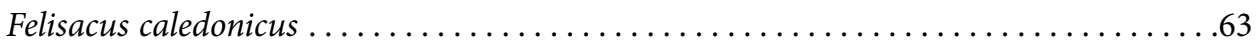

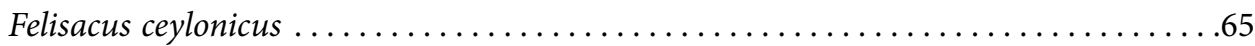

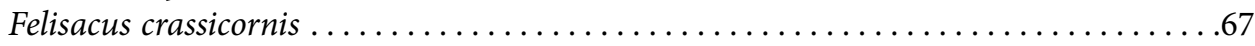

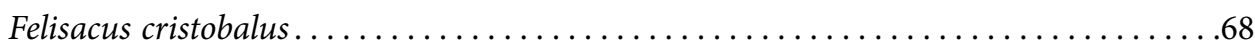

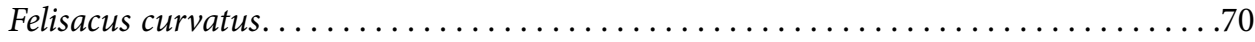

Felisacus dauloi............................................

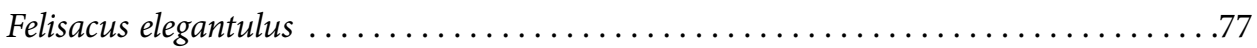

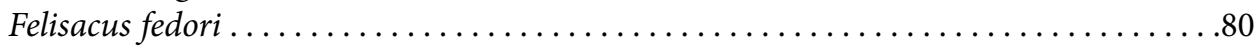

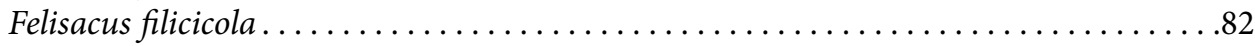

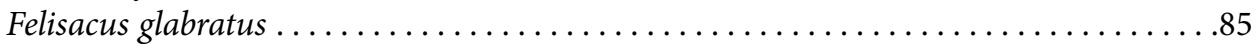

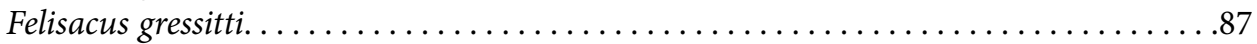

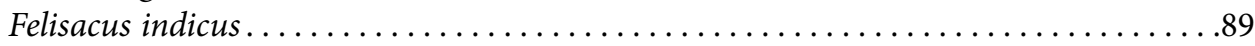

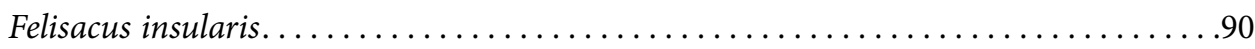

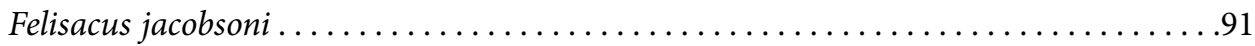

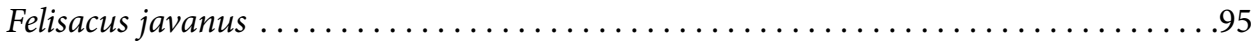

Felisacus lambkinae . . . . . . . . . . . . . . . . . . . . . . . . . . . . 98

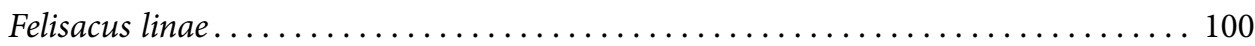

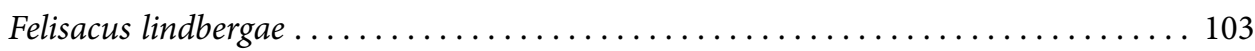

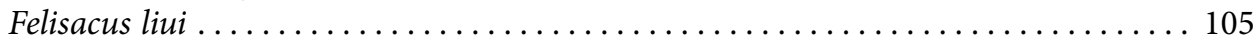

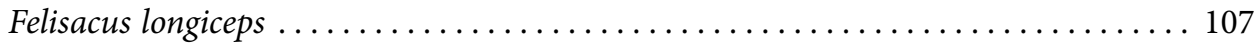




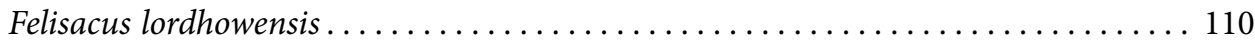

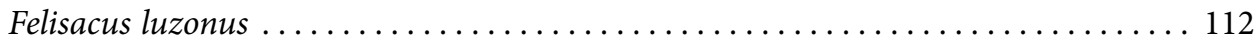

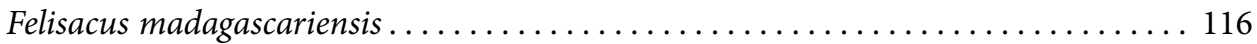

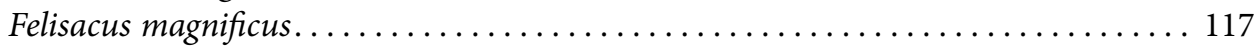

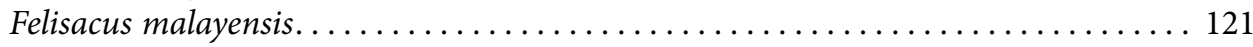

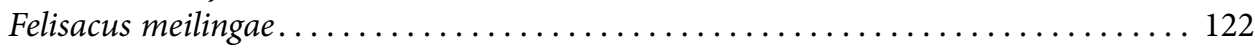

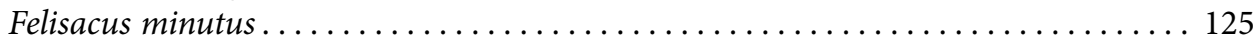

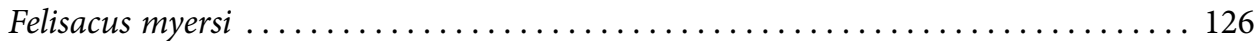

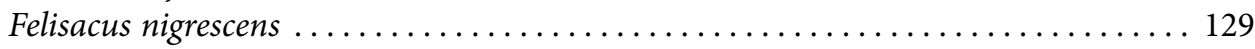

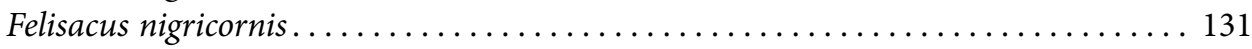

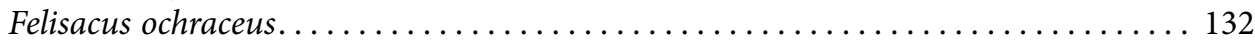

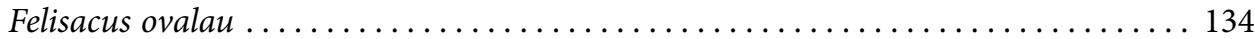

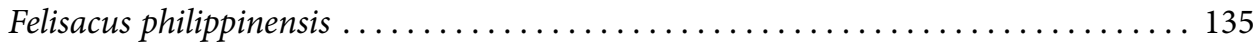

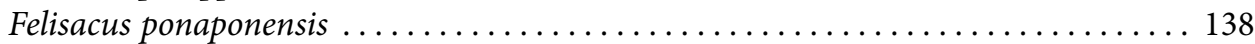

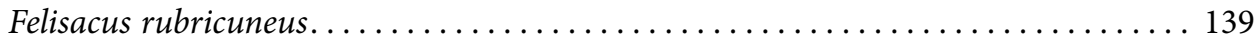

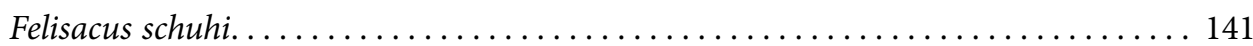

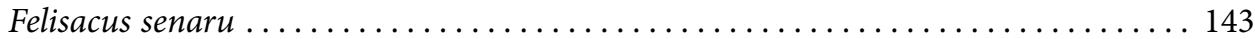

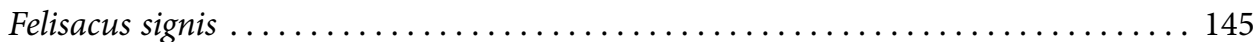

Felisacus solomonicus. ...................................... 146

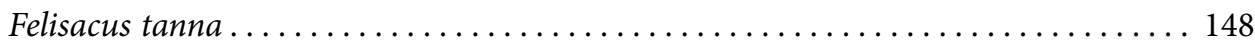

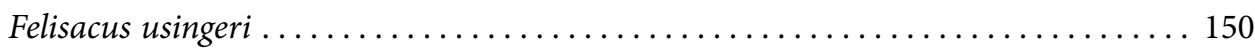

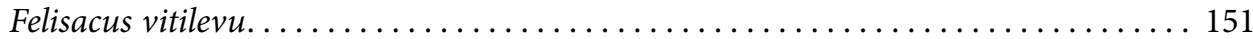

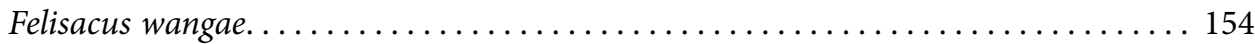

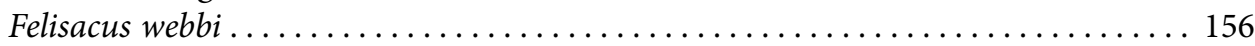

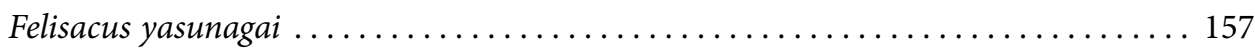

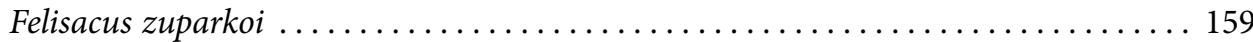

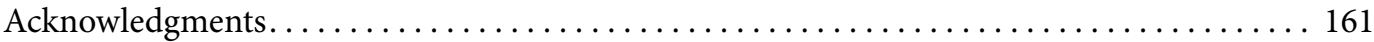

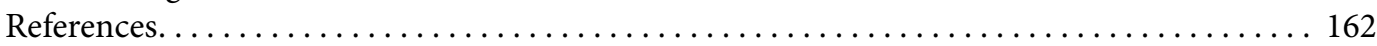

Appendix 1: Characters and character states used in the phylogenetic analysis ....... 165

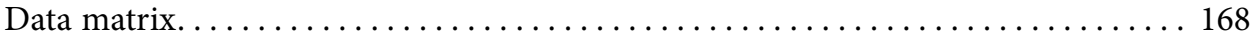




\begin{abstract}
The fern-feeding genus Felisacus (Miridae: Bryocoronae) was revised. The genus contains 55 species, 29 are new to science, they are: Felisacus albus, F. australicus, F. bau, F. bismarckiensis, F. bradi, F. caledonicus, F. ceylonicus, F. cristobalus, F. fedori, F. indicus, F. lamkinae, F. linae, F. lindbergae, F. liui, F. lordhowensis, F. luzonus, F. malayensis, F. meilingae, F. myersi, F. ovalau, F. schuhi, F. senaru, F. solomonicus, F. tanna, F. vitilevu, F. wangae, F. webbi, F. yasunagai, F. zuparkoi. Felisacus capitatus is synonymized with F. magnificus; F. okinawanus is synonimized with $F$. longiceps $F$. carpenterae is synonymized with $F$. javanus. Felisacus jacobsoni, previously synonymized with $F$. javanus, is treated as a separated species. The status of $F$. signis, described as a subspecies of $F$. carpenterae, is raised to a separate species. Genus Felisacoris is synonymized with Felisacus. The diagnosis and key are provided for all species and descriptions are provided for the species, where the specimens were available. The drawings of male genitalia are provided where available, and drawings of female genitalia are given for some species. Phylogenetic analysis with inclusion of most of the species has been performed and discussed.
\end{abstract}

KeYwords: systematics, taxonomy, species, description, diagnosis, key, fern-feeding

\section{INTRODUCTION}

Felisacus Distant, 1904, belongs to the hyperdiverse family Miridae (Insecta: Heteroptera), and is comprised of more than 11,000 species (Cassis and Schuh, 2012). The genus belongs to the morphologically heterogeneous subfamily Bryocorinae, for which we recently erected a new tribe-the Felisacini (Namyatova et al., 2016; Namyatova and Cassis, 2016). Felisacus has an Indo-Pacific distribution (Schuh and Stonedahl, 1986), a pattern that is repeated for other mirid genera, including Helopeltis Signoret, 1858 (Stonedahl, 1991), Coridromius Signoret, 1862 (Tatarnic and Cassis, 2010), Ragwelellus Odhiambo, 1962 (Namyatova and Cassis, 2016), Peritropis Uhler, 1891 (Gorcyza, 2000; Moulds and Cassis, 2006) and Pseudoloxops Kirkaldy, 1905 (Schuh, 1995; Schuh, 2002-2013).

Felisacus is noteworthy because of its associations with ferns, which is atypical for insects (e.g., Weintraub et al., 1995; Jensen and Holman, 2000; Konstantinov and Knyshov, 2015; Schneider, 2016). Within the Miridae, fernassociated taxa include Felisacus, species of the tribe Bryocorini (Konstantinov and Knyshov, 2015) and a single Macrolophus Fieber, 1858, species which belongs to the tribe Dicyphini (Wheeler et al., 1979).
Motschulsky (1863) described Liocoris Motschulsky, 1863, for a single species, L. glabratus (Motschulsky, 1863), in the suprageneric division Capsides (= Miridae). Liocoris was preoccupied and Distant (1904) gave Felisacus as a replacement name and transferred it to the family Capsidae, subfamily Mirinae, division Cylaparia. Reuter (1904) described Hyaloscytus Reuter, 1904, which was synonymized with Felisacus by Poppius (1911). Prior to this work the genus comprised 26 species. Woodward $(1954,1958)$ treated a majority of Felisacus species and recognized two informal species groups: "magnificus group" and "elegantulus group," based on external morphology and the shape of the parameres.

Other works of significance, inlcude Carvalho's $(1956,1981)$ treatment of the Micronesian and Papua New Guinean species; $\mathrm{Hu}$ and Zheng (2001), Lin (2000), Miyamoto (1965), and Usinger (1946) described new species from China, Taiwan, Japan, and Guam respectively; and Hsiao (1944) described new species based on material housed in the United States National Museum.

The aim of this paper is to provide a detailed diagnosis and redescription of the genus and its included species, redescription of numerous new species, as well as determining the phylogenetic relationships of the species. 


\section{METHODS AND MATERIALS}

\section{SPECIMENS}

Around 800 specimens were examined for the present study and were borrowed from the following collections:

AM Australian Museum (Sydney, Australia)

AMNH American Museum of Natural History (New York)

ANIC Australian National Insect Collection (Canberra, Australia)

BMNH Natural History Museum (London, UK)

BPBM Bernice P. Bishop Museum (Honolulu)

CAS California Academy of Sciences (San Francisco)

HNHM Hungarian Natural History Museum

IOZ Institute of Zoology, Chinese Academy of Sciences (Beijing, China)

ISNB Royal Institute of Natural Science of Belgium (Brussels, Belgium)

MNHN National Museum of Natural History (Paris, France)

MVMA Museum of Victoria (Melbourne, Australia)

MZH Finish Museum of Natural History (Helsinki, Finland)

NHRS Naturhistorika riksmuseet (Stockholm, Sweden)

NKMU Nankai University Insect Collection (Tianjin, China)

NML Nationaal Natuurhistorische Museum (Leiden, the Netherlands)

NMNS National Museum of Natural Science (Taichung, Taiwan)

NTM Northern Territory Museum (Darwin, Australia)

QM Queensland Museum (Brisbane, Australia)

SAMA South Australian Museum (Adelaide, Australia)

TAMU Texas A\&M University (College Station, Texas)

TYCN Tomohide Yasunaga personal collection (Nagasaki, Japan)
UNSW University of New South Wales (Sydney, Australia)

UCB University of California, Berkeley

USNM United Stated National Museum, Smithsonian Institution (Washington, D.C.)

WAMP Western Australian Museum (Perth, Australia)

ZISP Zoological Institute, Russian Academy of Sciences (St. Petersburg, Russia)

A unique specimen identifier (USI) with a matrix code was attached to each specimen. Those codes have a AMNH_PBI prefix, unless otherwise stated. All collection-event data and host-plant information were entered in the Plant Bug Planetary Biodiversity Inventory Locality Database (https://research.amnh.org/pbi/locality/), and these data are also served on the Discover Life website (http://www.discoverlife.org/) and Heteroptera Species Pages (http://research. amnh.org/pbi/heteropteraspeciespage/).

MAPs: Coordinates were mapped using ArcGIS (https://www.arcgis.com/features/), using the ESRI World Physical Map as a background.

Terminology: Terminology of male genitalia follows Kerzhner and Konstantinov (1999) (see fig. 10B, $\mathrm{C}$ for structures' names) with aedeagus divided into conjunctiva and vesica (= endosoma of Cassis, 2008). The terminology of female genitalia follows Davis (1955) and Schwartz (2011).

MicRosCOPY AND IMAGING: Genitalia were dissected using Leica MZ 16 microscope in the University of New South Wales and Nikon SMZ 1500 microscope in the Saint Petersburg State University. Most dorsal habitus images were taken at the University of New South Wales using a Visionary Digital BK Plus Lab photographic system (www. visionarydigital.com) with a Canon EOS 40D camera. Images of type specimens of Felisacus auritulus Distant, 1913, were taken in Sackler's Biodiversity Imaging Lab at the Natural History Museum, London, using a Canon 450D camera attached to a Leica MZ 9.5 stereomicroscope. Images of the specimens of F. adamsi Carvalho, 1956, Felisacus fedori, sp. nov., F. senaru, sp. nov., F. carpenterae Hsiao, 1944, F. ponaponensis Carvalho, 1956, F. rubricuneus Carvalho, 1956, F. signis Hsiao, 1944, and F. 
webbi, sp. nov., and male of F. jacobsoni Poppius, 1914, were made in the Department of Entomology, Saint Petersburg State University using Nikon D700 SLR digital camera attached to Nikon SMZ 1500 stereomicroscope. Multiple images of all specimens were merged using Helicon Focus software (http://www.heliconsoft.com). All images were processed using Adobe Photoshop CS3 extended and CS5.1 extended software.

MeAsurements: Measurements are shown in table 1 and include the following: body length, clypeus to cuneus length, length of antennal segments I and II, head width, vertex width, pronotum length and width. Measurements were mostly taken using a digital micrometer and recorded with Winwedge software (www.winwedge.com).

All scalebars are $0.1 \mathrm{~mm}$ in length, unless otherwise stated.

Phylogenetic analysis: The character matrix was created in Mesquite software (Maddison and Maddison, 2010), and includes 72 characters of external and genitalic morphology (see SI 1 for matrix). Characters and character states are listed in appendix 1. More than half of the characters coded pertain to the male genitalia (appendix 1).

All analyses were run using TNT (http://www. cladistics.com/aboutTNT.html) (Goloboff et al., 2000, 2008) and NONA (http://www.cladistics. com/aboutNona.htm) (Goloboff, 1993) implemented through Winclada (http://www.cladistics.com/wincDownload.htm) (Nixon, 1999) software, with parsimony as the optimally criterion. For the analyses in TNT, we employed traditional searches with 10000 replications and 10 trees saved per replications. All characters were treated as unweighted and unordered. Searches were also undertaken using implied weights with $\mathrm{K}=3-20$. All unsupported nodes were collapsed after each analysis.

Bremer support values (Bremer, 1994) were calculated using the Bremer script in TNT. Bootstrap resampling (Felsenstein, 1985) based on unweighted trees was performed as implemented in Winclada with 10,000 replications.
Forty-eight species of Felisacus were analyzed. We did not include F. nigricornis Poppius, 1912 , as specimens were unavailable for study. We also excluded F. adamsi, F. auritulus Distant, 1913, F. crassicornis Usinger, 1946, F. gressitti Miyamoto, 1965, F. madagascariensis Poppius, 1912, and F. usingeri Woodward, 1954, because males were unavailable.

Four outgroup taxa included two Bryocorinae species: Pachypeltis reuteri (Stål, 1871) and Nesidiocoris tenuis (Reuter, 1895). The trees were rooted with Stenotus binotatus (Fabricius, 1794) (Mirinae).

\section{MORPHOLOGY}

Species of Felisacus all have very similar morphology. There are only a few external characters that have diagnostic and phylogenetic value, including: shape of head from dorsal view; shape and relative length of antennal segment I; length of labium, length and shape of labial segments I-III; shape of cuneus; and coloration of antennal segments I-II, pronotum, hemelytron, and femora (see generic description for the details).

The female genitalia are diagnostic for major groups of species, but are more or less uniform within these groups. In one group, the dorsal labiate plate is very small and transparent, which rendered it of limited diagnostic and phylogenetic value.

The key characters within the genus are those of the male genitalia, particularly the aedeagus and parameres. These characters are variable at the subclade level and between closely related species. The genital capsule is less variable and simple.

The right parameres were drawn mostly in the ventral view to demonstrate setal pattern, which is not visible in the dorsal view. We used descriptive terms for the right paramere, with the position of components referred to as basal, medial or apical, and outer and inner angles. All of these are shown on figure 11. The left paramere is illustrated in dorsal view.

Aedeagal characters were used extensively for species differentiation, and these included: 
shape of sclerite around secondary gonopore, sclerotization of conjunctiva and number and shape of vesical spicules. The vesica of species within clades 2 and 14 possesses spicules of different shape. Within clade 3, only F. zuparkoi, sp. nov., has a small claw-shaped spicule. Within clade 18, comprising 30 species, the spicules are usually distinct.

In some cases we homologized the spicules based on their position. Spicule A occurs in 21 species and is placed dorsally on the right-hand side; it is sinuate, curved dorsoventrally, and is usually broad basally and elongate. In F. filicicola and F. tanna, sp. nov., spicule A has the same position and shape, but is short (figs. 8I, 9M), whereas in F. meilingae, sp. nov., and F. myersi, sp. nov., it is straight (figs. 9B, C).

Spicule B occurs in 21 species and is placed ventrally on the right-hand side or medially, or dorsal with respect to other spicules; it is more or less C-shaped and usually broad medially. This spicule exhibits continuous variation in size in this group; from very short in F. amboinae (fig. $8 \mathrm{~B})$ to very long in F. australicus, sp. nov., and $F$. ochraceus Usinger, 1946 (figs. 8C, 9F). In F. filicicola (Kirkaldy, 1908), F. jacobsoni Poppius, 1914, and F. signis Hsiao, 1944, spicule B is not broad medially (figs. 8M, 9K).

Spicule $\mathrm{C}$ is present in 12 species and is placed on the left dorsal position, and is sinuate or broad medially, and is usually dorsoventrally curved basally.

Spicule D is small, basal, and dorsal in orientation. Spicule I is elongate, broad basally and placed on the right-hand side, and more proximal to the middle. These spicules are found only in F. meilingae and F. myersi (fig. 9B, C).

Spicule E is placed dorsally on the right-hand side, sclerotized apically and membranous mediobasally. It occurs in F. filicicola, F. lordhowensis, sp. nov., and F. tanna (figs. 8I, R, 9M).

Spicule $\mathrm{F}$ is long, needle shaped, placed on the left-hand side, is ventral in position and can be obscured by other spicules in dorsal view. It occurs in F. albus, sp. nov., F. glabratus (Motschul- sky, 1863), F. indicus, sp. nov., and F. insularis Miyamoto, 1965 (fig. 8A, J, K, L).

The spicules placed on the left-hand side have a tendency to form a concavity apically. Their homologization is hampered, as those spicules vary in size and position, and in some cases there are two or more spicules with similar concavities within the same species (e.g., figs. 8K, M, 9D, K). However, we were able designate a spicule $\mathrm{H}$ in F. australicus and F. ochraceus (figs. 8C, 9F). This spicule is placed on the left-hand side adjacent to spicule $\mathrm{C}$, and has a distinct hook-shaped concavity apically, and is narrow and of moderate length. In addition, we delimit a spicule G, which is broad and long, has a distinct concavity apically, and is placed ventrally on the left-hand side (figs. 8E, G, 9B, C).

\section{RESULTS}

\section{Phylogeny}

The unweighted analysis in TNT produced 8750 equally parsimonious trees with 172 steps, $\mathrm{CI}=0.47$ and $\mathrm{RI}=0.83$. The implied weight analyses with $\mathrm{K}$ from 3 through 20 resulted in 70 $(\mathrm{K}=9,19)$ to $811(\mathrm{~K}=3)$ trees. In the current analysis, the consensus trees obtained from analyses with $\mathrm{K}=3-6$ are identical, and consensus trees with $\mathrm{K}=7-11$ are also identical and have better resolution. The analyses run with $\mathrm{K}=$ 16-20 were also stable, slightly differing in topology from the trees obtained with $\mathrm{K}=7-11$ at node 18 . We have chosen one of the most parsimonious trees obtained with the $\mathrm{K}=7$ for optimization of characters. There are alternative views on $\mathrm{K}$ value selected for optimization, with some authors finding more-resolved trees of greater trees with $\mathrm{K}>5$ results (Reinert et al., 2009; Harbach et al., 2012; Penz et al., 2013; Valdez-Mondragon, 2013, 2014; Namyatova et al., 2016). Trees with $K>10$ are very rarely chosen (e.g., Namyatova et al., 2016). Our results correspond with the "plateaus of stability" found in Reinert et al. (2009) and Harbach et al. (2012).

Bremer supports and bootstrap support values are given in figure 1. 
TABLE 1

Measurements of Felisacus spp.

\begin{tabular}{|c|c|c|c|c|c|c|c|c|c|}
\hline \multirow[b]{2}{*}{ Species } & & \multicolumn{5}{|c|}{ Length } & \multicolumn{3}{|c|}{ Width } \\
\hline & & Body & Cun-Clyp & Pronotum & AntSeg2 & AntSeg1 & Head & Pronotum & InterOcDi \\
\hline \multicolumn{10}{|l|}{ F. adamsi } \\
\hline \multirow[t]{2}{*}{ ธิ $(N=2)$} & $\mathrm{F} 1$ & 2.90 & 2.38 & 0.63 & 0.90 & 0.85 & 0.48 & 0.75 & 0.25 \\
\hline & $\mathrm{F} 2$ & 3.10 & 2.33 & 0.65 & 0.90 & 0.78 & 0.48 & 0.78 & 0.25 \\
\hline \multicolumn{10}{|l|}{ F. albus } \\
\hline \multirow[t]{2}{*}{$\widehat{\delta}(N=2)$} & M1 & 3.72 & 2.55 & 0.71 & 1.02 & 0.83 & 0.58 & 0.87 & 0.24 \\
\hline & M2 & 4.25 & 2.87 & 0.75 & 1.15 & 0.88 & 0.61 & 1.02 & 0.26 \\
\hline ㅇ $(N=1)$ & $\mathrm{F} 1$ & 3.81 & 2.70 & 0.74 & 1.02 & 0.73 & 0.59 & 1.03 & 0.28 \\
\hline \multicolumn{10}{|l|}{ F. amboinae } \\
\hline \multirow[t]{2}{*}{$\widehat{\delta}(N=2)$} & M1 & 3.00 & 2.63 & 0.63 & 0.96 & 0.80 & 0.48 & 0.74 & 0.22 \\
\hline & M2 & 3.34 & 2.61 & 0.66 & 1.09 & 0.90 & 0.55 & 0.76 & 0.24 \\
\hline \multirow{4}{*}{ ㅇ $(N=4)$} & $\mathrm{F} 1$ & 3.43 & 2.91 & 0.70 & 1.07 & 0.83 & 0.52 & 0.76 & 0.24 \\
\hline & $\mathrm{F} 2$ & 3.30 & 2.76 & 0.67 & - & - & 0.50 & 0.78 & 0.22 \\
\hline & F3 & 3.26 & 2.87 & 0.67 & 1.04 & 0.85 & 0.48 & 0.78 & 0.22 \\
\hline & $\mathrm{F} 4$ & 3.26 & 2.83 & 0.70 & 0.96 & 0.85 & 0.50 & 0.76 & 0.24 \\
\hline \multicolumn{10}{|l|}{ F. auritulus } \\
\hline Sex unknown $(N=5)$ & SU1 & 3.96 & - & 0.8 & 0.88 & 0.56 & 0.44 & 1.0 & 0.28 \\
\hline \multicolumn{10}{|l|}{ F. australicus } \\
\hline \multirow[t]{2}{*}{$\delta(N=2)$} & M1 & 3.91 & 2.79 & 0.76 & 1.19 & 1.00 & 0.61 & 0.92 & 0.27 \\
\hline & M2 & 4.20 & 2.94 & 0.77 & 1.21 & 0.95 & 0.63 & 1.01 & 0.27 \\
\hline 우 $(N=1)$ & $\mathrm{F} 1$ & 4.42 & 3.14 & 0.84 & 1.49 & 0.97 & 0.68 & 1.02 & 0.27 \\
\hline \multicolumn{10}{|l|}{ F. bau } \\
\hline$\widehat{\partial}(N=1)$ & M1 & 3.47 & 2.71 & 0.67 & - & 0.93 & 0.54 & 0.83 & 0.25 \\
\hline 우 $(N=1)$ & $\mathrm{F} 1$ & 3.75 & 2.77 & 0.66 & 1.11 & 0.93 & 0.52 & 0.81 & 0.25 \\
\hline \multicolumn{10}{|l|}{ F. bellus } \\
\hline \multirow[t]{2}{*}{$\delta(N=2)$} & M1 & 4.45 & 3.12 & 0.81 & 1.33 & 0.95 & 0.63 & 1.02 & 0.28 \\
\hline & M2 & 3.74 & 2.68 & 0.74 & 1.12 & 0.88 & 0.53 & 0.86 & 0.27 \\
\hline \multirow[t]{4}{*}{ ㅇ $(N=4)$} & $\mathrm{F} 1$ & 4.08 & 3.03 & 0.80 & 1.10 & 0.89 & 0.58 & 0.96 & 0.29 \\
\hline & $\mathrm{F} 2$ & 4.04 & 3.01 & 0.82 & 1.11 & 0.80 & 0.61 & 1.04 & 0.30 \\
\hline & F3 & 4.30 & 3.08 & 0.78 & - & - & 0.61 & 1.05 & 0.30 \\
\hline & $\mathrm{F} 4$ & 4.42 & 3.15 & 0.84 & 1.25 & 1.86 & 1.05 & 1.56 & 0.62 \\
\hline \multicolumn{10}{|l|}{ F. bismarckensis } \\
\hline ธิ $(N=1)$ & M1 & 3.07 & 2.09 & 0.61 & 0.84 & 0.48 & 0.49 & 0.78 & 0.25 \\
\hline \multirow[t]{3}{*}{ q $(N=3)$} & $\mathrm{F} 1$ & 3.53 & 2.46 & 0.69 & - & 0.55 & 0.53 & 0.86 & 0.27 \\
\hline & $\mathrm{F} 2$ & 3.72 & 2.62 & 0.74 & 0.93 & 0.62 & 0.55 & 0.92 & 0.29 \\
\hline & $\mathrm{F} 3$ & 3.57 & 2.39 & 0.68 & 0.91 & 0.54 & 0.53 & 0.88 & 0.27 \\
\hline
\end{tabular}


TABLE 1 (Continued)

\begin{tabular}{|c|c|c|c|c|c|c|c|c|c|}
\hline \multirow[b]{2}{*}{ Species } & & \multicolumn{5}{|c|}{ Length } & \multicolumn{3}{|c|}{ Width } \\
\hline & & Body & Cun-Clyp & Pronotum & AntSeg2 & AntSeg1 & Head & Pronotum & InterOcDi \\
\hline \multicolumn{10}{|l|}{ F. bradi } \\
\hline$\widehat{\delta}(N=1)$ & M1 & 4.27 & 3.24 & 0.79 & 1.25 & 0.83 & 0.64 & 1.01 & 0.30 \\
\hline 우 $(N=1)$ & $\mathrm{F} 1$ & 4.94 & 3.83 & 0.88 & 1.22 & 0.75 & 0.74 & 1.19 & 0.37 \\
\hline \multicolumn{10}{|c|}{ F. caledonicus } \\
\hline \multirow{5}{*}{$\widehat{\delta}(N=5)$} & M1 & 3.67 & 2.49 & 0.66 & 1.20 & 1.00 & 0.52 & 0.85 & 0.26 \\
\hline & M2 & 3.54 & 2.58 & 0.71 & 1.13 & 0.99 & 0.55 & 0.79 & 0.26 \\
\hline & M3 & 3.71 & 2.56 & 0.69 & 1.14 & 0.98 & 0.54 & 0.81 & 0.25 \\
\hline & M4 & 3.56 & 2.58 & 0.68 & 1.13 & 0.79 & 0.53 & 0.78 & 0.27 \\
\hline & M5 & 3.80 & 2.61 & 0.66 & 1.20 & 0.97 & 0.55 & 0.85 & 0.27 \\
\hline \multirow[t]{5}{*}{ 우 $(N=3)$} & $\mathrm{F} 1$ & 3.99 & 2.72 & 0.71 & 1.14 & 0.96 & 0.56 & 0.95 & 0.28 \\
\hline & $\mathrm{F} 2$ & 3.76 & 2.52 & 0.62 & 1.26 & 0.93 & 0.54 & 0.90 & 0.29 \\
\hline & F3 & 3.76 & 2.59 & 0.70 & 1.20 & 0.97 & 0.56 & 0.88 & 0.28 \\
\hline & $\mathrm{F} 4$ & 3.88 & 2.71 & 0.69 & 1.20 & 0.96 & 0.55 & 0.89 & 0.28 \\
\hline & F5 & 3.74 & 2.70 & 0.73 & 1.15 & 0.91 & 0.51 & 0.89 & 0.28 \\
\hline \multicolumn{10}{|c|}{ F. ceylonicus } \\
\hline \multirow[t]{2}{*}{$\widehat{\delta}(N=2)$} & M1 & 2.61 & 2.28 & 0.61 & 0.63 & 0.43 & 0.35 & 0.67 & 0.15 \\
\hline & M2 & 2.91 & 2.48 & 0.67 & 0.61 & 0.52 & 0.37 & 0.78 & 0.20 \\
\hline \multicolumn{10}{|c|}{ F. crassicornis } \\
\hline \multirow[t]{5}{*}{ 우 $(N=5)$} & $\mathrm{F} 1$ & 3.35 & 2.33 & 0.68 & 0.75 & 0.57 & 0.60 & 0.89 & 0.33 \\
\hline & $\mathrm{F} 2$ & 3.44 & 2.44 & 0.69 & 0.78 & 0.56 & 0.59 & 0.90 & 0.33 \\
\hline & F3 & 3.47 & 2.41 & 0.70 & 0.89 & 0.64 & 0.58 & 0.88 & 0.32 \\
\hline & $\mathrm{F} 4$ & 3.36 & 2.32 & 0.66 & 0.80 & 0.55 & 0.58 & 0.91 & 0.33 \\
\hline & F5 & 3.31 & 2.50 & 0.68 & 0.86 & 0.66 & 0.59 & 0.93 & 0.31 \\
\hline \multicolumn{10}{|l|}{ F. cristobalus } \\
\hline$\widehat{\delta}(N=1)$ & M1 & 3.48 & 2.50 & 0.78 & 1.06 & 0.68 & 0.58 & 0.85 & 0.26 \\
\hline \multirow[t]{2}{*}{ 우 $(N=2)$} & $\mathrm{F} 1$ & 4.16 & 2.94 & 0.83 & 1.14 & 0.72 & 0.63 & 0.96 & 0.29 \\
\hline & $\mathrm{F} 2$ & 4.21 & 2.95 & 0.84 & 1.10 & 0.80 & 0.64 & 0.99 & 0.31 \\
\hline \multicolumn{10}{|l|}{ F. curvatus } \\
\hline \multirow[t]{5}{*}{$\delta(N=5)$} & M1 & 4.19 & 2.86 & 0.91 & 1.04 & 0.75 & 0.54 & 0.95 & 0.25 \\
\hline & M2 & 4.54 & 3.18 & 0.91 & - & 0.78 & 0.54 & 0.99 & 0.27 \\
\hline & M3 & 4.45 & 3.20 & 0.98 & 1.08 & 0.79 & 0.56 & 1.05 & 0.28 \\
\hline & M4 & 4.60 & 3.12 & 0.91 & 0.93 & 0.86 & 0.56 & 1.10 & 0.29 \\
\hline & M5 & 4.76 & 3.39 & 1.03 & 1.22 & 0.87 & 0.61 & 1.13 & 0.29 \\
\hline \multirow[t]{3}{*}{$q(N=5)$} & $\mathrm{F} 1$ & 5.42 & 3.81 & 1.11 & 1.32 & 0.86 & 0.61 & 1.24 & 0.30 \\
\hline & $\mathrm{F} 2$ & 5.39 & 3.45 & 0.95 & 1.18 & 0.82 & 0.58 & 1.23 & 0.28 \\
\hline & F3 & 4.37 & 2.98 & 0.80 & 0.99 & 0.80 & 0.54 & 1.06 & 0.27 \\
\hline
\end{tabular}


TABLE 1 (Continued)

\begin{tabular}{|c|c|c|c|c|c|c|c|c|c|}
\hline \multirow[b]{2}{*}{ Species } & & \multicolumn{5}{|c|}{ Length } & \multicolumn{3}{|c|}{ Width } \\
\hline & & Body & Cun-Clyp & Pronotum & AntSeg2 & AntSeg1 & Head & Pronotum & InterOcDi \\
\hline & $\mathrm{F} 4$ & 5.17 & 3.53 & 1.09 & 1.22 & 0.85 & 0.61 & 1.23 & 0.31 \\
\hline & F5 & 4.94 & 3.49 & 1.03 & 1.10 & 0.76 & 0.59 & 1.19 & 0.29 \\
\hline \multicolumn{10}{|l|}{ F. dauloi } \\
\hline \multirow[t]{4}{*}{$\widehat{o}(N=4)$} & M1 & 3.89 & 2.69 & 0.72 & - & - & 0.65 & 1.04 & 0.30 \\
\hline & M2 & 3.94 & 2.72 & 0.74 & 1.23 & 0.96 & 0.58 & 1.03 & 0.25 \\
\hline & M3 & 3.80 & 2.68 & 0.63 & - & 0.92 & 0.61 & 0.99 & 0.28 \\
\hline & M4 & 3.98 & 2.76 & 0.72 & - & - & 0.57 & 0.93 & 0.25 \\
\hline \multirow[t]{5}{*}{$q(N=5)$} & $\mathrm{F} 1$ & 4.52 & 3.08 & 0.80 & 1.22 & 0.99 & 0.67 & 1.08 & 0.32 \\
\hline & $\mathrm{F} 2$ & 4.36 & 2.93 & 0.77 & 1.20 & 0.98 & 0.65 & 1.04 & 0.30 \\
\hline & F3 & 4.51 & 3.02 & 0.80 & 1.25 & 0.93 & 0.58 & 1.03 & 0.25 \\
\hline & $\mathrm{F} 4$ & 4.32 & 2.92 & 0.79 & 1.26 & 1.03 & 0.61 & 0.99 & 0.28 \\
\hline & F5 & - & 3.04 & 0.85 & 1.35 & 0.19 & 0.57 & 0.93 & 0.25 \\
\hline \multicolumn{10}{|c|}{ F. elegantulus } \\
\hline \multirow[t]{5}{*}{ ๙ิ $(N=5)$} & M1 & 3.95 & 2.68 & 0.67 & 1.09 & 0.82 & 0.53 & 0.90 & 0.25 \\
\hline & M2 & 4.09 & 2.81 & 0.74 & 1.11 & 0.96 & 0.57 & 0.97 & 0.26 \\
\hline & M3 & 4.19 & 2.84 & 0.72 & 1.16 & 0.93 & 0.56 & 0.98 & 0.26 \\
\hline & M4 & 4.18 & 2.81 & 0.73 & 1.13 & 0.96 & 0.53 & 0.99 & 0.26 \\
\hline & M5 & 4.02 & 2.76 & 0.74 & 1.08 & 0.91 & 0.58 & 0.96 & 0.27 \\
\hline \multirow[t]{5}{*}{$q(N=5)$} & $\mathrm{F} 1$ & 4.68 & 3.25 & 0.83 & 1.20 & 0.93 & 0.63 & 1.13 & 0.31 \\
\hline & $\mathrm{F} 2$ & 4.42 & 2.96 & 0.78 & 1.22 & 0.97 & 0.59 & 1.03 & 0.30 \\
\hline & F3 & 4.44 & 3.01 & 0.79 & 1.17 & 0.89 & 0.61 & 1.04 & 0.31 \\
\hline & $\mathrm{F} 4$ & 4.08 & 2.78 & 0.71 & 1.13 & 0.92 & 0.59 & 0.98 & 0.29 \\
\hline & F5 & 4.18 & 2.78 & 0.75 & 1.10 & 0.83 & 0.58 & 1.00 & 0.28 \\
\hline \multicolumn{10}{|l|}{ F. fedori } \\
\hline \multirow[t]{2}{*}{ ๙ิ $(N=2)$} & M1 & 4.46 & 0.81 & 0.92 & 1.42 & 0.81 & 0.71 & 1.10 & 0.32 \\
\hline & M2 & 4.39 & 0.78 & 0.92 & 1.49 & 0.78 & 0.67 & 1.10 & 0.28 \\
\hline \multirow[t]{3}{*}{$q(N=3)$} & $\mathrm{F} 1$ & 5.81 & 1.03 & 1.03 & 1.70 & 1.03 & 0.78 & 1.45 & 0.28 \\
\hline & $\mathrm{F} 2$ & 5.10 & 0.92 & 0.96 & 1.49 & 0.92 & 0.78 & 1.27 & 0.32 \\
\hline & F3 & 4.88 & 0.88 & 1.06 & 1.45 & 0.88 & 0.74 & 1.27 & 0.32 \\
\hline \multicolumn{10}{|l|}{ F. filicicola } \\
\hline \multirow[t]{5}{*}{$\widehat{\jmath}(N=5)$} & M1 & 3.76 & 2.61 & 0.67 & 1.10 & 0.89 & 0.55 & 0.85 & 0.27 \\
\hline & M2 & 3.51 & 2.47 & 0.67 & 1.09 & 0.91 & 0.57 & 0.80 & 0.27 \\
\hline & M3 & 3.61 & 2.61 & 0.70 & 1.12 & 0.97 & 0.59 & 0.85 & 0.26 \\
\hline & M4 & 3.73 & 2.63 & 0.69 & 1.12 & 1.00 & 0.55 & 0.86 & 0.26 \\
\hline & M5 & 3.64 & 2.58 & 0.69 & 1.17 & 0.96 & 0.57 & 0.86 & 0.28 \\
\hline \multirow[t]{3}{*}{$q(N=5)$} & $\mathrm{F} 1$ & 3.86 & 2.65 & 0.70 & 1.08 & 0.89 & 0.58 & 0.89 & 0.26 \\
\hline & $\mathrm{F} 2$ & 3.47 & 2.38 & 0.62 & 0.95 & 0.85 & 0.53 & 0.79 & 0.25 \\
\hline & F3 & 3.91 & 2.69 & 0.74 & 1.10 & 1.02 & 0.62 & 0.94 & 0.30 \\
\hline
\end{tabular}


TABLE 1 (Continued)

\begin{tabular}{|c|c|c|c|c|c|c|c|c|c|}
\hline \multirow[b]{2}{*}{ Species } & & \multicolumn{5}{|c|}{ Length } & \multicolumn{3}{|c|}{ Width } \\
\hline & & Body & Cun-Clyp & Pronotum & AntSeg2 & $\overline{\text { AntSeg1 }}$ & Head & Pronotum & InterOcDi \\
\hline & $\mathrm{F} 4$ & 3.82 & 2.65 & 0.69 & 1.13 & 0.85 & 0.62 & 0.91 & 0.30 \\
\hline & F5 & 3.46 & 2.51 & 0.72 & 1.09 & 0.89 & 0.62 & 0.85 & 0.30 \\
\hline \multicolumn{10}{|l|}{ F. glabratus } \\
\hline$\widehat{\delta}(N=1)$ & M1 & 3.85 & 2.73 & 0.75 & - & - & 0.58 & 0.96 & 0.29 \\
\hline 우 $(N=1)$ & $\mathrm{F} 1$ & 4.03 & 2.91 & 0.82 & 1.06 & 0.81 & 0.60 & 1.04 & 0.30 \\
\hline \multicolumn{10}{|l|}{ F. gressitti } \\
\hline 우 $(N=1)$ & $\mathrm{F} 1$ & 3.09 & 2.74 & 0.59 & 0.78 & 0.61 & 0.48 & 0.76 & 0.22 \\
\hline \multicolumn{10}{|l|}{ F. indicus } \\
\hline$\widehat{\partial}(N=1)$ & M1 & 3.96 & 2.74 & 0.75 & 1.05 & 0.81 & 0.61 & 0.93 & 0.24 \\
\hline \multicolumn{10}{|l|}{ F. insularis } \\
\hline \multirow[t]{4}{*}{ ธิ $(N=4)$} & M1 & 4.21 & 2.91 & 0.73 & 0.95 & 0.86 & 0.62 & 1.04 & 0.31 \\
\hline & M2 & 3.73 & 2.59 & 0.68 & 1.10 & 0.90 & 0.50 & 0.81 & 0.24 \\
\hline & M3 & 4.30 & 3.02 & 0.84 & 1.09 & 0.80 & 0.68 & 1.01 & 0.31 \\
\hline & M4 & 3.90 & 2.71 & 0.74 & 1.01 & 0.78 & 0.59 & 0.97 & 0.28 \\
\hline \multirow[t]{4}{*}{ 우 $(N=4)$} & $\mathrm{F} 1$ & 4.07 & 2.80 & 0.79 & 1.09 & 0.82 & 0.58 & 0.97 & 0.26 \\
\hline & $\mathrm{F} 2$ & 4.30 & 3.10 & 0.83 & 1.01 & 0.74 & 0.58 & 1.04 & 0.27 \\
\hline & F3 & 3.82 & 2.69 & 0.76 & 0.98 & 0.77 & 0.55 & 0.83 & 0.26 \\
\hline & $\mathrm{F} 4$ & 3.83 & 2.65 & 0.66 & 1.04 & 0.74 & 0.58 & 0.95 & 0.25 \\
\hline \multicolumn{10}{|l|}{ F. jacobsoni } \\
\hline \multirow[t]{2}{*}{$\delta(N=2)$} & M1 & 4.66 & 3.21 & 0.85 & 1.37 & 1.06 & 0.65 & 1.01 & 0.27 \\
\hline & M2 & 4.40 & 3.00 & 0.79 & 1.44 & 1.03 & 0.63 & 1.01 & 0.29 \\
\hline \multirow[t]{2}{*}{ 우 $(N=2)$} & $\mathrm{F} 1$ & 4.77 & 3.36 & 0.88 & 1.39 & 0.96 & 0.65 & 1.10 & 0.31 \\
\hline & $\mathrm{F} 2$ & 4.61 & 3.31 & 0.82 & 1.29 & 1.01 & 0.58 & 0.91 & 0.26 \\
\hline \multicolumn{10}{|l|}{ F. javanus } \\
\hline \multirow[t]{5}{*}{$\widehat{\jmath}(N=5)$} & M1 & 3.04 & 2.40 & 0.65 & - & 0.82 & 0.51 & 0.71 & 0.20 \\
\hline & M2 & - & 2.37 & 0.65 & - & 0.87 & 0.53 & 0.73 & 0.25 \\
\hline & M3 & 3.69 & 2.68 & 0.72 & 1.10 & 0.88 & 0.55 & 0.83 & 0.27 \\
\hline & M4 & - & 2.72 & 0.72 & 1.06 & 0.83 & 0.58 & 0.87 & 0.25 \\
\hline & M5 & 3.40 & 2.45 & 0.73 & - & - & 0.55 & 0.83 & 0.18 \\
\hline \multirow[t]{5}{*}{$\uparrow(N=5)$} & $\mathrm{F} 1$ & 3.57 & - & 0.64 & 1.10 & - & 0.57 & 0.86 & 0.27 \\
\hline & $\mathrm{F} 2$ & 3.54 & - & 0.75 & - & 0.87 & 0.59 & 0.89 & 0.25 \\
\hline & F3 & 3.89 & 2.87 & 0.74 & 1.07 & 0.84 & 0.64 & 0.95 & 0.32 \\
\hline & $\mathrm{F} 4$ & 4.02 & 2.92 & 0.75 & - & 0.87 & 0.58 & 0.91 & 0.27 \\
\hline & F5 & 4.06 & 2.98 & 0.77 & - & - & 0.62 & 0.92 & 0.28 \\
\hline \multicolumn{10}{|c|}{ F. lambkinae } \\
\hline \multirow[t]{3}{*}{$\widehat{\delta}(N=5)$} & M1 & 3.17 & 2.29 & 0.56 & 0.94 & 0.76 & 0.49 & 0.71 & 0.19 \\
\hline & $\mathrm{M} 2$ & & 2.50 & 0.56 & 0.96 & 0.62 & 0.51 & 0.72 & 0.21 \\
\hline & M3 & 3.14 & 2.36 & 0.62 & 0.90 & 0.73 & 0.47 & 0.69 & 0.18 \\
\hline
\end{tabular}


TABLE 1 (Continued)

\begin{tabular}{|c|c|c|c|c|c|c|c|c|c|}
\hline \multirow[b]{2}{*}{ Species } & & \multicolumn{5}{|c|}{ Length } & \multicolumn{3}{|c|}{ Width } \\
\hline & & Body & Cun-Clyp & Pronotum & AntSeg2 & AntSeg1 & Head & Pronotum & InterOcDi \\
\hline & $\mathrm{F} 1$ & 3.45 & 2.41 & 0.59 & 0.94 & 0.81 & 0.53 & 0.79 & 0.26 \\
\hline & $\mathrm{F} 2$ & 3.18 & 2.37 & 0.63 & 0.95 & 0.73 & 0.52 & 0.76 & 0.24 \\
\hline & F3 & & 2.57 & 0.65 & 0.92 & 0.77 & 0.49 & 0.83 & 0.24 \\
\hline & $\mathrm{F} 4$ & 3.33 & 2.42 & 0.64 & 0.92 & 0.75 & 0.53 & 0.82 & 0.25 \\
\hline \multicolumn{10}{|l|}{ F. linae } \\
\hline \multirow{5}{*}{$\widehat{\delta}(N=5)$} & M1 & 3.79 & 2.62 & 0.71 & 1.27 & 1.03 & 0.57 & 0.86 & 0.26 \\
\hline & M2 & 3.90 & 2.84 & 0.73 & 1.24 & 1.08 & 0.57 & 0.87 & 0.27 \\
\hline & M3 & 3.67 & 2.53 & 0.65 & 1.14 & 0.89 & 0.53 & 0.80 & 0.25 \\
\hline & M4 & 3.67 & 2.75 & 0.67 & 1.21 & 0.91 & 0.51 & 0.86 & 0.24 \\
\hline & M5 & 3.71 & 2.67 & 0.71 & 1.18 & 1.03 & 0.56 & 0.87 & 0.25 \\
\hline \multirow[t]{5}{*}{ ㅇ $(N=5)$} & $\mathrm{F} 1$ & 3.82 & 2.64 & 0.69 & 1.27 & 0.95 & 0.61 & 0.92 & 0.29 \\
\hline & $\mathrm{F} 2$ & 4.07 & 2.80 & 0.72 & 1.22 & 0.93 & 0.64 & 1.02 & 0.28 \\
\hline & F3 & 3.99 & 2.80 & 0.73 & 1.20 & 0.93 & 0.62 & 0.90 & 0.30 \\
\hline & $\mathrm{F} 4$ & 3.83 & 2.98 & 0.82 & 1.27 & 0.96 & 0.69 & 0.96 & 0.33 \\
\hline & F5 & 4.17 & 2.73 & 0.79 & 1.18 & 1.01 & 0.57 & 1.03 & 0.28 \\
\hline \multicolumn{10}{|c|}{ F. lindbergae } \\
\hline \multirow[t]{5}{*}{$\widehat{o}(N=5)$} & M1 & 3.47 & 2.39 & 0.66 & 0.89 & 0.72 & 0.62 & 0.90 & 0.28 \\
\hline & M2 & 3.54 & 2.51 & 0.74 & 0.99 & 0.72 & 0.68 & 0.99 & 0.29 \\
\hline & M3 & 3.61 & 2.55 & 0.78 & 1.01 & 0.76 & 0.65 & 1.00 & 0.31 \\
\hline & M4 & 3.40 & 2.31 & 0.68 & 0.95 & 0.64 & 0.62 & 0.95 & 0.29 \\
\hline & M5 & 4.12 & 2.85 & 0.83 & 1.08 & 0.71 & 0.66 & 1.08 & 0.29 \\
\hline \multirow[t]{5}{*}{ ㅇ $(N=5)$} & $\mathrm{F} 1$ & 3.69 & 2.52 & 0.76 & 0.97 & 0.73 & 0.62 & 0.90 & 0.28 \\
\hline & $\mathrm{F} 2$ & 4.24 & 2.96 & 0.89 & 1.05 & 0.83 & 0.68 & 0.99 & 0.29 \\
\hline & F3 & 4.05 & 2.83 & 0.83 & 0.95 & 0.72 & 0.65 & 1.00 & 0.31 \\
\hline & $\mathrm{F} 4$ & 3.99 & 2.77 & 0.84 & - & 0.71 & 0.62 & 0.95 & 0.29 \\
\hline & F5 & 4.41 & 3.06 & 0.92 & 1.20 & 0.78 & 0.66 & 1.04 & 0.29 \\
\hline \multicolumn{10}{|l|}{ F. liui } \\
\hline \multirow[t]{3}{*}{ ô $(N=3)$} & M1 & 3.09 & 2.24 & 0.62 & 1.01 & 0.66 & 0.55 & 0.72 & 0.26 \\
\hline & M2 & 3.40 & 2.62 & 0.65 & 1.00 & 0.78 & 0.56 & 0.71 & 0.26 \\
\hline & M3 & 3.30 & 2.34 & 0.65 & 1.04 & 0.71 & 0.64 & 0.75 & 0.30 \\
\hline \multirow[t]{3}{*}{$q(N=3)$} & $\mathrm{F} 1$ & 3.31 & 2.44 & 0.68 & 0.96 & 0.77 & 0.56 & 0.80 & 0.27 \\
\hline & $\mathrm{F} 2$ & 3.42 & 2.50 & 0.70 & 1.04 & 0.77 & 0.57 & 0.80 & 0.28 \\
\hline & F3 & 3.35 & 2.46 & 0.71 & 0.96 & 0.69 & 0.53 & 0.76 & 0.25 \\
\hline \multicolumn{10}{|l|}{ F. longiceps } \\
\hline \multirow[t]{3}{*}{ ๙ิ $(N=5)$} & M1 & 3.42 & 2.18 & 0.65 & 0.67 & 0.49 & 0.42 & 0.81 & 0.21 \\
\hline & M2 & 3.13 & 2.10 & 0.58 & - & 0.43 & 0.45 & 0.77 & 0.22 \\
\hline & M3 & 3.10 & 2.20 & 0.63 & 0.65 & 0.51 & 0.41 & 0.79 & 0.22 \\
\hline
\end{tabular}


TABLE 1 (Continued)

\begin{tabular}{|c|c|c|c|c|c|c|c|c|c|}
\hline \multirow[b]{2}{*}{ Species } & & \multicolumn{5}{|c|}{ Length } & \multicolumn{3}{|c|}{ Width } \\
\hline & & Body & Cun-Clyp & Pronotum & AntSeg2 & AntSeg1 & Head & Pronotum & InterOcDi \\
\hline & M4 & 3.00 & 2.11 & 0.59 & 0.73 & 0.50 & 0.43 & 0.76 & 0.22 \\
\hline & M5 & 3.25 & 2.28 & 0.65 & 0.69 & 0.53 & 0.41 & 0.83 & 0.23 \\
\hline \multirow[t]{5}{*}{ 우 $(N=4)$} & $\mathrm{F} 1$ & 3.48 & 2.39 & 0.66 & 0.65 & 0.54 & 0.46 & 0.92 & 0.23 \\
\hline & $\mathrm{F} 2$ & 3.58 & 2.44 & 0.74 & 0.60 & 0.49 & 0.44 & 0.89 & 0.22 \\
\hline & F3 & 3.81 & 2.64 & 0.77 & 0.80 & 0.59 & 0.50 & 0.97 & 0.24 \\
\hline & $\mathrm{F} 4$ & 3.44 & 2.37 & 0.69 & 0.60 & 0.57 & 0.49 & 0.90 & 0.26 \\
\hline & M1 & 3.42 & 2.18 & 0.65 & 0.67 & 0.49 & 0.42 & 0.81 & 0.21 \\
\hline \multicolumn{10}{|c|}{ F. lordhowensis } \\
\hline \multirow[t]{5}{*}{$\delta(N=5)$} & M1 & - & 2.59 & 0.68 & 1.08 & 0.89 & 0.47 & 0.84 & 0.24 \\
\hline & M2 & 3.84 & 2.74 & 0.72 & 1.11 & 0.90 & 0.52 & 0.81 & 0.26 \\
\hline & M3 & 3.95 & 2.79 & 0.69 & 1.22 & 0.94 & 0.58 & 0.86 & 0.31 \\
\hline & M4 & 3.54 & 2.55 & 0.64 & 0.97 & 0.78 & 0.48 & 0.77 & 0.26 \\
\hline & M5 & - & 2.70 & 0.71 & 1.15 & 0.94 & 0.53 & 0.89 & 0.27 \\
\hline \multirow[t]{5}{*}{ ㅇ $(N=5)$} & $\mathrm{F} 1$ & 3.93 & 2.72 & 0.73 & 1.04 & 0.98 & 0.47 & 0.86 & 0.23 \\
\hline & F2 & 4.08 & 2.88 & 0.72 & 1.13 & 0.96 & 0.57 & 0.87 & 0.27 \\
\hline & F3 & 3.87 & 2.84 & 0.74 & 1.17 & 0.92 & 0.58 & 0.91 & 0.28 \\
\hline & $\mathrm{F} 4$ & 4.46 & 3.23 & 0.76 & 1.13 & 0.88 & 0.51 & 0.92 & 0.26 \\
\hline & F5 & 4.14 & 2.91 & 0.74 & 1.28 & 1.00 & 0.56 & 0.88 & 0.29 \\
\hline \multicolumn{10}{|l|}{ F. luzonus } \\
\hline के $(N=1)$ & M1 & 3.79 & 2.50 & 0.67 & 0.86 & 0.71 & 0.51 & 0.94 & 0.22 \\
\hline 우 $(N=1)$ & $\mathrm{F} 1$ & 4.07 & 2.73 & 0.82 & - & - & 0.52 & 0.98 & 0.21 \\
\hline \multicolumn{10}{|c|}{ F. madagascariensis } \\
\hline ㅇ $(N=1)$ & $\mathrm{F} 1$ & 4.02 & 2.76 & 0.70 & - & 0.94 & 0.56 & 0.96 & 0.29 \\
\hline \multicolumn{10}{|l|}{ F. magnificus } \\
\hline \multirow[t]{5}{*}{$\delta(N=5)$} & M1 & 3.46 & 3.46 & 0.74 & 0.70 & 0.60 & 0.49 & 0.49 & 0.24 \\
\hline & M2 & 3.42 & 3.42 & 0.68 & 0.66 & 0.53 & 0.46 & 0.46 & 0.24 \\
\hline & M3 & 3.55 & 3.55 & 0.63 & 0.72 & 0.52 & 0.46 & 0.46 & 0.24 \\
\hline & M4 & 3.96 & 3.96 & 0.81 & - & - & 0.52 & 0.52 & 0.28 \\
\hline & M5 & 3.79 & 3.79 & 0.79 & 0.67 & 0.51 & 0.48 & 0.48 & 0.24 \\
\hline \multirow[t]{5}{*}{ 우 $(N=5)$} & $\mathrm{F} 1$ & 3.89 & 3.89 & 0.75 & 0.74 & 0.59 & 0.49 & 0.49 & 0.24 \\
\hline & F2 & 3.92 & 3.92 & 0.80 & 0.78 & 0.60 & 0.49 & 0.49 & 0.24 \\
\hline & F3 & 4.03 & 4.03 & 0.77 & 0.77 & 0.59 & 0.49 & 0.49 & 0.25 \\
\hline & F4 & 3.71 & 3.71 & 0.66 & 0.69 & 0.51 & 0.44 & 0.44 & 0.23 \\
\hline & F5 & 3.62 & 3.62 & 0.69 & 0.77 & 0.52 & 0.47 & 0.47 & 0.24 \\
\hline \multicolumn{10}{|c|}{ F. malayensis } \\
\hline$\widehat{\jmath}(N=1)$ & M1 & 3.47 & 2.71 & 0.67 & - & 0.93 & 0.54 & 0.83 & 0.25 \\
\hline ㅇ $(N=1)$ & $\mathrm{F} 1$ & 3.75 & 2.77 & 0.66 & 1.11 & 0.93 & 0.52 & 0.81 & 0.25 \\
\hline
\end{tabular}


TABLE 1 (Continued)

\begin{tabular}{|c|c|c|c|c|c|c|c|c|c|}
\hline \multirow[b]{2}{*}{ Species } & & \multicolumn{5}{|c|}{ Length } & \multicolumn{3}{|c|}{ Width } \\
\hline & & Body & Cun-Clyp & Pronotum & AntSeg2 & AntSeg1 & Head & Pronotum & InterOcDi \\
\hline \multicolumn{10}{|l|}{ F. meilingae } \\
\hline \multirow[t]{5}{*}{$\widehat{o}(N=5)$} & M1 & 4.10 & 3.03 & 0.78 & 1.28 & 1.06 & 0.64 & 0.98 & 0.30 \\
\hline & M2 & 4.24 & 2.90 & 0.79 & 1.20 & 0.92 & 0.55 & 0.94 & 0.24 \\
\hline & M3 & 4.02 & 2.79 & 0.77 & 1.28 & 1.06 & 0.65 & 0.89 & 0.27 \\
\hline & M4 & 4.21 & 2.88 & 0.77 & 1.21 & 0.98 & 0.57 & 0.94 & 0.27 \\
\hline & M5 & 4.10 & 2.86 & 0.74 & 1.09 & 0.99 & 0.59 & 0.96 & 0.24 \\
\hline \multirow[t]{5}{*}{$q(N=5)$} & $\mathrm{F} 1$ & 4.42 & 3.16 & 0.82 & 1.07 & 0.92 & 0.59 & 1.02 & 0.26 \\
\hline & $\mathrm{F} 2$ & 4.33 & 3.03 & 0.79 & 1.14 & 1.06 & 0.65 & 1.03 & 0.29 \\
\hline & F3 & 4.36 & 2.96 & 0.79 & 1.13 & 0.96 & 0.60 & 1.01 & 0.27 \\
\hline & $\mathrm{F} 4$ & 4.27 & 2.98 & 0.78 & 1.14 & 0.88 & 0.63 & 0.97 & 0.31 \\
\hline & F5 & 4.15 & 2.91 & 0.84 & 1.14 & 1.03 & 0.59 & 0.98 & 0.27 \\
\hline \multicolumn{10}{|l|}{ F. minutus } \\
\hline$\widehat{\delta}(N=1)$ & M1 & 2.61 & 2.20 & 0.52 & 0.85 & 0.70 & 0.43 & 0.61 & 0.17 \\
\hline \multicolumn{10}{|l|}{ F. myersi } \\
\hline \multirow[t]{5}{*}{ đิ $(N=5)$} & M1 & 3.43 & 2.38 & 0.57 & 1.01 & 0.93 & 0.52 & 0.75 & 0.24 \\
\hline & M2 & 4.18 & 2.92 & 0.77 & 1.37 & 1.20 & 0.60 & 0.94 & 0.28 \\
\hline & M3 & 3.84 & 2.78 & 0.70 & 1.23 & 1.08 & 0.55 & 0.84 & 0.27 \\
\hline & M4 & 3.53 & 2.34 & 0.66 & 1.07 & 1.01 & 0.55 & 0.79 & 0.25 \\
\hline & M5 & 3.38 & 2.46 & 0.64 & 1.05 & 0.92 & 0.51 & 0.76 & 0.25 \\
\hline \multirow[t]{5}{*}{ ㅇ $(N=5)$} & $\mathrm{F} 1$ & 4.23 & 2.90 & 0.76 & 1.12 & 1.08 & 0.54 & 0.92 & 0.27 \\
\hline & $\mathrm{F} 2$ & 3.94 & 2.74 & 0.74 & 1.19 & 0.93 & 0.57 & 0.91 & 0.28 \\
\hline & F3 & 3.73 & 2.62 & 0.65 & 1.04 & 0.87 & 0.53 & 0.80 & 0.26 \\
\hline & $\mathrm{F} 4$ & 4.15 & 2.84 & 0.76 & 1.21 & 1.07 & 0.60 & 0.96 & 0.29 \\
\hline & F5 & 3.96 & 2.84 & 0.68 & 1.21 & 1.12 & 0.57 & 0.88 & 0.28 \\
\hline \multicolumn{10}{|l|}{ F. nigrescens } \\
\hline \multirow[t]{3}{*}{ oิ $(N=3)$} & M1 & 4.58 & 3.04 & 0.73 & 1.10 & 0.93 & 0.70 & 0.97 & 0.29 \\
\hline & M2 & 4.17 & 2.95 & 0.74 & 1.06 & 0.85 & 0.55 & 0.93 & 0.26 \\
\hline & M3 & 4.21 & 2.83 & 0.68 & 1.00 & 0.89 & 0.57 & 0.97 & 0.25 \\
\hline \multirow[t]{3}{*}{ ㅇ $(N=3)$} & $\mathrm{F} 1$ & 4.84 & 3.18 & 0.79 & 1.12 & 0.86 & 0.58 & 0.99 & 0.30 \\
\hline & $\mathrm{F} 2$ & 4.57 & 3.01 & 0.76 & 1.02 & 0.88 & 0.59 & 1.02 & 0.29 \\
\hline & F3 & 4.40 & 2.84 & 0.76 & 1.04 & 0.83 & 0.60 & 1.02 & 0.30 \\
\hline \multicolumn{10}{|l|}{ F. ochraceus } \\
\hline \multirow[t]{4}{*}{ ธิ $(N=4)$} & M1 & 3.99 & 2.92 & 0.67 & - & 0.87 & 0.59 & 0.27 & 0.27 \\
\hline & M2 & 3.80 & 2.71 & 0.67 & 1.24 & 0.92 & 0.62 & 0.27 & 0.27 \\
\hline & M3 & 3.85 & 2.52 & 0.67 & 1.22 & 0.92 & 0.61 & 0.26 & 0.26 \\
\hline & M4 & 3.56 & 2.53 & 0.69 & 1.17 & 0.86 & 0.60 & 0.25 & 0.25 \\
\hline \multirow[t]{2}{*}{ ㅇ $(N=2)$} & $\mathrm{F} 1$ & 3.91 & 2.71 & 0.71 & - & & 0.57 & 0.26 & 0.26 \\
\hline & $\mathrm{F} 2$ & 3.75 & 2.70 & 0.71 & 1.19 & 0.73 & 0.63 & 0.27 & 0.27 \\
\hline
\end{tabular}


TABLE 1 (Continued)

\begin{tabular}{|c|c|c|c|c|c|c|c|c|c|}
\hline \multirow[b]{2}{*}{ Species } & & \multicolumn{5}{|c|}{ Length } & \multicolumn{3}{|c|}{ Width } \\
\hline & & Body & Cun-Clyp & Pronotum & AntSeg2 & AntSeg1 & Head & Pronotum & InterOcDi \\
\hline \multicolumn{10}{|l|}{ F. ovalau } \\
\hline$\widehat{\delta}(N=1)$ & M1 & 3.17 & 2.83 & 0.63 & 0.87 & 0.65 & 0.48 & 0.70 & 0.24 \\
\hline \multicolumn{10}{|c|}{ F. philippinensis } \\
\hline \multirow[t]{5}{*}{ ๙ิ $(N=5)$} & M1 & 3.97 & 2.77 & 0.78 & 1.10 & 0.77 & 0.60 & 0.86 & 0.24 \\
\hline & M2 & 3.92 & 2.68 & 0.77 & 1.15 & 0.79 & 0.56 & 0.89 & 0.23 \\
\hline & M3 & 4.03 & 2.86 & 0.86 & 1.09 & 0.77 & 0.55 & 0.91 & 0.23 \\
\hline & M4 & 4.12 & 2.84 & 0.75 & 1.08 & 0.79 & 0.50 & 0.93 & 0.23 \\
\hline & M5 & 3.86 & 2.69 & 0.74 & 1.03 & 0.77 & 0.53 & 0.85 & 0.23 \\
\hline \multirow[t]{5}{*}{ 우 $(N=5)$} & $\mathrm{F} 1$ & 4.30 & 3.02 & 0.86 & 1.03 & 0.79 & 0.53 & 0.95 & 0.22 \\
\hline & $\mathrm{F} 2$ & 4.74 & 3.20 & 0.92 & 1.09 & 0.85 & 0.56 & 1.01 & 0.24 \\
\hline & $\mathrm{F} 3$ & 4.89 & 3.33 & 0.93 & 1.13 & 0.87 & 0.61 & 1.08 & 0.26 \\
\hline & $\mathrm{F} 4$ & 4.65 & 3.32 & 0.98 & 1.24 & 0.77 & 0.59 & 1.04 & 0.26 \\
\hline & F5 & 4.94 & 3.42 & 0.99 & 1.19 & 0.85 & 0.58 & 1.10 & 0.26 \\
\hline \multicolumn{10}{|c|}{ F. ponaponensis } \\
\hline \multirow[t]{2}{*}{ ऽ $(N=2)$} & M1 & 3.50 & 2.43 & 0.93 & 1.00 & 0.78 & 0.58 & 1.00 & 0.25 \\
\hline & M2 & 3.60 & 2.55 & 0.93 & 1.05 & 0.85 & 0.58 & 0.98 & 0.28 \\
\hline \multirow[t]{2}{*}{ 우 $(N=2)$} & $\mathrm{F} 1$ & 3.60 & 2.55 & 0.93 & 0.93 & 0.83 & 0.55 & 1.03 & 0.33 \\
\hline & $\mathrm{F} 2$ & 3.80 & 2.90 & 1.08 & 0.98 & 0.90 & 0.60 & 1.13 & 0.35 \\
\hline \multicolumn{10}{|c|}{ F. rubricuneus } \\
\hline \multirow[t]{2}{*}{ ธิ $(N=2)$} & M1 & 3.80 & 2.78 & 0.75 & 1.05 & 0.78 & 0.53 & 0.88 & 0.28 \\
\hline & M2 & 3.60 & 2.68 & 0.73 & 1.03 & 0.73 & 0.50 & 0.80 & 0.25 \\
\hline \multicolumn{10}{|l|}{ F. schuhi } \\
\hline \multirow[t]{5}{*}{$\lesssim(N=5)$} & M1 & 3.93 & 2.68 & 0.72 & 1.31 & 0.97 & 0.63 & 0.93 & 0.29 \\
\hline & M2 & - & 2.76 & 0.66 & 1.29 & 1.06 & 0.64 & 0.95 & 0.31 \\
\hline & M3 & 4.05 & 2.88 & 0.76 & 1.27 & 0.97 & 0.62 & 0.90 & 0.27 \\
\hline & M4 & 4.18 & 2.93 & 0.78 & 1.40 & 1.10 & 0.64 & 0.96 & 0.30 \\
\hline & M5 & 4.26 & 2.89 & 0.74 & 1.32 & 1.08 & 0.66 & 0.99 & 0.30 \\
\hline \multirow[t]{5}{*}{$q(N=5)$} & $\mathrm{F} 1$ & 4.14 & 2.91 & 0.74 & 1.25 & 0.97 & 0.62 & 0.93 & 0.31 \\
\hline & $\mathrm{F} 2$ & 4.35 & 3.08 & 0.88 & 1.43 & 1.03 & 0.64 & 1.04 & 0.29 \\
\hline & F3 & 4.58 & 3.20 & 0.88 & 1.36 & 1.03 & 0.66 & 1.02 & 0.29 \\
\hline & $\mathrm{F} 4$ & 4.48 & 3.07 & 0.79 & 1.44 & 1.01 & 0.66 & 1.08 & 0.34 \\
\hline & F5 & 4.53 & 3.15 & 0.84 & 1.40 & 1.08 & 0.66 & 1.08 & 0.30 \\
\hline \multicolumn{10}{|l|}{ F. senaru } \\
\hline \multirow[t]{3}{*}{$\delta(N=3)$} & M1 & 3.56 & 2.55 & 0.69 & 1.17 & 0.94 & 0.51 & 0.79 & 0.22 \\
\hline & M2 & 3.83 & 2.74 & 0.69 & 1.08 & 0.90 & 0.51 & 0.81 & 0.22 \\
\hline & M3 & 3.68 & 2.60 & 0.69 & 1.14 & 0.88 & 0.54 & 0.83 & 0.25 \\
\hline \multirow[t]{2}{*}{$q(N=3)$} & $\mathrm{F} 1$ & 3.84 & 2.69 & 0.70 & 1.08 & 0.87 & 0.54 & 0.87 & 0.25 \\
\hline & $\mathrm{F} 2$ & 4.10 & 2.87 & 0.74 & 1.12 & 0.90 & 0.54 & 0.90 & 0.29 \\
\hline
\end{tabular}




\section{TABLE 1 (Continued)}

\begin{tabular}{|c|c|c|c|c|c|c|c|c|c|}
\hline \multirow[b]{2}{*}{ Species } & & \multicolumn{5}{|c|}{ Length } & \multicolumn{3}{|c|}{ Width } \\
\hline & & Body & Cun-Clyp & Pronotum & AntSeg2 & AntSeg1 & Head & Pronotum & InterOcDi \\
\hline & F3 & 3.97 & 2.80 & 0.74 & 1.21 & 0.92 & 0.52 & 0.88 & 0.29 \\
\hline \multicolumn{10}{|l|}{ F. signis } \\
\hline ๙ $(N=1)$ & M1 & 3.30 & 2.68 & 0.68 & 1.10 & 0.88 & 0.55 & 0.78 & 0.23 \\
\hline 우 $(N=1)$ & $\mathrm{F} 1$ & 3.50 & 4.95 & 1.09 & 4.01 & 2.21 & 0.55 & 0.83 & 0.23 \\
\hline \multicolumn{10}{|c|}{ F. solomonicus } \\
\hline \multirow[t]{5}{*}{$\widehat{\jmath}(N=5)$} & M1 & 2.63 & 1.86 & 0.51 & 0.67 & 0.58 & 0.42 & 0.57 & 0.21 \\
\hline & M2 & 2.57 & 1.82 & 0.47 & 0.73 & 0.60 & 0.42 & 0.57 & 0.21 \\
\hline & M3 & 2.77 & 1.96 & 0.53 & 0.83 & 0.68 & 0.51 & 0.60 & 0.27 \\
\hline & M4 & 2.76 & 1.88 & 0.50 & 0.77 & 0.55 & 0.45 & 0.59 & 0.24 \\
\hline & M5 & 2.81 & 1.98 & 0.52 & 0.79 & 0.62 & 0.46 & 0.58 & 0.23 \\
\hline \multirow[t]{2}{*}{ 우 $(N=2)$} & $\mathrm{F} 1$ & 2.92 & 2.15 & 0.57 & 0.80 & 0.61 & 0.45 & 0.68 & 0.21 \\
\hline & $\mathrm{F} 2$ & 2.87 & 2.11 & 0.56 & 0.81 & 0.70 & 0.46 & 0.63 & 0.23 \\
\hline \multicolumn{10}{|l|}{ F.tanna } \\
\hline \multirow[t]{5}{*}{$\widehat{\jmath}(N=5)$} & M1 & 3.51 & 2.35 & 0.60 & 1.02 & 0.85 & 0.52 & 0.79 & 0.26 \\
\hline & M2 & 3.50 & 2.38 & 0.62 & 0.99 & 0.88 & 0.48 & 0.80 & 0.24 \\
\hline & M3 & 3.50 & 2.39 & 0.59 & 1.00 & 0.72 & 0.48 & 0.77 & 0.21 \\
\hline & M4 & 3.55 & 2.41 & 0.62 & 1.08 & 0.84 & 0.49 & 0.80 & 0.23 \\
\hline & M5 & 3.41 & 2.27 & 0.56 & 1.04 & 0.73 & 0.48 & 0.76 & 0.23 \\
\hline \multirow[t]{5}{*}{ 오 $(N=5)$} & $\mathrm{F} 1$ & 3.81 & 2.62 & 0.65 & 0.98 & 0.84 & 0.51 & 0.81 & 0.26 \\
\hline & F2 & 3.56 & 2.45 & 0.63 & 1.00 & 0.81 & 0.48 & 0.76 & 0.25 \\
\hline & F3 & 3.52 & 2.34 & 0.61 & 1.03 & 0.82 & 0.50 & 0.79 & 0.24 \\
\hline & $\mathrm{F} 4$ & 3.54 & 2.42 & 0.60 & 1.02 & 0.89 & 0.54 & 0.83 & 0.28 \\
\hline & F5 & 3.48 & 2.44 & 0.64 & 0.94 & 0.86 & 0.49 & 0.84 & 0.24 \\
\hline \multicolumn{10}{|l|}{ F. vitilevu } \\
\hline \multirow[t]{5}{*}{ ఠิ $(N=5)$} & M1 & 0.57 & 0.43 & 0.65 & 1.12 & 2.59 & 0.57 & 0.83 & 0.30 \\
\hline & M2 & 1.28 & 1.02 & 0.73 & 1.14 & 2.77 & 0.58 & 0.81 & 0.29 \\
\hline & M3 & 5.59 & 3.93 & 0.81 & 1.15 & 2.92 & 0.60 & 0.89 & 0.31 \\
\hline & M4 & 6.88 & 4.95 & 0.66 & 1.03 & 2.38 & 0.51 & 0.74 & 0.25 \\
\hline & M5 & - & - & 0.78 & 1.19 & 3.07 & 0.58 & 0.92 & 0.29 \\
\hline \multirow[t]{5}{*}{$q(N=5)$} & $\mathrm{F} 1$ & 6.04 & 4.35 & 0.78 & 1.04 & 2.91 & 0.55 & 0.93 & 0.28 \\
\hline & $\mathrm{F} 2$ & 0.57 & 0.43 & 0.80 & 1.19 & 3.08 & 0.63 & 0.98 & 0.32 \\
\hline & $\mathrm{F} 3$ & 1.28 & 1.02 & 0.78 & 1.17 & 2.95 & 0.58 & 0.92 & 0.30 \\
\hline & $\mathrm{F} 4$ & 5.59 & 3.93 & 0.79 & 1.17 & 2.90 & 0.58 & 0.94 & 0.31 \\
\hline & F5 & 6.88 & 4.95 & 0.87 & 1.25 & 3.15 & 0.66 & 1.03 & 0.32 \\
\hline \multicolumn{10}{|l|}{ F. wangae } \\
\hline \multirow[t]{2}{*}{$\widehat{\delta}(N=2)$} & M1 & 4.56 & 3.24 & 1.00 & 1.27 & 0.99 & 0.79 & 1.19 & 0.32 \\
\hline & M2 & 4.66 & 3.22 & 0.92 & 1.32 & 1.12 & 0.79 & 1.17 & 0.33 \\
\hline
\end{tabular}


TABLE 1 (Continued)

\begin{tabular}{|c|c|c|c|c|c|c|c|c|c|}
\hline \multirow[b]{2}{*}{ Species } & & \multicolumn{5}{|c|}{ Length } & \multicolumn{3}{|c|}{ Width } \\
\hline & & Body & Cun-Clyp & Pronotum & AntSeg2 & AntSeg1 & Head & Pronotum & InterOcDi \\
\hline \multicolumn{10}{|l|}{ F. yasunagai } \\
\hline \multirow[t]{5}{*}{ ชิ $(N=5)$} & M1 & 3.29 & 2.32 & 0.73 & 0.65 & 0.63 & 0.45 & 0.83 & 0.23 \\
\hline & M2 & 3.49 & 2.54 & 0.79 & 0.67 & 0.67 & 0.45 & 0.83 & 0.21 \\
\hline & M3 & 3.46 & 2.49 & 0.77 & 0.69 & 0.71 & 0.46 & 0.88 & 0.22 \\
\hline & M4 & 3.43 & 2.36 & 0.78 & 0.67 & 0.66 & 0.47 & 0.84 & 0.24 \\
\hline & M5 & 3.44 & 2.41 & 0.75 & 0.64 & 0.57 & 0.45 & 0.85 & 0.23 \\
\hline \multirow[t]{5}{*}{ ㅇ $(N=5)$} & $\mathrm{F} 1$ & 3.83 & 2.71 & 0.85 & 0.68 & 0.58 & 0.48 & 0.93 & 0.24 \\
\hline & $\mathrm{F} 2$ & 3.77 & 2.80 & 0.85 & 0.60 & 0.62 & 0.45 & 0.99 & 0.20 \\
\hline & F3 & 3.45 & 2.65 & 0.82 & 0.76 & 0.68 & 0.51 & 0.92 & 0.24 \\
\hline & $\mathrm{F} 4$ & 3.46 & 2.47 & 0.73 & 0.67 & 0.61 & 0.49 & 0.89 & 0.23 \\
\hline & F5 & 3.76 & 2.71 & 0.82 & 3.67 & 1.97 & 1.06 & 1.21 & 0.50 \\
\hline \multicolumn{10}{|l|}{ F. zuparkoi } \\
\hline \multirow[t]{5}{*}{$\widehat{\jmath}(N=5)$} & M1 & 3.21 & 2.22 & 0.69 & 0.77 & 0.55 & 0.47 & 0.77 & 0.21 \\
\hline & M2 & 3.16 & 2.23 & 0.63 & 0.72 & 0.55 & 0.45 & 0.81 & 0.20 \\
\hline & M3 & 3.10 & 2.20 & 0.69 & 0.78 & 0.56 & 0.46 & 0.78 & 0.21 \\
\hline & M4 & 2.97 & 2.08 & 0.67 & - & - & 0.47 & 0.77 & 0.22 \\
\hline & M5 & 3.05 & 2.14 & 0.69 & - & 0.48 & 0.43 & 0.79 & 0.19 \\
\hline \multirow[t]{3}{*}{ 우 $(N=5)$} & $\mathrm{F} 1$ & 3.36 & 2.29 & 0.70 & 0.73 & 0.51 & 0.48 & 0.85 & 0.24 \\
\hline & F2 & 3.33 & 2.35 & 0.63 & - & 0.47 & 0.43 & 0.85 & 0.23 \\
\hline & F3 & 3.38 & 2.35 & 0.77 & - & - & 0.52 & 0.93 & 0.26 \\
\hline
\end{tabular}




\section{Discussion of MAjor Nodes}

Nodes of major clades are numbered from 1 to 30. Relationships of Felisacus with other Bryocorinae grouping are discussed in Namyatova et al. (2016) and Namyatova and Cassis (2016). Character-state distributions for each node are as follows:

Node 1. Felisacus. The genus is supported by five synapomorphies: buccula posterior closed, binding labial segment I (Namyatova et al., 2016: fig. 6D, E) (4-1); labial segment I shorter than or as long as wide (6-0); setae on hemelytron absent or present only anteriorly (16-0); parempodia asymmetrical (Namyatova et al., 2016: fig. 20A, C) (24-1); right paramere longer than left one (figs. 11-13) (29-0). Although these states are unique for Felisacus in this analysis, they also occur in other bryocorine groups (see Namyatova et al., 2016). Felisacus is characterized by the unique combination of characters of the thorax, labium, pretarsus, and male genitalia (see generic diagnosis below).

Node 2. Felisacus curvatus $\mathrm{Hu}$ and Zheng, $2001,+F$. wangae, sp. nov. The node is supported by two contradicted synapomorphies: labial segment I twice as long as wide (6-1); dorsal labiate plate distinctly striated (fig. 16L, N) (70-1). F. curvatus and $F$. wangae are very distinct species not very similar to each other or any other Felisacus species.

Node 3. This clade is supported by four uncontradicted synapomophies: left paramere with clump of setae on inner angle (51-1) (e.g., figs. $11 \mathrm{~T}, \mathrm{AB}, 12 \mathrm{M}, \mathrm{W})$; at least apical half of ductus seminis sclerotized (52-2) (e.g., fig. 10A, C, D); dorsal labiate plate very small and thin, placed entirely between valvulae apodemes (fig. $16 \mathrm{E}, \mathrm{G}, \mathrm{K})$ (67-1); spermathecal gland placed at the anterior margin of dorsal labiate plate (e.g., fig. 16E, G) (71-1). It is also supported by a contradicted synapomorphy: distinct teeth on vesica and spicules absent (66-0). All species in this clade also have the inner margin of the cuneus straight (as in Namyatova et al., 2016: fig. 13D), that is unique within the genus. Many species within this clade are characterized by the
C-shaped marking on the hemelytron, the elongate sclerotized part of ductus seminis and the absence of vesical spicules, except for F. zuparkoi, which has a small claw-shaped spicule.

This clade includes F. philippinensis Hsiao, 1944, F. longiceps Poppius, 1915, and F. magnificus (Distant, 1904), which were assigned to the "magnificus group" by Woodward (1954). He also included F. crassicornis Usinger, 1946, and F. usingeri Woodward, 1954, but we excluded them from the phylogenetic analysis (see Methods and Materials). According to Woodward (1954: 49):

This group is characterised by the subbasally swollen first antennal segment, by the nearly straight, scarcely emarginate base of the pronotum, and by the necklike postocular part of the head gradually narrowing to the base, without a cylindrical basal collum sharply and completely constricted from a wider region behind the eyes. In magnificus, philippinensis, and crassicornis, at least, the right clasper [= paramere] of the male has the form of a curved rod, slender throughout its length, not considerably widened and flattened basally; the left clasper is nearly straight and only feebly curved on its outer margin; the right clasper is slightly knobbed or spatulate at apex, and either the right or the left clasper, or both, may give off a shorter or longer internal branch; ventral margin of apex of abdomen narrowly convex between right and left claspers.

We did not find that any of the characters described by Woodward (1954) delimit this group and were not recovered as synapomorphies.

Node 4. Felisacus luzonus, sp. nov., and F. philippinensis. This clade is supported by three contradicted synapomorphies: vertex flat (as in Namyatova et al., 2016: fig. 6E) (0-0); distance between transverse depression and pronotum as long as or longer than eye diameter (3-2); apical part of right paramere distinct (31-1). Felisacus luzonus and F. philippinensis are also restricted to the Philippines.

Node 5. This node is supported by two synapomorphies: inner margin of middle part of right paramere without swelling, straight or con- 


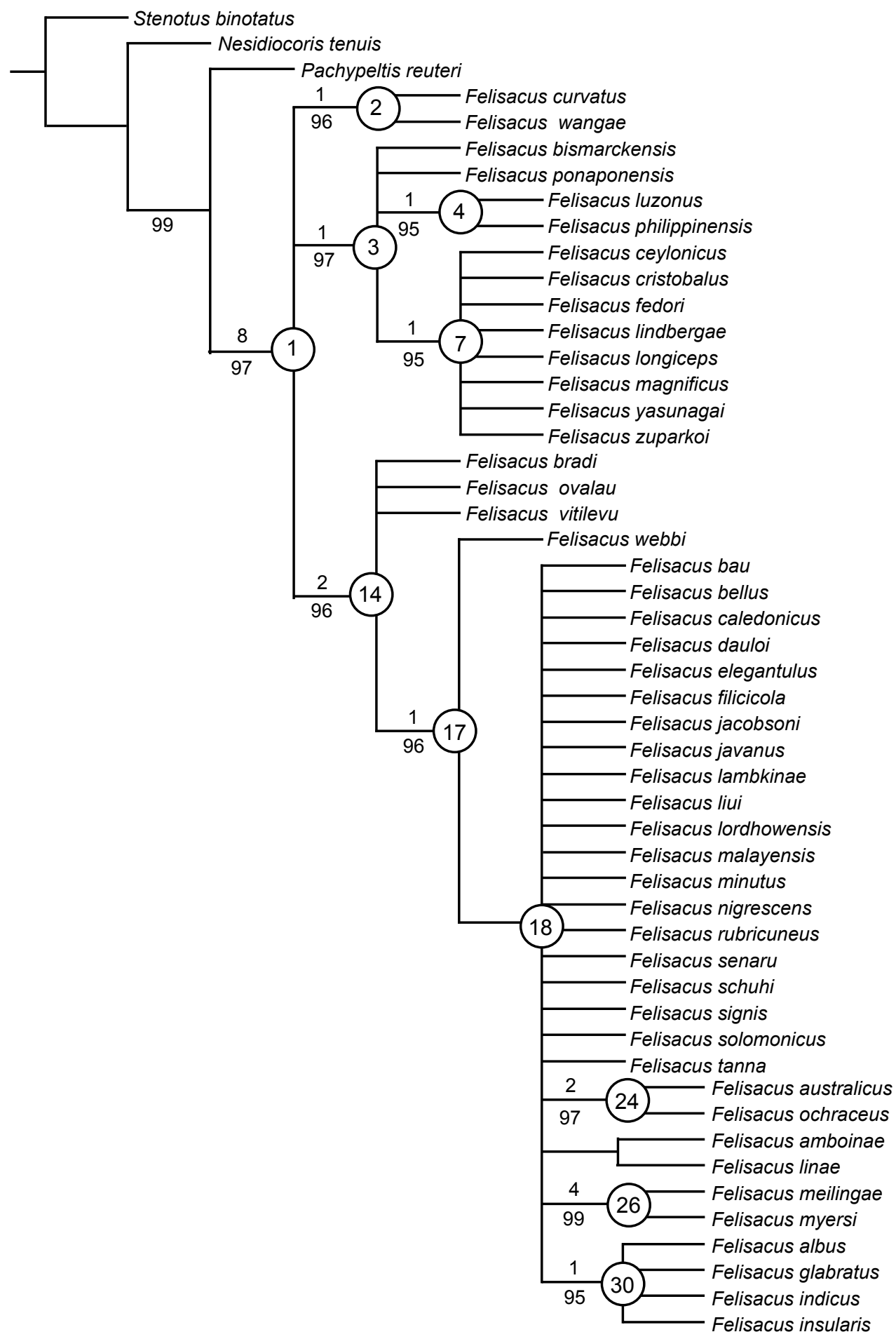

FIGURE 1. Strict consensus tree, unweighted analysis. The numbers above branches correspond to the Bremer supports values and those below branches correspond to the Bootstrap support values. 
cave (e.g., fig. 11R, T, AB) (34-0); outgrowth on posterior side of left paramere apically present (e.g., figs. $12 \mathrm{~N}, \mathrm{R}, 13 \mathrm{~J}, \mathrm{AC})(43-1)$. State (34-0) is contradicted. Felisacus ponaponensis (Carvalho, 1956) has a basal position and differs from other species of this clade in many characters (see discussion for this species below).

NoDE 6. This node is supported by three contradicted synapomorphies: posterior part of pronotum uniformly brown, dark brown to black (14-2); C-shaped marking on corium present (21$1)$; middle part of right paramere narrower than basal part (e.g., figs. 11L, T, 12M, U) (35-2). This node comprises all species with both arms of C-shaped marking on the hemelytron developed.

Node 7. This node is supported by five synapomorphies: dorsal side of head flat (as in Namyatova et al., 2016: fig. 6E) (0-0); distance between transverse depression and pronotum as long as or longer than eye diameter (3-2); swelling or outgrowth at the inner margin of proximal inflection of right paramere present (e.g., fig. $12 \mathrm{M}, \mathrm{Q}, \mathrm{W})$ (38-1); outgrowth on inner margin of left paramere elongate (figs. 11S, 12R, X) (48$2)$; distal sclerotized part of ductus seminis curved (e.g., fig. 10C, D, F) (53-1). Only state 38-1 is noncontradicted. Felisacus ceylonicus, sp. nov., has a basal position in this clade, but is similar to F. magnificus Distant, 1904, F. lindbergae, sp. nov., and F. longiceps Poppius, 1915.

Node 8 . This node is supported by a single noncontradicted synapomorphy: small tooth on posterior margin of genital capsule present (e.g., fig. 14I, T, V) (26-1). F. magnificus has a basal position in this clade. Externally it is almost indistinguishable from $F$. longiceps.

NoDE 9. This node is supported by a single synapomorphy: outer margin of left paramere distinctly concave (figs. 11U, AC, 12R, 13AE) (46-1).

NODE 10. This node is supported by a single contradicted synapomorphy: outgrowth on dorsal side of apical part of left paramere present (e.g., figs. $11 \mathrm{C}, \mathrm{AC}, 12 \mathrm{~N}, \mathrm{R}, 13 \mathrm{AC})(50-1)$. This character also present in Felisacus ceylonicus, sp. nov., which is similar externally to F. longiceps and F. lindbergae.
Node 11. This node is supported by a single noncontradicted synapomorphy: elongate outgrowth on inner angle of right paramere straight (figs. 11AB, 12M) (40-0).

Node 12 . This node is supported by a single contradicted synapomorphy: outer margin of left paramere straight or convex (figs. $12 \mathrm{~N}$, 13AC) (46-0).

Node 13. Felisacus cristobalus, sp. nov., $+F$. fedori, sp. nov. This node is supported by two contradicted synapomorphies: dorsal side of head posteriorly at least slightly swollen (as in Namyatova et al., 2016: fig. 6D) (0-1); distance between transverse depression on head and pronotum shorter than eye diameter (3-1). Also, it is supported by the noncontradicted synapomorphy-the C-shaped marking on the hemelytron, with anterior arm short, not reaching $\mathrm{R}+\mathrm{M}$ (221). F. cristobalus and F. fedori are very similar to each other in male genitalic structure, as well as the C-shaped marking on the hemelytron.

Node 14. This node is supported by two noncontradicted synapomorphies: dorsal surface of labial segment II elongate, covering base of segment III (8-1) (Namyatova et al., 2016: fig. 6D); semioval sclerite on dorsal labiate plate present (fig. 16C; as in Namyatova et al., 2016: fig. 23F) (68-1). It is also supported by two contradicted synapomorphies: labial segment III subequal to or longer than ventral side of head (Namyatova et al., 2016: fig. 6E) (9-1); outer margin of right paramere straight, slightly concave or convex (e.g., fig. 11A, C, H) (3-0). The state 9-1 is unique within Felisacus. The species within this clade mostly have a pale hemelytron and are very similar. However, three basal species, F. bradi, sp. nov., F. ovalau, sp. nov., and F. vitilevu, sp. nov., differ from the rest by the structure of the secondary gonopore, which is more or less enlarged or elongate (figs. $9 \mathrm{~N}, 10 \mathrm{E}, \mathrm{M}$ ), whereas it is small and cuplike in the remaining representatives of this clade (e.g., fig. 8A-D).

Node 15 . This node is supported by a single noncontradicted synapomorphy: transverse depression delimiting occipital region distinct, surrounding neck (Namyatova et al., 2016: figs. 


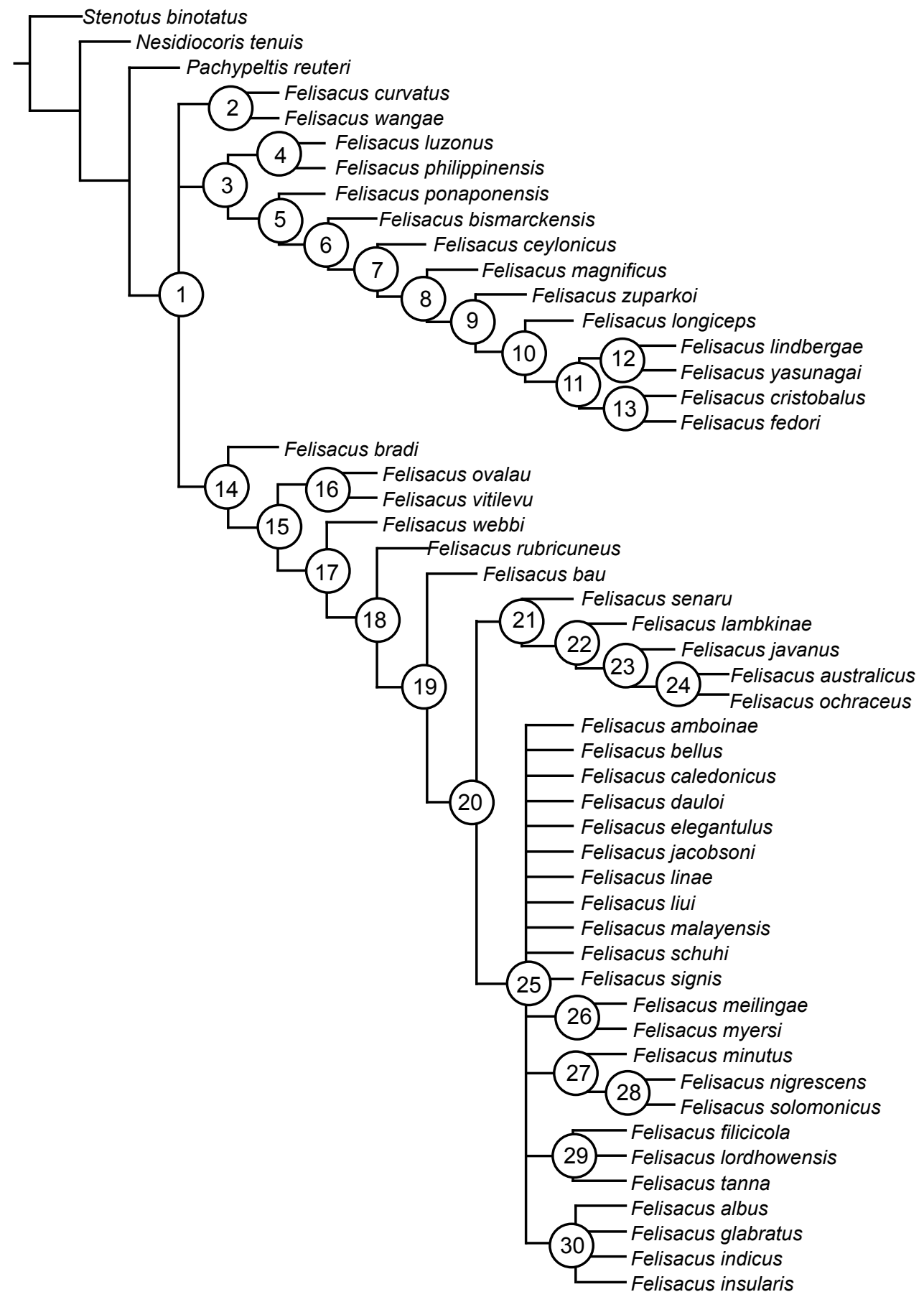

FIGURE 2. Strict consensus tree, implied weight analysis, $\mathrm{k}=7$. 
4E, 6D) (1-2). The node includes all species of node 11 except for F. bradi. Externally this species is similar to F. ovalau.

Node 16. The node is supported by two contradicted synapomorphies: apex of genital capsule curved dorsally (fig. 15F, L) (27-1); inner margin of middle part of right paramere without swelling, straight or concave (34-0) (fig. 13E, V). This clade includes $F$. ovalau and F. vitilevu. Although the clade has insignificant resampling support, both species are similar to each other externally and in genital morphology, and both are known from Fiji.

Node 17. The node is supported by three contradicted synapomorphies: transverse depression surrounding occipital region (as in Namyatova et al., 2016: fig. 4E) (2-2); antennal segment I straight (as in Namyatova et al., 2016: fig. 8A) (5-0); distinct teeth or spicules on vesica absent (66-0). State 5-0 is unique in Felisacus; F. webbi, sp. nov., the only species known from Madagascar included in the analysis, is sister to the remainder of this clade, and differs from other species of this group by having only a single curved vesical spicule (fig. 10N). In contrast, other species have many vesical spicules. Although the clade is relatively well supported, the relationships of $F$. webbi with other species are doubtful.

This node can be associated with the Woodward's (1954) "elegantulus" group, as the latter includes F. elegantulus (Reuter, 1904), F. filicicola (Kirkaldy, 1908), F. jacobsoni Poppius, 1914, F. ochraceus Usinger, 1946, and F. amboinae Woodward, 1954. He also included F. nigricornis Poppius, 1912, which was excluded from our analysis (see Methods and Materials). Woodward (1954: 49) defined this group as having

cylindrical first antennal segment, not swollen subbasally, the distinctly excavated base of the pronotum, and the differentiation of the base of the head as a cylindrical collum sharply and completely constricted from a wider region just behind the eyes. In F. elegantulus F. filicicola, F. ochraceus, and F. amboinae, at least, the right clasper [ = paramere] of the male is considerably widened and flattened basally and narrowed and curved apically, the inner margin with a more or less pronounced subbasal expansion; the left clasper is strongly curved upward and inward, with its outer margin strongly convex; ventral margin of apex of abdomen widely convex between right and left claspers.

The cylindrical antennal segment I and constriction of the postocular region are contradicted synapomorphies. The species of this group also have very similar or identical parameres.

Node 18. This node is supported by two synapomorphies: inner part of clavus dark brown to black (18-1); tooth on posterior side of left paramere medially present (fig. 11G) (44-1). The former is contradicted and the latter is uncontradicted. The species of this clade are similar to each other externally, varying mostly in coloration. They also have similar structure of the male genitalia, including genital capsule, parameres, and vesica with elongate spicules. The species of this node mostly differ in shape and number of those spicules.

Node 19. This node is supported by two uncontradicted apomorphies: spicule A (convoluted, placed on right-hand side) present (e.g., fig. 8A-E) (54-1); spicule C (convoluted, placed on left-hand side) present (e.g., fig. $8 \mathrm{~B}, \mathrm{D}, \mathrm{N}$ ) (58-1). This clade includes all species from clade 18 except for F. rubricuneus Carvalho, 1956.

NoDE 20. This node is supported by two synapomorphies: apical part of right paramere more or less distinctly demarcated (e.g., fig. 11C, E, J, P) (31-1); spicule B (curved, placed from righthand side (e.g., fig. 8B, E, F). This clade includes all species from clade 18 except for $F$. bau, sp. nov., and F. rubricuneus.

Node 21. This node is supported by a single uncontradicted synapomorphy: outer margin of right paramere distinctly concave (figs. 11E, 12G, I, 13D, N) (33-1). This clade comprises F. australicus, sp. nov., F. javanus Reuter, 1908, F. lambkinae, sp. nov., F. ochraceus Usinger, 1946, F. senaru, sp. nov. These species also possess similar vesical spicules (figs. 8C, N, O, 9F, I).

Node 22. This node is supported by a single contradicted synapomorphy: base of spicule C 


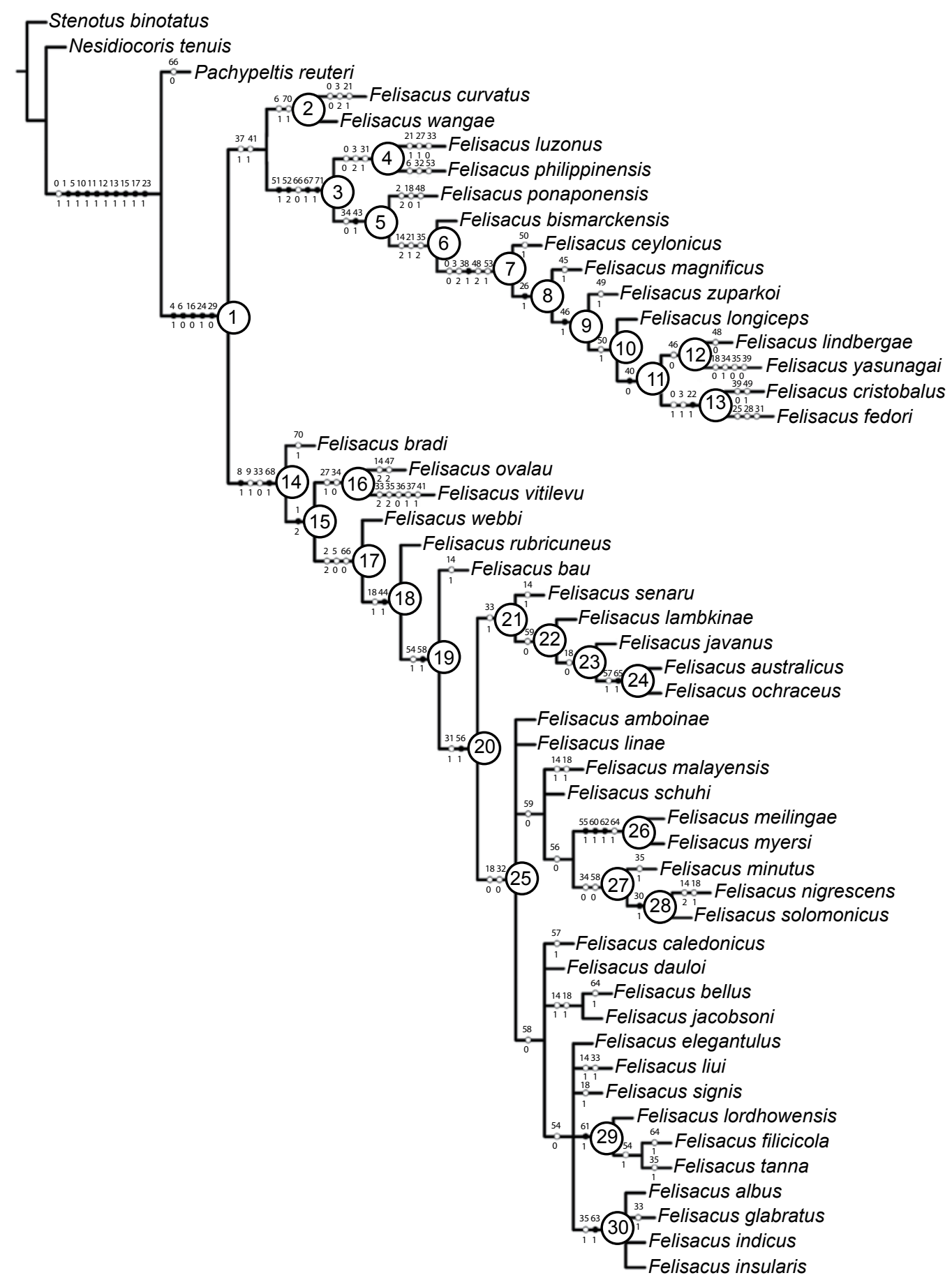

FIGURE 3. One of the shortest trees found in the analysis using implied weights, $\mathrm{K}=7$. The white circle corresponds to homoplasy, the characters occurring in two or more clades. The black circle corresponds to apomorphy, the character unique for the clade, even if it is lost in some its members. The characters were mapped using unambiguous optimization. 
(convolute, placed from left-hand side) approximately on the same level with other spicules (figs. 8C, N, O, 9F) (59-0). The clade includes four species: F. australicus, sp. nov., F. javanus Reuter, 1908, F. lambkinae, sp. nov., and F. ochraceus Usinger, 1946. All those species have similar coloration with a red cuneus and they also have similar parameres and vesical spicules (figs. 8C, $\mathrm{N}, \mathrm{O}, 9 \mathrm{~F})$. Felisacus javanus and F. lambkinae have almost identical spicules (fig. $8 \mathrm{~N}, \mathrm{O}$ ), and the spicules in F. australicus and F. ochraceus are also very similar (figs. 8C, 9F).

NoDE 23. This node is supported by a single uncontradicted synapomorphy: inner part of clavus transparent, whitish to pale brown (18-0). This clade comprises F. javanus, F. australicus, and F. ochraceus.

Node 24. This node is supported by two synapomorphies: apical arm of spicule B (curved, placed from right-hand side) (figs. 8C, 9F) (571 ); spicule $\mathrm{H}$ (hook shaped, placed from lefthand side) present (figs. 8C, 9F) (65-1). This clade includes $F$. australicus and F. ochraceus. Those two species are very similar to each other structurally and have nearly identical male genitalia (figs. $8 \mathrm{~N}, 9 \mathrm{~F}$ ), but they differ in coloration (see diagnoses and discussions for these species). They are widely separated species geographically, with F. ochraceus from Guam (Mariana Is.) and F. australicus from Queensland (Australia).

Node 25. This node is supported by two noncontradicted synapomorphies: inner part of clavus transparent, whitish to pale brown (18-0); apical part of right paramere as long as or longer than medial part (e.g., fig. 11C, J, P) (32-0).

Node 26. F. myersi, sp. nov., + F. meilingae, sp. nov. This node is supported by three uncontradicted apomorphies: spicule A (convoluted on right had side) almost straight (55-1); spicule D (small, placed basally) present (60-1); spicule I (convolute basally, medial) present (62-1); and by a single contradicted synapomorphy: spicules G (long and distinctly concave apically, arising from left-hand side) present (fig. 9B, C) (64-1). Although, species F. myersi and F. meilingae dif- fer slightly from each other in vesical spicules and coloration (see discussion for those species), overall they are very similar to each other externally and in genital monophyly, and they are both distributed in Vanuatu.

Node 27. This node is supported by two contradicted apomorphies: inner margin of middle part of right paramere without swelling, straight or concave (figs. 12AC, 13A, R) (34-0); spicule C (convolute, placed from lefthand side) absent (fig. 9D, E, L) (58-0). This clade includes F. minutus Carvalho, 1981, F. nigrescens Carvalho, 1981, and F. solomonicus, sp. nov., which are not similar to each other externally, and the proposed close relationship in this analysis is doubtful.

Node 28. This node is supported by a single uncontradicted synapomorphy: apex of right paramere distinctly concave (fig. 13A, R) (30-1). This clade comprises F. nigrescens and F. solomonicus. Although those two species are very different externally and their vesical spicules are not very similar (fig. 9E, L), they have strikingly similar right parameres and they are geographically proximal, with $F$. nigrescens known from New Guinea and F. solomonicus known from Solomon Islands.

Node 29. The node is supported by a single contradicted synapomorphy: spicules E (weekly sclerotized, placed from right-hand side) present (figs. 8I, R, 9M) (61-1). The clade includes $F$. filicicola (Kirkaldy, 1908), F. lordhowensis, sp. nov., and F. tanna, sp. nov. These three species are similar externally, including pale coloration.

Node 30 . This node is supported by two synapomorphies: middle part of right paramere twice as wide as basal part (figs. 11A, AF, 12A, C) (35-1); spicule F (long, needle shaped, placed from left-hand side), present (fig. 8A, J, K, L) (63-1). The former state is contradicted and the latter is uncontradicted. This clade comprises four species distributed from the Oriental region: F. albus, sp. nov., F. glabratus (Motschulsky, 1863), F. indicus, sp. nov., and F. insularis Miyamoto, 1965. The species of this clade are similar in the structure of the spicules and parameres, as 
well as external morphology and pale coloration.

\section{TAXONOMY}

Felisacus Distant, 1904

Liocoris Motschulsky, 1863: 86 (gen. nov.; type species Liocoris glabratus Motschulsky, 1863, by monotypy); Distant, 1904: 438 (junior homonym of Liocoris Fieber, 1858 (Hemiptera); Carvalho, 1957: 103 (catalog); Schuh, 1995: 510 (catalog).

Felisacus Distant, 1904: 438 (replacement name for Liocoris Motschulsky, 1863); Kirkaldy, 1906: 134 (list); Reuter, 1910: 163 (catalog); Poppius, 1911: 3 (description); Poppius, 1912: 181 (description); Bergroth, 1922: 55 (list); China, 1944: 174 (key to genera); Carvalho, 1952: 55 (catalog); Woodward, 1954: 41 (discussion, description); Carvalho, 1955: 34 (key to genera); Carvalho, 1957: 103 (catalog); Woodward, 1958: 236 (discussion); Carvalho, 1981: 51, 61 (key to genera, description, key to species); Cassis and Gross, 1995: 141 (catalog); Schuh, 1995: 510 (catalog); Lin, 2000: 233 (key to species).

Hyaloscytus Reuter, 1904: 1 (original description; type species: Hyaloscytus elegantulus Reuter, 1904, by monotypy); Kirkaldy, 1906: 134 (list); Reuter, 1910: 153 (catalog); Poppius, 1911: 3 (synonymy); Carvalho, 1957: 103 (catalog); Schuh, 1995: 510 (catalog)

Felisacoris Carvalho, 1956: 24 (gen. nov.; type species: Felisacoris ponaponensis Carvalho, 1956, by monotypy); new synonymy.

Diagnosis: Felisacus is separated from other bryocorine taxa by the following characters: labial segments I and II almost as long as wide (Namyatova et al., 2016: figs. 6D, E, 9C ), sometimes twice as long as wide, but each of them distinctly shorter than segment III; pronotum with two pairs of punctures laterally on sulcus delimiting calli and with pair of punctures ante- riorly to sulcus (Namyatova et al., 2016: fig. 4E); unique structure of pleura with distinct triangular scent gland evaporative area, oval spiracle, surrounded with few evaporative bodies; mesopleural/metapleural suture inferiorly obsolete (Namyatova et al., 2016: fig. 14B); parempodia asymmetrical, outer parempodium shorter than inner one (Namyatova et al., 2016: fig. 20A, C).

Description: Male. Body small and elongate, 2-4 mm. COLORATION (figs. 4-7): Head, pronotum, and thoracic pleura usually yellow or pale brown, sometimes with brown to dark brown marking or uniformly dark brown to black; hemelytron often whitish yellow and translucent, often with brown to dark brown C-shaped marking or at least with dark stripe along inner margin of corium; coloration of cuneus varying from whitish yellow to dark brown, sometimes with reddish tinge or bright red; membrane sometimes with grayish tinge or brown; appendages of same color or paler than dorsum, usually whitish yellow, yellow or pale brown, antennal segment I sometimes dark brown to black; femur sometimes with brown or reddish bands. SURFACE AND VESTITURE: Body mostly smooth, often with shallow punctures; lateral margins of scutellum with shallow striations (Namyatova et al., 2016: fig. 11A, B); $\mathrm{R}+\mathrm{M}$ impunctate or with shallow punctures; body clothed with pale simple setae, mostly missing on hemelytron, only with few setae on clavus and anterior margin of corium; trichobothria surrounded by dense fields of trichoma. STRUCTURE: Head: Hypognathous, in dorsal view eyes distinctly removed from pronotum, roundish; area between head to pronotum straight or slightly swollen, sometimes with transverse depression, delimiting occipital region; longitudinal sulcus present, its length varying from very short to almost reaching anterior margin of head; frons straight, not convex (Namyatova et al., 2016: fig. 4E); in anterior view head slightly higher than wide, eye oval, shorter than head height, its inner margin distinctly concave; clypeus as long as eye, its base placed above inferior margin of eye; antennal fossa tubercu- 
late, shorter than half of eye height, attached near midline of eye, its inferior margin not reaching inferior margin of eye (Namyatova et al., 2016: fig. 3C); in lateral view eye oval, its inferior margin not reaching maxillary plate; antennal fossa inserted slightly above base of clypeus; clypeus slightly swollen basally; buccula short and ringlike, tightly binding labial segment I; gula long and straight, $2-3 \times$ as long as buccula (Namyatova et al., 2016: fig. 6D, E). Antenna: Slightly shorter than or subequal to body length; length of segment I slightly greater than or subequal to head width, cylindrical or swollen medially (Namyatova et al., 2016: fig. 8A, B); segment II subequal to or slightly longer than segment I, segment III as long as or slightly longer than segment II; segment IV usually slightly shorter than or subequal to half the length of segment I. Labium (Namyatova et al., 2016: figs. 6D, E, 9C): Length variable, reaching from posterior margin of prosternum to posterior margin of metasternum; labial segments I and II shortened, often wider than long or as long as wide, rarely somewhat longer than wide; labial segment III sometimes telescoped into segment II; segment III usually 2-3 times longer than, rarely as long as segments I and II combined; segment IV usually almost twice as long as segment III, rarely only slightly longer than segment III. Thorax: Pronotum (Namyatova et al., 2016: figs. 4E, 6D). Length of pronotum subequal to its width at base; collar often more or less delimited laterally and medially, in F. ponaponensis collar not delimited; calli fused, delimited with sulcus posteriorly; pair of punctures of lateral side of this sulcus and anteriorly to sulcus present. Scutellum and mesoscutum (Namyatova et al., 2016: fig. 11A, B). Sulcus between scutellum and mesoscutum with pair of punctures medially; apex of scutellum acute. Pleura (Namyatova et al., 2016: fig. 14B). Meso- and metapleuron not separated, suture between them obsolete inferiorly; mesothoracic apodeme round; metathoracic spiracle open and oval, with single row of evaporative bodies inferiorly; opening of scent gland distinct, surrounded by triangular evaporative area; met- epimeron narrow, without lobe; posterior margin of metasternum straight. Hemelytron (Namyatova et al., 2016: figs. 11A, 13E, F): Clavus with row of punctures, medial margin longer than scutellum; medial fracture very short; $\mathrm{R}+\mathrm{M}$ long, reaching cuneus, impunctate or with some very small and shallow punctures; claval commissure with straight margins; cuneus 2-4 times as long as wide at base, its inner margin straight or convex; membrane with single or two cells, often vein between them faint; cells not reaching apex of membrane, forming right angle, shorter than distance between apex of cell and apex of membrane. Legs: Forecoxae contiguous with each other, middle and hind coxae separated (Namyatova et al., 2016: fig. 17C), in lateral view coxae short, not reaching upper margin of thoracic pleura; femora slender, not modified (Namyatova et al., 2016: fig. 18E), forefemur shorter than length of head and pronotum combined; hind femur longer than other femora; tibia straight; tarsal segments almost subequal in length, segment III dilate (Namyatova et al., 2016: fig. 19C). Pretarsus (Namyatova et al., 2016: fig. 20A-C). Unguitractor with three rows of contiguous tiles, those of middle row straight; basal claw spicules absent; claw broadly rounded, often with basal subtriangular tooth, sometimes only with short outgrowth basally; claw without medial or apical tooth; parempodia setiform, tapering toward apex, asymmetrical, with outer parempodium shorter than inner one; pseudopulvilli present, attached to unguitractor and base of claw, distinctly longer than claw. Genitalia: Genital capsule (figs. 14, 15; Namyatova et al., 2016: fig. 22L) subtriangular, $1-1.5 \times$ as long as wide; without supragenital bridge, sometimes with outgrowths on apical margin of ventral wall and swelling at sides. Parameres (Namyatova et al., 2016: figs. 11-13, fig. 22J, K). Right paramere longer than left, parameres usually sickle shaped or L-shaped, but sometimes right paramere straight or left paramere of irregular shape. Aedeagus (Namyatova et al., 2016: figs. 8-10, figs. 22I, M) phallotheca moderately sclerotized; endosoma voluminous, subdivided into vesica and conjunc- 
tiva (fig. 10; Namyatova et al., 2016: figs. 22I, M), with or without long spicules, rarely with fields of small spicules or with single small claw-shaped spicule; ductus seminis with small sclerotized ring around secondary gonopore, sometimes apical half of ductus seminis sclerotized, straight or hook shaped apically.

Female. Similar to male, not showing sexual dimorphism in external characters, but females usually slightly larger than males. Genitalia (fig. 16; Namyatova et al., 2016: figs. 23F, G): Dorsal labiate plate with or without sclerotized rings, sometimes with semioval sclerite medially; often without striations, smooth, sometimes with striations, rarely with membranous longitudinal ridge; lateral oviducts attached medially or in posterior half; place of attachment on spermathecal gland varying, often medially or near anterior margin; posterior wall of bursa copulatrix membranous, with or without small tubercles, sometimes with membranous lobe anteriorly; vulva indistinct, without sclerotization.

Distribution: The genus is mostly distributed in tropical areas of the Indo-Pacific region. Felisacus is distributed mainly in Australian and Oriental regions, with 34 and 22 species respectively. Three species are also known from the Ethiopian region. Felisacus jacobsoni, F. javanus, F. longiceps, and F. magnificus are distributed in the Australian and Oriental regions. Most species inhabit small areas, especially, those found on islands; however, some species have broader distribution: F. bellus Lin, 2000 (from southern China to southern parts of Vietnam and Thailand), F. elegantulus (east coast of Australia and New Zealand), F. filicicola (Samoa, Fiji, Vanuatu), F. insularis (southern China, Japan, Thailand, Vietnam), F. javanus (from Malay to New Guinea), F. longiceps (from South China to Ambon Is.), F. magnificus (from Thailand and Japan to Lombok Is.).

The phylogeny of Felisacus is divided into two main clades (3 and 14) and a single small Asian clade 2 with unclear affinities (figs. 1-3). Clades 3 and 14 are broadly overlapping in the Oriental region. Clade 3 includes 12 species of which eight are distributed in southeast Asia. Only five species are known from Australian region, including a single species each from mainland Papua New Guinea, New Britain, and Micronesia, and two species from the Solomon Islands (fig. 22). Species of clade 14 are distributed in the Australian and Oriental regions, ranging from southern China and Japan to the southeast coast of Australia and New Zealand; it is also widely distributed in islands of the southwest Pacific and occurs in Madagascar (fig. 22). This pattern is similar to Coridromius, which is distributed in Indo-Pacific although its two main subclades are largely divided at Wallacea (Tatarnic and Cassis, 2010).

Host PLANTs: Little is known about the feeding habits of Felisacini, but they are assumed to be fern feeders based on their common and specialized association with ferns ( 15 species of Felisacus of 55 described with host-plant data). Fourteen species have been collected from ferns (Kirkaldy, 1908; Usinger, 1946; Miyamoto, 1965; Woodward, 1958; also, this work). The host-plant records of Felisacus do not indicate phylogenetic restrictedness to any fern clade, and are instead known from distantly related genera, including Nephroplepis Schott, Polystichum Roth (Polypodiaceae), Diplazium Schwartz, Plesioneuron Holttum (Aspleniaceae), Pteris L. (Pteridaceae), Hypoplepis Bernh., Pteridium Gled. ex Scop. (Dennstaedtiaceae), Schizaea Sm. (Schizaeaceae) (see Christenhusz and Chase, 2014, for the latest phylogeny of ferns). Moreover, there are cases where a Felisacus species is known from two or more species, with these multiple fern species belonging to different families. This broad fern affiliation is also found in the tribe Bryocorini (Konstantinov and Knyshov, 2015). Felisacus elegantulus, F. lindbergae, and F. nigrescens have been recorded from angiosperms, but these likely represent sitting records, because records are either singletons or doubletons.

Discussion: Felisacus is well delimited and although the species within it vary considerably in salient and genital structures, the genus is not similar to any other genus of Miridae. Here we synonymize Felisacoris Carvalho, 1952, with Feli- 
sacus. Although the single species of Felisacoris, $F$. ponaponensis, is morphologically distinct, it is undoubtedly nested within Felisacus, in particular in clade 3 , and possesses male genitalia very similar to other species in this group (see figs. 1-3, 10).

Although Felisacus is a speciose taxon, containing 55 species, there are more undescribed species known to us. We examined such specimens belonging to the Bishop Museum, and likely represent new species, but we refrained from treating them as they were in poor condition.

Confusion exists in the literature concerning the type species and synonymy of the valid genus and junior synonyms. In particular, the type species of Liocoris is L. glabratus, which Carvalho (1957) listed as being synonymous with Hyaloscytus elegantulus, which he attributed to Poppius (1911). This is in error in both the relevant available names and the date of Poppius' work. Poppius (1911) redescribed Felisacus and F. glabratus, synonymized Hyaloscytus with Felisacus, but made no mention of species synonymy. Carvalho (1957) indicated that Poppius (1911) synonymized Felisacus glabratus with Hyaloscytus elegantulus. Kerzhner and Jansson (1985) indicated that Carvalho's citation of Poppius was incorrect, and identified Poppius (1914) as the work with the synonymy of Feliascus glabratus and Hyaloscytus elegantulus javanus, and not the nominotypical subspecies of the latter. Cassis and Gross (1995) followed the Poppius attribution of Kerzhner and Jansson (1985) but also indicated that $H$. elegantulus was synonymous with F. glabratus (as Liocoris), following Carvalho's (1957) species nomenclatorial history of F. glabratus. Schuh (1995) cited Liocoris glabratus as the type of Felisacus and gave it as a separate species with no synonyms. We revise the status of Hyaloscytus elegantulus java$n u s$ in this work and raise it to species rank.

\section{Checklist of Felisacus species}

Valid names are given in italics; synonyms are given in regular type. Full nomenclatorial listings for previously described species can be found in
Carvalho (1957) and Schuh (1995). Under each specimen treatment only citation of the original description and synonymy is given.

Felisacus adamsi Carvalho, 1956 (Micronesia)

Felisacus albus, sp. nov. (Thailand)

Felisacus amboinae Woodward, 1954 (Ambon Is.)

Felisacus auritulus Distant, 1913 (Seychelles)

Felisacus australicus, sp. nov. (Australia)

Felisacus bau, sp. nov. (Borneo)

Felisacus bellus Lin, 2000 (South Asia)

Felisacus bismarckensis, sp. nov. (New Britain)

Felisacus bradi, sp. nov. (Society Is.)

Felisacus caledonicus, sp. nov. (New Caledonia)

Felisacus capitatus Miyamoto, 1965, junior syn onym of F. magnificus

Felisacus carpenterae Hsiao, 1944, junior synonym of $F$. javanus

Felisacus ceylonicus, sp. nov. (Sri Lanka)

Felisacus crassicornis Usinger, 1946 (Guam)

Felisacus cristobalus, sp. nov. (Solomon Is.)

Felisacus curvatus $\mathrm{Hu}$ and Zheng, 2001 (South Asia)

Felisacus dauloi Woodward, 1958 (Papua New Guinea)

Felisacus elegantulus (Reuter, 1904) (Australia)

Felisacus fedori, sp. nov. (Sulawesi)

Felisacus filicicola (Kirkaldy, 1908) (Fiji, Samoa, Vanuatu)

Felisacus glabratus (Motschulsky, 1863) (Sri Lanka)

Felisacus gressitti Miyamoto, 1965 (Japan)

Felisacus indicus, sp. nov. (India)

Felisacus insularis Miyamoto, 1965 (South Asia)

Felisacus jacobsoni Poppius, 1914, stat. nov. (Java, Lombok Is.)

Felisacus javanus Reuter, 1908 (South Asia)

Felisacus lambkinae, sp. nov. (Christmas Is.)

Felisacus linae, sp. nov. (East Timor)

Felisacus lindbergae, sp. nov. (Solomon Is.)

Felisacus liui, sp. nov. (Solomon Is.)

Felisacus longiceps Poppius, 1915 (South Asia)

Felisacus lordhowensis, sp. nov. (Lord Howe Is.)

Felisacus luzonus, sp. nov. (Philippines)

Felisacus madagascariensis Poppius, 1912 (Madagascar)

Felisacus magnificus Distant, 1904 (South Asia) 
Felisacus malayensis, sp. nov. (Penang, Malaysia)

Felisacus meilingae, sp. nov. (Vanuatu)

Felisacus minutus Carvalho, 1981 (Papua New Guinea)

Felisacus myersi, sp. nov. (Vanuatu)

Felisacus nigrescens Carvalho, 1981 (Papua New Guinea)

Felisacus nigricornis Poppius, 1912 (New Guinea)

Felisacus ochraceus Usinger, 1946 (Guam)

Felisacus okinawanus Miyamoto, 1965, junior synonym of $F$. longiceps

Felisacus ovalau, sp. nov. (Fiji)

Felisacus philippinensis Hsiao, 1944 (Philippines)

Felisacus ponaponensis (Carvalho, 1956) (Micronesia)

Felisacus pulchellus Poppius, 1915, junior synonym of F. magnificus

Felisacus rubricuneus Carvalho, 1956 (Micronesia)

Felisacus schuhi, sp. nov. (East Timor, Vanuatu,

New Caledonia, Solomon Is.)

Felisacus senaru, sp. nov. (Lombok Is.)

Felisacus signis Hsiao, 1944, stat. nov. (Borneo)

Felisacus solomonicus, sp. nov. (Solomon Is.)

Felisacus tanna, sp. nov. (Vanuatu)

Felisacus usingeri Woodward, 1954 (Philippines)

Felisacus vitilevu, sp. nov. (Fiji)

Felisacus wangae, sp. nov. (South Asia)

Felisacus webbi, sp. nov. (Madagascar)

Felisacus yasunagai, sp. nov. (Philippines)

Felisacus zuparkoi, sp. nov. (Borneo, Philippines)

Key to Felisacus species

1. Corium with distinct, C-shaped, brown to dark brown marking, reaching $\mathrm{R}+\mathrm{M}$ anteriorly and posteriorly (e.g., fig. 5, F. lindbergae, F. longiceps)

- Marking on corium not reaching $\mathrm{R}+\mathrm{M}$ anteriorly, sometimes only in shape of narrow marking along inner margin of corium (e.g., fig. 5, F. elegantulus, F. jacobsoni, F. madagascariensis)

.8

2. Distance between longitudinal sulcus on vertex and anterior margin of pronotum shorter than eye diameter; vertex distinctly upraised (as in Namyatova et al., 2016: fig. 6D); sclerotized part of ductus seminis straight (fig. 10A......F. bismarckensis, sp. nov. (fig. 4)

- Distance between longitudinal sulcus of vertex and anterior margin of pronotum as long as eye diameter; vertex flat or only slightly upraised (Namyatova et al., 2016: fig. 6E); sclerotized part of ductus seminis curved at least basally and/or medially (e.g., fig. $10 \mathrm{H}$, I) 3

3. Anterior part of C-shaped marking on corium distinctly inclined posteriorly; labium reaching posterior margin of metasternum. .F. yasunagai, sp. nov. (fig. 7)

- Anterior part of C-shaped marking on corium directed outward only or slightly inclined posteriorly (fig. 5; F. lindbergae, F. longiceps); labium slightly surpassing posterior margin of mesosternum or shorter .4

4. Labium slightly surpassing posterior margin of prosternum, not reaching middle of mesosternum; inner angle of right paramere with straight outgrowth (fig. 12M); medial part of left paramere without outgrowth (fig. 12N) ..F. lindbergae, sp. nov. (fig. 5)

- Labium reaching or almost reaching posterior margin of mesosternum; inner angle of left paramere with curved outgrowth (figs. 11R, 12Q, W, 13AD); medial part of left paramere with outgrowth (figs. 11S, 12R, X, 13AE).. 5

5. Lateral margins of postocular regions of vertex convex....F. ceylonicus, sp. nov. (fig. 4)

- Lateral margins of postocular regions of vertex straight 6

6. Right paramere almost straight (fig. 12W); apical part of left paramere widened, flat, without outgrowth on dorsal surface (fig. 12X).................... magnificus Distant (fig. 6)

- Right paramere distinctly curved (figs. 12Q, 13AD); apical part of left paramere narrow, outgrowth on dorsal surface of its apical part present (figs. 12R, 13AE)............................... 7

7. Outgrowth on inner angle of right paramere distinctly curved (fig. 13AD); outgrowth on middle part of left paramere wide and serrate (fig. 13AE); vesica with single claw- 
shaped spicule (fig. 10P)

.F. zuparkoi, sp. nov. (fig. 7)

- Outgrowth on inner angle of right paramere only slightly curved (fig. 12Q); outgrowth on middle part of left paramere narrow and smooth (fig. 12R); vesica without spicules (fig. 10H)............. longiceps Poppius (fig. 5)

8. Collar not delimited with depression, anterior part of pronotum distinctly upraised, and covering posterior part of head (Carvalho, 1956: fig. 14)................ ponaponensis (fig. 6)

- Collar more or less delimited, not covering posterior part of head (Namyatova et al., 2016: fig. 4E) . .9

9. Posterior part of marking on corium subequal or wider than eye diameter.

F. curvatus (fig. 4)

- Marking on hemelytron either short, not extending towards $\mathrm{R}+\mathrm{M}$ or its posterior part narrower than eye diameter.......10

10. Anterior part of marking on corium wide, subequal to or wider than eye diameter (fig. 4, F. cristobalus, F. fedori). . .11

- Marking on hemelytron either short, not extending towards $\mathrm{R}+\mathrm{M}$ or its anterior part very narrow, stripelike, distinctly narrower than eye diameter (e.g., fig. 5, F. filicicola, F. lambkinae, F. luzonus)

11. Body length in males $4.4-4.5 \mathrm{~mm}$, in females 4.9-5.9 mm; pronotum yellow brown, more or less darkened along posterior margin; cuneus red (fig. 4); outgrowth on right paramere rounded (fig. 11AB)

.F. fedori, sp. nov. (fig. 4)

- Body length in male $3.5 \mathrm{~mm}$, in female 4.2 $\mathrm{mm}$; pronotum mostly brown to dark brown; with pale brown stripe medially; cuneus colorless, with brown margins (fig. 4 ); outgrowth on inner part of right paramere abrupt (fig. 11T)

..F. cristobalus, sp. nov. (fig. 4)

12. Apical half of ductus seminis sclerotized (fig. 10I, K).

- Ductus seminis mostly membranous, only small area around ductus seminis sclerotized (e.g., figs. 9, 10N) ...14
13. Marking on corium reaching $\mathrm{R}+\mathrm{M}$ posteriorly; labium reaching middle of mesosternum; ductus seminis hooked apically (fig. 10I)................. luzonus, sp. nov. (fig. 5)

- Marking on corium short, not extending toward $\mathrm{R}+\mathrm{M}$, labium slightly surpassing posterior margin of mesosternum; ductus seminis not hooked apically (fig. 10K)...........

..F. philippinensis, sp. nov. (fig. 6)

14. Head, pronotum and scutellum red. .F. nigricornis Poppius

- At least posterior part of pronotum yellow to dark brown.. 15

15. Dorsal side of labial segment II as long as ventral side (Namyatova et al., 2016: fig. 6E).....16

- Dorsal side of labial segment II longer than ventral side (Namyatova et al., 2016:fig. 6D).......17

16. Antennal segment I almost straight, only slightly swollen; vertex upraised; pronotum with three dark markings posteriorly (fig. 7); corium impunctate; inner margin of cuneus curved (as in Namyatova et al., 2016: fig. 13E) ....................... wangae, sp. nov. (fig. 7)

- Antennal segment I distinctly widened (as in Namyatova et al., 2016: fig. 8B); vertex flat (as in Namyatova et al., 2016: fig. 6E); posterior part of pronotum mostly brown, with yellow to pale brown longitudinal stripe medially; corium distinctly punctate; inner margin of cuneus straight (as in Namyatova et al., 2016: fig. 13F).

.F. crassicornis Usinger (fig. 4)

17. Posterior part of pronotum brown to dark brown laterally, with yellow, pale brown or reddish brown longitudinal stripe medially (fig. 5, F. gressitti, F. madagascariensis; fig. 6, F. minutus, F. rubricuneus, fig. $7, F$. vitilevu). .18

- Posterior part of pronotum whitish yellow to pale brown, sometimes with reddish tinge, sometimes with humeral angles or markings near humeral angles or stripe along posterior margin brown to dark brown....22

18. Transverse depression on vertex, delimiting occipital region present dorsally and laterally (as in Namyatova et al., 2016: fig. 6E); 
cuneus mostly red (fig. 6, F. minutus, F. rubricuneus). 19

- Transverse depression on vertex, delimiting occipital region present only dorsally; cuneus mostly colorless, sometimes with yellow tinge .20

19. Body length in male 2.6; antennal segment II red; scutellum yellow; inner part of clavus yellow with reddish tinge; medial part of right paramere distinctly wider than basal part (fig. 12AC); vesical spicules as in figure 9D............F. minutus Carvalho (fig. 6)

- Body length in male 3.4; antennal segment II whitish yellow to yellow, with reddish or brownish tinge apically; scutellum pale brown with reddish tinge; inner part of clavus brown to black; medial part of right paramere as wide as basal part (Carvalho, 1956: fig. 17a); vesical spicules as in figure 9H................. rubricuneus Carvalho (fig. 6)

20. Labium reaching middle of mesosternum; anterior part of pronotum brown

.F. madagascariensis Poppius (fig. 5)

- Labium reaching at least posterior margin of metasternum or surpassing it; anterior part of pronotum yellow or pale brown, sometimes with reddish tinge. .21

21. Clypeus mostly dark brown, antennal segment II in male and female ca. $1.6 \times$ as long as head width

.F. gressitti Miyamoto (fig. 5)

- Clypeus mostly yellow to pale brown, sometimes red; antennal segment II in male ca. 1.9-2.1× and in female ca. 1.9-2.0 $\times$ as long as head width; vesica as in figure $9 \mathrm{~N}$.

F. vitilevu, sp. nov. (fig. 7)

22. Depression delimiting occipital region present only dorsally.

- Depression delimiting occipital region present dorsally and laterally (as in Namyatova et al., 2016: fig. 4E)... .27

23. Labium reaching abdominal venter.............24

- Labium reaching middle of mesosternum....26

24. Pronotum yellow, without brown to dark brown markings (fig. 4); antennal segment I brown; left paramere with single outgrowth posteriorly (fig. 11O); vesica as in figure 10B.................. bradi, sp. nov. (fig. 4)

- Pronotum yellow with a pair of brown to dark brown markings (fig. 6, F. ovalau; fig. 7, F. webbi); antennal segment I yellow with reddish tinge or markings; left paramere with three rounded outgrowths (fig. 13F) or without outgrowth(s) (fig. 13AA)........25

25. Ventral wall of genital capsule not curved apically (fig. 15N); left paramere narrow and sickle shaped, without outgrowths (fig. 13AA); vesica with long curved spicule, without toothlike spinules (fig. 10N) .F. webbi, sp. nov. (fig. 7)

- Ventral wall of genital capsule curved apically (fig. 15F); left paramere wide with three rounded outgrowths (fig. 13F); vesica with a number of small toothlike spinules only (fig. 9G).................. ovalau, sp. nov. (fig. 6)

26. Distance from eye to pronotum slightly shorter than eye diameter; antennal segment I dark brown with yellow base.

.F. auritulus Distant (fig. 4)

- Distance from eye to pronotum slightly longer than eye diameter; antennal segment I yellow, brown apically

.F. usingeri Woodward (fig. 7)

27. Anterior part of pronotum brown to dark brown... 28

- Pronotum mainly yellow to pale brown, sometimes with brown markings on collar and posterior part of pronotum ...............30

28. Body length in male 4.4-4.7, in female 4.44.8; posterior part of pronotum brown to dark brown; spicules as in figure $9 \mathrm{E}$

$$
\text { .F. nigrescens Carvalho (fig. 6) }
$$

- Body length in males $2.6-3.2 \mathrm{~mm}$, in females 2.9-3.5 mm; posterior part of pronotum mostly yellow to pale brown with brown markings.

.29

29. Labium reaching posterior margin of metasternum; antennal segment I yellow to pale brown, sometimes with reddish tinge; scent gland evaporative area uniformly whitish yellow; inner part of clavus pale brown to brown; cuneus mostly red; middle part of 
right paramere subequal in length to basal and apical parts combined (fig. 12I); vesical spicules as in figure $8 \mathrm{O}$.

..F. lambkinae, sp. nov. (fig. 5)

- Labium reaching posterior margin of mesosternum or slightly surpassing it; antennal segment I reddish with yellow base; scent gland evaporative area pale brown to brown with red apex; inner part of clavus colorless or yellow with red or pale brown margins; cuneus colorless, with brown, orange or red marking along inner margin and brown margins; middle part of right paramere shorter than basal and apical parts combined (fig. 12O); vesical spicules as in figure 8Q..........F. liui, sp. nov. (fig. 5)

30.Labium reaching posterior margin of metasternum. 31

- Labium reaching at most middle of metasternum. .33

31. Cuneus mostly red; head and pronotum yellow, brown marking on dorsal surface of head and along posterior margin of pronotum absent; inner part of clavus brown (fig. 5); scent gland evaporative area brown; vesical spicules as in figure $8 \mathrm{M}$

F. jacobsoni Poppius (fig. 5)

- Cuneus colorless or with yellow tinge; head and pronotum whitish yellow to yellow, sometimes with reddish tinge, without brown markings; inner part of clavus whitish yellow to yellow, sometimes brown basally; scent gland evaporative area whitish yellow, sometimes yellow or red apically or with greenish tinge. .32

32. Cuneus transparent with pale brown margins; scent gland evaporative area whitish yellow, sometimes with greenish tinge; medial part of right paramere only slightly wider than basal part (fig. 12S); vesical spicules as in figure $8 \mathrm{R}$

..F. lordhowensis, sp. nov. (fig. 5)

- Cuneus transparent or with reddish tinge; scent gland evaporative area whitish basally and yellow or red apically; medial part of right paramere distinctly wider, than basal part (fig. 13T); vesical spicules as in figure $9 \mathrm{M}$. .F. tanna, sp. nov. (fig. 7)

33. Collar whitish yellow to yellow with lateral sides often brown to dark brown; left paramere widened, its apical part twice as long as wide (fig. 11Q); vesical spicules as in figure 8F...F. caledonicus, sp. nov. (fig. 4)

- Collar uniformly colored, from whitish yellow to brown, often with anterior margin darkened; left paramere narrow, its apical part ca. $3-5 \times$ as long as wide (e.g., figs. 11I, K, 12A F)....... 34

34. Darker, pronotum yellow to pale brown with brown transversal stripe posteriorly or at least humeral angles brown; inner part of clavus pale brown to brown; cuneus at least partly red (fig. 4, F. bau, F. bellus; fig. 6, F. malayensis, F. senaru, F. signis)...........35

- Paler, usually mostly yellow with clavus and cuneus yellow or colorless; in some species humeral angles of pronotum brown, clavus pale brown and cuneus with red marking, but those characters never present in combination (e.g., fig. 4, F. albus, $F$ australicus, F. caledonicus; fig. 5, F. filicicola; F. linae, fig. 7, F. solomonius, F. tanna) . .37

35. Medial part of right paramere twice as wide as basal part (fig. 11J); vesical spicules as in figure $8 \mathrm{E}$.

F. bellus Liu (fig. 4)

- Medial part of right paramere only slightly wider than basal part (figs. 11H, 12Y)......36

36. Vesical spicules as in figure 8D.

..F. bau, sp. nov. (fig. 4)

- Vesical spicules as in figure 9A. ..F. malayensis, sp. nov. (fig. 6)

37. Brown marking along posterior part of pronotum present; vesical spicules as in figure 9I. .F. senaru, sp. nov. (fig. 6)

- Brown marking along posterior part on pronotum absent, sometimes only marking near humeral angle present..... 38

38. Head yellow to pale brown with brown marking on head dorsally; vesical spicules as in figure 9C.. ..F. myersi, sp. nov. (fig. 6) 
- Head whitish yellow to pale brown, without marking on head dorsally, sometimes with reddish tinge. ..39

39. Cuneus at least with yellow tinge or yellow apically; sometimes whitish yellow and opaque, sometimes mostly yellow or red...40

- Cuneus colorless and transparent, sometimes brown apically. . .53

40. Medial part of right paramere twice as wide as basal part (figs. 11A, AF, 12A, C)

- Medial part of right paramere only slightly wider or as wide as basal part (e.g., figs. 11C, E, $12 \mathrm{~K})$ .44

41. Cuneus opaque and white, brown apically; vesical spicules as in figure $8 \mathrm{~K}$

.F. indicus, sp. nov. (fig. 5)

- Cuneus opaque or translucent, at least with yellow tinge or yellow apically or along inner margin, sometimes mostly red or yellow......42

42. Labium reaching posterior margin of mesosternum; vesical spicules as in figure 8A........ .F. albus, sp. nov. (fig. 4)

- Labium reaching middle of mesosternum....43

43. Cuneus mostly with faint yellow tinge; vesical spicules as in figure 8J

.F. glabratus (Motschulsky) (fig. 5)

- Cuneus often yellow at least apically, rarely only with reddish or yellow tinge, spicules as in figure 8L.......F. insularis Miyamoto (fig. 5)

44. Clavus brown and cuneus red; vesical spicules as in figure 9K......F. signis Hsiao (fig. 6)

- Clavus mostly colorless or yellow, sometimes reddish; rarely brown or pale brown, but in this case cuneus mostly colorless and transparent or yellow......

45. Outer margin of medial part of right paramere distinctly concave, medial part of right paramere longer than apical part (figs. 11E, $12 \mathrm{G}, 13 \mathrm{C})$....

- Outer margin of medial part of right paramere straight or only slightly concave, medial part of right paramere as long as or shorter than apical part (e.g., fig. 11X, Z, AD)......47

46. Head and pronotum pale brown; vesical spicules as in figure $8 \mathrm{C}$ ..F. australicus, sp. nov. (fig. 4)
- Head and pronotum mostly yellow. 48

47. Cuneus ca. $2.5 \times$ as long as wide, mostly red; coloration of cuneus varying from transparent with red margins to almost entirely red; vesical spicules as in figure $8 \mathrm{~N}$

F. javanus Reuter (fig. 5)

- Cuneus ca. $3 \times$ as long as wide, often yellow, sometimes mostly colorless with yellow marking along inner margin or yellow with red marking along inner margin; vesical spicules as in figure 9F........... o. ochraceus Usinger (fig. 6)

48. Apical part of right paramere swollen (Carvalho, 1956: fig. 17c)

.F. adamsi Carvalho (fig. 4 )

- Apical part of right paramere not swollen, evenly tapering toward apex (e.g., figs. 11X, Z, 12K, AA, 13R). 49

49. Apical part of right paramere distinctly concave; vesical spicules as in figure 9L

.F. solomonicus, sp. nov. (fig. 7)

- Apical part of right paramere straight or only slightly concave (figs. 11C, X, AD, 12K)...50

50. Labium reaching middle of mesosternum; cuneus entirely red or yellow; vesical spicules as in figure 8B...F. amboinae Woodward (fig. 4)

- Labium almost reaching or reaching posterior margin of mesosternum; coloration of cuneus varying from colorless to uniformly red or yellow.. . .51

51. Vesica with seven spicules (fig. 8I) .F. filicicola (Kirkaldy) (fig. 5)

- Vesica with six spicules (figs. 8G, P)..............52

52. Inner part of clavus pale brown; vesical spicules as in figure 8P.......F. linae, sp. nov. (fig. 5)

- Inner part of clavus mostly whitish yellow to yellow with margin reddish or pale brown; vesical spicules as in figure 8G.

F. dauloi Woodward part 1 (fig. 4)

53. Labium reaching middle of mesosternum or slightly surpassing it; inner part of clavus pale brown. . .54

- Labium reaching posterior margin of mesosternum; inner part of clavus often colorless of whitish, sometimes pale brown, in this case humeral angles brown to dark brown............55 
54. Pair of brown to dark brown markings near humeral angles present, distinct; vesical spicules as in figure $9 \mathrm{~B}$

.F. meilingae, sp. nov. (fig. 6)

- Pair of markings near humeral angles absent or faint, mostly pale brown; vesical spicules as in figure 9J.........F. schuhi, sp. nov. (fig. 6)

55. Setae on femora mostly longer than antennal segment II diameter; humeral angles of pronotum often brown to dark brown; antennal segment I often pale brown to brown, rarely yellow; vesical spicules as in figure 8H............ elegantulus Reuter (fig. 5)

- Setae on femora shorter than antennal segment II diameter; humeral angles not darkened; antennal segment I often yellow; sometimes pale brown or reddish brown; spicules as in figure 8G...F. dauloi Woodward part 2 (fig. 4)

\section{Felisacus adamsi Carvalho, 1956}

Figures 4, 17

Felisacus adamsi Carvalho, 1956: 26 (original description).

Diagnosis: Recognized by the following combination of characters: dorsum mostly whitish yellow to yellow with reddish markings (fig. 4); antennal segment I cylindrical (as in Namyatova et al., 2016: fig. 8A), dorsal surface of labial segment II elongate posteriorly (Namyatova et al., 2016: fig. 6D); apical part of right paramere widened; middle part of right paramere less than twice as wide as basal part (Carvalho, 1956: fig. 17c).

Description: Male. See Carvalho (1956) for the original description. Female. Total length 2.9-3.1. COLORATION (fig. 4): Head: Whitish yellow to yellow, with reddish tinge and markings. Eye brown to dark brown, often with reddish margins. Labium: Yellow. Antenna: Segment I mostly red with yellow base, segments II reddish brown, segments III-IV brown to dark brown. Pronotum. Yellow with pale brown anterior margin, anterior part with longitudinal red stripe laterally; mesoscutum yellow; scutellum yellow. Thoracic pleura. Yellow; scent gland evaporative area whitish yel- low. Hemelytron: Mostly colorless and translucent; inner part of clavus mostly opaque, with reddish margins; marking along inner margin of corium faint, whitish yellow; embolium and cuneus with reddish margins, embolium yellow apically; membrane with whitish-yellow cell. Legs: Yellow with reddish markings and pale pretarsus. Abdomen: Mostly yellow, genital segments with reddish marking. SURFACE AND VESTITURE: Dorsum and femora clothed with simple setae shorter than antennal segment II diameter; antennal segment I clothed with suberect setae subequal to or shorter than antennal segment II diameter; abdomen clothed with suberect setae of different length. STRUCTURE AND MEASUREMENTS: Body 3.9-4.0 $\times$ as long as pronotum width. Head: Depression, delimiting occipital region present dorsally and laterally (as in Namyatova et al., 2016: fig. 4E); distance between depression and pronotum distinctly shorter than eye diameter; longitudinal sulcus on dorsal surface of head longer than eye diameter; distance from eye to pronotum as long as eye diameter, slightly swollen at sides (as in Namyatova et al., 2016: fig. 4E); vertex $2.2 \times$ as wide as eye; upraised (as in Namyatova et al., 2016: fig. 6D). Labium (as in Namyatova et al., 2016: figs. 6D, 9C): Segments I and II strongly reduced, combined less than half as long as segment III; segment I shorter than wide, segment II slightly longer than wide, its dorsal surface elongate posteriorly; segment III slightly shorter than head length ventrally. Antenna: Segment I cylindrical (as in Namyatova et al., 2016: fig. 8A), 1.6$1.8 \times$ as long as head width, ca. $0.9 \times$ as long as pronotum width; segent II ca. $1.6-1.8 \times$ as long as width of head, ca. $1.0-1.1 \times$ as long as pronotum width; segment IV ca. $0.25 \times$ as long as segment III. Thorax: Anterior part of pronotum distinctly shorter than posterior part; collar delimited; posterior part slightly upraised posterior margin of pronotum straight; pronotum $1.2 \times$ as long and ca. $1.6 \times$ as wide as head; mesoscutum slightly exposed. Hemelytron: Area along inner margin of corium not swollen; inner margin of cuneus convex (as in Namyatova et al., 2016: fig. 13E), medial margin of cuneus ca. $3 \times$ as long as base. Genitalia 
(from Carvalho, 1956): Genital capsule and aedeagus not examined. Right paramere (Carvalho, 1956: fig. 17c). Apical part distinct, broad, straight posteriorly; medial part less than twice as wide as basal part, bearing setae, with outer margin slightly concave and inner margin with distinct swelling; outer angle distinct, widened; inner angle rounded, without setae; basal part twice shorter than rest of paramere. Left paramere (Carvalho, 1956: fig. 17d) paramere L-shaped; apical part not flattened, with toothlike outgrowth on posterior side medially and without outgrowth on dorsal surface; middle part widened, without swelling or outgrowth(s).

Distribution: Micronesia, Ponape Is. (fig. 17). Host Plants: Unknown.

Discussion: F. adamsi has similar external morphology to several other species, including $F$. auritulus, F. dauloi, F. filicicola, F. insularis, F. ochraceus, F. schuhi, and F. tanna. (figs. 4-7). We have not been able to examine the male genitalia of this species, because only paratype females were available for study from the NMNH. According to the illustrations given by Carvalho (1956), F. adamsi has a unique right paramere with a broad apical part (Carvalho, 1956: fig. 17c).

Material eXAmined: Paratypes: MICRONESIA: Pohnpei: Ponape Island, Tolotom, $6.83602^{\circ} \mathrm{N}$ $158.16668^{\circ} \mathrm{E}, 518 \mathrm{~m}$, Jun $1950-$ Sep 1950 , P.A. Adams, $2+$ (00338824; 00341130) (USNM).

\section{Felisacus albus, sp. nov.}

Figures 4, 8A, 11A, B, 14A, 17

Diagnosis: Recognized by the following combination of characters: pale yellow to white coloration of dorsum with cuneus mostly red (fig. 4), antennal segment I cylindrical (as in Namyatova et al., 2016: fig. 8A), transverse depression delimiting occipital region extending laterally, vertex upraised, dorsal surface of labial segment II elongate posteriorly (as in Namyatova et al., 2016: fig. 6D); and unique combination of seven vesical spicules, having spicules $B$ and $F$ and lacking spicule A, and having large weekly sclerotized serrate spicule (fig. 8A).
Description: Male. Total length 3.7-4.3. ColORATION (fig. 4): Head: Mainly whitish yellow to yellow with reddish tinge and markings, dorsal surface of head darker anteriorly and along transverse depression. Eye brown with reddish tinge. Labium: Segments I-III whitish yellow to yellow, segment IV yellow. Antenna: Segments I-II yellow with reddish stripes, segments III-IV yellow to pale brown, with reddish tinge. Pronotum. Anterior part yellow with whitish yellow collar; anterior margin and punctures between anterior and posterior parts pale brown; stripe laterally reddish; posterior part whitish yellow, with brown posterior angles; scutellum and mesoscutum whitish yellow with pale brown punctures between them. Thoracic pleura. Yellow markings near forecoxa whitish yellow; scent gland evaporative area whitish yellow with yellow apex. Hemelytron: Mostly translucent, colorless; inner part sometimes with yellow tinge, translucent or opaque, with yellow to pale brown margins; corium with marking along inner margin of corium pale brown, darker anteriorly, not extending toward $\mathrm{R}+\mathrm{M}$; embolium whitish yellow, opaque, with reddish apex and pale brown outer margin; cuneus whitish yellow to yellow with reddish tinge, opaque with pale brown apex and brownish margins; membrane cell whitish yellow. Legs: Coxae whitish yellow; femora whitish yellow, yellow apically, with reddish stripe; tibiae whitish yellow to yellow with reddish stripe; tarsi pale brown. Abdomen: Whitish yellow, red dorsally. SURFACE AND VESTITURE: Corium smooth, with shallow and scarce punctures. Dorsum with suberect setae longer than antennal segment II diameter; antennal segment I and femora with suberect setae shorter than antennal segment II diameter; abdomen clothed with suberect mostly short simple setae. STRUCTURE AND MEASUREMENTS: Body ca. $4.2-4.3 \times$ as long as pronotum width. Head: Depression delimiting occipital region present dorsally and laterally (as in Namyatova et al., 2016: fig. 4E); distance between depression and pronotum distinctly shorter than eye diameter; longitudinal sulcus on dorsal surface longer than eye diameter; distance from eye to pronotum 
slightly longer than eye diameter, not swollen laterally (as in Namyatova et al., 2016: fig. 4E); vertex ca. $1.5 \times$ as wide as eye; upraised (as in Namyatova et al., 2016: fig. 6D); buccula ca. $0.2-0.25 \times$ as long as clypeus. Labium (as in Namyatova et al., 2016: figs. 6D, 9C): Reaching posterior margin of mesosternum or slightly surpassing it; segments I and II strongly reduced, together less than half as long as segment II; segment I as long as wide, segment II slightly longer than wide, its dorsal surface elongate posteriorly; segment III slightly longer than ventral side of head; segment IV ca. $1.5 \times$ as long as segment III. Antenna: Segment I cylindrical (as in Namyatova et al., 2016: fig. 8A), ca. 1.4× as long as head, ca. $1.1-1.2 \times$ as long as pronotum width; segment III slightly longer than segment II; segment IV ca. $0.3 \times$ as long as segment III. Thorax: Anterior and posterior parts subequal in length; collar distinct; posterior part slightly upraised; posterior margin concave; pronotum ca. $1.2-1.4 \times$ as wide as long and ca. $1.5-1.7 \times$ as wide as head; mesoscutum exposed. Hemelytron: Area along inner margin of clavus almost flat; inner margin of cuneus convex (as in Namyatova et al., 2016: fig. 13E), outer margin of cuneus ca. $2.5 \times$ as long as base. Abdomen: Genital capsule rotated left at right angle relative to rest of abdomen. Genitalia: Genital capsule (fig. 14A) as long as wide, its ventral wall almost twice as long as dorsal wall; posterior margin of ventral wall smooth, semioval, without outgrowth, not pointed, not curved dorsally; its apex inclined rightward; walls of genital capsule not modified; angles of paramere sockets rounded; distance between paramere sockets subequal to half width of genital capsule at base. Right paramere (fig. 11A) outer margin of apical part slightly concave; medial part more than twice as wide as basal part, bearing setae, with outer margin straight and inner margin convex; outer angle distinct, not widened; inner angle rounded, without setae; basal part ca. $0.2-0.25 \times$ as long as rest of paramere. Left paramere (fig. 11B) L-shaped; apical part not flattened, with toothlike outgrowth on posterior side medially (as in fig. $11 \mathrm{G}$ ) and without outgrowth on dorsal surface; middle part widened, without swelling or outgrowth(s); setae present only on middle part near outer margin. Aedeagus (general view as in Namyatova et al., 2016: fig. 22I) conjunctiva weakly sclerotized; secondary gonopore placed at base of vesica in repose; sclerotization of ductus seminis around secondary gonopore shorter than wide; vesica with seven spicules, including spicules $\mathrm{A}$ and $\mathrm{F}$ (fig. 8A).

Female. Total length 3.8. COLORATION (fig. 4): Similar to male, but dorsal surface of head with reddish tinge anteriorly and along transverse depression; posterior part of pronotum whitish yellow with brown posterior margin, clavus whitish and transparent with pale brown margins. SURFACE AND VESTITURE: As in male. STRUCTURE AND MEASUREMENTS: Structure as in male; body ca. $3.7 \times$ as long as pronotum width; vertex in males ca. $1.8 \times$ as wide as eye; antennal segment I ca. $1.2 \times$ as long as head width, ca. $0.7 \times$ as long as pronotum width; segment II ca. $1.7 \times$ as long as head width, ca. $1.0 \times$ as long as pronotum width; pronotum ca. $1.4 \times$ as wide as long and ca. $1.8 \times$ as wide as head.

Distribution: Known from Taiwan (fig. 17).

Host PLANTs: Collected from Lygodium flexuosum (Schizaeaceae).

Eтyмоlogy: The species is named for its very pale, almost white coloration, albus in Latin, meaning "white."

Discussion: Female genitalia were not dissected. Felisacus albus forms a monophyletic group with F. glabratus, F. indicus and F. insularis (figs. 1-3). All those species are similar to each other in coloration (figs. 4,5 ), in the middle part of the right paramere more than twice as wide as its basal part (figs. 11A, AF, 12A, C), and in the shape and configuration of the vesical spicules (fig. 8A, J, K, L). Felisacus albus is most similar to $F$. insularis externally and in morphology of spicules, including spicules $\mathrm{B}$ and $\mathrm{F}$ (cf. fig. 8A with L). Felisacus insularis differs in having a yellow body (fig. 5) and the presence of five vesical spicules (fig. 8K). Felisacus glabratus and F. indicus differ from $F$. albus in having a mostly yellow or colorless cuneus and five vesical spicules. 

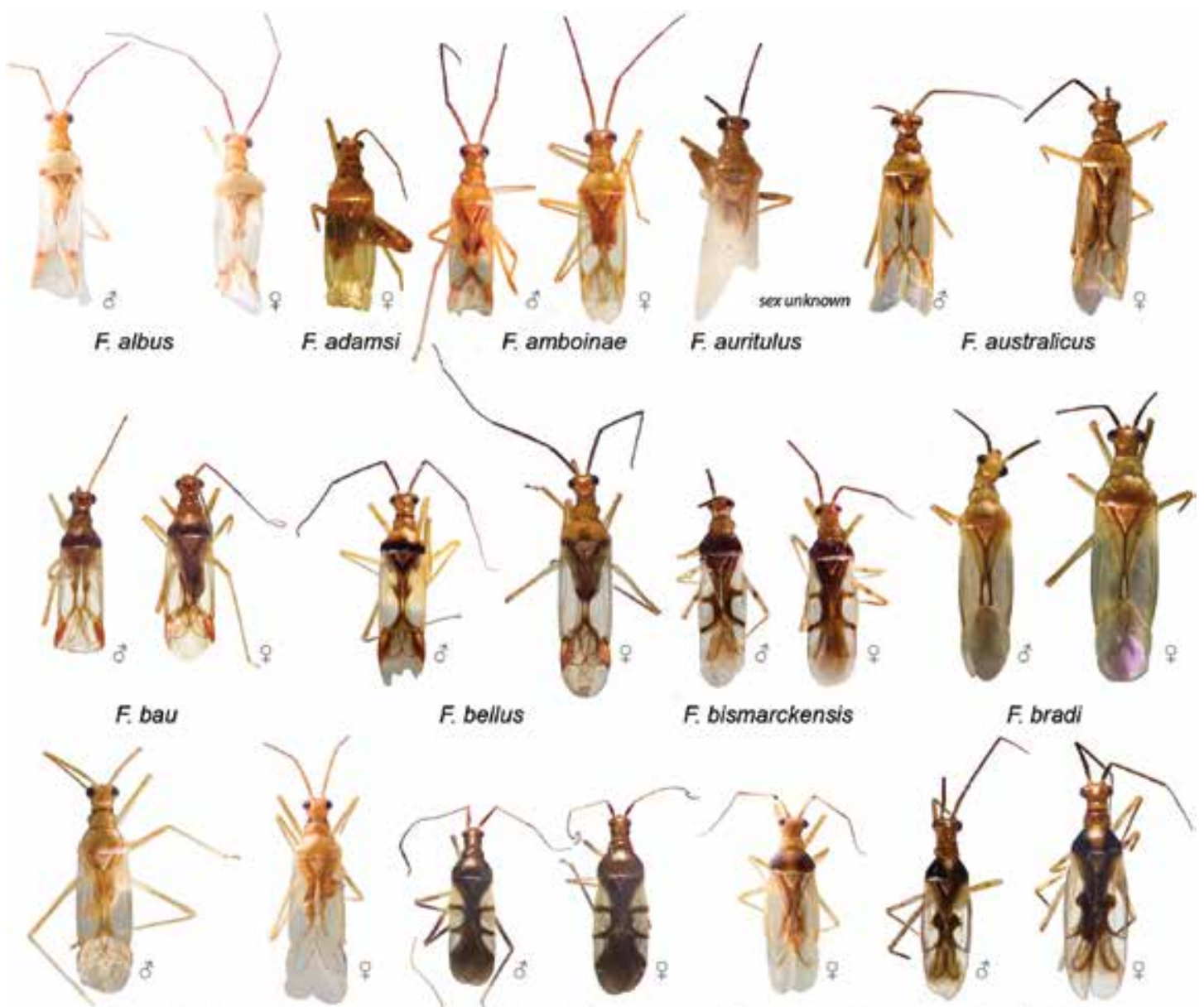

F. bellus

F. bismarckensis
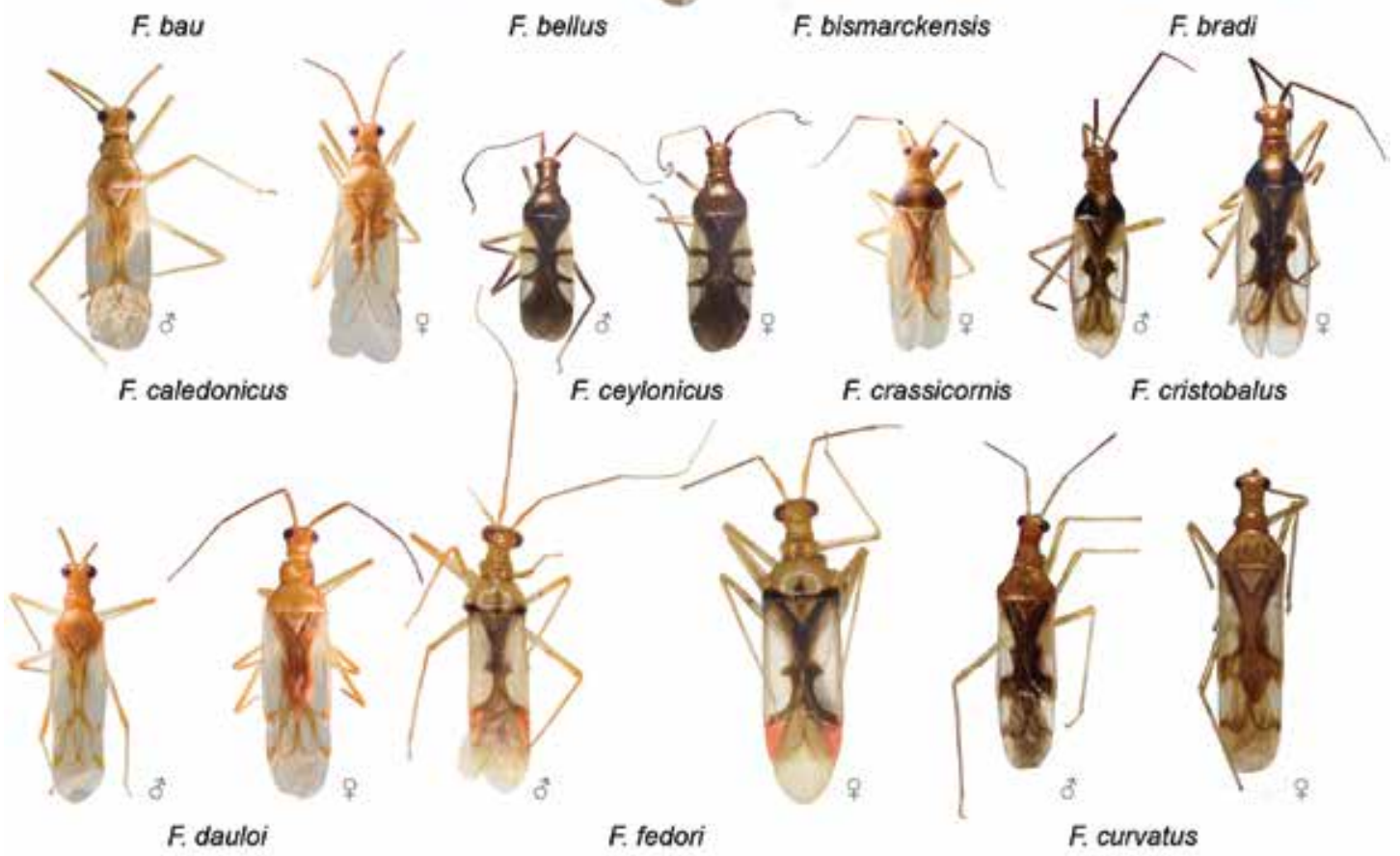

FIGURE 4. Habitus of Felisacus species. 


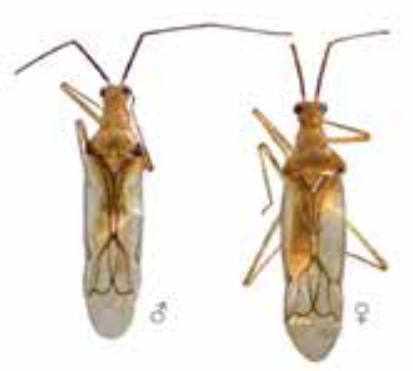

F. elegantulus
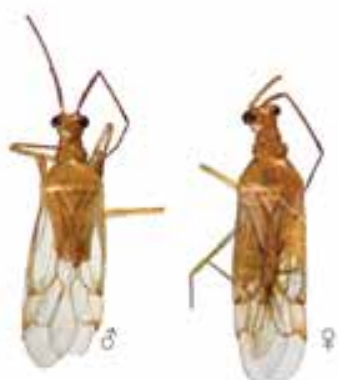

F. insularis
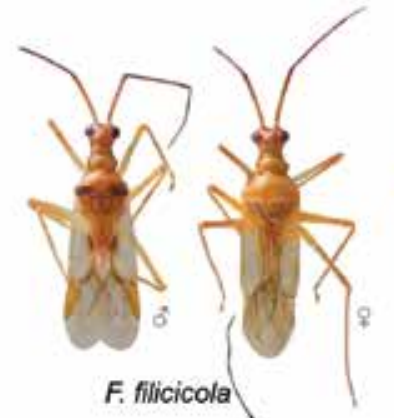

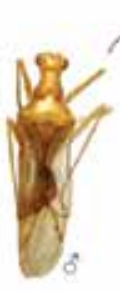

F. glabratus

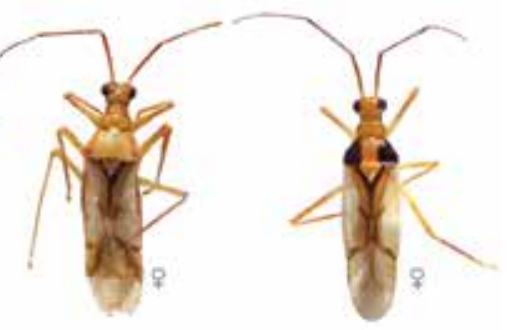

F. gressitti
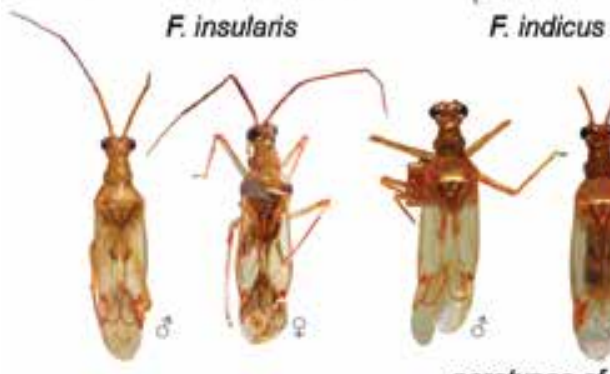

$\boldsymbol{F}$. indicus
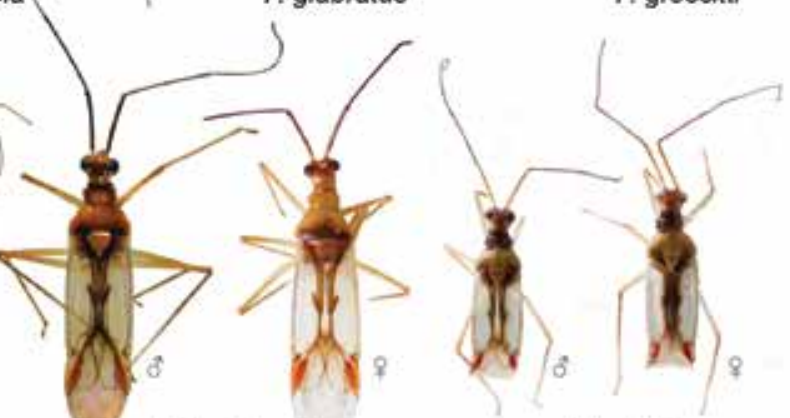

F jacobsoni

F. lambkinae

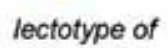

$F$. javanus

F. javanus

paratypes of

F. carpenterae

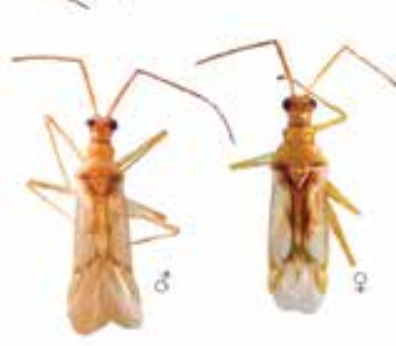

F. linee

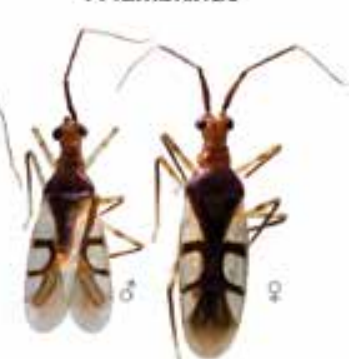

F. lindbergae

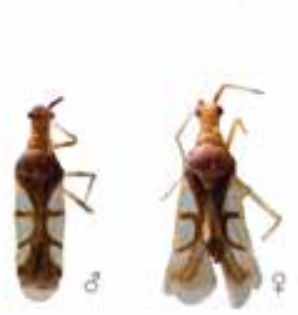

F. longiceps

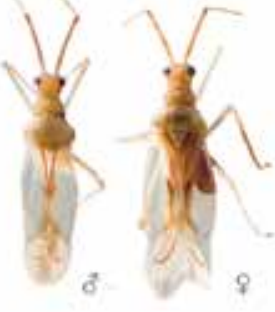

F. lordhowensis

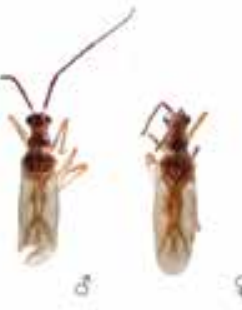

F. liui

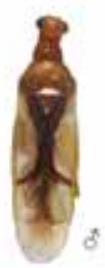

F. luzonus

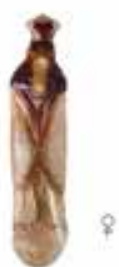

F. madagascaniensis

FIGURE 5. Habitus of Felisacus species. 


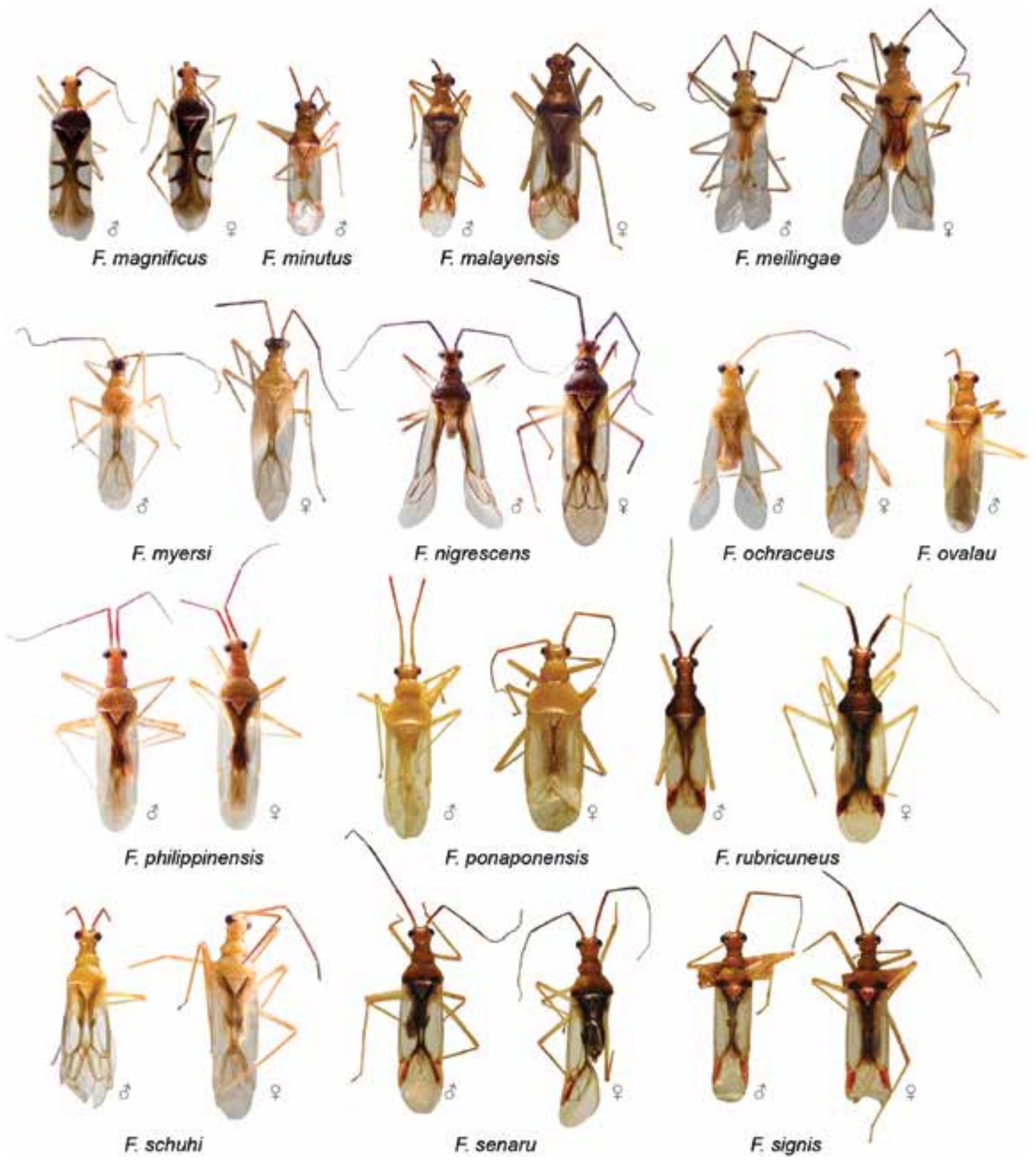

FIGURE 6. Habitus of Felisacus species. 


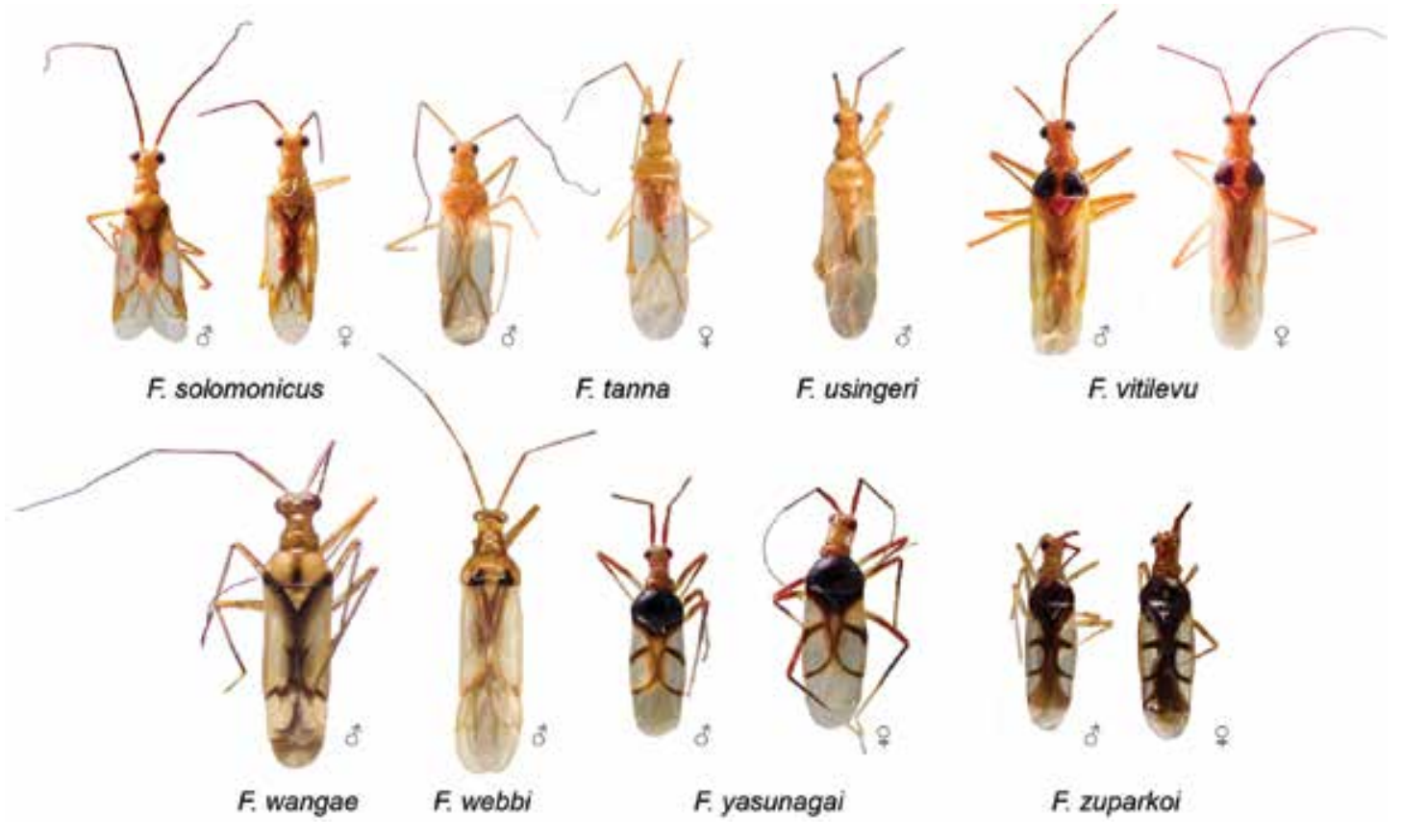

FIGURE 7. Habitus of Felisacus species.

Material examined: Holotype: THAILAND: Changwat Chiang Mai: Chomtong: Mae Klang Waterfall, $18.54944^{\circ} \mathrm{N} 98.56722^{\circ} \mathrm{E}, 28 \mathrm{Nov}$ 1998, A.D. Wright, Lygodium flexuosum (Schizaeaceae), 10 (00017861) (AM). Paratypes: THAILAND: Changwat Chiang Mai: Chomtong: Mae Klang Waterfall, $18.54944^{\circ} \mathrm{N} 98.56722^{\circ} \mathrm{E}, 28 \mathrm{Nov}$ 1998, A.D. Wright, Lygodium flexuosum (Schizaeaceae), 1 하 (00017860), 1 우 (00017862) (AM).

\section{Felisacus amboinae Woodward}

Figures 4, 8B, 11C, D, 14B, 17

Felisacus amboinae Woodward, 1954: 45 (original description).

Diagnosis: Recognized by the following combination of characters: mostly yellow coloration of dorsum with reddish tinge on cuneus (fig. 4), cylindrical antennal segment I (as in Namyatova et al., 2016: fig. 8A), transverse depression on head extending laterally, vertex upraised, dorsal surface of labial segment II elongate posteriorly (Namyatova et al., 2016: fig. 6D); body length $3.0-3.3$ in male; cuneus ca. $2.5 \times$ as long as base; inner margin middle part of right paramere less than twice as wide as basal part and its apical part as long as medial part, in outer margin only slightly concave posteriorly (fig. $11 \mathrm{C}$ ), vesica with four straight spicules, including spicules A, B, and C (fig. 8B).

Redescription: Male. Total length 3.0-3.3. COLORATION (fig. 4): Head: Mostly pale brown, with reddish tinge, ventral side yellow to pale brown. Eye dark brown to black. Labium: Yellow. Antenna: Segment I yellow with reddish tinge, segment II reddish brown; segment III brown. Thorax: Pronotum and scutellum yellow; pronotum with pale brown marking close to humeral angle, anterior margin sometimes pale brown; thoracic pleura yellow; scent gland evaporative area yellow, reddish apically. Hemelytron: Mostly translucent, colorless; inner part of clavus with yellow tinge and reddish yellow margins; marking along inner margin of corium mostly yellow to pale brown, brown along apical part of clavus; embolium with pale brown or red margins; cuneus yellow with reddish tinge or margins sometimes reddish brown. Legs: Coxae 
yellow; femora yellow, reddish apically; tibiae mostly reddish yellow, yellow apically; tarsi yellow with segment III reddish. Abdomen: Mostly yellow. SURFACE AND VESTITURE: Body clothed with setae mostly shorter than antennal segment II diameter; dorsum with scarce setae mostly shorter than antennal segment II diameter; antennal segments I, II and femora clothed with suberect setae mostly shorter than width antennal segment II diameter; abdomen clothed with short setae. STRUCTURE AND MEASUREMENTS: Body ca. $4.1-4.4 \times$ as long as pronotum width. Head: Depression delimiting occipital region distinct dorsally and laterally (as in Namyatova et al., 2016: fig. 4E); distance between depression and pronotum shorter than eye diameter; longitudinal sulcus on dorsal surface subequal to eye diameter; distance from eye to pronotum subequal to or slightly longer than eye diameter, not swollen laterally (as in Namyatova et al., 2016: fig. 4E); vertex ca. 1.6-1.7× as wide as eye, upraised (Namyatova et al., 2016: fig. 6D). Labium (as in Namyatova et al., 2016: figs. 6D, 9C): Reaching middle of mesosternum; segments I and II strongly reduced; combined less than half as long as segment III; segment II slightly swollen and elongate dorsally; covering base of segment III; segment III slightly shorter than length of head ventrally; segment IV twice as long as segment III. Antenna: Segment I cylindrical (as in Namyatova et al., 2016: fig. $8 \mathrm{~A})$, ca. $1.6-1.7 \times$ as long as head width, ca. 1.1$1.2 \times$ as long as pronotum width; segment II ca. $2.0 \times$ as long as head width, ca. $1.3-1.4 \times$ as long as pronotum width. Thorax: Anterior part of pronotum distinctly shorter than posterior part; collar distinct; posterior part of pronotum only slightly upraised; posterior margin of pronotum slightly concave; pronotum ca. $1.2 \times$ as wide as long and $1.4-1.6 \times$ as wide as head. Hemelytron: Area along inner margin of corium almost flat; inner margin of cuneus convex (as in Namyatova et al., 2016: fig. 13E), outer margin of cuneus ca. $2.5 \times$ as long as base. Abdomen: Genital capsule rotated left at right angle relative to rest of abdomen. Genitalia: Genital capsule (fig.
14B) ventral wall ca. $1.7 \times$ as long as dorsal wall; its posterior margin smooth, semioval, without outgrowth, rounded, not curved dorsally; apex slightly inclined leftward; sides of genital capsule not modified, angles of paramere sockets more or less rounded, not projecting; distance between paramere sockets subequal to half width of genital capsule at base; right angle of left paramere socket not projecting. Right paramere (fig. 11C) apical part distinct; apex only slightly concave posteriorly; medial part only slightly wider than basal part, bearing setae, with outer margin slightly concave and inner margin convex; outer angle distinct, widened; inner angle rounded, without setae; basal part ca. $0.15-0.2 \times$ as long as rest of paramere. Left paramere (fig. 11D) L-shaped; apical part not flattened, with toothlike outgrowth on posterior side medially and without outgrowth on dorsal surface; middle part widened, without swelling or outgrowth(s); setae placed only on middle part near outer margin of paramere. Aedeagus (general view as in Namyatova et al., 2016: fig. 2IF, G) conjunctiva weakly sclerotized; secondary gonopore placed at base of vesica in repose; sclerotization of ductus seminis around secondary gonopore shorter than wide; vesica bearing four spicules, including spicules $\mathrm{A}, \mathrm{B}$, and $\mathrm{C}$ (fig. 8B).

Female. Total length 3.1-3.4. Coloration (fig. 4): Similar to male, but antennal segment IV brown; head and pronotum often with reddish tinge; tarsal segments I-II yellow and segment III pale brown to brown or entire tarsi pale brown to brown; scent gland evaporative area as in male or whitish yellow, yellow apically, sometimes uniformly yellow; abdomen yellow with red markings. SURFACE AND VESTITURE: As in male. STRUCTURE AND MEASUREMENTS: As in male, antennal segment III subequal to segment II, segment IV ca. $0.7 \times$ as long as segment III. Genitalia (general view as in Namyatova et al., 2016: fig. 23F, G): Dorsal labiate plate wider than distance between apodemes of second valvula; mostly smooth, without distinct striations, with semicircular sclerite and distinct 

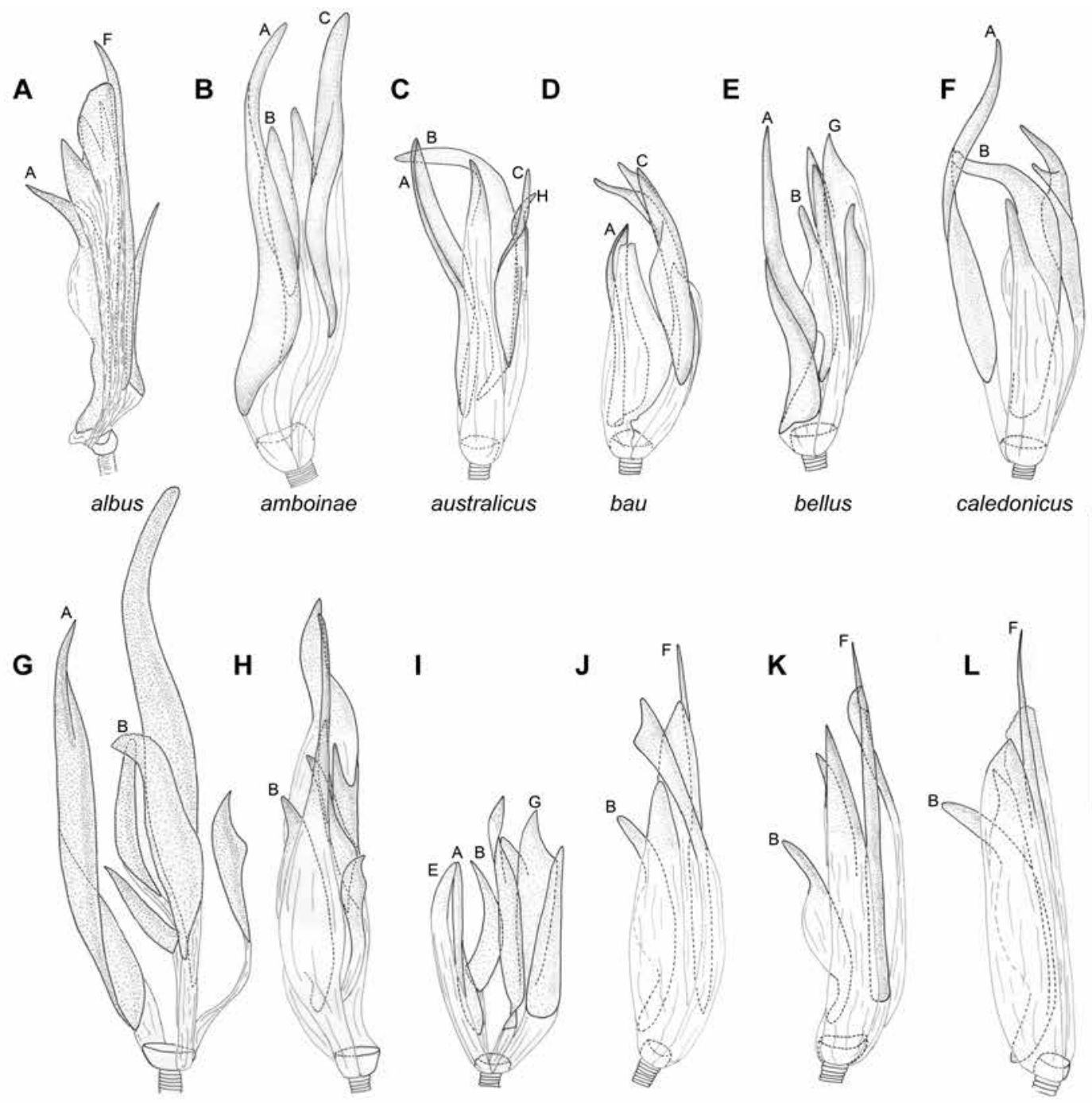

bau

$$
\text { bellus }
$$

caledonicus
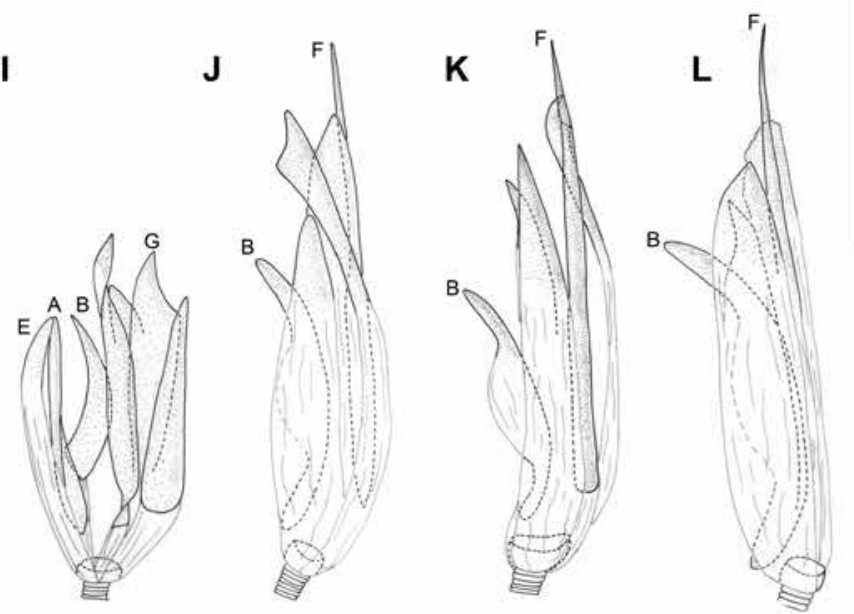

dauloi

elegantulus

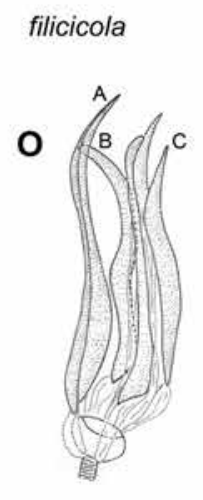

glabratus ne indicus

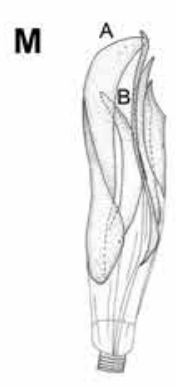

jacobsoni

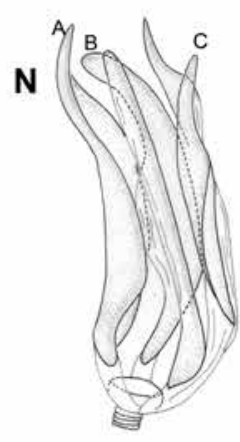

javanus

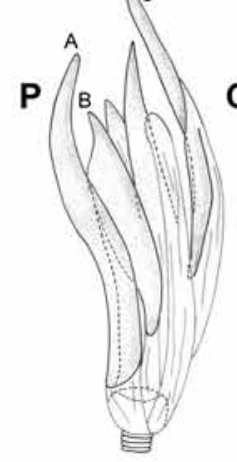

linae

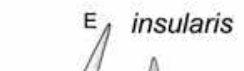

Q

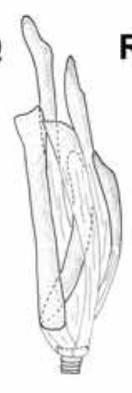

liui

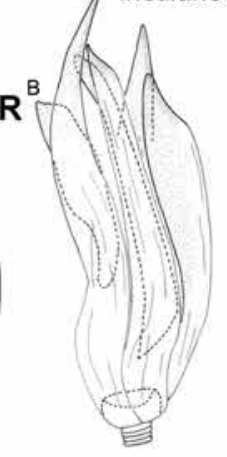

lordhowensis

FIGURE 8. Vesical spicules of Felisacus species. 

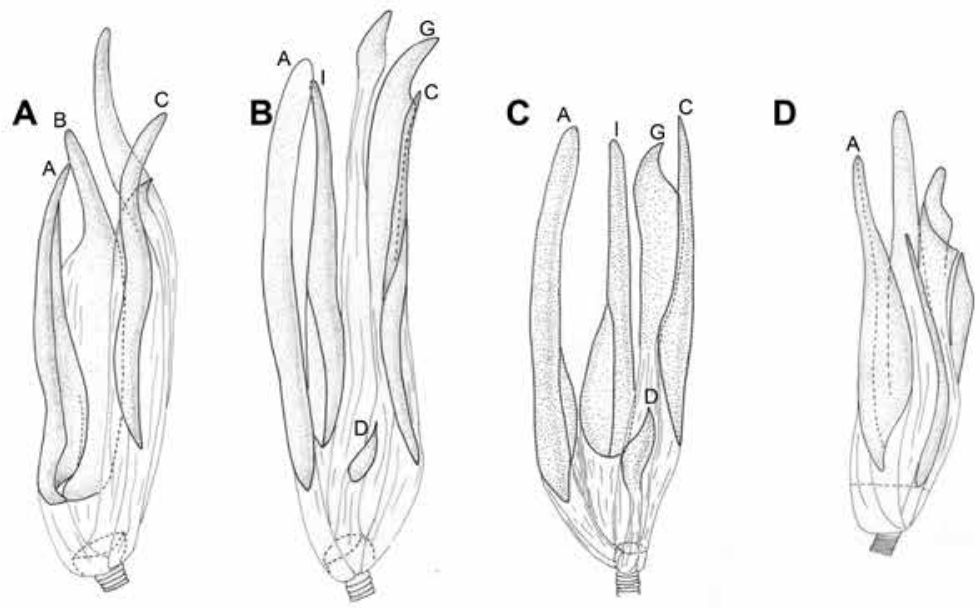

malayensis

meilingae

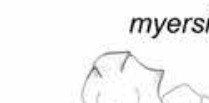

minutus

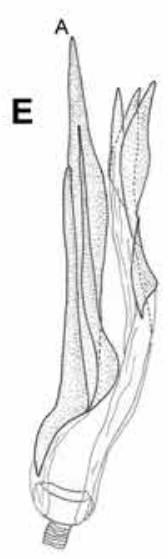

F

G
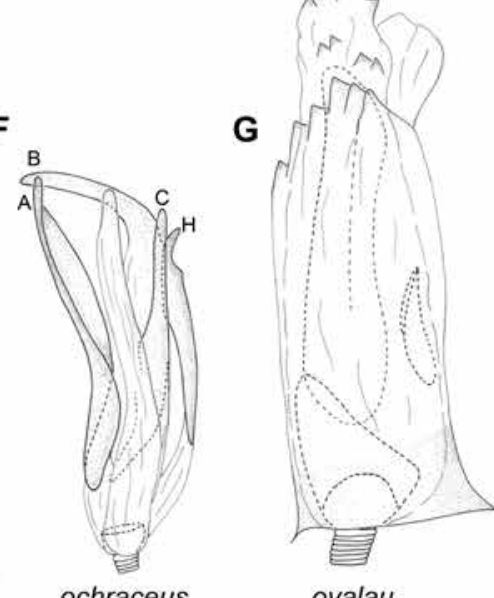

H

I
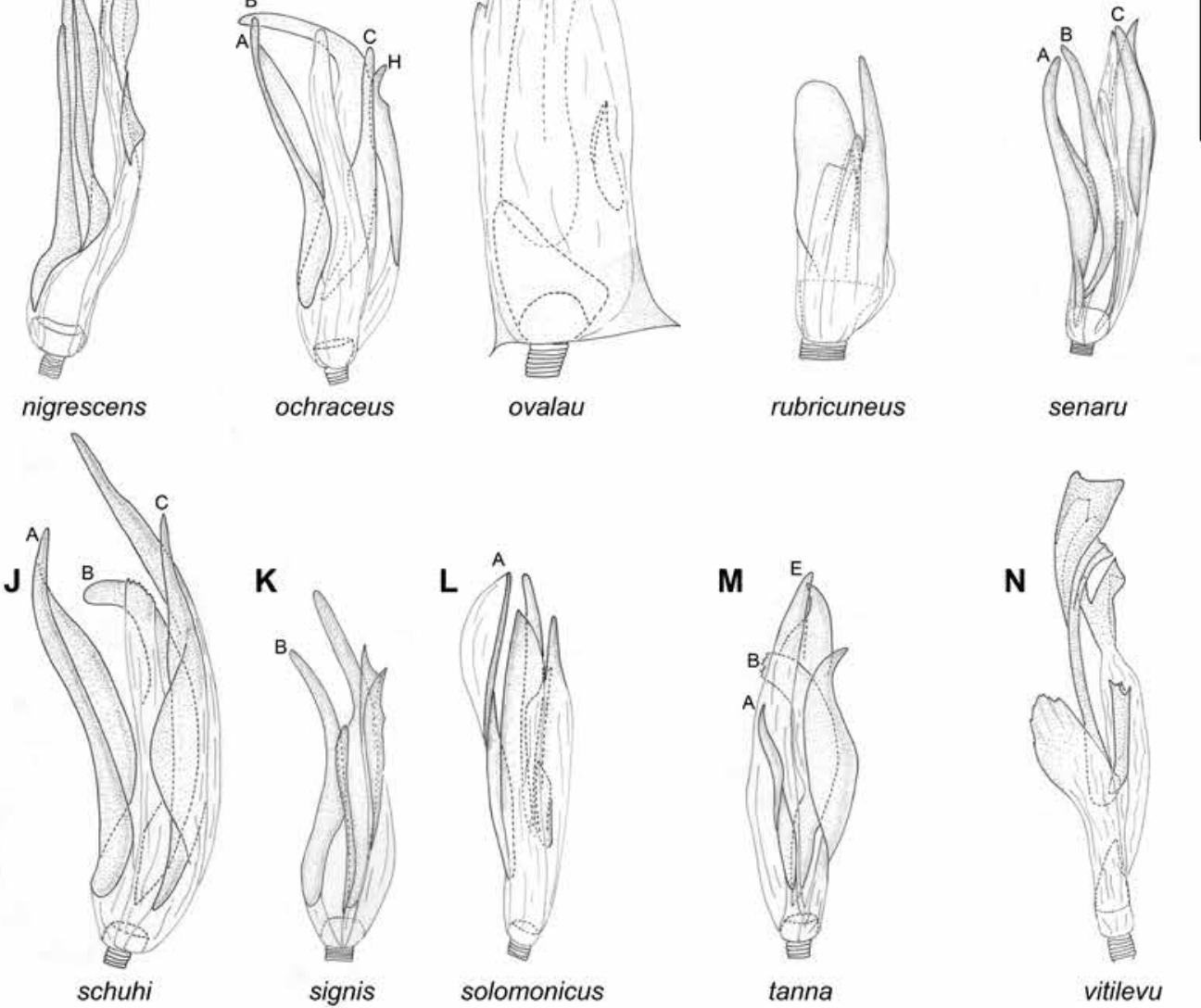

$$
\text { ochraceus }
$$

ovalau

rubricuneus

senaru

K

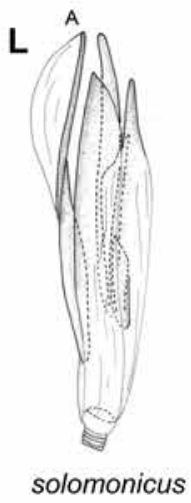

M

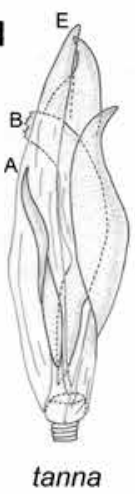

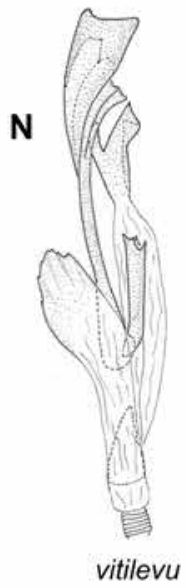

FIGURE 9. Vesical spicules of Felisacus species. 
A

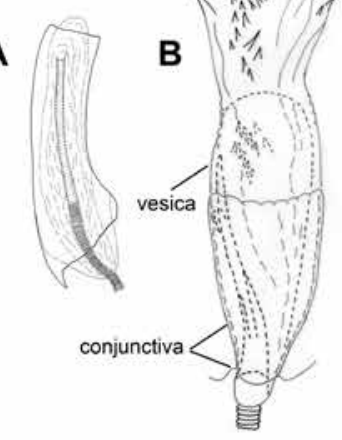

bismarckensis bradi

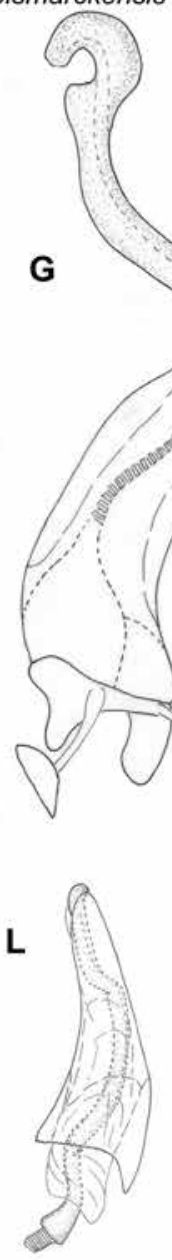

ponaponensis

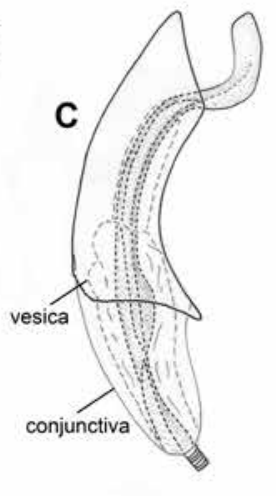

ceylonicus

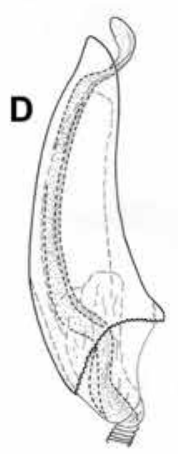

cristobalus
E

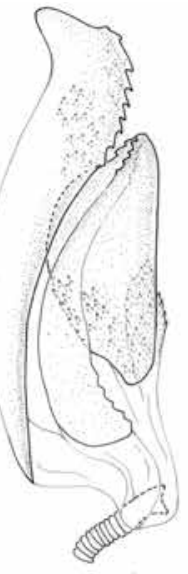

curvatus

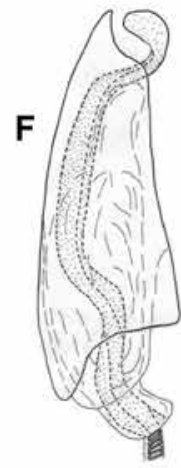

lindbergae

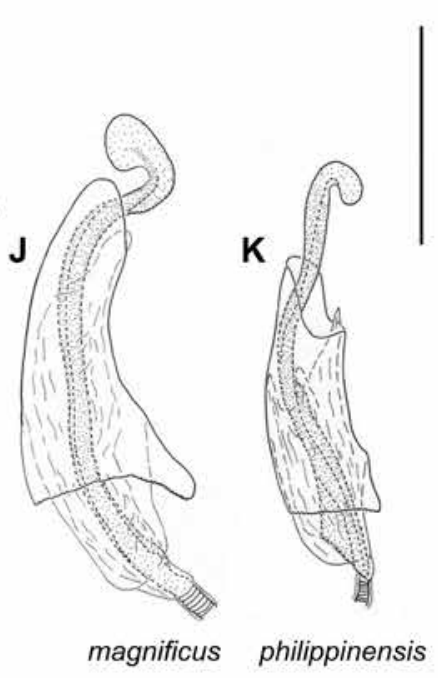

magnificus philippinensis

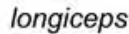

longiceps

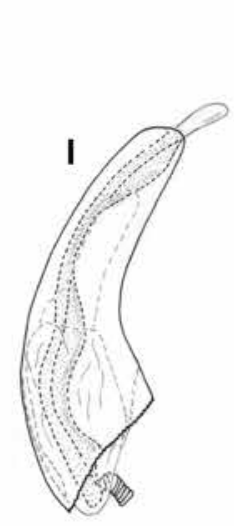

luzonus

luzonus

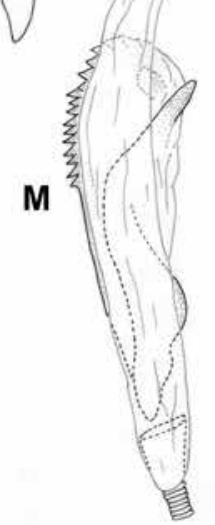

wangae

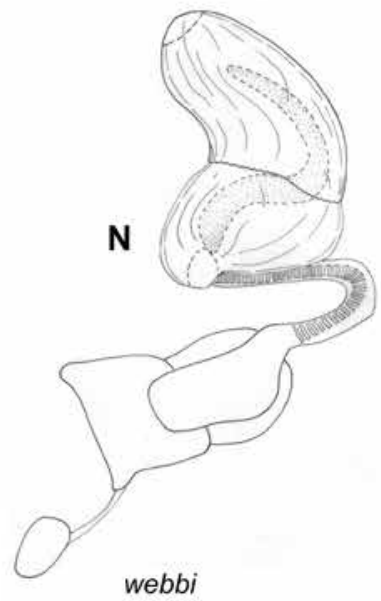

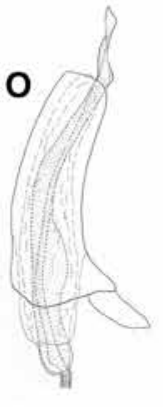

yasunagai

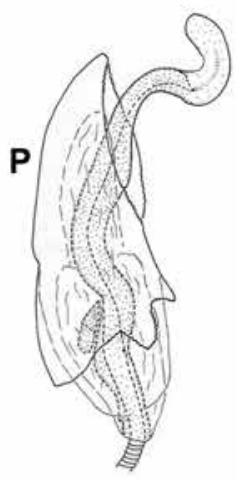

zuparkoi

FIGURE 10. A, C-L, O, P. Apical part of aedeagus of Felisacus species B, E, M. Vesica of Felisacus species. N. Aedeagus of $F$. webbi. 

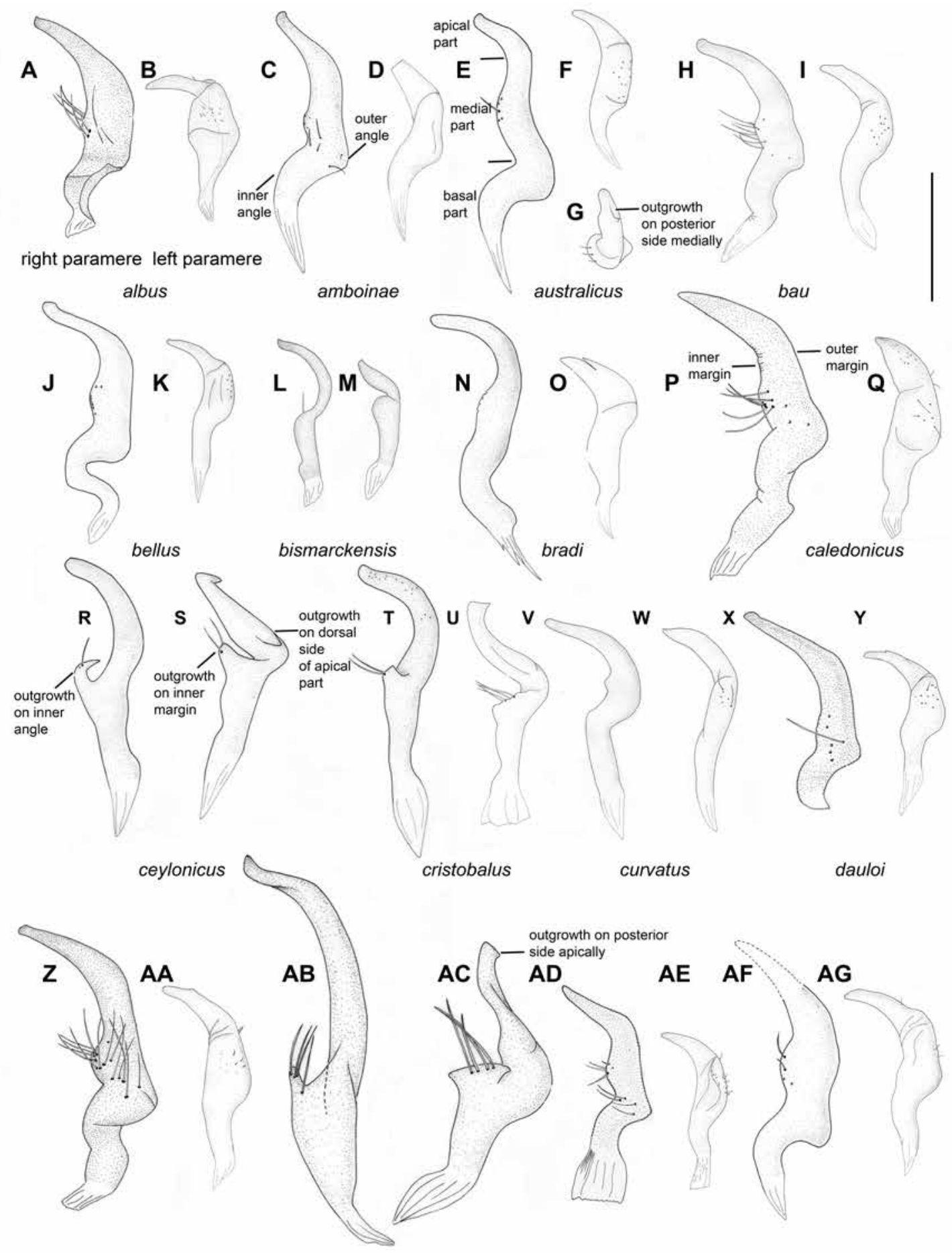

elegantulus

fedori

filicicola

glabratus

FIGURE 11. Parameres of Felisacus species. 
46

BULLETIN AMERICAN MUSEUM OF NATURAL HISTORY

NO. 403

A

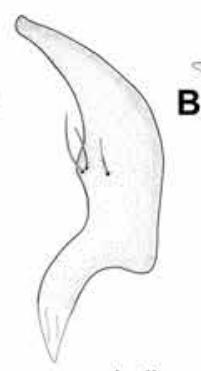

indicus

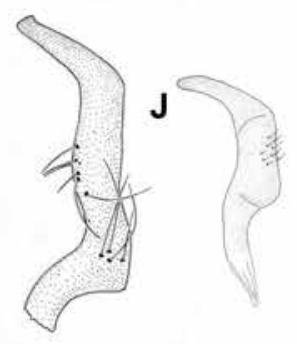

lambkinae
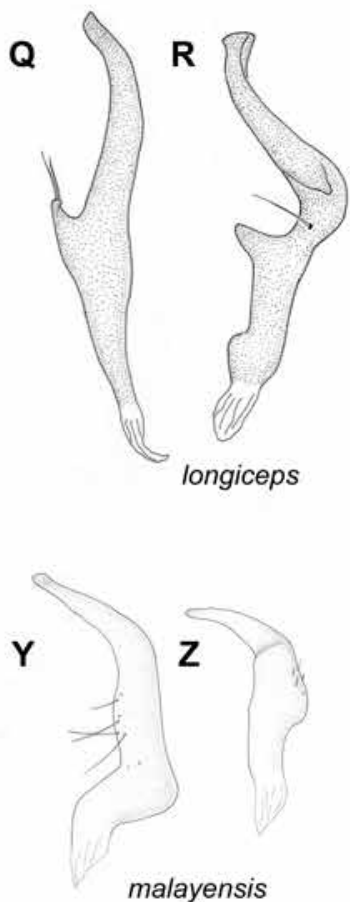
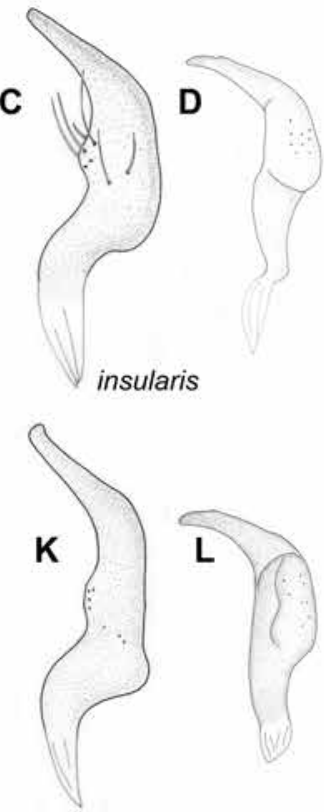

linae

S

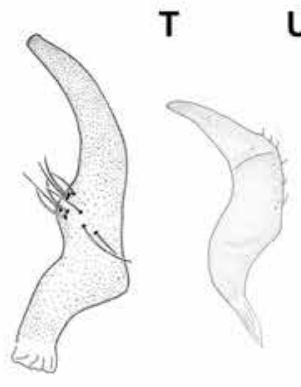

lordhowensis

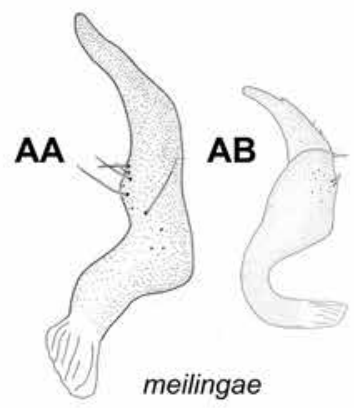

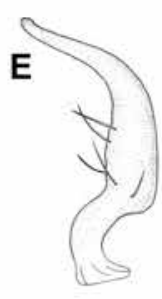

$\mathbf{F}$

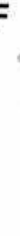

jacobsoni

L

N

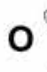

javanus

G

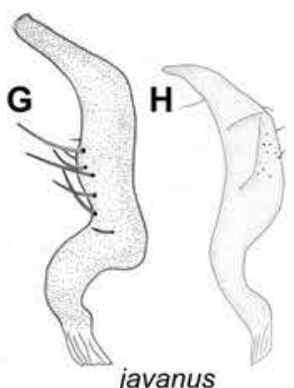

o

$\mathbf{P}$

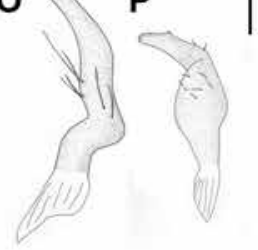

lindbergae

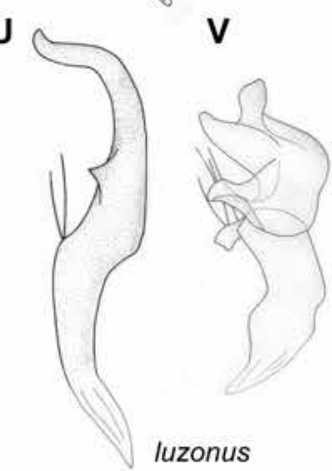

W

liui

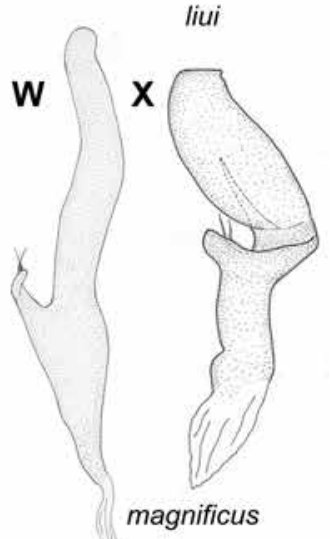

FIGURE 12. Parameres of Felisacus species. 

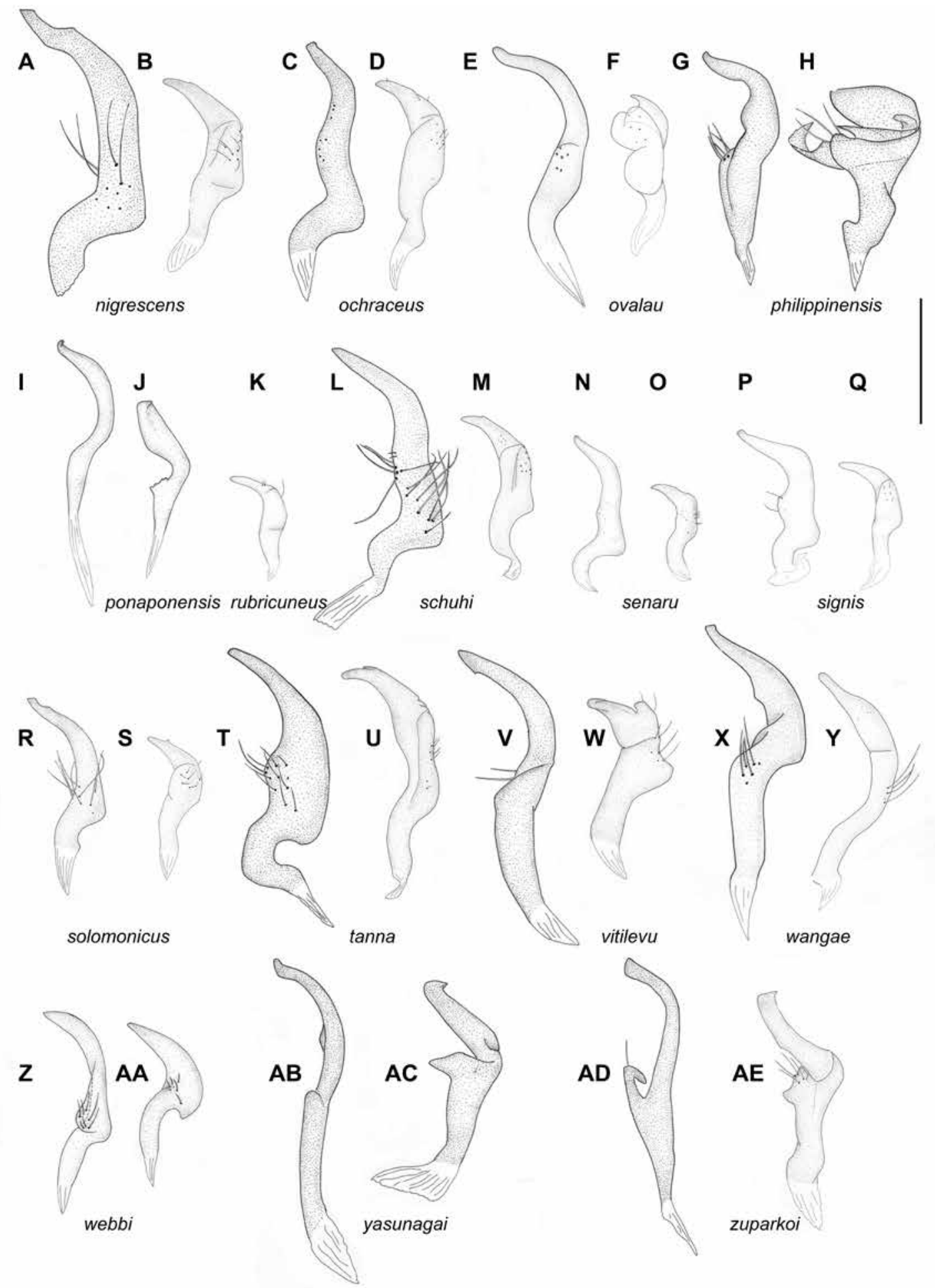

FIGURE 13. Parameres of Felisacus species. 
A

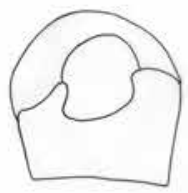

albus

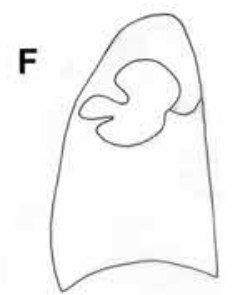

bradi

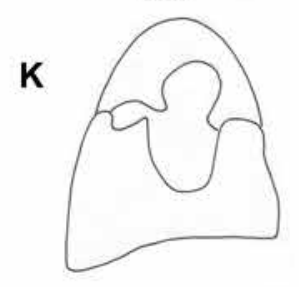

dauloi

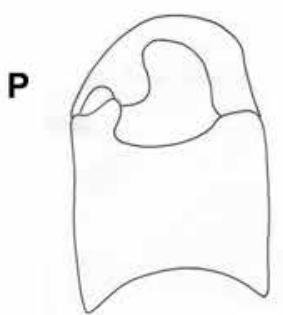

insularis

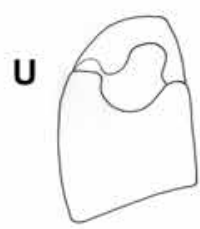

liui
B

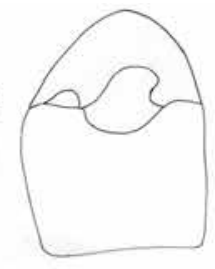

amboinae
C
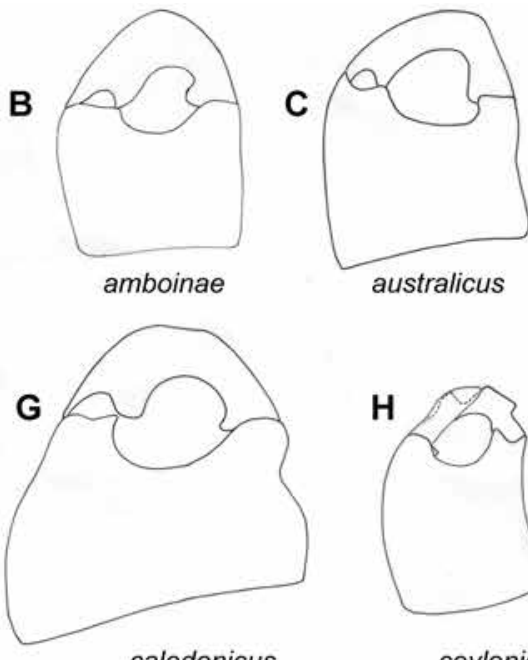

caledonicus

australicus
D

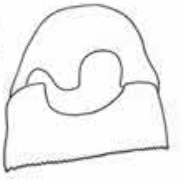

bau

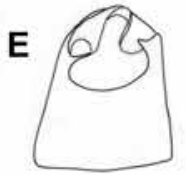

bismarckensis

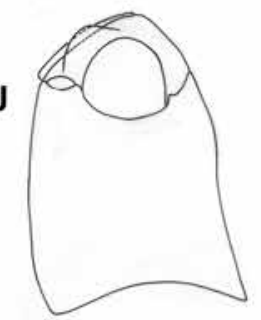

curvatus
H

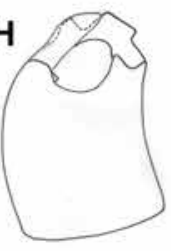

ceylonicus

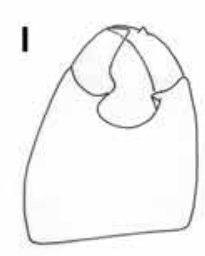

cristobalus

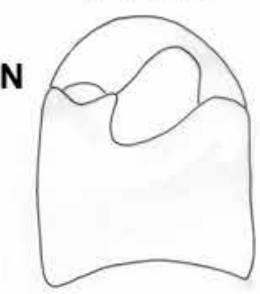

glabratus

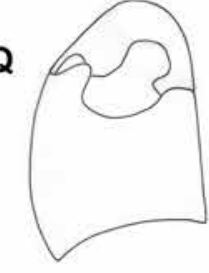

javanus

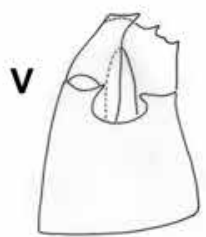

longiceps
R

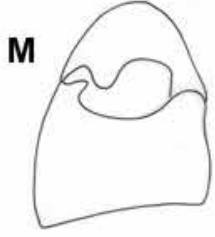

filicicola

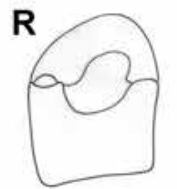

lambkinae

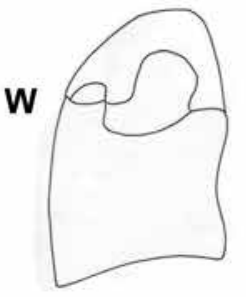

lordhowensis

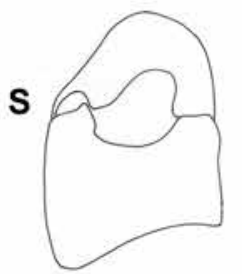

linae

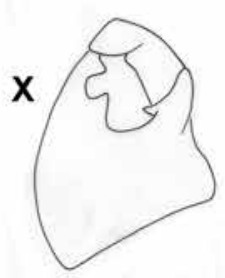

luzonus

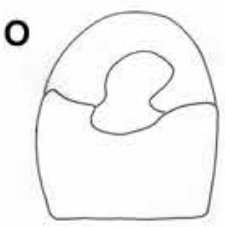

indicus

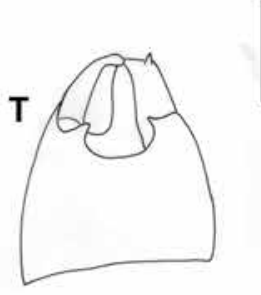

lindbergae

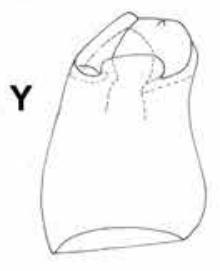

magnificus

FIGURE 14. Genital capsule of Felisacus species. 

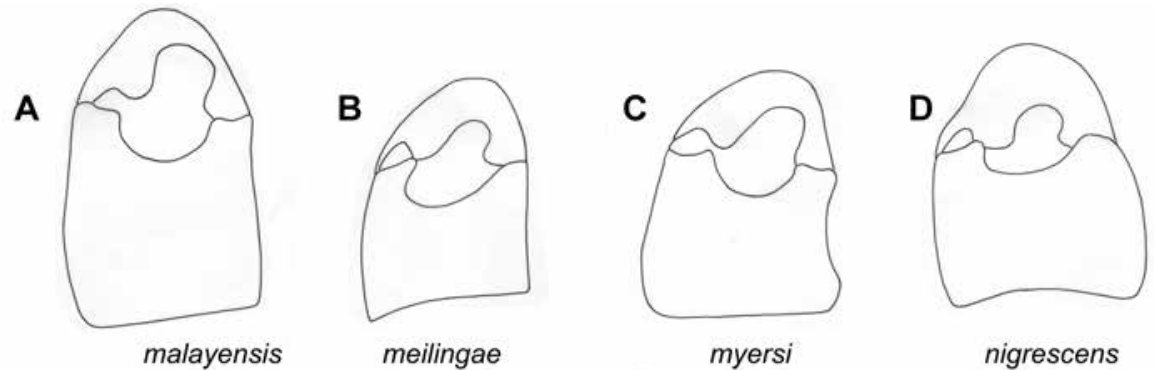

myersi

nigrescens
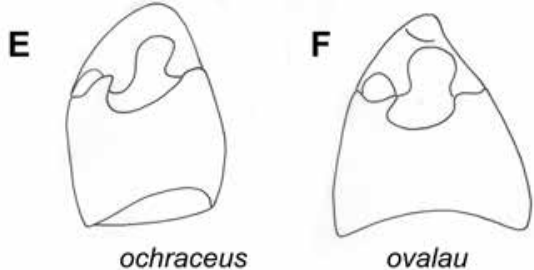

G
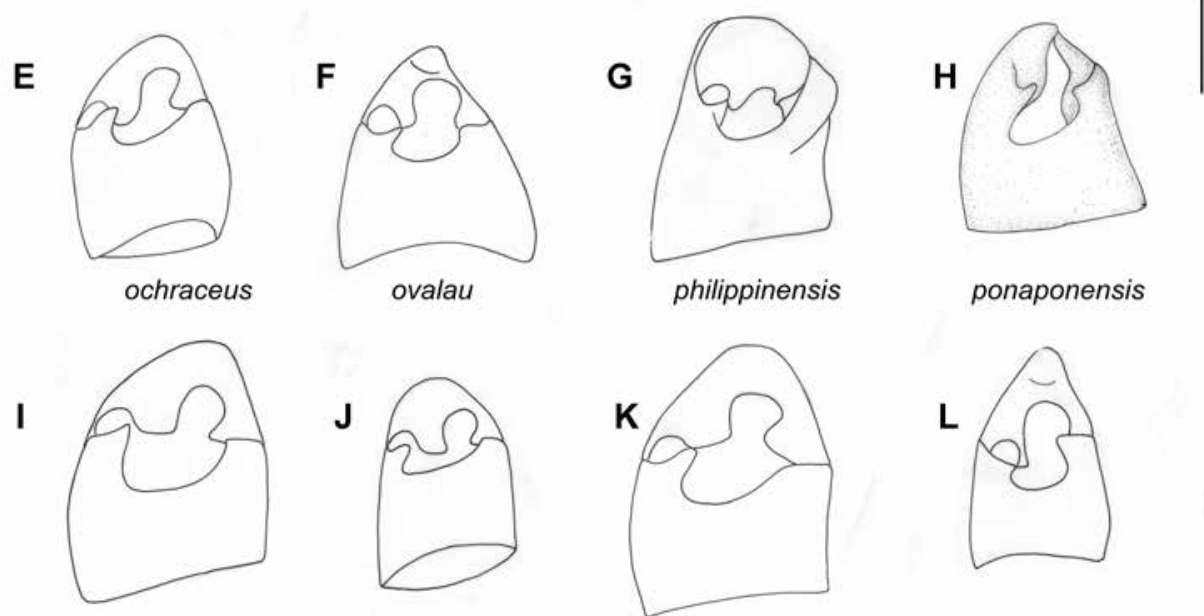

solomonicus

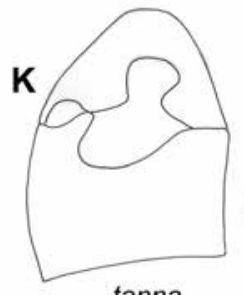

tanna

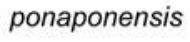

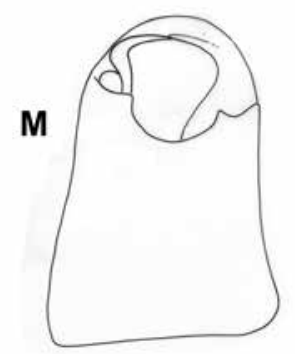

wangae

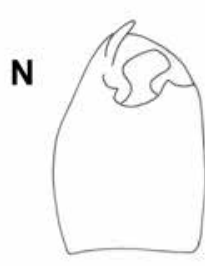

webbi

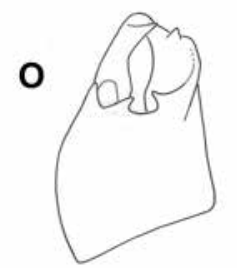

yasunagai

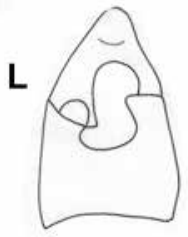

vitilevu

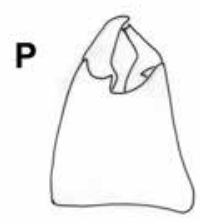

zuparkoi

FIGURE 15. Genital capsule of Felisacus species. 


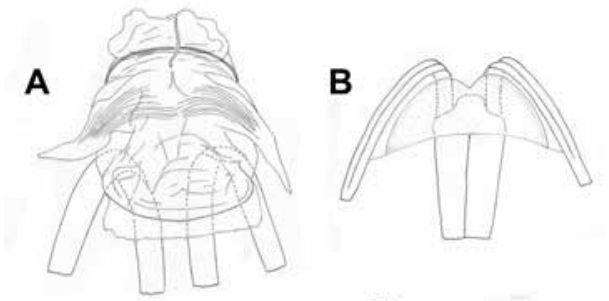

magnificus
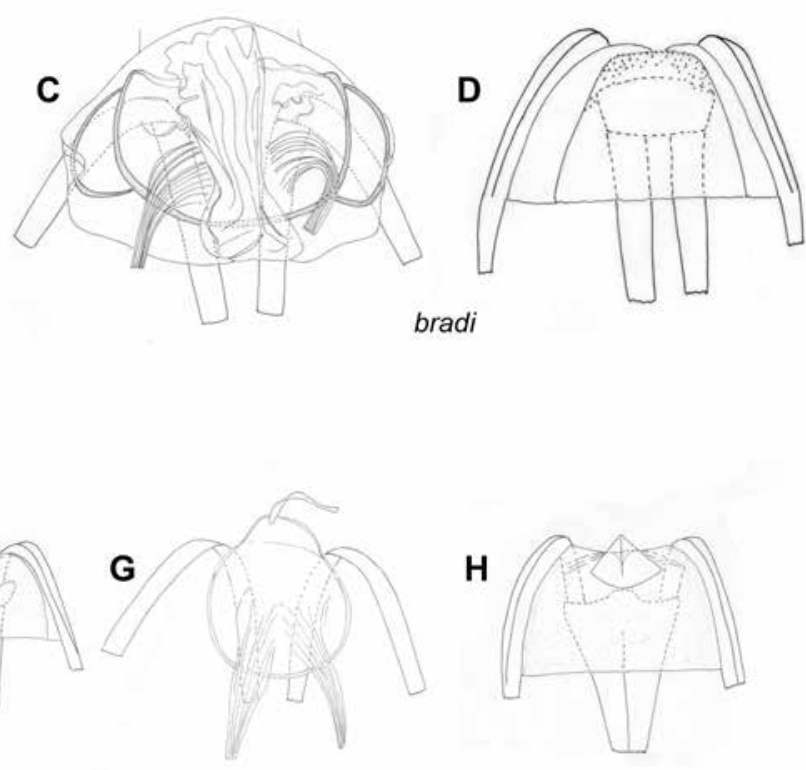

philippinensis

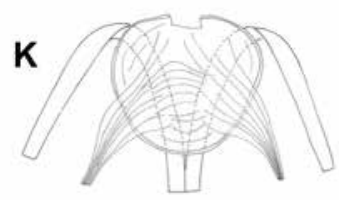

yasunagai
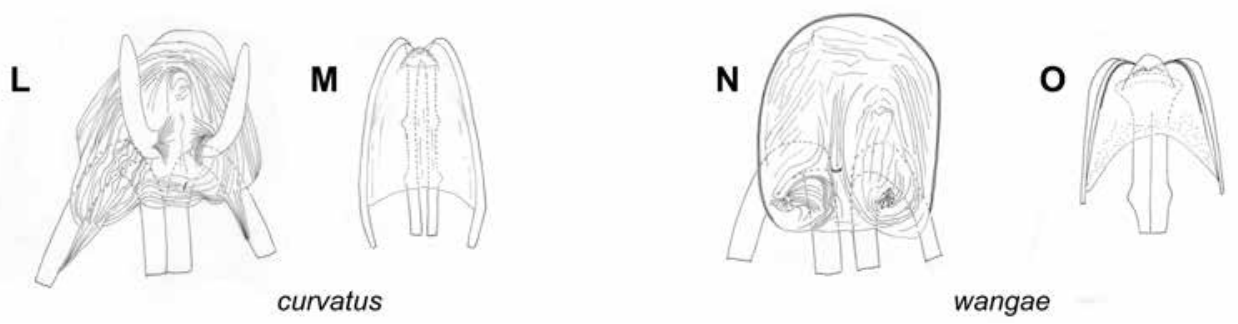

FIGURE 16. A, C, E, G, I, K, L, N. Dorsal labiate plate of bursa copulatrix of Felisacus species B, D, F, H, J, M, O. Posterior wall of bursa copulatrix of Felisacus species The small scale is for F. curvatus and F. wangae, the large scale for all others. 
sclerotized rings laterally; lateral oviducts placed almost medially, very close to each other, spermathecal gland placed between lateral oviducts; dorsal labiate plate with distinct tubercles, without membranous lobe medially.

Distribution: Ambon Is., Indonesia (fig. 17).

Host plants: Unknown.

Discussion: Genitalia of the male holotype and female nontype specimen sampled from the type locality were examined. Felisacus amboinae is most similar in coloration to F. albus, F. dauloi, F. filicicola, F. javanus, F. linae, F. ochraceus, and F. solomonicus (figs. 4-7), all of them being yellow with the cuneus at least partly yellow or red. Among those species, F. dauloi, F. filicicola and F. linae are similar to F. amboinae in shape of the right paramere (cf. fig. $11 \mathrm{C}$ with figs. $11 \mathrm{D}, \mathrm{AD}$, $12 \mathrm{~K}$ ) and distribution, however, those three species have an alternative combination of vesical spicules (cf. fig. 8B with 8G, I, P). Vesical spicules of $F$. amboinae are most similar to those of the Timorese species $F$. linae, with both species having spicules $\mathrm{A}, \mathrm{B}, \mathrm{C}$, with spicule $\mathrm{C}$ distinctly posterior in position (cf. fig. $8 \mathrm{~B}$ with $8 \mathrm{P}$ ), although the latter species has six spicules.

Material eXamined: Holotype: INDONESIA: Maluku: Ambon Is.: Amboina, $3.66^{\circ} \mathrm{S}$ $128.166^{\circ} \mathrm{E}$, no date provided, F. Muir, $10^{\top}$ (00400377) (CAS). Paratypes: INDONESIA: Maluku: Ambon Is.: Amboina, $3.66^{\circ} \mathrm{S} 128.166^{\circ} \mathrm{E}$, no date provided, F. Muir, $10^{\text {to }}$ (00399741), 1 우 (00399745) (CAS). Additional material: INDONESIA: Maluku: Ambon Is.: Amboina, $3.66^{\circ} \mathrm{S}$ $128.166^{\circ} \mathrm{E}$, no date provided, F. Muir, 4 우 (00399742-00399744, 00399746), 2 sex unknown (00399752, 00399756), 1 †ิ (00399748) (CAS).

\section{Felisacus auritulus Distant}

Figures 4, 17

Felisacus auritulus Distant, 1913: 177 (original description).

Diagnosis: Recognized by the following combination of characters: antennal segment I distinctly widened (as in Namyatova et al., 2016: fig. 8B), dark brown with yellow base; segment II dark brown; head and pronotum whitish yellow to yellow, dorsal surface of labial segment II elongate posteriorly (as in Namyatova et al., 2016: fig. 6D); head and pronotum mostly yellow without brown or red markings (fig. 4); body length 4; labium reaching middle of mesosternum; distance between eye and pronotum slightly shorter than eye diameter.

Description (based on a single, partly destroyed holotype; see also original description of Distant, 1912): Total length 4. COLORATION (fig. 4): Head: Yellow to pale brown. Eye dark brown to black. Labium: Yellow to pale brown. Antenna: Segment I dark brown with yellow base, segment II dark brown. Thorax: Pronotum and scutellum yellow; thoracic pleura and scent gland evaporative area yellow. Hemelytron: Mostly translucent, colorless, inner part of clavus with yellow tinge. Legs: Coxae yellow, femora and tibiae yellow to pale brown, apices of femora and bases of tibiae somewhat darker, hind tarsus with segment I pale brown and segments II-III brown. SURFACE AND VESTITURE: Setae on dorsum and antennal segment I and II mostly shorter than antennal segment II diameter; setae on antennal segments I and II and femora with suberect setae mostly shorter than antennal segment II diameter. STRUCTURE AND MEASUREMENTS: Body ca. $4 \times$ as long as pronotum width. Head: Depression, delimiting occipital region present only dorsally; distance between depression and pronotum slightly shorter than eye diameter; longitudinal sulcus on dorsal surface shorter than eye diameter; vertex ca. $3.5 \times$ as wide as eye, flat; distance from eye to pronotum slightly shorter than eye diameter, not swollen laterally. Labium (as in in Namyatova et al., 2016: figs. 6D, 9C): Reaching middle of mesosternum; segments I and II strongly reduced, combined subequal to half of segment III; segment I as long as wide, segment II slightly longer than wide, its dorsal elongate posteriorly segment III slightly shorter than length of head ventrally; segment IV twice as long as segment III. Antenna: Segment I dis- 
tinctly swollen (as in Namyatova et al., 2016: fig. $8 \mathrm{~B}), 1.3 \times$ as long as head width, $0.6 \times$ as long as pronotum width; segment II $2 \times$ as long as head width, $0.9 \times$ as long as pronotum width. Thorax: Anterior part of pronotum distinctly shorter than posterior part; collar distinctly delimited; posterior part of pronotum slightly upraised; posterior margin of pronotum slightly concave; pronotum ca. $1.3 \times$ as wide as long and ca. $2.3 \times$ as wide as head; mesoscutum slightly exposed.

Distribution: Seychelles (fig. 17).

Host Plants: Unknown.

Discussion: The description of Felisacus auritulus is based on the holotype, which is seriously damaged, with the abdomen, antennal segments III-IV, most of the hemelytra (except right clavus), and fore- and middle tibiae lost.

Felisacus auritulus is similar to F. bradi, F. ovalau, F. usingeri and F. vitilevu (figs. 4-7) in the following characters: broad antennal segment I (as in Namyatova et al., 2016: fig. 8B), dorsal surface of labial segment II elongate posteriorly and pronotum yellow (as in Namyatova et al., 2016: fig. 6D). Felisacus usingeri is most similar to F. auritulus, but the latter species differs in having the distance from eye to pronotum slightly longer than the diameter of an eye, antennal segment I is mostly yellow and is known from the Philippines. Felisacus bradi, F. ovalau and $F$. vitilevu differ in having a narrower antennal segment I. Additional characters that separate these species from F. auritulus include: F. bradi is known from Tahiti and its labium reaches abdominal segment VII; F. ovalau is known from Fiji and antennal segment I is mostly yellow and the labium reaches abdominal segment V; F. vitilevu is known from Fiji, and antennal segment $I$ is mostly yellow and the labium reaches the margin of the metasternum or slightly surpasses it.

Material eXamined: Holotype: SEYCHELLES: Silhouette, Mare aux Cochons, $4.48333^{\circ} \mathrm{S} 55.23333^{\circ} \mathrm{E}, 500 \mathrm{~m}$, Aug 1908, Percy Sladen Trust Expedition, 1 sex unknown (00019490) (BMNH).

\section{Felisacus australicus, sp. nov.}

Figures 4, 8C, 11E-G, 14C, 17

Diagnosis: Recognized by the following combination of characters: relatively dark coloration with head and pronotum mostly pale brown without darker markings or stripes; antennal segment I pale brown; inner part of clavus pale brown to brown; scent gland evaporative area pale brown; cuneus matte, yellow or at least partly red (fig. 4); cylindrical antennal segment I (as in Namyatova et al., 2016: fig. $8 \mathrm{~A}$ ); transverse depression on head extending laterally, vertex upraised; dorsal surface of labial segment II elongate posteriorly (as in Namyatova et al., 2016: fig. 6D); medial part of right paramere only slightly wider than basal part with outer margin distinctly concave, apical part of right paramere distinctly shorter than medial part (fig. 11C); vesica with five spicules, including spicules $\mathrm{A}, \mathrm{B}, \mathrm{C}, \mathrm{H}$, spicule $\mathrm{B}$ with elongate apical arm (fig. 8C).

Description: Male. Total length 3.9. COLORATION (fig. 4): Head: Yellow to pale brown, longitudinal sulcus and sides of clypeus brown. Labium: Segments I-III whitish yellow, segment IV yellow. Antenna: Segment I pale brown, segments II-IV brown to dark brown. Thorax: Pronotum yellow to pale brown; mesoscutum and scutellum yellow; thoracic pleura and scent gland evaporative area pale brown, slightly paler than pleura. Hemelytron: Inner part of clavus opaque, pale brown; outer part of clavus translucent, colorless; corium translucent, colorless with area along inner margin of corium brown; embolium opaque, whitish yellow with brown margins; cuneus opaque, whitish yellow with pale brown tinge at outer part and reddish at inner part, margins brown; membrane translucent with greyish tinge; membrane cell pale brown with reddish tinge. Legs: Yellow to pale brown, tibiae often paler apically. Abdomen: Whitish yellow with pale brown tinge. SURFACE AND VESTITURE: Corium smooth, with shallow punctures. Dorsum with suberect setae mostly longer than antennal segment II diameter; antennal segment 

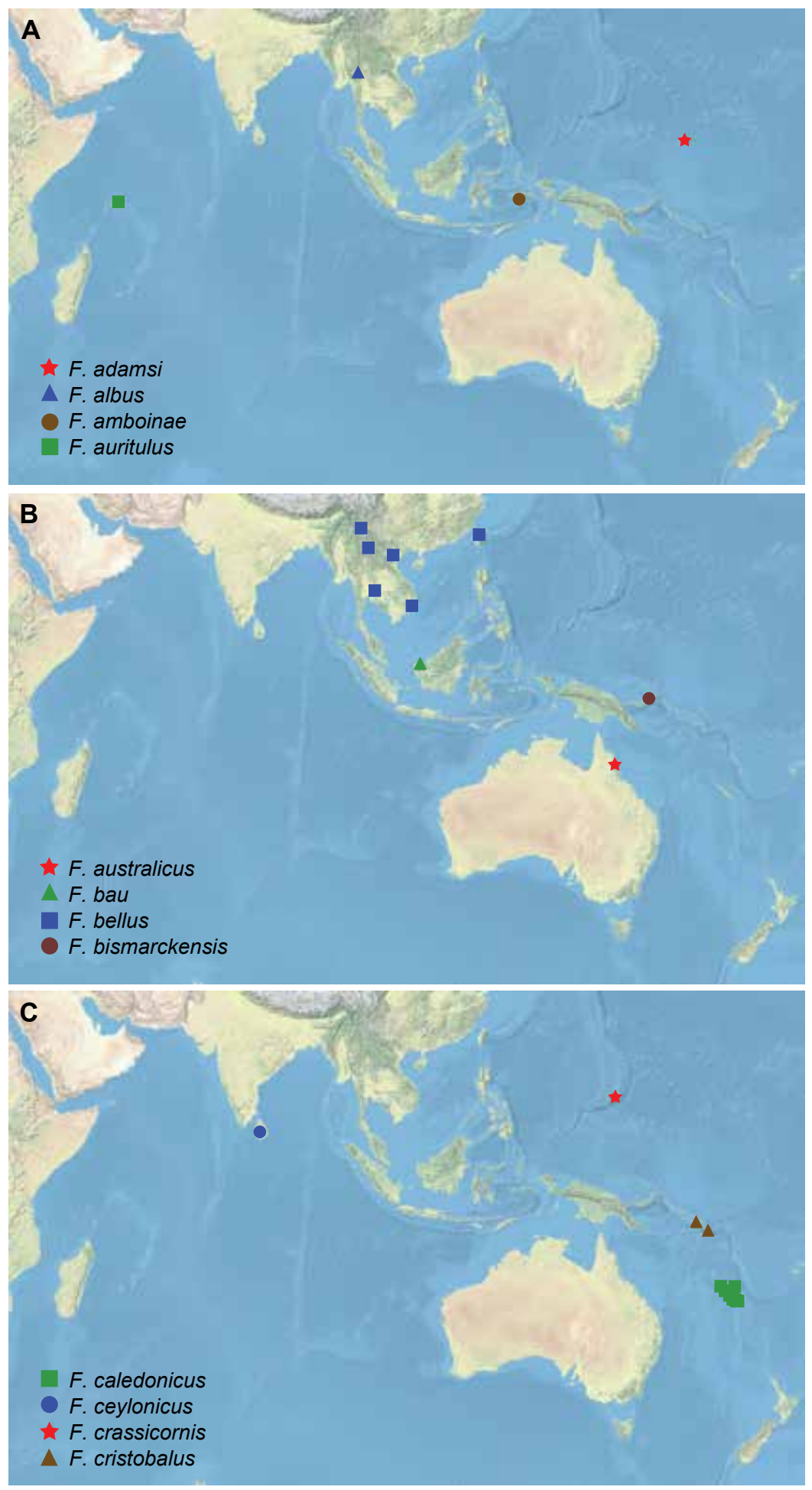

FIGURE 17. Distribution of Felisacus species. 
I and femora with suberect setae shorter than antennal segment II diameter; setae on antennal segment I scarce; abdomen clothed with suberect, mostly short simple setae. STRUCTURE AND MEASUREMENTS: Body ca. $4.3 \times$ as long as pronotum width. Head: Depression delimiting occipital region present dorsally and laterally (as in Namyatova et al., 2016: fig. 4E); distance between depression and pronotum distinctly shorter than eye diameter; longitudinal sulcus on dorsal surface longer than eye diameter; distance from eye to pronotum slightly longer than eye diameter, not swollen laterally (as in Namyatova et al., 2016: fig. $4 \mathrm{E}$ ); vertex ca. $1.6 \times$ as wide as eye, upraised (Namyatova et al., 2016: fig. 6D); buccula ca. $0.20-0.25 \times$ as long as clypeus. Labium (as in Namyatova et al., 2016: figs. 6D, 9C): Reaching posterior margin of mesosternum; segments I and II strongly reduced, combined shorter than segment III half; segment I shorter than wide; segment II slightly longer than wide, elongate dorsally; segment III slightly longer than length of head ventrally; segment IV ca. $1.5 \times$ as long as segment III. Antenna: Segment I cylindrical (as in Namyatova et al., 2016: fig. 8A), ca. 1.6x as long as head width, ca. $1.1 \times$ as long as pronotum width; segment II ca. $2.0 \times$ as long as head width, ca. $1.3 \times$ as long as pronotum width; segments III slightly longer than segment II; segment IV ca. $0.3 \times$ as long as antennal segment III. Thorax: Anterior part of pronotum only slightly shorter than posterior part; collar delimited, posterior part slightly raised; posterior margin concave, pronotum ca. $1.2-1.3 \times$ as wide as long and ca. 1.5-1.6x as wide as head; mesoscutum exposed. Hemelytron: Area along inner margin of corium not swollen; inner margin of cuneus convex (as in Namyatova et al., 2016: fig. 13E), outer margin of cuneus ca. $3 \times$ as long as base. Genitalia: Genital capsule (fig. 14C) approximately $1.5 \times$ as long as wide; ventral wall ca. $1.7 \times$ as long as dorsal wall, posterior margin smooth, without outgrowth(s), slightly tapering, not curved distally; apex inclined leftward; sides of genital capsule not modified; angles of paramere sockets more or less rounded, distance between paramere sockets subequal to half of genital capsule length at base; right angle of left paramere socket not projecting. Right paramere (fig. 11E) apical part distinct, slightly concave posteriorly, twice shorter than medial part; medial part slightly wider than basal part, bearing setae, its outer margin concave and inner margin convex; outer angle distinct; inner angle rounded, without setae; basal part ca. $0.15-0.2 \times$ as long as rest of paramere. Left paramere (fig. 11F, G) L-shaped; apical part not flattened, with toothlike outgrowth on posterior side medially (as in fig. 11G) and without outgrowth on dorsal surface; middle part widened, without swelling or outgrowth(s); setae placed only on middle part near outer margin of paramere. Aedeagus conjunctiva weakly sclerotized; secondary gonopore placed at base of vesica in repose; sclerotization of ductus seminis around secondary gonopore shorter than wide; vesica with five spicules, including spicules $\mathrm{A}, \mathrm{B}, \mathrm{C}$, and $\mathrm{H}$, spicule $B$ with elongate apical arm (fig. 8C).

Female. Total length 4.2-4.4. Coloration (fig. 4): Head: As in male. Labium: Segments I-III whitish yellow and segment IV pale brown, or labium uniformly pale brown. Antenna: Similar to male, but segment I pale brown with reddish tinge or brown. Thorax: Similar to male, scent gland evaporative area sometimes_whitish yellow. Hemelytron: Similar to male, but inner part of clavus brown, embolium sometimes pale brown with brown margins, cuneus uniformly reddish or whitish. Legs: Similar to male, coxae sometimes whitish yellow. Abdomen: Whitish yellow with pale brown tinge, sometimes brown ventrally and dorsally. Surface and vestiture: As in male. STRUCTURE AND MEASUREMENTS: Structure as in males; body ca. $4.1-4.3 \times$ as long as pronotum width; vertex ca. $1.3-1.5 \times$ as wide as eye; antennal segment I ca. 1.4-1.5× as long as head width, ca. $0.9-1.0 \times$ as long as pronotum width; segment II ca. $1.9-2.2 \times$ as long as head width, ca. $1.2-1.5 \times$ as long as pronotum width; pronotum ca. $1.2-1.3 \times$ as wide as long and ca. 1.5-1.6x as wide as head. Genitalia (as in Namyatova et al., 2016: fig. 23F, $\mathrm{G})$ : Dorsal labiate plate wider than distance between apodemes of second valvula; mostly 
smooth, without distinct striations or longitudinal membranous ridge, with semicircular sclerites and distinct sclerotized rings laterally; lateral oviducts placed almost medially, very close to each other, spermathecal gland placed between lateral oviducts; dorsal labiate plate with distinct tubercles, without membranous lobe medially.

Distribution: Known from South Queensland (Australia) (fig. 17).

Host Plants: Unknown.

Eтymology: The species is named after the continent of Australia, where it was collected.

Discussion: Felisacus australicus is similar in structure to the Micronesian species F. ochraceus and has almost identical male genitalia (cf. figs. $11 \mathrm{E}-\mathrm{G}$ and $13 \mathrm{C}, \mathrm{D}$ for parameres and figs. 8C and 9F for vesical spicules). However, F. ochraceus differs from the new species in coloration (fig. 6), possesses a whitish-yellow to yellow head and pronotum, antennal segment $\mathrm{I}$ is yellow basally and pale brown apically, is sometimes reddish yellow, the inner part of the clavus is whitish yellow with pale brown or brown margins, and the scent gland evaporative area is whitish yellow.

Material examined: Holotype: AUSTRALIA: Queensland: $3 \mathrm{~km} \mathrm{~N}$ on Black Mountain Road, $16.66725^{\circ} \mathrm{S} 145.4891^{\circ} \mathrm{E}, 21$ Apr 1990, J. Heraty, $10^{\hat{}}$ (00018517) (QM). Paratypes: AUSTRALIA: Queensland: $3 \mathrm{~km}$ N on Black Mountain Road, $16.66725^{\circ} \mathrm{S} 145.4891^{\circ} \mathrm{E}, 21$ Apr 1990, J. Heraty, $2+(00018518,00018519)$ (TAMU).

Felisacus bau, sp. nov.

Figures $4,8 \mathrm{D}, 11 \mathrm{H}, \mathrm{I}, 14 \mathrm{D}, 17$

Diagnosis: Recognized by the following combination of characters: dark coloration, head pale brown with brown marking dorsally; pronotum pale brown with dark brown marking along posterior margin; inner part of clavus brown; marking along inner margin of corium brown, narrow not extending toward $\mathrm{R}+\mathrm{M}$; scent gland evaporative area dark brown, pale brown basally; cuneus red, sometimes with brown marking along inner margin (fig. 4); antennal segment I cylindrical (as in Namyatova et al., 2016: fig. 8A), depression delimiting occipital region present dorsally and laterally, vertex upraised (as in Namyatova et al., 2016: fig. 6D); body small, length in male 3.2-3.7, in female 3.8; labium reaching posterior margin of mesosternum or slightly surpassing it; vesica with six spicules, including spicules $\mathrm{A}$ and $\mathrm{C}$, spicule A shortened (fig. 8D).

Description: Male. Total length 3.5. COLORATION (fig. 4): Head: Mostly pale brown, dorsal surface of head brown anteriorly; longitudinal sulcus brown, maxillary plate whitish yellow, slightly paler than surrounding areas. Eye dark brown, reddish at sides. Labium: Uniformly yellow. Antenna: Segment I brown, yellow basally, segment II brown. Thorax: Anterior part of pronotum pale brown with brown anterior margin; posterior part or pronotum pale brown anteriorly and brown posteriorly; mesoscutum pale brown, scutellum pale brown, brown apically; thoracic pleura brown to dark brown; scent gland evaporative area dark brown, pale brown basally. Hemelytron: Mostly translucent, colorless; inner part of clavus opaque, brown; outer part of clavus brown apically; area along inner margin of corium brown; embolium with brown margins and reddish apex; cuneus red or with brown marking along inner margin, margins reddish; anterior part of membrane with pale brown shading; membrane cell pale brown, partly reddish. Legs: Coxae whitish yellow; femora whitish yellow basally and pale brown with reddish tinge apically; tibiae pale brown with reddish tinge basally and whitish yellow apically; fore- and middle tarsi yellow to pale brown, hind tarsus whitish yellow. Abdomen: Ventral and lateral sides mostly whitish yellow, genital capsule pale brown with reddish tinge, dorsal surface brown. SURFACE AND VESTITURE: Corium smooth, with shallow and scarce punctures. Dorsum, antennal segment I and femora with suberect setae mostly shorter than antennal segment II diameter; abdomen clothed with suberect mostly short simple setae. STRUCTURE AND MEASUREMENTS: Body $4.2 \times$ as long as pronotum width. Head: Depres- 
sion delimiting occipital region present dorsally and laterally; distance between depression and pronotum shorter than eye diameter; longitudinal sulcus on dorsal surface longer than eye diameter; distance from eye to pronotum slightly longer than eye diameter, not swollen laterally (as in Namyatova et al., 2016: fig. 4E); vertex ca. $1.7 \times$ as wide as eye, upraised (fig. 6D in Namyatova et al., 2016); buccula ca. $0.2-0.25 \times$ as long as clypeus height. Labium (as in Namyatova et al., 2016: figs. 6D, 9C): Reaching posterior margin of mesosternum or slightly surpassing it; segments I and II strongly reduced, combined shorter than half of segment III; segment I shorter than wide; segment II slightly longer than wide, its dorsal surface elongate posteriorly; segment III slightly longer than ventral side of head; segment IV $1.5 \times$ as long as segment III. Antenna: Segment I cylindrical (as in Namyatova et al., 2016: fig. 8A), ca. 1.7× as long as head width, ca. $1.1 \times$ as long as pronotum width; segment II ca. $2.1 \times$ as long as head width, ca. $1.4 \times$ as long as pronotum width. Thorax: Anterior part of pronotum only slightly shorter than posterior part; collar delimited; posterior part slightly upraised; posterior margin concave; pronotum ca. $1.2 \times$ as wide as long and ca. $1.5 \times$ as wide as head; mesoscutum exposed. Hemelytron: Area along inner margin of corium almost flat; cuneus narrow, its inner margin convex (as in Namyatova et al., 2016: fig. 13E), outer margin almost twice as long as base. Abdomen: Genital capsule rotated left at right angle relative to the rest of abdomen. Genitalia: Genital capsule (fig. 14D) posterior margin smooth, semioval, without outgrowth, not pointed, not curved or inclined, truncate; sides of genital capsule not modified; margins of paramere sockets more or less rounded; distance between paramere sockets ca. $0.7 \times$ as long as genital capsule width at base. Right paramere (fig. $11 \mathrm{H}$ ) apical part distinctly curved; apex slightly concave posteriorly; medial part slightly wider than basal part, bearing setae, with outer margin slightly concave and inner margin convex; outer angle distinct, not widened; inner angle rounded, without setae; basal part ca. $0.15-0.2 \times$ as long as rest of paramere. Left paramere (fig. 11G) L-shaped; api- cal part not flattened, with toothlike outgrowth on posterior side medially (as in fig. 11G) and without outgrowth on dorsal surface; middle part widened, without swelling or outgrowth; setae only on middle part near outer margin. Aedeagus (general view as in Namyatova et al., 2016: fig. 22I) conjunctiva weakly sclerotized; secondary gonopore placed at base of vesica; sclerotization of ductus seminis around secondary gonopore shorter than wide; vesica with five spicules, including spicules A and C, spicule A shortened, spicule C large and moved posteriorly (fig. 8D).

Female. Total length 3.8. COLORATION, SURFACE, AND VESTITURE: As in male (fig. 4): STRUCTURE AND MEASUREMENTS: Structure as in male; body ca. $4.7 \times$ as long as pronotum width; vertex ca. $1.8 \times$ as wide as eye; antennal segment I ca. $1.8 \times$ as long as head width, ca. $1.2 \times$ as long as pronotum width; segment II ca. $2.1 \times$ as long as head width, ca. $1.4 \times$ as long as pronotum width; pronotum ca. $1.2 \times$ as wide as long and ca. $1.6 \times$ as wide as head.

Distribution: Known from Sarawak, Borneo (Malaysia) (fig. 17).

Host PLANTS: Unknown.

Eтymology: The species is named after the Bau District, where it was collected.

Discussion: Antennal segments III-IV are lost in the specimens we examined and the anterior part of the genital capsule is broken. Felisacus bau is similar to F. bellus, F. jacobsoni, and F. signis in appearance (figs. 4 and 6). They all differ from one another in the configuration and shape of the vesical spicules (cf. fig. $8 \mathrm{D}$ with figs. $8 \mathrm{E}, \mathrm{M}, 9 \mathrm{~K}$ ); in particular F. bellus possesses an elongate spicule A, and F. jacobsoni and F. signis have only five spicules and lack spicule A. Felisacus jacobsoni can also be separated by its larger body size, 4.4-4.7 $\mathrm{mm}$ in males and $4.6-4.8 \mathrm{~mm}$ in females.

MATERIAL EXAmined: Holotype: MALAYSIA: Sarawak: Bau District: Bidi, Bau District, $1.38389^{\circ} \mathrm{N} 110.13357^{\circ} \mathrm{E}, 165 \mathrm{~m}, 02$ Sep 1958, T.C. Maa, $1 \delta^{\widehat{ }}$ (00043878) (BPBM). Paratype: MALAYSIA: Sarawak: Bau District: Bidi, Bau District, $1.38389^{\circ} \mathrm{N} 110.13357^{\circ} \mathrm{E}, 165 \mathrm{~m}, 02$ Sep 1958, T.C. Maa, 1 (00043879) (BPBM). 


\section{Felisacus bellus Lin}

Figures 4, 8E, 11J, K, 17

Felisacus bellus Lin, 2000: 233 (original description).

Diagnosis: Recognized by the following combination of characters: mostly dark coloration, head and pronotum yellow to pale brown, often with dark brown marking along posterior margin; inner part of clavus brown, sometimes with red outer margin; marking along inner margin of corium brown to reddish brown, not extending toward $\mathrm{R}+\mathrm{M}$ anteriorly; cuneus red with brown margins, often with yellow outer angle (fig. 4); antennal segment I cylindrical (as in Namyatova et al., 2016: fig. 8A), depression delimiting occipital region present dorsally and laterally; vertex upraised (as in Namyatova et al., 2016: fig. 6D); body length in male ca. 3.7-4.5, in female 4.0-4.4; labium reaching posterior margin of mesosternum; apical part of right paramere distinctly delimited, outer margin of right paramere straight (fig. 11J); vesica with six spicules, including spicules $A, B$ and $G$, with spicule A long and narrow (fig. 8E).

Redescription: Male. Total length 3.7-4.5. COLORATION (fig. 4): Head: Mostly yellow to pale brown, with brown markings and reddish tinge; labrum dark brown; labrum dark brown. Eye dark brown to black. Labium: Segments I-II whitish yellow to yellow, segments III-IV yellow to pale brown, segment III sometimes with reddish tinge. Antenna: Segment I pale brown to brown, segments II-IV brown to dark brown. Thorax: Pronotum yellow with anterior margin and $1 / 3$ of posterior part brown, anterior part sometimes with reddish tinge; mesoscutum pale brown, scutellum pale brown, brown medially and posteriorly; thoracic pleura yellow, metapleuron sometimes with brown marking; scent gland evaporative area whitish yellow basally and brown apically. Hemelytron: Mostly translucent, colorless; inner part of clavus opaque, brown, sometimes with red outer margin; area along inner margin or corium brown to reddish brown, not extending toward $\mathrm{R}+\mathrm{M}$ anteriorly and continuing to the posterior margin of embolium; embolium reddish apically, margins brown; cuneus red with brown margins, often with yellow outer angle; membrane with pale brown or grayish tinge; membrane cell pale brown or red. Legs: Coxae whitish yellow; femora whitish yellow basally and yellow to brown apically; tibiae mostly yellow to pale brown, often coloration gradually changing from brown or pale brown basally to yellow or whitish yellow apically; tarsi pale brown, tarsal segment I sometimes yellow. Abdomen: Ventral side whitish yellow, genital capsule pale brown with reddish posterior margin, lateral and dorsal surfaces brown. SURFACE AND VESTITURE: Corium with shallow and scarce punctures. Dorsum with suberect setae mostly as long as or slightly longer than antennal segment II diameter; antennal segment I and femora with suberect setae mostly as long as or slightly shorter than antennal segment II diameter; those on antennal segment I scarce; abdomen clothed with suberect mostly short simple setae. STRUCTURE AND MEASUREMENTS: Body ca. $4.3-4.4 \times$ as long as pronotum width. Head: Depression delimiting occipital region present dorsally and laterally (as in Namyatova et al., 2016: fig. 4E); distance from depression to pronotum distinctly as long as or longer than eye diameter; longitudinal sulcus on dorsal surface longer than eye diameter; distance from eye to pronotum slightly longer than eye diameter, not swollen laterally (as in Namyatova et al., 2016: fig. 4E); vertex ca. $1.7-1.9 \times$ as wide as eye; upraised (Namyatova et al., 2016: fig. 6D); buccula ca. $0.2-0.25 \times$ as long as clypeus. Labium (as in Namyatova et al., 2016: figs. 6D, 9C): Reaching posterior margin of mesosternum; segment I and II strongly reduced, combined shorter than half of segment III; segment I shorter than wide; segment II slightly longer than wide, its dorsal side elongate posteriorly; segment III slightly longer than ventral side of head length; segment IV twice as long as segment III. Antenna: Segment I cylindrical (as in Namyatova et al., 2016: fig. 8A), ca. 1.5-1.7x 
as long as head width, ca. $0.9-1.0 \times$ as long as pronotum width; segment II ca. $2.1 \times$ as long as head width, ca. $1.3 \times$ as long as pronotum width; segments III slightly longer than segment II, ca. $0.3 \times$ as long as antennal segment IV. Thorax: Anterior part of pronotum slightly shorter than posterior part; posterior part of pronotum slightly upraised, collar delimited; posterior margin concave, pronotum ca. $1.2-1.3 \times$ as wide as long and ca. $1.7 \times$ as wide as head; mesoscutum exposed. Hemelytron: Area along inner margin of corium almost flat; inner margin of cuneus convex, outer margin of corium ca. 2.5$3 \times$ as long as base. Abdomen: Genital capsule rotated left at right angle relative to the rest of abdomen. Right paramere (fig. 11J) apical part distinct; apex slightly concave posteriorly; medial part less than twice as wide as basal part, bearing setae, with outer margin straight and inner margin swollen; outer angle distinct; inner angle rounded, without setae; basal part ca. $0.15-0.2 \times$ as long as rest of paramere. Left paramere (fig. $11 \mathrm{~K}$ ) L-shaped; apical part not flattened, with toothlike outgrowth on posterior side medially (as in fig. 11G) and without outgrowth on dorsal surface; middle part widened, without swelling or outgrowth; setae only on middle part near outer margin. Aedeagus (as in fig. 8E) conjunctiva weakly sclerotized; secondary gonopore placed at base of vesica; sclerotization of ductus seminis around secondary gonopore shorter than wide; vesica bearing six spicules, including spicules A, B and G, with spicules A long and narrow (fig. 8E).

Female. Total length 4.0-4.4. COLORATION (fig. 4): Head: Yellow, often anterior and ventral surfaces, buccula, mandibular, maxillary plates and clypeus whitish yellow to yellow; frons, dorsal and lateral sides and clypeus basally sometimes with reddish tinge. Eye dark brown to black. Labium: Similar to male, sometimes uniformly yellow. Antennae. As in male. Thorax: Pronotum yellow with pale brown anterior margin, often with reddish tinge laterally, posterior margin with markings medially and near humeral angles brown to dark brown, some- times entire posterior margin brown to dark brown or medial marking indistinct; mesoscutum yellow to pale brown; scutellum yellow to pale brown, brownish apically, sometimes medial part also brown, rarely with narrow, brown longitudinal stripe from center to apex; thoracic pleura yellow, sometimes with brown markings; scent gland evaporative area whitish yellow basally, yellow to brown apically, sometimes mostly brown. Hemelytron: Similar to male, but inner part of clavus sometimes yellow or pale brown with brown margins; area along inner margin of corium sometimes short; not reaching $\mathrm{R}+\mathrm{M}$; cuneus rarely mostly whitish yellow with reddish tinge with pale brown margins and red apical third. Legs: Similar to male, femora sometimes uniformly yellow, middle tibia rarely pale brown, tibiae sometimes with pale brown apex. Abdomen: Ventral and lateral sides whitish yellow, lateral side often with pale brown to brown markings, segment IX pale brown, or whitish yellow with reddish apex, dorsal surface whitish yellow to brown; rarely abdomen uniformly whitish yellow with reddish apex. SURFACE AND VESTITURE: As in male. STRUCTURE AND MEASUREMENTS: Structure as in male; body ca. $3.9-4.4 \times$ as long as pronotum width; vertex ca. $1.9-2.2 \times$ as wide as eye; antennal segment I ca. $1.3-1.7 \times$ as long as head width, ca. $0.8-1.0 \times$ as long as pronotum width; segment ca. II $1.8-2.1 \times$ as long as head width, ca. $1.1-1.2 \times$ as long as pronotum width; pronotum ca. $1.2-1.3 \times$ as wide as long and ca. $1.7 \times$ as wide as head. Genitalia (as in Namyatova et al., 2016: fig. 23F, G): Dorsal labiate plate wider than distance between apodemes of second valvula; mostly smooth, without distinct striations or longitudinal membranous ridge, with semicircular sclerites and distinct sclerotized rings laterally; lateral oviducts placed almost medially, very close to each other, spermathecal gland placed between lateral oviducts; dorsal labiate plate with distinct tubercles, without membranous lobe medially.

Distribution: China, Taiwan, Vietnam (fig. 17). 
Host PLANTS: Unknown.

Discussion: We examined one female paratype and a digital image of the holotype that is deposited in the Taiwan Agriculture Research Institute. We were therefore unable to examine the male genitalia. However, the additional specimens we were able to examine are very similar to the types and also were collected in southeast Asia (Vietnam and China), and we concluded that they are conspecific with F. bellus.

Felisacus bellus is almost indistinguishable from F. jacobsoni in coloration (fig. 4), having similar size and body structure, but the latter species differs in the labium reaching the posterior part of the metasternum and differs in the morphology of the vesical spicules (cf. figs. 8E with $8 \mathrm{M}$ ); in particular, $F$. jacobsoni possesses only five spicules with spicule 1 broad.

Felisacus bellus is also similar to F. bau in external morphology, coloration (fig. 4) and in the number of spicules (cf. figs. $8 \mathrm{D}$ with $8 \mathrm{E}$ ), but the latter species is lacking spicules $B$ and $G$ and possesses spicule C. Felisacus bau also has the right paramere with the apical part not delimited (fig. 11H).

Material examined: Paratype: TAIWAN: Nantou: Tungpu, Nantou Hsien, $23.91448^{\circ} \mathrm{N}$ $120.6812^{\circ} \mathrm{E}, 1200 \mathrm{~m}, 20$ Jun $1983-24$ Jun 1983 , K.C. Chou and C.Y. Wong, 19 (00005119) (NMNS). Additional material: CHINA: Yunnan: Longyang, $35.16666^{\circ} \mathrm{N} 117.25^{\circ} \mathrm{E}, 1600 \mathrm{~m}$, 12 Aug 2006, unknown, 19 (00017868) (NKMU). Menghai, $21.97145^{\circ} \mathrm{N} 100.44914^{\circ} \mathrm{E}$, 05 Oct 1979, Le-Yi Zheng, 19 00018515) (NKMU). THAILAND: Nakhon Ratchasima: Wang Nam Khieo: Sakaerat Environmental Research Station, $14.5075^{\circ} \mathrm{N} 101.9275^{\circ} \mathrm{E}, 410 \mathrm{~m}$, 19 Aug 2008-21 Aug 2008, Yasunaga and Shishido, 1 ㅇ (00021582) (TYCN). VIETNAM: Hòa Bình: Hoa Binh: Near Mai Chau [Mai Chon, Mai Chou], $20.667^{\circ} \mathrm{N} 105.084^{\circ} \mathrm{E}, 04 \mathrm{Nov}$ 1990, Belokobylskij, 20 (00018447), 1 우 (00018514) (ZISP). Lam Dong: 6 km S Dalat, $11.91724^{\circ} \mathrm{N} 108.44464^{\circ} \mathrm{E}, 1450 \mathrm{~m}, 09$ Jun $1961-$ 07 Jul 1961, N.R. Spencer, $2+$ (00017873, 00271514) (BPBM).
Felisacus bismarckensis, sp. nov.

Figures 4, 10A, 11L, M, 14E, 17

Diagnosis: Recognized by the following combination of characters: dark brown to black C-shaped marking on corium, extending toward $\mathrm{R}+\mathrm{M}$ anteriorly and posteriorly, its anterior part not inclined posteriorly (fig. 4); head not swollen laterally behind eyes; vertex upraised; antennal segment I widened (as in Namyatova et al., 2016: fig. $8 \mathrm{~B}$ ); right paramere without outgrowth on inner angle (fig. 11L); and at least half of ductus seminis sclerotized, straight apically (fig. 10A).

Description: Male. Total length 3.1. COLORATION (fig. 4): Head: Mostly yellow to pale brown, buccula and clypeus brown apically. Eye reddish brown. Labium: Segments I-II brown, segment III pale brown, yellow apically, segment IV yellow. Antenna: Segment I reddish brown with yellow base; segment II brown, segments III-IV pale brown. Thorax: Anterior part yellow to pale brown, with anterior margin and marking near forecoxa brown; posterior part brown; mesoscutum and scutellum uniformly brown, scutellum sometimes with reddish apex; thoracic pleura and scent gland evaporative area brown. Hemelytron: Clavus opaque, uniformly brown; corium, embolium and cuneus mostly translucent, colorless; corium with C-shaped brown marking, reaching $\mathrm{R}+\mathrm{M}$ anteriorly and posteriorly, anterior part of this marking not inclined posteriorly; embolium with margins and apex brown; cuneus yellow apically, with outer margin brown and inner margin colorless; membrane translucent, gradually changing color from pale brown anteriorly and whitish yellow posteriorly; membrane cell pale brown to brown. Legs: Forecoxa brown, middle and hind coxae yellow with pale brown to brown markings medially; foreand middle femora yellow apically, sometimes with reddish or pale brown marking; hind femur yellow with yellow, pale brown or red apex and pale brown or red marking at apical half; tibiae yellow, red or pale brown basally; tarsi yellow to pale brown. Abdomen: Ventral side yellow, lateral side brown basally and reddish apically; dorsal 
surface brown. SURFACE AND VESTITURE: Corium smooth, with shallow, scarce punctation. Dorsum, antennal segment I and femora clothed with setae shorter than antennal segment II diameter; abdomen clothed with long erect setae. STRUCTURE AND MEASUREMENTS: Body ca. $4.0 \times$ as long as pronotum width. Head: Transverse depression delimiting occipital region present only dorsally, not extending laterally (Namyatova et al., 2016: fig. 6E), distance between depression and pronotum shorter than eye diameter; longitudinal sulcus on dorsal surface of head shorter than eye diameter; eye diameter slightly longer than distance between eye and pronotum; vertex ca. $2.1 \times$ as wide as eye; vertex upraised. Labium: Reaching posterior margin of metasternum; segments I and II shorter than width, combined subequal to half of segment III; dorsal surface of segment II not elongate posteriorly (as in Namyatova et al., 2016: fig. 6E); segment III as long as ventral side of head length; segment IV twice as long as segment III. Antenna: Segment I as long as head width, widened (as in Namyatova et al., 2016: fig. $8 \mathrm{~B})$, ca. $1.0 \times$ as long as head width, ca. $0.6 \times$ as long as pronotum width; segment II ca. $1.7 \times$ as long as head width, ca. $1.1 \times$ as long as pronotum width; segment III slightly shorter than segment II and ca. $1.5 \times$ as long as segment IV. Thorax: Anterior part of pronotum shorter than posterior part; collar delimited; posterior part of pronotum slightly upraised; posterior margin of pronotum straight or concave; pronotum ca. $1.3 \times$ as wide as long and ca. $1.6 \times$ as wide as head; mesoscutum slightly exposed or not exposed. Hemelytron: Area along inner margin of corium swollen; cuneus with inner margin straight (Namyatova et al., 2016: fig. 13F), outer margin of cuneus twice as long as base. Genitalia: Genital capsule (fig. $14 \mathrm{E}$ ) ventral wall ca. $1.3 \times$ as long as dorsal wall, with posterior margin of ventral wall oval, slightly acute with apex placed almost medially, not curved dorsally, without toothlike outgrowth; sides of genital capsule not modified; margins of paramere sockets distinctly acute; distance between paramere sockets subequal to half of genital capsule width at base. Right paramere (fig. 11L) distinctly curved apically; apex slightly concave, medial part narrower than basal part, without setae, outer margin of medial part convex, inner margin concave, not widened; outer angle absent; inner angle present, rounded, without outgrowth, bearing setae; basal part slightly shorter than rest of paramere. Left paramere (fig. $11 \mathrm{M}$ ) apical part slightly flattened, with toothlike outgrowth apically, without outgrowth dorsally; middle part widened dorsally, inner margin of middle part swollen, without setae and outgrowth. Aedeagus (general view as in Namyatova et al., 2016: fig. 22M) vesica without spicules; apical half of ductus seminis sclerotized, straight, secondary gonopore placed near phallotheca mouth in repose (fig. 10A).

Female. Total length 3.5-3.7. COLORATION (fig. 4): Head: Similar to male, but clypeus sometimes uniformly brown, eye dark brown. Labium: As in male. Antenna: Segment I brown to reddish brown with yellow base, segment II brown, segments III and IV pale brown to brown. Thorax: Similar to male; metapleuron sometimes pale brown with brown posterior margin. Abdomen: Yellow ventrally and brown dorsally and apically. STRUCTURE AND MEASUREMENTS: Structure as in male; body ca. $4.0-4.1 \times$ as long as pronotum width; vertex ca. $2.1-2.2 \times$ as wide as eye; antennal segment I ca. $1.0-1.1 \times$ as long as head width, ca. $0.6-0.7 \times$ as long as pronotum width; segment II ca. $1.7 \times$ as long as head width, ca. $1.0 \times$ as long as pronotum width; pronotum ca. $1.2-1.3 \times$ as wide as long and ca. $1.6-1.7 \times$ as wide as head. Genitalia (as in fig. 16A, B): Dorsal labiate plate very small and transparent, as wide as distance between apodemes of second valvulae, without striations or membranous ridge medially; semicircular sclerite and sclerotized rings absent; lateral oviducts placed in anterior part; spermathecal gland attached near anterior margin; dorsal labiate plate without distinct tubercles, without membranous lobe posteriorly.

Distribution: Bismarck Archipelago (New Britain Is.) (fig. 17).

Host PLANTs: Unknown. 
Eтyмology: The species is named after Bismarck Archipelago, where it was collected.

Discussion: The genital capsule was not examined. The external morphology of Felisacus bismarckensis is similar to F. lindbergae, F. longiceps, F. magnificus, and F. zuparkoi (figs. 4-7), but those four species differ in having a flat vertex (as in Namyatova et al., 2016: fig. 6E), a distinct outgrowth on the inner angle of the right paramere (cf. fig. 11L with figs. 12M, Q, W, $13 \mathrm{AD}$ ) and the ductus seminis is distinctly sickle shaped apically (cf. fig. 10A with 10F, H, J, O).

Material examined: Holotype: PAPUA NEW GUINEA: East New Britain Province: Gazelle Peninsula, Gaulim, $4.45^{\circ} \mathrm{S} 142.08333^{\circ} \mathrm{E}$, 04 Nov 1962, R.W. Strandtmann, 1 ơ (00043207) (BPBM). Paratypes: PAPUA NEW GUINEA: East New Britain Province: Gazelle Peninsula, Gaulim, $4.45^{\circ} \mathrm{S} 142.08333^{\circ} \mathrm{E}, 04$ Nov 1962, R.W. Strandtmann, 10 (00043208), 2 우 (00043209, 00043210), sex unknown (00043211) (BPBM).

\section{Felisacus bradi, sp. nov.}

Figures 4, 10B, 11N, O, 14F, 16C, D, 21

Diagnosis: Recognized by the following combination of characters: antennal segment I slightly widened; head and pronotum whitish yellow to yellow, without brown markings (fig. 4); antennal segment I mostly brown; dorsal surface of labial segment II elongate posteriorly (as in Namyatova et al., 2016: fig. 6D); labium reaching abdominal segment VII; ventral wall of genital capsule not curved apically (fig. 14F); left paramere widened with large outgrowth posteriorly (fig. 11O); sclerotization of ductus seminis around secondary gonopore elongate, but distinctly shorter than remaining part of ductus seminis, dorsal wall of the sclerotized portion of ductus seminis longer than ventral wall; vesica with a number of small toothshaped sclerites apically and large sclerotized areas (fig. 10B).

Description: Male. Total length 4.3. COLORATION (fig. 4): Head: Mostly whitish yellow to yellow, dorsal and lateral sides pale brown behind eye, longitudinal stripe pale brown, buccula, frons pale brown with reddish tinge near clypeus base, clypeus mostly brown, whitish yellow only basally. Eye dark brown. Labium: Segments I-II whitish yellow, segment III yellow, segment IV pale brown basally and gradually darkened to brown apically. Antenna: Brown, segment I whitish yellow basally. Thorax: Anterior part of pronotum whitish yellow, posterior part of pronotum yellow; mesoscutum and scutellum yellow with reddish tinge; thoracic pleura and scent gland evaporative area whitish yellow. Hemelytron: Mostly translucent, whitish yellow; clavus with yellow tinge and brown depression delimiting part of clavus; area along inner margin of corium brown, narrow and short, not extending toward $\mathrm{R}+\mathrm{M}$; embolium with outer margin partly dark brown; membrane with pale brown tinge; membrane cell pale brown. Legs: Coxae whitish yellow; femora whitish yellow basally and yellow to pale brown apically; tibiae yellow to pale brown; tarsi brown. Abdomen: Whitish yellow. SURFACE AND VESTITURE: Corium smooth, with shallow and dense punctures. Dorsum, antennal segment I and femora clothed with suberect setae shorter than antennal segment II diameter; abdomen with suberect mostly short simple setae. STRUCTURE AND MEASUREMENTS: Body ca. $4.3 \times$ as long as pronotum width. Head: Depression delimiting occipital region present only dorsally, not extending laterally (Namyatova et al., 2016: fig. $6 \mathrm{E})$; distance between depression and pronotum as long as eye diameter; longitudinal sulcus on dorsal surface shorter than eye; distance from eye to pronotum slightly shorter than eye diameter, not swollen dorsally; vertex ca. $1.8 \times$ as wide as eye; vertex slightly raised; buccula ca. $0.2-$ $0.25 \times$ as long as clypeus. Labium: Reaching abdominal segment VII; segments I and II reduced, subequal to half of segment III; segment I shorter than wide; segment II slightly longer than wide, its dorsal surface elongate posteriorly (as in Namyatova et al., 2016: fig. 6D); segment III slightly longer than length of head ventrally; segment IV ca. $0.3 \times$ as long as 
segment III. Antenna: Segment I slightly longer than head width, slightly widened medially (Namyatova et al., 2016: fig. 8B), ca. 1.3× as long as head width, ca. $0.8 \times$ as long as pronotum width; segment II ca. $2.0 \times$ as long as head width, ca. $1.2 \times$ as long as pronotum width; segments III shorter than segment II; segment IV ca. $0.25 \times$ as long as antennal segment III. Thorax: Anterior part of pronotum distinctly shorter than posterior part; posterior part slightly upraised; posterior margin concave, pronotum ca. $1.3 \times$ as wide as long and ca. $1.6 \times$ as wide as head; mesoscutum exposed. Hemelytron: Area along inner margin of corium almost flat; inner margin of corium convex (as in Namyatova et al., 2016: fig. $13 \mathrm{E}$ ), outer margin of corium ca. $3 \times$ as long as base. Abdomen: Genital capsule rotated left at right angle relative to rest of abdomen. Genitalia: Genital capsule (fig. 14F) twice as long as wide; ventral wall ca. $1.3 \times$ as long as dorsal wall, its posterior margin smooth, semioval, without outgrowth, apex slightly inclined to left-hand side, rounded, not curved dorsally; sides of genital capsule not modified; margins of paramere sockets angulate; distance between paramere sockets ca. $0.3 \times$ as long as width of genital capsule at base. Right paramere (fig. $11 \mathrm{~N}$ ) curved in apical part, but apical part only weakly delimited; apex straight posteriorly; medial part only slightly wider than basal part, its outer margin straight, inner margin slightly widened, bearing setae; outer angle present, very shallow; inner angle rounded, not bearing setae or outgrowth; basal part ca. $0.25-0.3 \times$ as long as rest of paramere. Left paramere (fig. 11O) L-shaped, widened; apical part not flattened, with large outgrowth on posterior side medially and without outgrowth on dorsal surface; middle part widened, without swelling or outgrowth(s); setae present only posteriorly. Aedeagus conjunctiva sclerotized only basally, secondary gonopore placed at base of vesica; sclerotized part of ductus seminis around secondary gonopore elongate, but distinctly shorter than rest of ductus seminis; dorsal wall of sclerotized part of ductus seminis longer than its ventral wall; vesica with number of small toothlike sclerites and two large sclerites (fig. 10B).

Female. Total length 4.9. COLORATION (fig. 4): Head: Mostly yellow to pale brown, ventral side yellow, apical part of clypeus brown; eyes dark brown. Labium: As in male. Antennae. Brown to dark brown, segment I yellow basally. Thorax: Anterior part of pronotum whitish yellow, posterior part of pronotum mostly pale brown; mesoscutum and scutellum as in male; mesopleuron yellow; metapleuron and scent gland evaporative area whitish yellow with greenish tinge. Legs: Similar to male, but tarsal segments I and II of fore- and middle tibia pale brown. Hemelytron: As in male. Abdomen: Whitish yellow with green tinge. SURFACE AND VESTITURE: As in male. STRUCTURE AND MEASUREMENTS: Structure similar to male, but labium reaching abdominal segment VIII; body ca. $4.2 \times$ as long as pronotum width; vertex ca. $2.0 \times$ as wide as eye; antennal segment I ca. $1.0 \times$ as long as head width, ca. $0.6 \times$ as long as pronotum width; segment II ca. $1.7 \times$ as long as width of head, ca. $1.0 \times$ as long as width of pronotum; pronotum ca. $1.4 \times$ as wide as long and ca. $1.6 \times$ as wide as head. Genitalia (fig. 16C, D): Dorsal labiate plate wider than distance between apodemes of second valvula; with striated longitudinal membranous ridge, with semicircular sclerites and distinct sclerotized rings laterally; lateral oviducts placed almost medially, shifted posteriorly, very close to each other, spermathecal gland placed between lateral oviducts; dorsal labiate plate with distinct tubercles anteriorly, without membranous lobe medially.

Distribution: Tahiti (fig. 21).

Host Plants: Unknown.

ЕтумоLоgy: This species is named after Brad Balukjian, who provided material for this study.

Discussion: Antennal segment IV is lost in the male. Felisacus bradi is most similar to $F$. auritulus, F. usingeri, and F. ovalau in the combination of the broad antennal segment I and the dorsal surface of labial segment II is elongate posteriorly (as in Namyatova et al., 2016: fig. 6D). Felisacus usingeri is known from the Philip- 
pines and differs by antennal segment I yellow, brown apically, and the labium reaching the middle of the mesosternum. Felisacus ovalau is known from Fiji and differs by the antennal segment I yellow with a reddish tinge, the pronotum with pair of brown markings near the humeral angles, the left paramere is broad with three rounded outgrowths (fig. 13F), and sclerotization of the ductus seminis at the secondary gonopore is broad and almost as long as wide (fig. 9G). Felisacus auritulus is known from the Seychelles and differs by antennal segment I being distinctly broad and the labium reaches the middle of the mesosternum.

Material examined: Holotype: FRENCH POLYNESIA: Society Islands: Moorea Is.: Uufau Pass, $17.536^{\circ} \mathrm{S} 149.8697^{\circ} \mathrm{W}, 420 \mathrm{~m}, 15$ Mar 2009, Peter Oboyski, 1 ơ $^{-00399753)}$ (UCB). Paratype: FRENCH POLYNESIA: Society Islands: Moorea Is.: ridge between Mt Mouaroa and Mt Ruahite, near Mt Mouaroa overlook, $17.54794^{\circ} \mathrm{S}$ $149.84955^{\circ} \mathrm{W}, 488 \mathrm{~m}, 11$ Dec 2008, C.P. Ewing, 1 우 (00399754) (UCB).

\section{Felisacus caledonicus, sp. nov.}

Figures 4, 8F, 11P, Q, 14G, 17

Diagnosis: Recognized by the following combination of characters: dorsum mostly whitish yellow to yellow coloration with lateral sides of collar often brown; humeral angles whitish yellow (fig. 4), cylindrical antennal segment I (as in Namyatova et al., 2016: fig. 8A), transverse depression delimiting occipital region present dorsally and laterally, vertex upraised (as in Namyatova et al., 2016: fig. 6D); labium reaching posterior margin of mesosternum; cuneus ca. $3 \times$ as long as base; apical part of left paramere widened, twice as long as wide (fig. 11Q); vesica with four spicules, including spicules A and B (fig. 8F).

Description: Male. Total length 3.5-3.8. COLORATION (fig. 4): Head: Mostly whitish yellow to yellow, sometimes pale brown dorsally, sometimes with reddish tinge and markings; longitudinal sulcus yellow to pale brown. Eye pale brown to dark brown, often with reddish tinge laterally. Labium: Whitish yellow to yellow, segment I sometimes somewhat darker than other segments, segment III sometimes with reddish stripe ventrally. Antenna: Segment I yellow to pale brown often darker apically, sometimes with reddish tinge; segment II varying from almost yellow to pale brown or reddish brown, sometimes with reddish tinge, often darker than segment II; segments III-IV brown to dark brown. Thorax: Pronotum whitish yellow to yellow with anterior margin pale brown to brown, often lateral sides of collar brown; collar rarely with reddish tinge; posterior part of pronotum sometimes with pair of brown markings on posterior margin at distance from humeral angles; mesoscutum whitish to yellow, scutellum whitish to whitish yellow, sometimes somewhat paler than mesoscutum; thoracic pleura yellow to pale brown, sometimes with pale brown to brown marking; scent gland evaporative area whitish yellow, rarely with greenish tinge. Hemelytron: Mostly translucent, colorless; inner part of clavus sometimes yellow with yellow to pale brown margins; area along inner margin of corium whitish yellow to pale brown; embolium often with yellow apex and yellow to pale brown margins; margins of cuneus yellow to brown; membrane cell yellow. Legs: Coxae whitish yellow; femora whitish yellow basally and yellow apically, rarely uniformly yellow, sometimes with red apices; tibia uniformly whitish yellow to yellow, sometimes with red bases; tarsi pale brown, often segment I and sometimes segment II whitish to yellow. Abdomen: Ventral and lateral side of abdomen whitish yellow, dorsal surface of pregenital segments and entire genital capsule yellow to pale brown, sometimes abdomen uniformly yellow to pale brown. SURFACE AND VESTITURE: Corium smooth, often with very shallow, indistinct punctures. Dorsum, antennal segment I, femora and abdomen clothed with setae mostly subequal to or somewhat shorter than antennal segment II diameter, those setae sometimes; abdomen clothed with erect short setae subequal to or 
shorter than antennal segment II diameter. STRUCTURE AND MEASUREMENTS: Body ca. $4.3-4.6 \times$ as long as pronotum width. Head: Depression, delimiting occipital region present dorsally and laterally (as in Namyatova et al., 2016: fig. 4E); distance between depression and pronotum distinctly shorter than eye diameter; longitudinal sulcus on dorsal surface of head subequal to eye diameter; distance from eye to pronotum longer than eye diameter, not swollen laterally (as in Namyatova et al., 2016: fig. 4E); vertex ca. $1.8-2.1 \times$ as wide as eye diameter; upraised (Namyatova et al., 2016: fig. 6D). Labium (as in Namyatova et al., 2016: figs. 6D, 9C): Reaching posterior part of mesosternum or slightly surpassing it; segments I and II reduced, combined shorter than half of segment III; segment I shorter than wide; segment II slightly longer than wide, its dorsal surface elongate posteriorly; segment III subequal to length of head ventral side; segment IV ca. $1.5 \times$ longer than segment III. Antenna: Segment I cylindrical (as in Namyatova et al., 2016: fig. 8A), ca. $1.5-1.9 \times$ as long as head width, ca. $1.0-1.3 \times$ as long as pronotum width; segment II ca. $2.1-2.3 \times$ as long as head width, ca. $1.4-1.5 \times$ as long as pronotum width; segment III slightly longer than segment II; segment III ca. $0.3 \times$ as long as segment IV. Thorax: Anterior part of pronotum slightly shorter than posterior part; collar delimited; posterior part slightly upraised; posterior margin slightly concave, pronotum ca. 1.1-1.3× as wide as long and ca. $1.4-1.6 \times$ as wide as head; mesoscutum exposed or not exposed. Hemelytron: Area along inner margin of corium almost flat; inner margin of cuneus convex (as in Namyatova et al., 2016: fig. 13E), outer margin of cuneus ca. $3 \times$ as long as base. Abdomen: Genital capsule rotated left at almost right angle relative to rest of abdomen. Genitalia: Genital capsule (fig. 14G) almost as long as wide, ventral wall ca. $1.5 \times$ as long as dorsal wall, with posterior margin of ventral wall rounded, smooth, not curved, without outgrowth(s); apex of genital capsule slightly inclined rightward; sides of genital capsule not modified; right paramere socket slightly acute and left one rounded; distance between paramere sockets ca. $0.4 \times$ as long width of genital capsule at base. Right paramere (fig. 11P) apical part distinct, straight; medial part only slightly less than twice as wide as basal part, bearing row of setae, with outer margin straight or slightly concave, and inner margin swollen; outer angle present; inner angle rounded, without setae or outgrowth; basal part ca. $0.5 \times$ as long as rest of paramere. Left paramere (fig. 11Q) widened, L-shaped, only slightly curved; apical part straight, twice as long as wide, with toothlike outgrowth on posterior side medially (as in fig. 11G); middle part widened, without outgrowth; setae only on middle part near outer margin. Aedeagus (general view as in Namyatova et al., 2016: fig. 22I) conjunctiva weakly sclerotized; secondary gonopore placed at base of vesica in repose; sclerotization of ductus seminis around secondary gonopore shorter than wide; vesica with four spicules, including $\mathrm{A}$ and B (fig. 8F).

Female. Total length 3.7-4.0. COLORATION (fig. 4): Head: Similar to male, sometimes head uniformly pale brown. Labium: Similar to male, rarely uniformly pale brown. Antenna: Similar to male, coloration of segment I varying from yellow to pale brown, sometimes darker apically or with reddish tinge. Thorax: Similar to male, scent gland evaporative area whitish yellow. Legs and hemelytron. As in male. Abdomen: Whitish yellow ventrally and yellow to pale brown dorsally, sometimes segment IX uniformly yellow to pale brown, sometimes abdomen uniformly whitish yellow to pale brown. SURFACE AND VESTITURE: As in male. STRUCTURE AND MEASUREMENTS: Structure as in male; body ca. $4.2-4.4 \times$ as long as pronotum width; vertex ca. $2.0-2.3 \times$ as wide as eye diameter; antennal segment I ca. $1.7-1.8 \times$ as long as head width, ca. $1.0-1.1 \times$ as long as pronotum width; segment II ca. $2.1-2.3 \times$ as long as head width, ca. 1.2-1.4× as long as pronotum width; pronotum ca. 1.2$1.4 \times$ as wide as long and ca. $1.6-1.7 \times$ wider than head. Genitalia (as in Namyatova et al., 2016: fig. 23F, G): Dorsal labiate plate wider than distance 
between apodemes of second valvula; mostly smooth, without distinct striations, with semicircular sclerite and distinct sclerotized rings laterally; lateral oviducts placed almost medially, very close to each other, spermathecal gland placed between lateral oviducts; dorsal labiate plate with distinct tubercles, without membranous lobe medially.

Distribution: New Caledonia, Loyalty Is. (fig. 17).

Host Plants: Unknown.

Eтymology: The species is named after New Caledonia from where the type material was collected.

Discussion: Felisacus caledonicus is very similar to F. elegantulus in external morphology (fig. 4) but the latter species can be separated by the following combination of characters: the lateral margins of the collar are yellow; the humeral angles of the pronotum are often brown to dark brown; the apical part of the left paramere is not broad, ca. $3 \times$ as long as wide; and the presence of five vesical spicules, including spicule $B$.

Material EXAmined: Holotype: NEW CALEDONIA: Province Sud: Yahoué, $22.19686^{\circ} \mathrm{S} 166.6655^{\circ} \mathrm{E}, 20 \mathrm{Feb} 1963$, C.M. Yoshimoto, 10 (00042285) (BPBM). Paratypes: NEW CALEDONIA: Province Nord: Hienghene, $20.68793^{\circ} \mathrm{S} 164.9434^{\circ} \mathrm{E}, 80 \mathrm{~m}, 14 \mathrm{Aug}$ 1979-17 Aug 1979, G.M. Nishida, 20 (00042282, 00042283), 4 우 (0004228900042292) (BPBM). Province Sud: Col de la Pirogue, $22.08161^{\circ} \mathrm{S} 166.3165^{\circ} \mathrm{E}, 330 \mathrm{~m}, 14 \mathrm{Feb}$ 1963, N.L.H. Krauss, 4 (00042298-00042300, 00042303) (BPBM). Col de la Pirogue, $22.08161^{\circ} \mathrm{S} 166.3165^{\circ} \mathrm{E}, 23$ Jan 1962, N.L.H. Krauss, 1 đ (00042286) (BPBM); 14 Feb 1963, N.L.H. Krauss, 49 (00042296, 00042297, 00042301, 00042302) (BPBM). Crouen, $21.53333^{\circ} \mathrm{S} 165.88333^{\circ} \mathrm{E}$, Mar 1959, N.L.H. Krauss, 2 (00042294, 00042295) (BPBM). Les Bois de Sud, $22.17^{\circ} \mathrm{S} 166.76^{\circ} \mathrm{E}, 200 \mathrm{~m}, 23 \mathrm{Apr}$ 2005, Cassis, Wall, Tatarnic, Monteith, $10^{\widehat{ }}$ (00039957) (AM). Monts des Koghis, $22.15151^{\circ} \mathrm{S}$ $166.53394^{\circ} \mathrm{E}, 500 \mathrm{~m}$, Jan 1969 , N.L.H. Krauss, 2 Ðิ (00042279, 00042281) (BPBM); Feb 1973,
N.L.H. Krauss, $1 \overbrace{}^{\dagger}$ (00042280) (BPBM). Mt. Koghi, $22.16666^{\circ} \mathrm{S} 166.53333^{\circ} \mathrm{E}, 525 \mathrm{~m}$, Dec 1983, N.L.H. Krauss, 2 ㅇ (00042287, 00042288) (BPBM). Yahoué, $22.19686^{\circ} \mathrm{S} 166.6655^{\circ} \mathrm{E}, \mathrm{Feb}$ 1976, N.L.H. Krauss, 1 우 (00042293), 1 우 (00042284) (BPBM). Province des Iles Loyauté: Fayaoue, Ouvea Is., $20.65774^{\circ} \mathrm{S} 166.54238^{\circ} \mathrm{E}, 25$ m, Dec 1968, N.L.H. Krauss, 10 (00042306) (BPBM). New Caledonia, 1940, unknown collector, 10 (00042304) (BPBM).

\section{Felisacus ceylonicus, sp. nov.}

\section{Figures 4, 10C, 11R, S, 14H, 17}

Diagnosis: Recognized by the following combination of characters: marking on corium dark brown, C-shaped, its anterior and posterior parts reaching $\mathrm{R}+\mathrm{M}$ (fig. 4); cuneus brown apically; antennal segment I widened (as in Namyatova and Cassis, in press: fig. 8B), red; antennal segment II yellow with red markings; vertex swollen laterally behind eye; ventral wall of genital capsule with angulate outgrowth posteriorly (fig. 14H); right paramere sickle shaped, with inner angle bearing distinctly curved outgrowth; inner margin of medial part of right paramere convex, without swelling (fig. 11R); apical part of left paramere narrow, with tooth apically and outgrowth dorsally; medial part with narrow outgrowth (fig. 11S); distal half of ductus seminis sclerotized (fig. 10C); vesica without spicules (fig. 10C).

Description: Male. Total length 2.6. COLORATION (fig. 4): Head: Mostly pale brown with reddish markings around eyes and antennal fossae and on clypeus. Eye red. Labium: Segments I-II pale brown; segments III-IV yellow. Antenna: Segment I red; segment II yellow with red markings; segments III-IV pale brown. Thorax: Anterior part of pronotum brown; posterior part of pronotum dark brown; scutellum and mesoscutum dark brown; thoracic pleura brown, scent gland evaporative area whitish yellow. Hemelytron: Clavus opaque, dark brown; corium, embolium, and cuneus mostly translucent and colorless; corium with brown anterior angles and $\mathrm{C}$-shaped dark brown marking with anterior and 
posterior parts of this marking reaching costal margin; embolium and cuneus brown apically; membrane and membrane cell brown. Legs: Coxae whitish yellow; femora mostly whitish yellow, fore- and middle femora reddish apically, hind femur with apical half reddish brown; tibiae mostly brown with apical $1 / 3$ whitish yellow; tarsi whitish yellow. Abdomen: Yellow, segments VIIIIX brown. SURFACE AND VESTITURE: Corium smooth with distinct punctation. Dorsum with setae mostly longer than antennal segment II diameter; antennal segment I clothed with suberect setae shorter than antennal segment II diameter; femora with suberect setae twice as long as antennal segment II diameter; abdomen with erect setae of different length. STRUCTURE AND MEASUREMENTS: Body ca. 3.9x as long as pronotum width. Head: Depression, delimiting occipital region, present only dorsally; distance between depression and pronotum slightly longer than eye diameter; longitudinal sulcus on dorsal surface distinctly shorter than eye diameter; distance from eye to pronotum distinctly longer than eye diameter, swollen laterally; vertex ca. $1.6 \times$ as wide as eye diameter, flat (Namyatova et al., 2016: fig. $6 \mathrm{E}$ ); buccula ca. $0.2 \times$ as long as clypeus. Labium: Almost reaching posterior margin of mesosternum; segments I and II reduced, combined slightly longer than half of segment III; dorsal surface of segment II not elongate posteriorly (as in Namyatova et al., 2016: fig. 6E); segment III shorter than ventral side of head; segment IV twice as long as segment III. Antenna: Segment I widened medially (as in Namyatova et al., 2016: fig. 8 B), ca. $1.3 \times$ as long as head width, ca. $0.7 \times$ as long as pronotum width; segment II ca. $1.8 \times$ as long as head width, ca. $0.9 \times$ as long as pronotum width; antennal segment III slightly longer than segment II and twice as long as segment IV. Thorax: Anterior part of pronotum distinctly shorter than posterior part; collar distinct; posterior part of pronotum distinctly upraised; posterior margin of pronotum usually straight, sometimes slightly concave; pronotum ca. 1.1$1.2 \times$ as wide as long and ca. $1.9 \times$ as wide as head; mesoscutum slightly exposed. Hemelytron: Area along inner margin of corium swollen; inner margin of cuneus straight (as in Namyatova et al., 2016: fig. 13F), outer margin of cuneus twice as long as base. Abdomen: Genital capsule rotated left $45^{\circ}$ relative to the rest of abdomen. Genitalia: Genital capsule (fig. 14H). Twice as long as wide; ventral wall ca. $1.5 \times$ longer than dorsal wall, with apex not curved dorsally; with angulate outgrowth at left side and with right side folded; left side of genital capsule not widened; margins of paramere sockets angulate; distance between paramere sockets ca. $0.3 \times$ as long as genital capsule width at base. Right paramere (fig. 11R) sickle shaped, medial part narrower than basal part, without setae, only slightly curved, its outer margin straight; inner margin concave without swelling; outer angle of right paramere absent, inner angle present, with curved outgrowth and bunch of setae on inner margin, basal part ca. $0.5 \times$ as long as rest of paramere. Left paramere (fig. 11S) curved medially; apical part not flattened, with toothlike outgrowth apically and with outgrowth on dorsal surface; inner margin of middle part with narrow outgrowth, bearing setae. Aedeagus vesica without spicules; half of ductus seminis sclerotized, secondary gonopore placed near phallotheca mouth in repose; ductus seminis hooked apically (fig. 10C).

Female. Total length 3.5. COLORATION (fig. 4): Head: Similar to male, but maxillary plate with reddish marking and eyes yellow with reddish tinge. Labium: Uniformly yellow. Antenna: As in male. Thorax: Similar to male, thoracic pleura pale brown, mesopleuron with brown marking. Hemelytron: As in male. Legs: Hind femur mostly reddish brown with basal $1 / 3$ whitish yellow. SURFACE AND VESTITURE: As in male. STRUCTURE AND MEASUREMENTS: Structure as in male; body ca. $3.9 \times$ as long as pronotum width; vertex ca. $2.2 \times$ as wide as eye diameter; segment I $1.4 \times$ as long as head width, $0.7 \times$ as long as pronotum width; segment II $1.7 \times$ as long as head width, $0.8 \times$ as long as pronotum width; pronotum ca. $1.2 \times$ as wide as long and ca. $2.1 \times$ as wide as head. Female genitalia were not investigated. 
Distribution: Sri Lanka (fig. 17).

Host Plants: Unknown.

Eтymology: The species is named after the former name of Sri Lanka, "Ceylon," where it was collected.

Discussion: Felisacus ceylonicus is similar to $F$. lindbergae, F. longiceps, F. magnificus, and F. zuparkoi (figs. 4-7) in the pattern of coloration and the structure of the ductus seminis (fig. 10C, F, H, J, P). Felisacus longiceps also has similar paramere structure (cf. fig. 11R, S with fig. 12Q, R). All aforementioned species differ from $F$. ceylonicus in having the vertex straight laterally behind the eye. Felisacus magnificus can also be separated from F. ceylonicus by the right paramere straight and the left paramere flattened. Felisacus zuparkoi also differs from F. ceylonicus in having claw-shaped vesical spicules, and F. zuparkoi differs in the labium not surpassing the posterior margin of the prosternum.

MATERIAL EXAMINED: Holotype: SRI LANKA: Central Prov.: Peradeniya, Univ. Peradeniya, $7.25416^{\circ} \mathrm{N} 80.60194^{\circ} \mathrm{E}, 335 \mathrm{~m}, 20$ Mar 1999, TJ Henry, A Wijesekara and C Ariyadasa, 10 (00399955) (USNM). Paratype: SRI LANKA: Central Prov.: Peradeniya, Univ. Peradeniya, $7.25416^{\circ} \mathrm{N} 80.60194^{\circ} \mathrm{E}, 335 \mathrm{~m}, 20$ Mar 1999, TJ Henry, A Wijesekara and C Ariyadasa, 19 (00399956) (USNM).

\section{Felisacus crassicornis Usinger, 1946}

Figures 4, 17

Felisacus crassicornis Usinger, 1946: 70 (original description).

Diagnosis: Recognized by the following combination of characters: pronotum mostly brown with yellow medial longitudinal stripe; marking along inner margin of corium pale brown to brown, short and narrow, not extending toward $\mathrm{R}+\mathrm{M}$ (fig. 4), antennal segment I mostly yellow, dark brown apically; antennal segment I widened (as in Namyatova and Cassis, in press: fig. $8 \mathrm{~B}$ ); dorsal surface of labial segment II not elongate posteriorly (as in Namyatova et al., 2016: fig. 6E); labial segment III shorter than ventral side of head; labium slightly surpassing middle of mesosternum; occipital region present only dorsally; distinctly protruding eye; hemelytron with distinct punctures; right and left parameres sickle shaped (Carvalho, 1956: fig. 17h, I).

Redescription: Male. No specimens were examined. See Usinger (1946) and Carvalho (1956) for description of male.

Female. Total length 3.3-3.5. COLORATION (fig. 4): Head: Whitish yellow to pale brown, buccula anteriorly, clypeus apically and tubercle around antennal fossa often pale brown. Eye brown, sometimes with reddish tinge. Labium: Uniformly yellow. Antenna: Segment I yellow dark brown apically and often pale to brown basally; segment II yellow basally and pale brown apically; segments III-IV brown to dark brown, rarely segment III basally or entire segment IV pale brown. Thorax: Anterior part of pronotum yellow to pale brown, often with anterior margin pale brown; punctures between anterior and posterior parts pale brown; posterior part of pronotum pale brown to brown with yellow or pale brown stripe medially; scutellum and mesoscutum whitish yellow to yellow with punctures between them pale brown; thoracic pleura whitish yellow to yellow; scent gland evaporative area whitish yellow to yellow. Hemelytron: Clavus opaque, its inner part yellow to brown, outer part yellow to pale brown; corium whitish, translucent, areas around punctures opaque; area along inner margin of corium pale brown to brown narrow and short, not extending toward $\mathrm{R}+\mathrm{M}$; embolium whitish yellow to yellow, translucent to opaque, with yellow margins; cuneus translucent, colorless with outer margin yellow; membrane translucent, colorless with pale brown or grayish tinge; membrane cell pale brown. Legs: Yellow, bases of coxae and femora often whitish yellow; tibia sometimes pale brown apically, tarsal segments I and II often pale brown. Abdomen: Yellow with pale brown dorsal surface. SURFACE AND VESTITURE: Corium often with distinct punctures. Dorsum and femora anteriorly clothed with suberect setae mostly longer than antennal segment II diameter; setae on dor- 
sum scarce; antennal segment I with rare suberect setae shorter than antennal segment II diameter; abdomen clothed with suberect mostly short simple setae. STRUCTURE AND MEASUREMENTS: Body ca. 3.6-3.9× as long as pronotum width. Head: Depression delimiting occipital region present only dorsally; distance between depression and pronotum distinctly longer than eye diameter; longitudinal sulcus on dorsal surface shorter than eye diameter; distance from eye to pronotum slightly longer than eye diameter, not swollen; vertex ca. $2.1-2.5 \times$ as wide as eye diameter; upraised; buccula ca. $0.2-$ $0.25 \times$ as long as clypeus. Labium: Reaching posterior margins of mesosternum but not surpassing it; segments I and II reduced, combined slightly longer than half of antennal segment III; segment I shorter than wide; segment II slightly longer than wide, subequal to half of segment III, its dorsal surface not elongate posteriorly (as in Namyatova et al., 2016: fig. 8B); segment III shorter than length of ventral side of head; segment IV subequal to half of segment III. Antenna: Segment I only slightly longer than head width, widened (as in Namyatova et al., 2016: fig. 8B), ca. 0.9-1.1 $\times$ as long as head width, ca. $0.6-0.7 \times$ as long as pronotum width; segment II ca. $1.2-1.5 \times$ as long as head width, ca. 0.8$1.0 \times$ as long as pronotum width; segment III distinctly longer than segment II; segment IV ca. $0.4-0.5 \times$ as long as segment III. Thorax: Anterior part of pronotum shorter than posterior part; collar distinct; posterior part of pronotum slightly upraised; posterior margin of pronotum straight or concave; pronotum ca. $1.3-1.4 \times$ as wide as long and ca. $1.5-1.6 \times$ as wide as head; mesoscutum usually exposed, sometimes not exposed. Hemelytron: Area along inner margin of corium swollen; inner margin of cuneus straight, outer margin of cuneus twice as long as base. Female genitalia were not examined.

Distribution: Mariana Is. (fig. 17).

Host Plants: Ferns (Usinger, 1946).

Discussion: Usinger (1946) described F. crassicornis from two females, housed in the BPBM. Carvalho (1956) also examined males and females in his redescription of the species. We had only females available for this study. Felisacus crassicornis can be confused with $F$. auritulus externally (fig. 4); the latter species differs by the antennal segment I dark brown with a yellow base, the dorsal surface of labial segment II elongate posteriorly, covering antennal segment II, and the punctures on the hemelytra absent or indistinct. The parameres of $F$. crassicornis are most similar to those of $F$. ponaponensis (cf. Carvalho, 1956: fig. 17h with fig. 13I, J). These two species are also similar in having a pale body, without any dark stripes or markings on the hemelytra. However, F. ponaponensis differs in the collar not being delimited posteriorly, and the pronotum covering the head to the depression delimiting the occipital region. We have no information on the structure of the aedeagus of $F$. crassicornis.

Material eXAmined: Holotype: GUAM: Machanao, 25 Nov 1936, O.H. Swezey, $1+$ (BPBM_TCN 00002954) (BPBM). Paratypes: GUAM: Machanao, 05 Jun 1936, R.L. Usinger, 19 (BPBM_TCN 00002955) (BPBM). Additional material: GUAM: Mariana Is.: Guam, Mt. Lamlam, Dec 1958, N.L.H. Krauss, 19 (00043260) (BPBM). Upi Trail, 05 May 1936, O.H. Swezey, 19 (00043252) (BPBM). Yigo, $13.53194^{\circ} \mathrm{N} 144.88027^{\circ} \mathrm{E}, 126 \mathrm{~m}$, Oct 1957 , N.L.H. Krauss, 69 (00043253-00043258) (BPBM); Feb 1958, N.L.H. Krauss, 19 (00043259) (BPBM).

Felisacus cristobalus, sp. nov.

Figures 4, 10D, 11T, U, 14I, 17

Diagnosis: Recognized by the following combination of characters: marking on hemelytron dark brown, with anterior part widened and not reaching $\mathrm{R}+\mathrm{M}$ (fig. 4); antennal segment I widened (as in Namyatova et al., 2016: fig. 8B), mostly brown to dark brown; cuneus mostly translucent, colorless; posterior part of pronotum mostly brown to dark brown with pale brown stripe medially; inner angle of right paramere with short and abrupt outgrowth (fig. 11T); out- 
growth on medial part of left paramere widened, angulate (fig. 11U); half of ductus seminis sclerotized, straight, sickle shaped apically (fig. 10D).

Description: Male. Total length 3.5. COLORATION (fig. 4): Head: Mostly yellow to pale brown, frontal side slightly paler, buccula anteriorly and clypeus apically brown. Eye brown with reddish tinge. Labium: Segment I yellow to pale brown; segment II brown; segment III yellow, pale brown ventrally; segment IV yellow. Antenna: Segment I pale brown basally and brown to dark brown apically, segment II brown to dark brown; segments III-IV pale brown to brown, sometimes somewhat paler than segment II. Thorax: Anterior part of pronotum pale brown with dark brown anterior margin; posterior part of pronotum dark brown with yellow or pale brown longitudinal sulcus medially; mesoscutum and scutellum pale brown to brown; thoracic pleura pale brown, with brown to dark brown markings; scent gland evaporative area whitish yellow. Hemelytron: Mostly translucent, only clavus opaque; inner part of clavus brown to dark brown; outer part of clavus pale brown to brown; corium translucent, colorless, with marking along inner margin of corium dark brown, its anterior part widened, wider than eye diameter, not reaching $\mathrm{R}+\mathrm{M}$ vein, posterior part of marking not widened, reaching costal vein; embolium colorless with brown margins; cuneus colorless with brown outer margin; membrane brown anteriorly and colorless posteriorly; membrane cell brown. Legs: Coxae whitish yellow; femora whitish yellow, often yellow apically, with pale brown or brown marking in apical half and often pale brown apically; foretibia pale brown with whitish yellow apex; middle and hind tibiae pale brown basally and whitish yellow apically; tarsal segments I whitish yellow; segments II-III yellow to pale brown. SURFACE AND VESTITURE: Corium smooth, with rare and shallow punctation. Dorsum and forefemur with setae slightly longer than antennal segment II diameter; antennal segment I, middle and hind femora clothed with suberect setae shorter than antennal segment II; abdomen with short erect setae.
STRUCTURE AND MEASUREMENTS: Body ca. $4.1 \times$ as long as pronotum width. Head: Transverse depression delimiting occipital region present only dorsally, not extending laterally (Namyatova et al., 2016: fig. 6E), distance between depression and pronotum slightly shorter than eye diameter; longitudinal sulcus on dorsal surface of head shorter than eye diameter; distance from head to pronotum distinctly longer than eye diameter; vertex ca. $1.6 \times$ as wide as eye, flat (Namyatova et al., 2016: fig. 6E). Labium: Reaching or slightly surpassing posterior margin of prosternum; segments I and II combined as long as segment III; segment I twice as long as wide; segment II slightly longer than wide, slightly shorter than segment I, its dorsal surface not elongate posteriorly (as in Namyatova et al., 2016: fig. 6E); segment III distinctly shorter than ventral side of head length; segment IV ca. $1.5 \times$ as long as segment III. Antenna: Segment I slightly longer than head width, swollen basally (as in Namyatova et al., 2016: fig. 8B), ca. $1.2 \times$ as long as head width, ca. $0.8 \times$ as long as pronotum width; segment II ca. $1.8 \times$ as long as head width, ca. $1.2 \times$ as long as pronotum width; segment III slightly longer than segment II; segment IV subequal to half of segment III. Thorax: Anterior part of pronotum shorter than posterior part; collar distinct; posterior part slightly upraised; posterior margin of pronotum slightly concave; pronotum ca. $1.1 \times$ as wide as long and ca. $1.5 \times$ as wide as head; mesoscutum usually exposed. Hemelytron: Area along inner margin of corium swollen; inner margin of cuneus straight (as in Namyatova et al., 2016: fig. 13F), outer margin of cuneus twice as long as base. Genitalia: Genital capsule (fig. 14I) ventral wall ca. $1.5 \times$ as long as dorsal wall, with posterior margin rounded, not curved dorsally, with toothlike outgrowth; margin of paramere sockets distinctly angulate; distance between paramere sockets ca. $0.25 \times$ as long as genital capsule width at base. Right paramere (fig. 11T) distinctly curved; in apical half; apex slightly concave posteriorly; medial part slightly wider than basal part, without setae, outer margin of medial part convex, inner margin concave 
without swelling; outer angle absent; inner angle present with abrupt swelling, bearing setae; basal part of paramere almost as long as rest of paramere. Left paramere (fig. 11U) apical part not flattened, with toothlike outgrowth on posterior side apically and with outgrowth on dorsal surface; middle part with wide outgrowth, bearing setae. Aedeagus vesica without spicules; half of ductus seminis sclerotized, secondary gonopore placed near phallotheca mouth; ductus seminis hooked apically (fig. 10D).

Female. Total length 4.2. COLORATION (fig. 4): Head: As in male. Labium: Similar to male, but labial segment I pale brown. Antenna: Similar to male, but segment I brown, same color as segment II. Thorax: Similar to male, but posterior part of pronotum dark brown with yellow stripe medially, mesoscutum brown; scutellum pale brown. Hemelytron and legs: As in male. Abdomen: Ventral whitish lateral sides, segment IX and dorsal surface brown. SURFACE AND VESTITURE: Similar to male, abdomen clothed with erect setae mostly as long as or shorter than antennal segment I width. STRUCTURE AND MEASUREMENTS: Structure as in male; body ca. $4.3 \times$ as long as pronotum width; vertex ca. 1.7-1.9 $\times$ as wide as eye; antennal segment I ca. $1.1-1.3 \times$ as long as head width, ca. $0.8 \times$ as long as pronotum width; segment II ca. $1.7-1.8 \times$ as long as head width, ca. $1.1-1.2 \times$ as long as pronotum width; pronotum ca. $1.2 \times$ as wide as long and ca. $1.5-1.6 \times$ as wide as head. Genitalia (as in fig. 16A, F): Dorsal labiate plate very small and transparent, as wide as distance with apodemes of second valvulae, without striations or membranous ridge medially; semicircular sclerite and sclerotized rings absent; lateral oviducts placed in anterior part; spermathecal gland attached near anterior margin; dorsal labiate plate without distinct tubercles, without membranous lobe posteriorly.

Distribution: Solomon Is. (fig. 17).

Host Plants: Unknown.

Eтymology: The species is named after San Cristobal Is., where two specimens out of three were collected.
Discussion: Antennal segment IV is lost in the female. Felisacus cristobalus is similar to F. fedori in the marking on the corium, with the anterior part not reaching $\mathrm{R}+\mathrm{M}$ and is broad (fig. 4): The latter species differs in having a yellow pronotum, brown to dark brown posteriorly, the cuneus is red, and the outgrowth on the right paramere is acute (fig. 11AB).

MATERIAl EXAMINED: Holotype: SOLOMON ISLANDS: San Cristobal: Kira-Kira, $10.44138^{\circ} \mathrm{S}$ 161.91666 ${ }^{\circ}$, 25 m, 05 Nov 1964, R. Straatman, 1 to (00043871) (BPBM). Paratypes: SOLOMON ISLANDS: Savo Is., West Coast, $9.13333^{\circ} \mathrm{S}$ $159.78333^{\circ} \mathrm{E}, 50 \mathrm{~m}, 19$ Oct 1970 , N.L.H. Krauss, 1 ㅇ (00043873) (BPBM). San Cristobal: Kira Kira, $10.44138^{\circ} \mathrm{S} 161.91666^{\circ} \mathrm{E}, 100 \mathrm{~m}$, Jan 1976 , collector unknown, 19 (00043872) (BPBM).

Felisacus curvatus $\mathrm{Hu}$ and Zheng, 2001

Figures 4, 10E, 11V, W, 14J, 16L, M, 18

Felisacus curvatus Hu and Zheng, 2001: 417 (original description).

DiAGNosis: Recognized by the following combination of characters: marking along inner margin of corium brown, with anterior part not reaching $\mathrm{R}+\mathrm{M}$ not widened, and posterior part reaching $\mathrm{R}+\mathrm{M}$ and noticeably widened (fig. 4); depression delimiting occipital region distinct only dorsally; segment I cylindrical (as in Namyatova et al., 2016: fig. 8A); head and pronotum yellow to pale brown; right paramere sickle shaped, with outer angle rounded and inner angle distinct, without outgrowth (fig. 11V); sclerotization of ductus seminis around secondary gonopore short, twice as long as wide; vesica with three serrate spicules, bearing toothlike outgrowths (fig. 10E).

Description: Male. Total length 4.2-4.8. COLORATION (fig. 4): Head: Mainly yellow to pale brown, with reddish tinge; buccula, tubercle around eye, marking below antennal fossa, mandibular and maxillary plates whitish yellow; clypeus brown apically. Eye dark brown with reddish tinge. Labium: Whitish yellow to yellow. Antenna: 
Segment I whitish yellow to yellow, reddish apically, sometimes uniformly whitish yellow; segment II yellow basally and pale brown to brown apically, sometimes uniformly pale brown to brown; segments II-IV pale brown to brown. Thorax: Anterior part of pronotum yellow to pale brown with anterior margin brown, often with reddish tinge; posterior part of pronotum often yellow to pale brown often with humeral angle brown, rarely posterior part of pronotum uniformly dark brown; mesoscutum yellow to pale brown, rarely with reddish tinge, sometimes with brown marking medially, rarely uniformly brown to dark brown; scutellum yellow to pale brown, rarely with reddish tinge; rarely brown to dark brown; thoracic pleura pale brown to dark brown; scent gland evaporative area whitish yellow basally and brown apically. Hemelytron: Mostly translucent and colorless, clavus opaque; inner part of clavus pale brown to brown, sometimes with reddish tinge; outer part of clavus, brown, often darker than inner part; marking along inner margin of corium reddish brown or brown; its anterior part very short not reaching $\mathrm{R}+\mathrm{M}$ and posterior part reaching $\mathrm{R}+\mathrm{M}$, twice as wide as middle part; embolium brown basally, often yellow to pale brown apically with margins partly pale brown to brown; cuneus reddish or reddish brown apically; membrane pale brown to brown; membrane cell brown, often with reddish tinge. Legs: Coxae whitish yellow, femora whitish yellow basally and yellow apically, sometimes with reddish tinge apically; hind and middle tibiae sometimes with reddish-brown marking on apical half; tibiae whitish yellow to yellow, sometimes with reddish tinge basally; tarsi whitish yellow to yellow. Abdomen: Whitish yellow to yellow ventrally and laterally, genital capsule pale brown, striped laterally and dorsal surface reddish, rarely abdomen uniformly reddish. SURFACE AND VESTITURE: Corium smooth, with rare and shallow punctation. Dorsum and femora with setae distinctly longer than antennal segment II diameter; antennal segment I clothed with suberect setae subequal to or slightly longer than antennal segment II diameter; abdomen clothed with short erect setae. STRUCTURE AND MEASUREMENTS: Body $4.2-4.6 \times$ as long as pronotum width. Head: Depression, delimiting occipital region, present only dorsally; distance between depression and pronotum as long as eye diameter; longitudinal sulcus on vertex shorter than eye diameter; distance from eye to pronotum distinctly longer than eye diameter, not swollen; vertex ca. $1.7-2.2 \times$ as wide as eye, flat (as in fig. 7E). Labium: Slightly surpassing posterior margin of prosternum; segment I twice as long as than wide, segment II slightly longer than wide, its dorsal surface not elongate posteriorly (as in Namyatova et al., 2016: fig. 6E); segments I and II combined almost subequal to segment III; segment III shorter than ventral side of head, segment IV ca. $1.5 \times$ as long as segment III. Antenna: Segment I cylindrical (as in Namyatova et al., 2016: fig. 8A), ca. $1.4-1.5 \times$ as long as head width, ca. $0.8 \times$ as long as pronotum width; segment II ca. $1.7-2.0 \times$ as long as head width, ca. $0.9-1.1 \times$ as long as pronotum width; segments III distinctly longer than segment II; segment IV subequal to half of segment III. Thorax: Anterior part of pronotum shorter than posterior part; collar delimited; posterior part slightly upraised; posterior margin of pronotum straight or concave; pronotum ca. 1.0$1.2 \times$ as wide as long and ca. $1.8-2.0 \times$ as wide as head; mesoscutum usually exposed. Hemelytron: Area along inner margin of corium swollen; inner margin of cuneus convex (as in Namyatova et al., 2016: fig. 13E), outer margin of cuneus ca. $3 \times$ as long as base. Abdomen: Genital capsule rotated left at small angle relative to rest of abdomen. Genitalia: Genital capsule (fig. 14J) twice as long as wide; ventral wall ca. $1.3 \times$ as long as dorsal wall, its posterior margin smooth, without outgrowths; semioval, slightly pointed, curved dorsally from right side; left side of genital capsule not widened; margins of socket slightly acute; distance between paramere sockets subequal to half of genital capsule width at base. Right paramere (fig. 11V) distinctly curved in apical half; apex straight posteriorly; medial part slightly wider than basal part, without setae, outer margin of medial part convex; inner margin convex; outer 

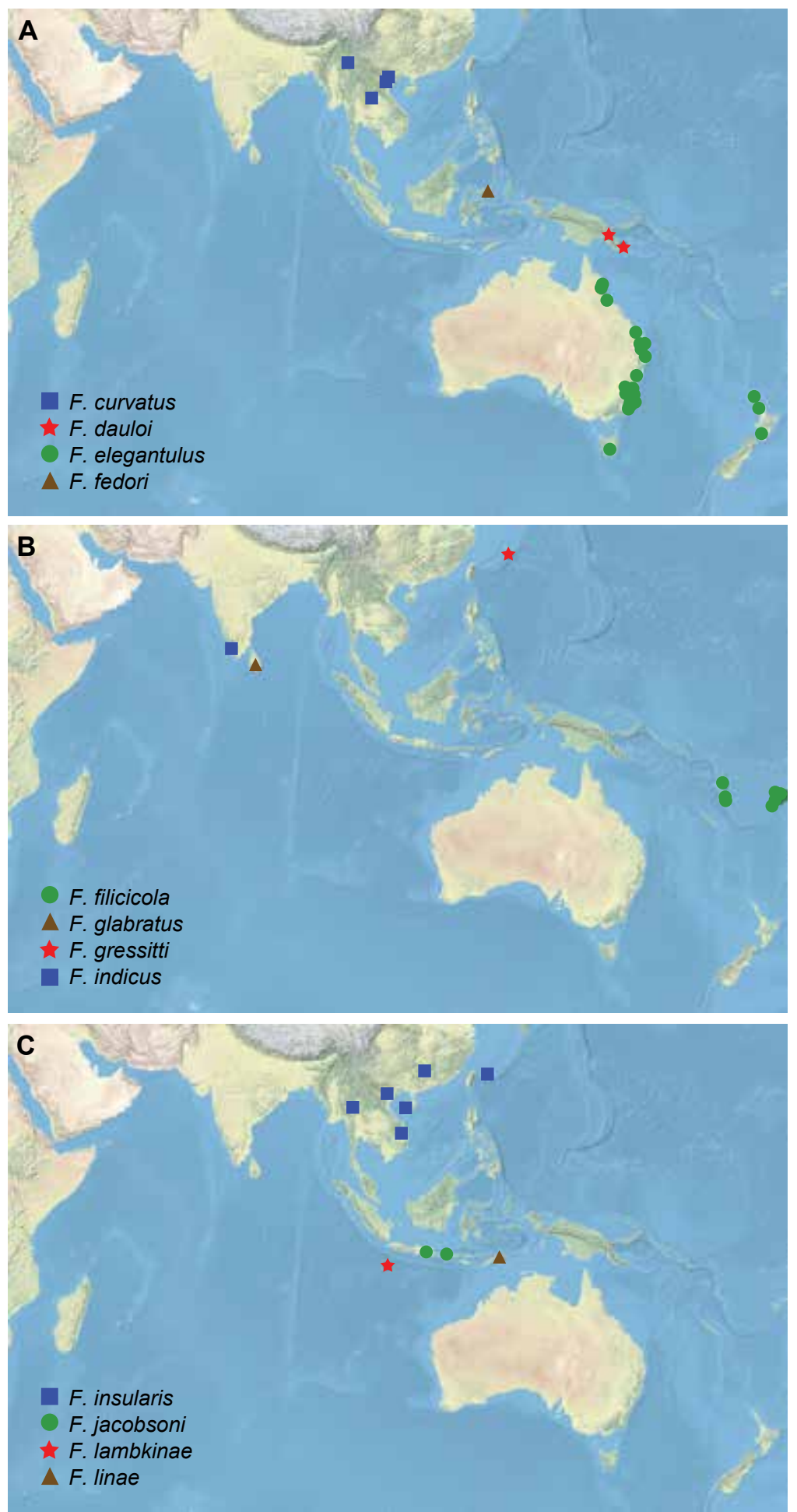

FIGURE 18. Distribution of Felisacus species. 
angle rounded; inner angle distinct, without outgrowths and setae; basal part of right parameres. $0.7 \times$ as long as rest of paramere. Left paramere (fig. 11W) L-shaped; apical part not flattened, without toothlike outgrowth apically or medially and without outgrowth on dorsal surface; middle part slightly widened, without swelling or outgrowth; setae placed on middle part near outer margin. Aedeagus (fig. 10E) conjunctiva entirely membranous; secondary gonopore placed at base of vesica in repose; sclerotized part of ductus seminis twice as long as wide; vesica with two serrate spicules, bearing toothlike outgrowths.

Female. Total length 4.4-5.2. COLORATION (fig. 4): Head and labium. As in male. Antenna: Similar to male, rarely segment II pale brown basally. Thorax: Similar to male, but posterior part of pronotum uniformly yellow to pale brown or with brown humeral angles; mesoscutum and scutellum yellow to pale brown, mesoscutum medially and scutellum basally sometimes brown; thoracic pleura pale brown to brown. Hemelytron: As in male. Legs: Coxae whitish yellow, femora whitish yellow basally and yellow apically, hind femora rarely with pale brown marking at apical half, rarely uniformly whitish yellow; tibia and tarsi whitish yellow to yellow. Abdomen: Whitish yellow to yellow ventrally, segment IX pale brown or reddish, stripe laterally and dorsal surface reddish to reddish brown. SURFACE AND VESTITURE: As in male. STRUCTURE AND MEASUREMENTS: Structure as in male; body ca. $4.1-4.4 \times$ as long as pronotum width; vertex ca. $1.8-2.0 \times$ as wide as eye diameter; antennal segment I ca. $1.3-1.5 \times$ as long as head width, ca. $0.6-0.8 \times$ as long as pronotum width; segment II ca. $1.8-2.2 \times$ as long as head width, ca. $0.9-1.1 \times$ as long as pronotum width; pronotum ca. $1.1-1.3 \times$ as wide as long and ca. $2.0-2.1 \times$ as wide as head. Genitalia (fig. 16L, M): Dorsal labiate plate wider than apodemes of second valvulae, with distinct striations, without membranous ridge medially; semicircular sclerite and sclerotized rings absent; lateral oviducts placed in posterior part, far from posterior margin; spermathecal gland attached near posterior margin, posterior to lateral oviducts; dorsal labiate plate with membranous semicircular lobe anteriorly, with tubercles only on this lobe and around it.

Distribution: China, Laos, Vietnam (fig. 18). Host PLANTs: Unknown.

Discussion: Felisacus curvatus was described by $\mathrm{Hu}$ and Zheng (2001) from China (Hainan). The holotype was thought to be housed in the collection of NKMU but we could not locate it and we consider it as lost.

We provide the following translation of the type series translated from Chinese by our colleague Xiaojing Wang (personal commun., translated from $\mathrm{Hu}$ and Zheng, 2001):

Body slender, yellowish brown, lateral sides parallel to each other, with pale hairs; vertex yellowish brown, with reddish tinge, with rare pale semierect setae, ratio of distance between anterior margin of head to posterior margin of eye and distance between posterior margin of eye to collar equal to 0.3:0.4; frons almost flat, frons and lateral sides of head yellowish brown; base of labium brown; neck yellowish brown, with slight reddish tinge; labium yellowish brown, reaching posterior margin of forecoxae; antennae yellowish brown, apex of antennal segment I and apical half of antennal segment II slightly darkened, with rare, pale and semierect hairs, the length of hairs on antennal segment I ca. $1.5 \times$ as long as antennal segment I width; hairs on antennal segment II subequal to the antennal segment I diameter; pronotum yellowish brown, with rare pale and semierect hairs, posterior margin brown, areas near posterior margin with slightly pale red tinge; lateral margins with slight depression; scutellum yellowish brown, length of hairs ca. $2.0 \times$ as long as antennal segment I width; inner part of clavus with the main part yellowish brown, outer part of clavus brown, with rare and pale semierect hairs, equal in length to the hairs on scutellum; corium yellowish brown, semitransparent, with arcshaped, broad and dark brown marking, reaching $1 / 5$ of claval length; cuneus yellowish brown, $1 / 4$ apex of inner margin red, length of outer margin twice as long as base; membrane pale yellowish brown, pos- 
terior half of wing cell and middle of membrane brownish yellow, veins yellowish brown, or with reddish tinge, apical angle round; legs yellowish brown, apex of femora and basal area of tibiae with red tinge; femora with rare, pale and semierect hairs, varying in length, short hairs subequal to middle part of femora width, longest ca. $1.5 \times$ as long as femur width; tibiae with hairs more adpressed than those on femora, hairs on half of apex dense and uniform, short hairs subequal to tibiae width, longest setae is ca. $2.0 \times$ as long as tibiae width; prosternum yellowish brown, mesosternum brown, with middle part yellowish brown, with pale semierect hairs; males with ventral side of abdomen yellowish brown, lateral side of the second segment with one long, small and red marking, segments IIIVII with red lateral margins; genital segment yellowish brown; females with lateral sides of abdominal II-VII segments red.

Measurements: Head length 0.6; head width 0.5; vertex width 0.3 ; antennal segments ratio 1.2:1.5:1.8:1.5; pronotum length 1.0, pronotum width 1.0; outer margin of corium 1.7; outer length of cuneus 0.7 ; base of cuneus width 0.3 ; length between apex of cuneus and end of membrane 0.6; body length 4.4-4.6.

Type: Male, from Hainan, 196403 28, Shengli LIU. This species is similar to F. ochraceus in yellowishbrown coloration, and marking around near inner margin of corium. The latter species differs in apex of antennal segment II not red; $2 / 3$ of inner part of clavus yellowish brown, outer part of clavus brown; apical 1/6 of inner margin of cuneus pale red; the band near inner margin of corium broader and longer; pronotum with posterior margin and posterior half of lateral margin brown; parameres different; ratio of antennal segments I-III in F. curvatus: 0.8:1.0:1.2 (in F. ochraceus 0.8:1.2:0.8: ratio between length and width of cuneus in F. curvatus: 0.66: 0.27, in F. ochraceus is 0.52:0.20).

We have examined additional specimens from southeast Asia, which fit the description of $F$. curvatus. They possess similar parameres $(\mathrm{Hu}$ and Zheng, 2001: fig. 2b, c), which are very distinct in comparison to all other Felisacus species. Based on this, we treat those additional specimens as F. curvatus.

Felisacus curvatus and F. wangae are sister species and have similar female genitalia with distinct striations (cf. fig. $16 \mathrm{~L}$ with $16 \mathrm{~N}$ ), the right-hand side of the genital capsule is slightly folded (cf. figs. 14J and 15M), and the apical sclerotized part of the ductus seminis is twice as long as wide (cf. fig. 10E with 10M). Felisacus wangae differs in that the marking on the inner margin of the corium is narrow, and its posterior part not widened (fig. 7), the labium reaches the middle of the mesosternum, and in the shape of the aedeagal spicules (fig. 10M).

MATERIAl EXAMined: CHINA: Yunnan: Ruili, $24.01655^{\circ} \mathrm{N} 97.85099^{\circ} \mathrm{E}, 1200 \mathrm{~m}, 29 \mathrm{Jul}$ 2006, Fan, 1 đิ (00017888) (NKMU). LAO PEOPLE'S DEMOCRATIC REPUBLIC: Vientiane Prov.: Ban Van Eue, $17.96666^{\circ} \mathrm{N} 102.6^{\circ} \mathrm{E}, 14 \mathrm{Apr}$ 1965-15 Apr 1965, J.L. Gressitt, 19 (00043876) (BPBM). VIETNAM: Ha Noi: 70 km NWW Ha Noi $\mathrm{BaVi}, 21.087^{\circ} \mathrm{N} 105.302^{\circ} \mathrm{E}, 22$ Nov 1990, Belokobylskij, 1 ㅇ (00017883) (ZISP). Ha Son Binh: Hoa Binh: Near Mai Chau, $20.667^{\circ} \mathrm{N}$ $105.084^{\circ} \mathrm{E}, 01$ Nov 1990, Belokobylskij, $4{ }^{\star}$ (00017882, 00271519), 2 (00017886) (ZISP); 02 Nov 1990, Belokobylskij, $30^{\star}$ (0001787900017881), 2 ㅇ (0001788400017885) (ZISP).

\section{Felisacus dauloi Woodward}

Figures 4, 8G, 11X, Y, 14K, 18

Felisacus dauloi Woodward, 1958: 236 (original description).

Diagnosis: Recognized by the following combination of characters: body mostly whitish yellow or yellow without brown markings, with reddish tinge and yellow or red cuneus (fig. 4); antennal segment I cylindrical (as in Namyatova et al., 2016: fig. 8A), transverse depression on head extending present dorsally and laterally, vertex upraised (as in Namyatova et al., 2016: fig. $6 \mathrm{D})$; relatively large body $3.8-4$ in male and $4.3-$ 
4.5 in female; cuneus ca. $3 \times$ as long as base; medial part of right paramere only slightly wider than basal part, shorter than basal and apical parts combined; outer margin of right paramere almost straight (fig. 11X); apical part of left paramere not widened, ca. $3 \times$ as long as wide (fig. $11 Y)$; six spicules vesical spicules, including spicules $A$ and B (fig. 8G).

Redescription: Male. Total length 3.8-4.0. COLORATION (fig. 4): Head: Mostly yellow with reddish tinge and marking; longitudinal sulcus sometimes yellow brown, tubercle around antennal fossae, maxillary plate and buccula sometimes whitish yellow; clypeus yellow with longitudinal red stripe; mandibular plate red or yellow with reddish marking. Eye brown to dark brown, often with reddish margins. Labium: Yellow, segment III with pale brown or red stripe ventrally. Antenna: Segment I yellow to reddish brown, darkened apically; segment II reddish brown. Thorax: Pronotum yellow with pale brown anterior margin, often with longitudinal red stripe laterally; mesoscutum yellow; scutellum yellow, sometimes with red longitudinal stripe; thoracic pleura yellow with reddish areas, sometimes mostly red; scent gland evaporative area whitish often with reddish tinge apically. Hemelytron: Mostly colorless and translucent; inner part of clavus sometimes opaque, whitish yellow to yellow, with margins yellow to pale brown or reddish; corium with area along inner margin of corium pale brown or red, narrow and short, not reaching $\mathrm{R}+\mathrm{M}$; embolium sometimes yellow, with yellow to pale brown or red apex and margins; cuneus with margins and often apex yellow or red, sometimes mostly yellow; membrane with grayish tinge, with membrane cell yellow to pale brown or red. Legs: Coxae whitish yellow; femora whitish yellow basally and yellow to red apically; tibiae whitish yellow to yellow, yellow or reddish basally; tarsi pale brown, sometimes tarsal segment I whitish yellow. Abdomen: Ventral and lateral sides of pregenital segments whitish yellow, dorsal surface of pregenital segments and entire genital capsule red. SURFACE AND VESTITURE:
Corium smooth, with shallow and scarce punctures. Dorsum, antennal segment I and femora clothed with setae mostly as long as or somewhat shorter than antennal segment II diameter; abdomen clothed with suberect mostly short simple setae. STRUCTURE AND MEASUREMENTS: Body ca. $4.4-4.7 \times$ as long as pronotum width. Head: Depression, delimiting occipital region, present dorsally and laterally (as in Namyatova et al., 2016: fig. 4E); distance between depression and pronotum distinctly shorter than eye diameter; longitudinal sulcus on dorsal surface of head longer than eye diameter; distance from eye to pronotum as long as eye diameter, not swollen laterally (as in Namyatova et al., 2016: fig. $4 \mathrm{E}$ ); vertex ca. $1.4-1.7 \times$ as wide as eye; vertex raised (as in Namyatova et al., 2016: fig. 6D); buccula ca. $0.2-0.25 \times$ as long as clypeus. Labium: Almost reaching posterior part of mesosternum; segments I and II strongly reduced, combined shorter than half of segment III; segment I shorter than wide (as in Namyatova et al., 2016: figs. 6E, 9C); segment II slightly longer than wide, its dorsal surface elongate posteriorly; segment III ca. as long as ventral side of head length; segment IV ca. 1.5 $\times$ as long as segment III. Antenna: Segment I cylindrical (as in Namyatova et al., 2016: fig. 8A), ca. 1.7$1.8 \times$ as long as head width, ca. $1.1 \times$ as long as pronotum width; segment II ca. $2.2 \times$ as long as width of head, ca. $1.4 \times$ as long as width of pronotum. Thorax: Anterior part of pronotum slightly shorter than posterior part; collar delimited; posterior part of pronotum slightly upraised; posterior margin of pronotum concave; pronotum ca. $1.2-1.3 \times$ as wide as long and ca. $1.4-1.7 \times$ as wide as head; mesoscutum slightly exposed. Hemelytron: Area along inner margin of corium flat; inner margin of cuneus convex (as in Namyatova et al., 2016: fig. 13E), medial margin of cuneus ca. $3 \times$ as long as base. Genitalia: Genital capsule (fig. $14 \mathrm{~K}$ ) slightly longer than wide; ventral wall twice as long as dorsal wall, with posterior margin of ventral wall semioval, smooth, without outgrowth(s), its apex inclined slightly leftward, not curved; sides 
of genital capsule not modified; right margin of paramere socket angulate, left margin rounded; distance between paramere sockets ca. $0.3 \times$ as long as base of genital capsule. Right paramere (fig. 11X) distinctly curved in apical half; apex straight dorsally; medial part only slighter wider than basal part, bearing setae, with outer margin straight and inner margin only slightly convex; outer angle distinct; inner angle rounded, without setae; basal part ca. $0.15-0.2 \times$ as long as rest of paramere. Left paramere (fig. 11Y) L-shaped; apical part not flattened, with toothlike outgrowth on posterior side medially (as in fig. $11 \mathrm{G}$ ) and without outgrowth on dorsal surface; middle part widened, without swelling or outgrowth; setae only on middle part near outer margin. Aedeagus conjunctiva weakly sclerotized, secondary gonopore placed at base of vesica in repose; sclerotized part of ductus seminis around secondary gonopore shorter than wide; vesica with six spicules, including spicules $A$ and $B$ (fig. 8G).

Female. Total length 4.3-4.5. COLORATION (fig. 4): Head: Similar to male, sometimes pale brown posteriorly; mandibular plate yellow, yellow with reddish tinge or red. Labium: As in male. Antenna: Similar to male, segment I uniformly yellow or pale brown, yellow at base, segments III-IV brown to dark brown. Thorax: Similar to male, but mesoscutum and scutellum yellow, thoracic pleura sometimes with pale brown markings. Hemelytron: As in male. Legs: Similar to male, tarsi pale brown, sometimes segment I and II whitish to yellow. Abdomen: Ventral side and partly lateral side of pregenital segments and segment VIII whitish yellow, upper part of lateral side and dorsal surface of segments II-VIII and entire segment IX red. SURFACE AND VESTITURE: As in male. STRUCTURE AND MEASUREMENTS: Structure as in male; body ca. $4.2-4.6 \times$ as long as pronotum width; vertex ca. $1.6-1.8 \times$ as wide as eye diameter; antennal segment I ca. $1.5-1.8 \times$ as long as head width, ca. $0.9-1.1 \times$ as long as pronotum width; segment II ca. 1.9-2.2 $\times$ as long as head width, ca. $1.2-1.4 \times$ as long as pronotum width; antennal segment III slightly longer than segment II; segment IV ca. $0.3 \times$ as long as segment III; pronotum ca. $1.2-1.3 \times$ as wide as long and ca. $1.6-1.8 \times$ as wide as head. Genitalia (as in Namyatova et al., 2016: fig. 23F, G): Dorsal labiate plate wider than distance between apodemes of second valvula; mostly smooth, without distinct striations, with semicircular sclerite and distinct sclerotized rings laterally; lateral oviducts placed almost medially, very close to each other, spermathecal gland placed between lateral oviducts; dorsal labiate plate with distinct tubercles, without membranous lobe medially.

Distribution: Papua New Guinea (fig. 18).

Host Plant: Ferns in wet tropics (Woodward, 1958).

REMARKs: Antennal segments III-IV in males were lost, in females only parts of antennal segment IV remain.

Discussion: Felisacus dauloi was described by Woodward (1958) from a single female. One of us (A.A.N.) examined the holotype, preserved in the Queensland Museum. We have some other nontype specimens from BPBM, collected also in Papua New Guinea, and we found that they are very similar to the type of $F$. dauloi and treat them as belonging to that species.

Felisacus dauloi is similar to F. filicicola, $F$. ochraceus, and F. tanna in coloration and external morphology (figs. 4-7). Felisacus filicicola differs from $F$. dauloi in the mostly yellow or reddish-yellow cuneus and the presence of seven vesical spicules, including spicules $A, B$, E, and G (fig. 8I). Felisacus ochraceus differs in the cuneus uniformly yellow or with yellow or red inner part, the medial part of the right paramere is as wide as the basal part, and shorter than the basal and apical parts combined, the outer margin of the right paramere is distinctly concave (fig. 13C), and there are five vesical spicules, including spicules $\mathrm{A}, \mathrm{B}, \mathrm{C}$, and $\mathrm{H}$ (fig. 9F). Felisacus tanna differs from $F$. dauloi in the apex of the cuneus colorless often with a yellow tinge and is never red, the middle part of the right paramere is broad, twice as wide as the 
basal part (fig. 13T), and the vesica has five spicules, including spicules $\mathrm{A}, \mathrm{B}$, and $\mathrm{E}$ (fig. 9M).

Material examined: Holotype: PAPUA NEW GUINEA: Eastern Highlands: Daulo Pass, 20 Aug 1956-22 Aug 1956, T.E. Woodward, 19 (00201839) (QM). Additional material: PAPUA NEW GUINEA: Morobe Province: Kaisenik Rd, Wau Subdistrict, $7.38012^{\circ} \mathrm{S}$ $146.77817^{\circ} \mathrm{E}, 1100 \mathrm{~m}, 02$ Mar 1978, W.C. Gagne, Pteris moluccanus (Pteridaceae), 4 우 (00042366, 00042367, 00042277, 00042278) Pteris moluccana (Pteridaceae), 30 (00042364, 00042365, 00043882), 1 (00043881) (BPBM). Northern Province: 9-10 km WSW of Tufi, SE Cape Nelson, $9.1^{\circ} \mathrm{S} 149.3^{\circ} \mathrm{E}, 585 \mathrm{~m}, 08 \mathrm{Sep}$ 1982-13 Sep 1982, G.A. Samuelson, 10 (00043880) (BPBM).

\section{Felisacus elegantulus (Reuter)}

Figures 5, 8H, 11Z, AA, 18

Hyaloscytus elegantulus Reuter, 1904: 2 (original description).

Hyaloscytus elegantulus var. filicicola Kirkaldy, 1908: 377 (original description); Knight, 1935: 200 (revised status).

Hyaloscytus elegantulus var. javanus Reuter, 1908: 187 (original description; synonymized by Poppius, 1914: 148 with Felisacus glabratus (Motschulsky, 1863).

Diagnosis: Recognized by the following combination of characters: dorsum mostly yellow to pale brown, without reddish tinge or any red markings; humeral angles of pronotum often brown to dark brown; antennal segment I cylindrical (as in Namyatova et al., 2016: fig. 8A); transverse depression on head extending laterally; labium reaching posterior margin of mesosternum; dorsal surface of labial segment II elongate posteriorly (as in Namyatova et al., 2016: fig. 6D); cuneus ca. $3 \times$ as long as base; medial part of right paramere as long as apical part, only slightly wider than basal part; outer margin of right paramere straight (fig. 11Z); api- cal part of left paramere not widened, ca. $3 \times$ as long as wide (fig. 11AA); vesica with five spicules, including spicule B (fig. $8 \mathrm{H}$ ).

Redescription: Male. Total length 4.0-4.2. COLORATION (fig. 5): Head: Whitish yellow to pale brown, rarely with greenish tinge, often dorsal surface and sometimes lateral side and frons somewhat darker than rest of head; head often with brown, dark brown, or red markings; clypeus whitish yellow to pale brown, often brown to dark brown apically. Eye dark brown, sometimes with reddish tinge, rarely eyes pale brown. Labium: Whitish yellow to yellow, segments I-II sometimes with greenish tinge, segment III sometimes with reddish tinge ventrally. Antenna: Segment I pale brown to brown with yellow base, rarely yellow with reddish tinge; segment II pale brown to dark brown, rarely with reddish tinge; segments III-IV brown to dark brown. Thorax: Pronotum whitish yellow to yellow, rarely with reddish tinge; anterior margin of pronotum sometimes pale brown; humeral angles of pronotum often pale brown to dark brown; pronotum sometimes uniformly colored; mesoscutum and scutellum whitish to yellow, scutellum sometimes brown apically, often paler than mesoscutum; punctures between mesoscutum and scutellum pale brown; thoracic pleura whitish yellow to yellow, rarely with greenish tinge; scent gland evaporative area uniformly whitish, rarely with greenish tinge. Hemelytron: Mostly translucent, colorless; inner part of clavus sometimes opaque, and yellow with margins yellow to brown; corium with marking along inner margin of corium yellow to brown; embolium sometimes opaque and yellow, with pale brown to brown margins; cuneus with yellow to brown margins, outer margin often somewhat darker than inner margin; membrane often with yellow or grayish tinge; membrane cell yellow to pale brown. Legs: Coxae whitish yellow to yellow; femora whitish yellow to yellow basally and darker, yellow to pale brown, apically, sometimes with reddish tinge; tibia whitish yellow to pale brown, often with paler, whitish to yellow, apical part, sometimes with reddish stripe; tarsi yellow 
to pale brown, sometimes tarsal segment I paler, whitish yellow to yellow. Abdomen: Whitish to yellow, sometimes with greenish tinge. SURFACE AND VESTITURE: Corium smooth, with shallow punctures. Dorsum, antennal segment II, and femora clothed with setae as long as or shorter than antennal segment II diameter; abdomen clothed with short erect setae, distinctly shorter than width of antennal segment II. STRUCTURE AND MEASUREMENTS: Body ca. $4.2-4.4 \times$ as long as pronotum width. Head: Depression delimiting occipital region present dorsally and laterally (as in Namyatova et al., 2016: fig. 4E); distance between depression and pronotum distinctly shorter than eye diameter; longitudinal sulcus on dorsal surface of head longer than eye diameter; distance from eye to pronotum distinctly longer than eye diameter, not swollen laterally (as in Namyatova et al., 2016: fig. 4E); vertex ca. $1.7-1.9 \times$ as wide as eye, upraised (as in Namyatova et al., 2016: fig. 6D); buccula ca. $0.2-0.25 \times$ as long as clypeus. Labium (as in Namyatova et al., 2016: figs. 6D, 9C): Reaching posterior margin of mesosternum or slightly surpassing it; segments I and II strongly shortened, combined shorter than half of segment III; segment I shorter than wide; segment II as long as wide, its dorsal surface elongate posteriorly; segment IV ca. $1.5 \times$ as long as segment III. Antenna: Segment I cylindrical (as in Namyatova et al., 2016: fig. 8A), ca. 1.5-1.8× as long as head width, ca. $0.9-1.0 \times$ as long as pronotum width; segment II ca. 1.9-2.1× as long as width of head, ca. 1.1-1.2× as long as pronotum width; segment III slightly longer than segment II; segment IV subequal to half of segment III. Thorax: Anterior part of pronotum only slightly shorter than posterior part; collar delimited; posterior part slightly upraised; posterior margin concave; pronotum ca. $1.3-1.4 \times$ as wide as long and ca. $1.7-1.9 \times$ as wide as head; mesoscutum exposed. Hemelytron: Area along inner margin of corium almost flat; inner margin of cuneus convex (as in Namyatova et al., 2016: fig. 13E), outer margin of cuneus ca. $3 \times$ as long as base. Abdomen: Genital capsule rotated left at right angle relative to rest of abdomen. Genitalia: Genital capsule (Namyatova et al., 2016: fig. $22 \mathrm{~L}$ ) ca. $1.5 \times$ as long as wide; ventral wall ca. $1.5 \times$ as long as dorsal wall, with posterior margin semioval, smooth, without outgrowth, slightly pointed, its apex slightly inclined leftward, not curved; sides of genital capsule not modified; right paramere socket slightly pointed, left paramere socket rounded; distance between paramere sockets subequal to half of genital capsule width at base. Right paramere (fig. 11Z) distinctly curved apically; apex straight; medial part only slighter wider than basal part, bearing setae, with outer margin straight or slightly concave and inner margin convex; outer angle distinct, slightly swollen; inner angle absent, without setae; basal part ca. $0.25 \times$ as long as rest of paramere. Left paramere (fig. 11AA) L-shaped; apical part not flattened, with toothlike outgrowth on posterior side medially and without outgrowth on dorsal surface; middle part widened, without swelling or outgrowth(s); setae only on middle part near outer margin. Aedeagus (Namyatova et al., 2016: fig. 22I) conjunctiva weakly sclerotized; secondary gonopore placed at base of vesica in repose; sclerotization of ductus seminis around secondary gonopore shorter than wide; vesica with five spicules, including small spicule $B$ and unique large bifurcate spicule ventrally (fig. $8 \mathrm{H}$ ).

Female. Total length 4.1-4.7. COLORATION (fig. 5). Similar to male, rarely coloration of body, pronotum, thoracic pleura and inner part of clavus pale brown, abdomen whitish to pale brown, rarely with greenish tinge, sometimes reddish apically. SURFACE AND VESTITURE: As in male. STRUCTURE AND MEASUREMENTS: Structure as in male; body ca. $4.2-4.3 \times$ as long as width of pronotum; vertex ca. $1.8-2.1 \times$ as wide as eye diameter; antennal segment I ca. 1.4-1.7× as long as head width, ca. $0.8-0.9 \times$ as long as pronotum width; segment II ca. 1.9-2.1 $\times$ as long as head width, ca. $1.1-1.2 \times$ as long as pronotum width; pronotum ca. $1.3-1.4 \times$ as wide as long and ca. $1.7-1.8 \times$ as wide as head. Genitalia (as in Namyatova et al., 2016: fig. 23F, G): Dorsal labiate plate wider than distance between apodemes 
of second valvula; mostly smooth, without distinct striations, with semicircular sclerite and distinct sclerotized rings laterally; lateral oviducts placed almost medially, very close to each other, spermathecal gland placed between lateral oviducts; dorsal labiate plate with distinct tubercles, without membranous lobe medially.

Distribution: Australia, New Zealand (fig. 18).

Host PLANTS: The species was collected mostly from ferns and a few specimens were also collected from angiosperms. The host plant for $F$. elegantulus is primarily Pteris tremula R.Br. (Pteridaceae) in New Zealand (35 specimens). Woodward (1954) also reported that many specimens of F. elegantulus were collected from Hypolepis muelleri N.A. Wakef. (Dennstaedtiaceae) in New South Wales, Australia (5 specimens); Pteris sp. (Pteridaceae) in New Zealand (2 specimens); and Polystichum sp. (Dryopteridaceae) in New Zealand (35 specimens). Plant records among angiosperms are considered sitting records only, and include Acmena smithii (Poir.) Merr. (Myrtaceae) in New South Wales (1 female specimen); Dendrocnide excelsa (Wedd.) Chew (Urticaceae) in Queensland (1 female specimen); and Pomaderris apetala Labill. (Rhamnaceae) in Tasmania (2 specimens).

Discussion: Felisacus elegantulus was described by Reuter (1904) from two males and we could not locate the syntypes, which we presume are lost. Nevertheless, there are abundant specimens, collected throughout Australia and New Zealand, fitting the original description. This species has been treated as F. elegantulus by Eyles and Schuh (2003), and we also consider it as conspecific to F. elegantulus. There is another species of Felisacus, collected in Queensland, but it has different coloration from the species, described by Reuter (1904) (see F. australicus). See generic discussion for the explanation of nomenclatural confusion in literature.

Felisacus elegantulus is similar to F. caledonicus, F. lordhowensis, and F. schuhi in the coloration and the structure. Felisacus caledonicus differs in the lateral margins of the collar being often brown, the humeral angles of the pronotum are whitish yellow, the apical part of the left paramere is broad, twice as long as wide (fig. $11 \mathrm{Q})$, and there are four vesical spicules, including spicules $A$ and $B$ (fig. 8F).

Felisacus lordhowensis differs from F. elegantulus in the labium reaching the posterior margin of the metasternum, the humeral angles of the pronotum is whitish yellow to yellow, the pronotum is brown posteriorly, and there are six vesical spicules, including spicules B and E (fig. 8R).

Felisacus schuhi differs from F. elegantulus in the humeral angles often yellow to pale brown, the inner part of the clavus often brown, the labium only slightly surpassing the middle of the mesosternum, and there are five spicules, including spicules $\mathrm{A}, \mathrm{B}$, and $\mathrm{C}$ (fig. 9J).

Material examined: AUSTRAlia: New South Wales: Bola Creek, Royal National Park, $34.11495^{\circ} \mathrm{S} 151.06544^{\circ} \mathrm{E}, 27 \mathrm{Feb} 1989$, G. Cassis, $2{ }^{\star}$ (00017724, 00017725), 19 (00017735) (AM). Jamieson Park, Narrabeen, $33.7169^{\circ} \mathrm{S}$ 151.28207 ${ }^{\circ}$ E, 01 Feb 1996, B. Day and P. Serov, 3 (00017739-00017741) (AM). Kings Rd., Federal, $28.65331^{\circ} \mathrm{S} 153.43432^{\circ} \mathrm{E}$, 02 Jan 2012 , G. Cassis, $10 \delta^{\text {t }}(00400524,00400110-$ $00400116, \quad 00400524,00191459), \quad 11$ ㅇ (00191458, 00191460, 00400501, 0040011800400123, 00400501, 00191458), 2 sex unknown (00191460, 00400117), 10 juvenile (00400124-00400133) (UNSW). Minnamurra Falls nr Kiama, $34.63333^{\circ} \mathrm{S} 150.71666^{\circ} \mathrm{E}, 07 \mathrm{Jan}$ 1961, D.K. McAlpine, $1 \delta^{\text {त }}$ (00017552) (AM). Mount Keira, $34.24^{\circ} \mathrm{S} 150.51^{\circ} \mathrm{E}, 09$ May 1970 , D.K. McAlpine and G.A. Holloway, $1 q$ (00017738) (AM). Porter's Dam Road, 16 km $\mathrm{NM}$ of Milton, $35.17925^{\circ} \mathrm{S} 150.44048^{\circ} \mathrm{E}, 09 \mathrm{Feb}$ 1974, Z. Liepa, $2 \widehat{0}$ (00033774, 00033775) (ANIC). Rotary L/out, Pigeon House Ra NW of Milton, $35.35061^{\circ} \mathrm{S} 150.26785^{\circ} \mathrm{E}, 22 \mathrm{Feb}$ 1979, Z. Liepa, 1 ㅇ (00033771) (ANIC). Royal National Park, Warumbul Picnic Area, $34.06667^{\circ} \mathrm{S} 151.1048^{\circ} \mathrm{E}, 20 \mathrm{~m}, 14$ Nov 2001, Cassis, Schuh, Schwartz, Silveira, Hypolepis muelleri N.A. Wakef. (Dennstaedtiaceae), det. NSW staff NSW666413, 30 (00021377, 00021375, 00021376), 2 ㅇ (00021373, 00021374) (AM). S Coast of Durras Lake, 
$35.65613^{\circ} \mathrm{S} 150.27268^{\circ} \mathrm{E}, 22$ Feb 1965 , D.H. Colless, $2+(00033769,00033770), 1$ sex unknown (00033772), 2 के (00033777, 00033778) (ANIC). Sydney Lea, $33.87309^{\circ} \mathrm{S}$ $151.16901^{\circ} \mathrm{E}$, no date provided, collector unknown, $1 \delta^{\dagger}$ (00017723) (AM). Wallaga Lake, Bermagui, $36.42279^{\circ} \mathrm{S} 150.06441^{\circ} \mathrm{E}, 21 \mathrm{Jul}$ 1973, Z. Liepa, 3 ㅇ (00033766-00033768), 1 하 (00033776) (ANIC). Wentworth Falls, Blue Mountains, $33.71083^{\circ} \mathrm{S} 150.37497^{\circ} \mathrm{E}, 20 \mathrm{Nov}$ 1958, D.K. McAlpine, 1 ㅇ (00017557) (AM). approx. $24 \mathrm{~km}$ NNW of Gloucester, $32.048^{\circ} \mathrm{S}$ $151.903^{\circ} \mathrm{E}, 05$ Dec 1990, G. and T. Williams, Acmena smithii (Poir.) Merr. and L.M. Perry (Myrtaceae), 1 ㅇ (00017737) (AM). Queensland: $5 \mathrm{mi} E$ Paluma, Northern Queensland, $19.00392^{\circ} \mathrm{S} 146.24205^{\circ} \mathrm{E}, 18$ Jan 1970, G.A. Holloway, $1+$ (00017558) (AM). Conondale Range, Bundaroo Creek, $26.683^{\circ} \mathrm{S}$ $152.617^{\circ} \mathrm{E}, 03 \mathrm{Dec} 1985, \mathrm{G}$. Cassis and D. Bickel, $5+$ (00017726-00017730), 4 juvenile (00017731-00017734), 8 ô (0001766300017667, 00017720-00017722) (AM). Mt. Edith Forest road, $1.5 \mathrm{mi}$ off Danbulla Road, $17.1^{\circ} \mathrm{S} 145.633^{\circ} \mathrm{E}, 06$ May 1967, D.H. Colless, $1+$ (00034248) (ANIC). Mt. Glorious, $27.333^{\circ} \mathrm{S}$ $152.767^{\circ} \mathrm{E}, 16$ Feb 1961-20 Feb 1961, L. and M. Gressitt, 1 đิ (00042309) (BPBM). Mt. Hypipamee, National Park “The Crater," $17.42388^{\circ} \mathrm{S}$ $145.48388^{\circ} \mathrm{E}, 25$ Apr 1998, G. Cassis, Dendrocnide excels (Urticaceae), 1 우 (00017736) (AM). Pinnock [Pinock] R., Gorge Hogback Ra., WSW of Bundaberg, $25.03481^{\circ} \mathrm{S} 151.80731^{\circ} \mathrm{E}$, 23 Sep 1972, H. Frauca, $2 \delta^{\star}$ (00033779, 00033780) (ANIC). Woombye, nr. Nambour, $26.665^{\circ} \mathrm{S} 152.976^{\circ} \mathrm{E}, 11$ Oct $1965-16$ Oct 1965 , D.H. Colless, $2+(00033764,00033765), 10$ (00033773) (ANIC). Tasmania: Mt. Field National Park, Russell Falls Visitor Centre, $42.68151^{\circ} \mathrm{S} 146.7168^{\circ} \mathrm{E}, 167 \mathrm{~m}, 16$ Jan 2004 , M.D. Schwartz and P.P. Tinerella, Pomaderris apetala Labill. (Rhamnaceae), det. NSW staff NSW658218, 1 ठ (00021542) (AMNH). Victoria: [Victoria], no date provided, Unknown, $2 q$ (00005120) (MVMA). NEW ZEALAND: Auckland: Cremorne St, Herne Bay, Auckland, $36.84291^{\circ} \mathrm{S} 174.73087^{\circ} \mathrm{E}, 30 \mathrm{Dec} 1997, \mathrm{G}$. Cassis, Polystichum sp. (Dryopteridaceae), 200 (00017562, 00017563, 00017742-00017745, 00017783-00017796), 1 juvenile (00017559), 14 우 (00017797-00017810) (AM). Upokorau Valley, $15 \mathrm{~km}$ W Takou Bay, Northland, $35.13883^{\circ} \mathrm{S} 173.84274^{\circ} \mathrm{E}, 16$ Jan 1998 , G. Cassis, 10 ๙ (00017746-00017755), 2 sex unknown (00017560, 00017561), 7 juvenile (0001775600017762), $20 \uparrow$ (00017763-00017782) (AM) North Auckland: Auckland, $36.8667^{\circ} \mathrm{S}$ $174.7667^{\circ} \mathrm{E}, 14$ Mar 1996, Tomkovich, $1 \delta^{\star}$ (00271527) (ZISP). Wellington: Whirokino [Whirikino], Manuwatu, $40.51826^{\circ} \mathrm{S}$ $175.25021^{\circ} \mathrm{E}, 7 \mathrm{~m}, 07$ Jan 1953, T.E. Woodward, Pteris sp. (Pteridaceae), 10 (00018975), $1+$ (00018974) (ISNB); 27 Jan 1957, T.E. Woodward, 19 (00021557) (AMNH).

Felisacus fedori, sp. nov.

Figures 4, 10G, 11AB, AC, 14L, 18

Diagnosis: Recognized by the following combination of characters: marking along inner margin of corium distinct, brown, its anterior part widened, not reaching $\mathrm{R}+\mathrm{M}$ (fig. 4), posterior part, reaching $\mathrm{R}+\mathrm{M}$; posterior part of pronotum mostly yellow, brown to dark brown only along posterior margin; cuneus red; inner margin of medial part of right paramere convex, without swelling; inner angle of right paramere with short and acute outgrowth (fig. 11AB); medial part of left paramere with wide outgrowth (fig. 11AC); distal half of ductus seminis sclerotized, sickle shaped apically; vesica without spicules (fig. 10G).

Description: Male. Total length 4.4-4.5. COLORATION (fig. 4): Head: Mostly yellow with red stripes on frons above antennal fossa and sometimes laterally behind eye and with reddish markings on tubercle of antennal fossa; ventral side of head and buccula whitish yellow. Eye dark brown with reddish tinge. Labium: Uniformly whitish yellow or with segments II-IV yellow. Antenna: Segment I yellow with reddish tinge; segment II reddish brown; segments III-IV 
brown. Thorax: Pronotum yellow, its posterior part slightly paler than anterior part, with brown humeral angles and medial stripe or all those markings merged; mesoscutum brown; scutellum yellow to pale brown with brown medial stripe, this stripe darker basally and pale apically; thoracic pleura mostly pale brown with dark brown markings; scent gland evaporative area whitish yellow. Hemelytron: Mostly translucent; inner part of clavus opaque, brown; outer part of clavus pale brown, dark brown basally; corium colorless with brown marking along inner margin of corium, its anterior part widened, not reaching $\mathrm{R}+\mathrm{M}$ vein, posterior part reaching $\mathrm{R}+\mathrm{M}$ vein; embolium colorless or pale brown, with brown base and outer margin and reddish apex; cuneus opaque, uniformly red; membrane brown basally and whitish and with greyish tinge apically; membrane cell pale brown to brown. Legs: Coxae whitish yellow; femora whitish yellow basally and yellow apically, forefemur with reddish stripe apically and medially, hind femur with red or brown marking in apical half; tibiae yellow basally and whitish yellow apically, with red stripe distinct basally and pale apically; tarsi whitish yellow. Abdomen: Whitish yellow, with brown dorsum and genital capsule. SURFACE AND VESTITURE: Corium smooth, with shallow and scarce punctation. Dorsum with setae subequal to antennal segment II diameter; antennal segment I clothed with suberect setae shorter than antennal segment II diameter; femora with suberect setae subequal to or longer than antennal segment II diameter; abdomen clothed with short erect setae. STRUCTURE AND MEASUREMENTS: Body ca. 4.0-4.1 $\times$ as long as pronotum width. Head: Depression delimiting occipital region present only dorsally, not extending laterally (Namyatova et al., 2016: fig. 6E); distance between depression and pronotum slightly shorter than eye diameter; longitudinal sulcus on dorsal surface of head shorter than eye diameter; distance from eye to pronotum subequal to eye diameter, not swollen laterally; vertex ca. 1.5-1.6x as wide as eye diameter; vertex raised; buccula ca. $0.3 \times$ as long as clypeus height. Labium: Slightly surpassing prosternum; each of segments I and II subequal to half of segment III; dorsal surface of labial segment II not elongate (as in Namyatova et al., 2016: fig. 6E); segment III shorter than ventral side of head; segment IV ca. $1.5 \times$ as long as segment III. Antenna: Segment I widened medially (as in Namyatova et al., 2016: fig. 8B), ca. $1.1-1.2 \times$ as long as head width, ca. $0.9 \times$ as long as pronotum width; segment II $2.0-2.2 \times$ as long as head width, $1.3-1.4 \times$ as long as pronotum width; antennal segment III almost as long as segment II; segment IV slightly shorter than segment III. Thorax: Anterior part of pronotum shorter than posterior part; collar delimited; posterior part slightly upraised, posterior margin of pronotum slightly concave; pronotum ca. $1.2 \times$ as wide as long and $1.6 \times$ as wide as head; mesoscutum slightly exposed or not exposed. Hemelytron: Area along inner margin of corium swollen; inner margin of cuneus straight, outer margin of cuneus $2 \times$ longer than width at base. Abdomen: Genital capsule rotated $45^{\circ}$ relative to other segments. Genitalia: Genital capsule (fig. 14L) ventral wall ca. $1.5 \times$ as long as dorsal wall, with posterior margin of ventral wall not curved dorsally, with small tooth-shaped outgrowth; right side of genital capsule curved, left side of genital capsule not widened; right paramere sockets angulate, left paramere socket rounded; distance between paramere sockets subequal to $1 / 4$ of genital capsule base width. Right paramere (fig. 11AB) distinctly curved in apical half; apex concave posteriorly; medial part narrower than basal part, outer margin of medial part convex and inner margin concave, without swelling, without setae; outer angle absent; inner angle present, with straight outgrowth, bearing setae; basal part of right paramere ca. $0.3 \times$ as long as rest of paramere. Left paramere (fig. 11AC) Apical part not flattened, with tooth on posterior side apically and with outgrowth on dorsal surface; middle part with short and wide outgrowth bearing setae. Aedeagus (fig. 10G) vesica without spicules; distal half of ductus seminis sclerotized, secondary gonopore placed near phallotheca mouth in repose; ductus seminis hooked apically. 
Female. Total length 4.9-5.9. COLORATION (fig. 4): Head: Similar to male, but without red stripes and markings; labial segments II-IV often yellow, segment II sometimes brown ventrally; antennal segment I sometimes reddish brown apically. Thorax: Similar to male; collar often brown to dark brown; scutellum yellow to pale brown with brown stripe medially; mesoscutum yellow, brown basally or uniformly brown; thoracic pleura yellow to pale brown with dark brown metepimeron, sometimes with markings also dark brown. Hemelytron: Similar to male, but outer part of clavus sometimes brown, same color as inner part; embolium pale brown with brownish base and reddish apex. Legs: Similar to male, but marking in apical half of femur red or reddish brown and sometimes absent on middle femur; abdomen similar to male, sometimes uniformly whitish yellow. SURFACE AND VESTITURE: As in male. STRUCTURE AND MEASUREMENTS: Structure as in male, body ca. $3.8-4.0 \times$ as long as pronotum width; vertex ca. $1.1-1.5 \times$ as wide as eye diameter; antennal segment I ca. $1.2-1.3 \times$ as long as head width, ca. $0.8-1.0 \times$ as long as pronotum width; segment II ca. 1.9-2.2× as long as head width, ca. 1.1-1.2 $\times$ as long as pronotum width; pronotum ca. $1.2-1.4 \times$ as wide as long and ca. 1.6$1.9 \times$ as wide as head.

Eтymology: The species is named after Fedor V. Konstantinov (St. Petersburg State University, Russia), who helped us to get many specimens for this study.

Distribution: Indonesia, Sulawesi Is. (fig. 18). Host Plants: Unknown.

Discussion: Antennal segments, and the middle and hind legs are lost in the female; the female genitalia were not dissected. Felisacus fedori is similar to F. cristobalus in the marking along the inner margin of corium and anterior part, which is broad and not reaching $\mathrm{R}+\mathrm{M}$ (fig. 4 ); in contrast, the latter species differs from $F$. fedori in the pronotum mostly brown to dark brown with pale brown stripe medially, the cuneus translucent, colorless with brown mar- gins, and the outgrowth on the inner part of right paramere abrupt (fig. 11T).

Material eXAmined: Holotype: INDONESIA: Sulawesi Utara: Dumoga-Bone National Park, Plot C, 400 m, 11 Feb 1985, Royal Entomological Society of London: Project Wallace, 10 (00019529) (BMNH). Paratypes: INDONE-

SIA: Sulawesi Utara: Dumoga-Bone National Park, Gunung Ambang Forest Reserve, near Kotamobagu, Fog. $7,0.55^{\circ} \mathrm{N} 123.98333^{\circ} \mathrm{E}, 1200$ m, 18 Feb 1985, Royal Entomological Society of London: Project Wallace, $2+$ (00019534, 00019531) (BMNH). Dumoga-Bone National Park, Plot B, Fog. 6/14, 315 m, 13 Feb 1985, Royal Entomological Society of London: Project Wallace, 1 ㅇ (00019535) (BMNH). Dumoga-Bone National Park, plot B, Fog 3, 315 m, Feb 1985, Royal Entomological Society of London: Project Wallace, 19 (00019530), 10 (00019528) (BMNH).

\section{Felisacus filicicola (Kirkaldy)}

Figures 5, 8I, 11AD, AE, 14N, 18

Hyaloscytus elegantulus var. filicicola Kirkaldy, 1908: 377 (original description).

Felisacus filicicola Knight, 1935: 200 (comb. nov.).

Diagnosis: Recognized by the following combination of characters: coloration of dorsum generally yellow, often with reddish tinge or markings; cuneus often yellow to red, or at least with reddish (fig. 4); cylindrical antennal segment I (as in Namyatova et al., 2016: fig. 8A), transverse depression delimiting occipital region extending laterally; vertex upraised (as in Namyatova et al., 2016: fig. 6D); body length in male 3.5-3.8 and in female 3.5-4.2; labium reaching posterior margin of mesosternum; medial part of right paramere slightly wider than basal part, shorter than basal and apical parts combined; its outer margin straight (fig. 11AD); apical part of left paramere not widened, ca. $3 \times$ as long as wide (fig. 11AE); vesica with seven spicules, including spicules A, B, E, and G (fig. 8I). 
Redescription: Male. Total length 3.5-3.8. COLORATION (fig. 5): Head: Yellow to pale brown, somewhat darker dorsally, sometimes with reddish tinge and reddish markings; longitudinal sulcus on dorsal surface yellow to pale brown; clypeus often darkened apically rarely with reddish longitudinal stripe. Eye brown to dark brown, often with reddish tinge. Labium: Yellow to pale brown, segment I and III sometimes somewhat darker than other segments, segment III sometimes with reddish tinge. Antenna: Segment I yellow to reddish or reddish brown, often paler at base and darkened apically; segment II yellow to pale brown with reddish tinge, often darker than segment I; segments III-IV brown to dark brown. Thorax: Pronotum yellow to pale brown, sometimes with reddish longitudinal stripe at sides; posterior part of pronotum yellow or pale brown, sometimes posterior margin brown laterally; mesoscutum yellow to pale brown; scutellum yellow to pale brown, often brown to dark apically, sometimes mostly pale brown, yellow to pale brown basally; thoracic pleura yellow to pale brown; scent gland evaporative area whitish yellow to yellow, often with yellow or red apex. Hemelytron: Mostly translucent and colorless; inner part of clavus whitish yellow to pale brown, sometimes red or brown apically, sometimes opaque; outer margin of clavus sometimes whitish yellow, sometimes with brown tinge or pale brown apically; marking along inner margin of corium yellow to brown; embolium sometimes with yellow tinge, rarely with reddish margins and yellow or red apically; cuneus yellow to reddish yellow, often with whitish yellow outer part, rarely cuneus with yellow tinge and yellow margins; membrane sometimes yellow or with grayish tinge, with yellow to pale brown membrane cell. Legs: Coxae whitish yellow to yellow; femora whitish yellow to yellow, darkened apically, sometimes reddish apically; tibiae yellow to pale brown, paler apically, sometimes with reddish tinge basally, rarely uniformly colored; tarsi yellow to brown, often with tarsal segment I whitish yellow to yellow. Abdomen: Ventral and lateral sides of pregenital segments often whitish yellow to yellow, sometimes lateral and ventral side red; dorsal surface of pregenital segments often red, sometimes yellow with red medial longitudinal stripe; genital capsule yellow to pale brown, sometimes with reddish tinge. SURFACE AND VESTITURE: Corium smooth, often with very shallow, scarce punctures. Body clothed with pale simple setae; dorsum and femora with setae subequal to or shorter than antennal segment II diameter; antennal segment I clothed with suberect setae mostly shorter than antennal segment II diameter; abdomen clothed with suberect setae, subequal to or shorter than width of antennal segment II. STRUCTURE AND MEASUREMENTS: Body ca. $4.2-4.4 \times$ as long as width of pronotum. Head: Depression delimiting occipital region present dorsally and laterally (as in Namyatova et al., 2016: fig. 4E); distance between depression and pronotum distinctly shorter than eye diameter; longitudinal sulcus on dorsal surface of head longer than eye diameter; distance between eye and pronotum slightly longer than eye diameter, not swollen laterally (as in Namyatova et al., 2016: fig. 4E); vertex ca. 1.6$2.0 \times$ as wide as eye, upraised (as in Namyatova et al., 2016: fig. 6D); buccula $0.15-0.2 \times$ as long as clypeus height. Labium: Reaching posterior margin of mesosternum or slightly surpassing it; segments I and II strongly reduced, combined shorter than half of segment III; segment I shorter than wide (as in Namyatova et al., 2016: figs. 6D, 9C); segment II slightly longer than wide, elongate dorsally; segment III slightly longer than ventral side of head length; labial segment IV ca. 1.5x as long as segment III. Antenna: Segment I cylindrical (as in Namyatova et al., 2016: fig. 8A), ca. $1.6-1.8 \times$ as long as head width, ca. $1.0-1.2 \times$ as long as pronotum width; segment II ca. $1.9-2.1 \times$ as long as width of head, ca. $1.3-1.4 \times$ as long as pronotum width; segment III slightly longer than segment II, segment IV ca. $0.3 \times$ as long as segment III. Thorax: Anterior part of pronotum slightly shorter than posterior part; collar delimited, posterior part slightly upraised; pronotum ca. $1.2-1.3 \times$ as wide as long and ca. 1.4-1.6x as wide as head with posterior margin concave; mesoscutum more or less exposed. Hemelytron: Area along inner mar- 
gin of corium almost flat; inner margin of corium convex (as in Namyatova et al., 2016: fig. 13E), outer margin of corium ca. 2.5-3× as long as base. Abdomen: Genital capsule rotated left at right angle relative to rest of abdomen. Genitalia: Genital capsule (fig. $14 \mathrm{~N}$ ) ca. $1.5 \times$ as long as wide; ventral wall ca. $1.5 \times$ as long as dorsal wall, with posterior margin of ventral wall semioval, smooth, not curved, without outgrowth(s), its apex placed medially; margins not modified; right paramere socket slightly acute and left paramere socket rounded; distance between paramere sockets ca. $0.7 \times$ as long as genital capsule broad at base. Right paramere (fig. 11AD) distinctly curved in apical half, apex straight; medial part only slightly wider than basal part, bearing setae, with outer margin straight and inner margin convex; outer angle distinct, not swollen; inner angle rounded, without setae; basal part of right paramere ca. $0.15-0.2 \times$ as long as rest of paramere. Left paramere (fig. 11AE) L-shaped; apical part not flattened, with toothlike outgrowth on posterior side medially (as in fig. $11 \mathrm{G}$ ) and without outgrowth on dorsal surface; middle part widened, without swelling or outgrowth; setae only on middle part near outer margin. Aedeagus (general view as in Namyatova et al., 2016: fig. 22I) vesica weakly sclerotized, secondary gonopore placed at base of vesica in repose; sclerotization of ductus seminis around secondary gonopore shorter than wide; vesica with seven spicules, including spicules $A, B$, and G (fig. 8I).

Female. Total length 3.5-4.2. COLORATION (fig. 5): Head: Similar to male, rarely head uniformly yellow with reddish tinge. Labium: Similar to male, segments I-II sometimes with reddish tinge. Antenna: As in male. Thorax, legs, and hemelytron: As in male. Abdomen: Ventral and lateral sides of pregenital segments and segment VIII often whitish yellow to yellow, sometimes pale brown, sometimes lateral sides partly reddish, rarely entire lateral and ventral surfaces red; ventral and lateral sides of segment IX yellow to reddish, sometimes pale brown, often darker than other segments; dorsal surface of abdomen red. SURFACE AND VESTITURE: As in male. STRUCTURE AND MEASUREMENTS: Structure as in male; body ca. $4.1-4.5 \times$ as long as pronotum width; vertex ca. $1.6-1.9 \times$ as wide as eye diameter; antennal segment I ca. $1.4-1.9 \times$ as long as head width, ca. $0.9-1.3 \times$ as long as pronotum width; segment II ca. $1.8-2.2 \times$ as long as head width, ca. $1.2-1.4 \times$ as long as pronotum width; pronotum ca. $1.2-1.3 \times$ as wide as long and ca. $1.4-1.7 \times$ as wide as head. Genitalia (as in Namyatova et al., 2016: fig. 23F, G): Dorsal labiate plate wider than distance between apodemes of second valvula; mostly smooth, without distinct striations, with semicircular sclerite and distinct sclerotized rings laterally; lateral oviducts placed almost medially, very close to each other, spermathecal gland placed between lateral oviducts; dorsal labiate plate with distinct tubercles, without membranous lobe medially.

Distribution: Fiji (Viti Levu Is., Ovalau Is., Kioa Is., Qamea Is., Laucala Is., Taveuni Is.), Western Samoa (Upolu Is.) and American Samoa (Tau Is.), Vanuatu (Efate Is.) (fig. 18).

Host PLANTs: Brackenlike ferns (Kirkaldy, 1908).

Discussion: Felisacus filicicola was described by Kirkaldy (1908) from Fiji without noting the type deposition. According to Kirkaldy, this species is similar to F. elegantulus, but its coloration is suffused with red. Kirkaldy's types are usually preserved in BPBM, BMNH, or CAS, but we did not find his filicicola material in the BPBM nor in the BMNH. In addition, the website of CAS (http://research.calacademy.org/ redirect?url = http://researcharchive.calacademy.org/research/entomology/typesDB/default. asp) does not refer to them.

We have examined numerous specimens from Fiji, Vanuatu, and Samoa that fit the description of F. filicicola of Kirkaldy (1908). Felisacus filicicola is variable externally and can be confused with a number of species, including $F$. albus, $F$. amboinae, $F$. dauloi, F. insularis, $F$. javanus, $F$. linae, F. ochraceus, and F. solomonicus (figs. 4-7). All of them differ from $F$. filicicola by the shape and number of vesical spicules (figs. 8A, B, G, L, M, P, 9F, L). Felisacus albus and F. insularis differ 
in the medial part of the right paramere twice as wide as its basal part (figs. 11A, 12C). Felisacus javanus and F. ochraceus differ in the medial part of the right paramere being distinctly concave (figs. 12G, 13C).

MATERIAL EXAMINED: AMERICAN SAMOA: Manu'a Islands: E of Tau Village, Tau, Manua, $14.22929^{\circ} \mathrm{S} 169.51111^{\circ} \mathrm{W}, 160 \mathrm{~m}, 18$ Feb 1965 , G.A. Samuelson, $10^{\star}$ (00042335) (BPBM). Tavalogi Ridge, Tau Is., $14.23185^{\circ} \mathrm{S} 169.46567^{\circ} \mathrm{W}$, 160 m, 16 Feb 1965-19 Feb 1965, G.A. Samuelson, 19 (00042336) (BPBM). FIJI: Central Division: Bilo $\mathrm{nr}$ Lami, Viti Levu Is., $18.11092^{\circ} \mathrm{S}$ $178.41011^{\circ} \mathrm{E}, 20 \mathrm{~m}, 27$ Sep 1979, M.K. Kamath, S.N. Lal, G.A. and S.L. Samuelson, 20 (00042231, 00042232) (BPBM). Colo-i-suva [Tholo-i-Suva], Viti Levu Is., $18.02336^{\circ} \mathrm{S} 178.42032^{\circ} \mathrm{E}$, Mar 1951, N.L.H. Krauss, $10^{\top}$ (00042346), 1 sex unkown (00042347) (BPBM). Lami, Viti Levu Is., $18.11092^{\circ} \mathrm{S} 178.41011^{\circ} \mathrm{E}$, Mar 1951, N.L.H. Krauss, 1 우 (00042270) (BPBM). Lami, Viti Levu Is., $18.11092^{\circ} \mathrm{S} 178.41011^{\circ} \mathrm{E}, 100 \mathrm{~m}$, Jan 1979, N.L.H. Krauss, $1+$ (00042269), $10^{\Uparrow}$ (00042230) (BPBM). Levuka, Ovalau Is., $17.68039^{\circ} \mathrm{S} 178.82994^{\circ} \mathrm{E}, 100$ m, Dec 1978, N.L.H. Krauss, 5 (0004235900042363), 2 đ (00042353, 00042354) (BPBM). Levuka, Ovalau Is., $17.68039^{\circ} \mathrm{S} 178.82994^{\circ} \mathrm{E}, 20$

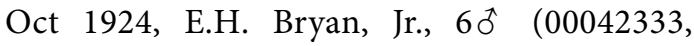
00042334, 00042348-00042351), 3 우 (0004235500042357) (BPBM). Northern Division: Dreketilailai, Vanua Levu Is., $16.56009^{\circ} \mathrm{S} 178.92191^{\circ} \mathrm{E}, 50$ m, 12 Oct 1979, S.N. Lal, G.A. and S.L. Samuelson, $2 \hat{o}$ (00042344, 00042343), 1 우 (00042332) (BPBM). Nadilo, Qamea Is., $16.79355^{\circ} \mathrm{S}$ $179.7641^{\circ}$ W, 25 m, 03 Oct 1979, M.K. Kamath, S.N. Lal, G.A. and S.L. Samuelson, 2 (00042275, 00042276), 3 đิ (00042237, 00042250, 00042342) (BPBM). Qilo Bay, Laucala Is., $16.75841^{\circ} \mathrm{S}$ $179.68381^{\circ} \mathrm{W}, 25$ m, 03 Oct 1979, M.K. Kamath, S.N. Lal, G.A. and S.L. Samuelson, 10 (00042236), 1 ㅇ (00042358) (BPBM). Savusavu, Vanua Levu Is., $16.77786^{\circ} \mathrm{S} 179.33976^{\circ} \mathrm{E}, 100 \mathrm{~m}$, Mar 1978 , N.L.H. Krauss, $2 q$ (00042272, 00042273) (BPBM). S coast to center, Kioa Is., $16.65143^{\circ} \mathrm{S}$ $179.91088^{\circ} \mathrm{E}, 30 \mathrm{~m}, 04$ Oct 1979, M.K. Kamath, S.N. Lal, G.A and S.L. Samuelson, 30 (00042233-
00042235), 19 (00042271) (BPBM). Waiyevo, Taveuni Is., $16.78411^{\circ} \mathrm{S} 179.98011^{\circ} \mathrm{W}, 50 \mathrm{~m}$, Jan 1972, N.L.H. Krauss, $10^{\star}$ (00042345) (BPBM). SAMOA: Upolu: Afiamalu, $13.91666^{\circ} \mathrm{S}$ $171.71666^{\circ} \mathrm{W}, 640 \mathrm{~m}, 06$ Jan 1956, T.E. Woodward, $10^{\star}$ (00037409) (QM). Malololelei, 13.9 ${ }^{\circ} \mathrm{S}$ $171.75^{\circ} \mathrm{W}, 610 \mathrm{~m}, 19$ Jan 1956, R.A. Cumber, $10^{\text {Tै }}$ (00037408), 2 9 00037406, 00037407) (QM). Mt. Vaea, $13.85^{\circ} \mathrm{S} 171.75^{\circ} \mathrm{W}, 427 \mathrm{~m}$, Sep 1969, N.L.H. Krauss, 19 00042312) (BPBM). VANUATU: Shefa: Efate Is.: Klem Butte, Efate Is., New Hebrides, $17.66666^{\circ} \mathrm{S} 168.26666^{\circ} \mathrm{E}, 175 \mathrm{~m}, 05 \mathrm{Dec} 1978$, N.L.H. Krauss, $10^{\star}$ (00042229) (BPBM). Vila, Efate Is., $17.41836^{\circ} \mathrm{S} 168.34517^{\circ} \mathrm{E}$, Aug 1950, N.L.H. Krauss, $10^{\pi}$ (00042242) (BPBM). Vila, Efate Is., $0-100 \mathrm{~m}, 17.74097^{\circ} \mathrm{S} 168.32099^{\circ} \mathrm{E}$, Mar 1978, N.L.H. Krauss, 13 đิ (00042238, 0004232000042328, 00042330, 00042249, 00042226), 6 우 (00042256-00042261) (BPBM); Nov 1978, N.L.H.

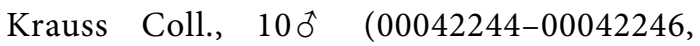
00042239, 00042240, 00042316, 00042318; 00042319, 00042331), 8 우 (00042220, 00042241, 00042251-00042255, 00042221), 3 juvenile (00042222, 00042225, 00042243) (BPBM); Dec 1978, N.L.H. Krauss, 2 ô (00042248, 00042227), 4 (00042262-00042265), 1 sex unknown (00042267) (BPBM); Feb 1981, N.L.H. Krauss, $3 q$ (00042223, 00042224, 00042266), 2 ऽ (00042228, 00042247) (BPBM), 3 ๙ (00018424, 00018425, 00018429), 3 우 (00018426-00018428) (MZH).

Felisacus glabratus (Motschulsky), status nov.

Figures 5, 8J, 11AF, AG, 14N, 18

Liocoris glabratus Motschulsky, 1863: 87 (original description).

Felisacus glabratus Distant, 1904: 439 (comb. nov.).

Hyaloscytus elegantulus var. javanus Reuter, 1908 (original description; synonymized by Poppius, 1914: 148); status nov.

Diagnosis: Recognized by the following combination of characters: mostly whitish yellow to yellow coloration of dorsum, cuneus colorless or with yellow tinge, translucent (fig. 4); antennal 
segment I cylindrical (as in Namyatova et al., 2016: fig. 8A); transverse depression delimiting occipital region on head extending laterally, vertex in male ca. $1.9 \times$ as long as eye diameter upraised (as in Namyatova et al., 2016: fig. 6D); antennal segment I ca. $1.3 \times$ as long as head width; cuneus ca. $3 \times$ as long as wide; labium reaching middle of mesosternum; ventral wall of genital capsule ca. $1.5 \times$ as long as dorsal wall (fig. $14 \mathrm{~N}$ ); medial part of right paramere twice as wide as basal part, and shorter than apical and basal parts combined; its outer margin concave and inner margin convex (fig. 11AF); vesica with five spicules, including spicules B and F (fig. 8J).

Redescription: Male. Total length 3.9. COLORATION (fig. 5): Head: Uniformly yellow. Eye pale brown. Labium: Yellow. Thorax: Pronotum, mesoscutum, scutellum and thoracic pleura yellow; scent gland evaporative area whitish yellow, brown apically. Hemelytron: Mostly translucent, colorless; inner margin of clavus whitish yellow, with pale brown margin; area along inner margin of corium mostly yellow, pale brown anteriorly; embolium and cuneus with yellow tinge and with pale brown margins; membrane cell yellow. Legs: Coxae, femora, and tibiae yellow. Abdomen: Uniformly yellow. SURFACE AND VESTITURE: Corium smooth, with scarce punctures. Dorsum with setae subequal to or slightly longer than antennal segment II diameter; setae on femora subequal to or shorter than antennal segment II diameter. STRUCTURE AND MEASUREMENTS: Body ca. 4.0× as long as pronotum width. Head: Depression delimiting occipital region present dorsally and laterally (as in Namyatova et al., 2016: fig. 4E), distance between depression and pronotum distinctly shorter than eye diameter; longitudinal sulcus on dorsal surface longer than eye diameter; distance from eye to pronotum slightly longer than eye diameter, not swollen laterally (as in Namyatova et al. 2016: fig. 4E); vertex ca. 1.9× as wide as eye; upraised (in Namyatova et al., 2016: fig. 6D ); buccula ca. $0.2-0.25 \times$ as long as clypeus. Labium: Surpassing middle of mesosternum but not reaching posterior part of metasternum; segments I and II strongly reduced, combined shorter than half of segment III; segment I shorter than wide (as in Namyatova et al., 2016: figs. 6D, 9C); segment II slightly longer than wide, elongate dorsally; segment III slightly longer than ventral side of head length; segment IV ca. $1.5 \times$ as long as segment III. Thorax: Anterior part of pronotum slightly shorter than posterior part; collar delimited; posterior part of pronotum slightly upraised; posterior margin of pronotum concave; pronotum ca. $1.3 \times$ as wide as long and ca. $1.6 \times$ as wide as head; mesoscutum exposed; outer margins of hemelytra only slightly convex medially. Hemelytron: Vein along behind clavus almost flat; inner margin of cuneus concave (as in Namyatova et al., 2016: fig. 13E), outer margin of cuneus ca. $3 \times$ as long as base. Abdomen: Genital capsule rotated left at small angle relative to rest of abdomen. Genital capsule (fig. $14 \mathrm{~N}$ ) ca. $1.5 \times$ as long as wide; ventral wall ca. $1.5 \times$ as long as dorsal wall, its posterior margin smooth, semioval, without outgrowth, not curved dorsally; its apex inclined rightward; sides of genital capsule not modified; right paramere socket slightly acute and left paramere rounded; distance between paramere sockets subequal to half of genital capsule width at base. Right paramere (fig. 11AF) distinctly curved apically; medial part twice as wide as basal part, bearing setae, with outer margin slightly concave; and inner margin convex; outer angle distinct, widened; inner angle rounded, without setae; basal part of right paramere ca. $0.15-0.2 \times$ as long as rest of paramere. Left paramere (fig. 11AG) L-shaped, apical part flattened, with toothlike outgrowth on posterior side medially (as in fig. 11G) and without outgrowth on dorsal surface; middle part widened, without swelling or outgrowth; setae present only on middle part near outer margin. Aedeagus conjunctiva weakly sclerotized; secondary gonopore placed at base of vesica in repose; sclerotization of ductus seminis around secondary gonopore shorter than wide; vesica with five spicules, including spicules $B$ and $\mathrm{F}$ (fig. 8J). 
Female. Total length 4.0. COLORATION (fig. 5): Head: Yellow with reddish longitudinal red stripe behind eye and red stripe above antennal fossae, tubercle around antennal fossa red laterally. Labium: As in male. Antenna: Segment I red with yellow base, segment II reddish brown, segment III brown. Eye brown. Thorax: Pronotum yellow with longitudinal red tripe laterally; thoracic pleura yellow; scent gland evaporative area whitish yellow basally and pale brown apically. Hemelytron: Similar to male, but inner part of clavus, embolium, and cuneus with red margins, cuneus with reddish tinge, membrane cell red. Legs: Yellow, femora apically and entire tibiae with red stripe, hind tarsus with yellow segment I, segments II-III pale brown. SURFACE AND VESTITURE: As in male; setae on antennal segment I shorter than antennal segment II diameter. STRUCTURE AND MEASUREMENTS: Structure as in male; body ca. $3.9 \times$ as long as pronotum width; vertex ca. $2.0 \times$ as wide as eye; antennal segment I cylindrical (as in Namyatova et al., 2016: fig. 8A), ca. $1.3 \times$ as long as head width, ca. $0.8 \times$ as long as pronotum width; segment II ca. $1.8 \times$ as long as head width, ca. $1.0 \times$ as long as pronotum width; pronotum ca. $1.3 \times$ as wide as long and ca. $1.7 \times$ as wide as head.

Distribution: Sri Lanka (fig. 18).

Host plants: Unknown.

Discussion: We examined the male lectotype and female paralectotype of F. glabratus. The specimens were damaged, and no information has been recorded for the antennae and tarsi of male I, the antennal segment IV in female, coloration of female abdomen, the apex of the right paramere (broken). In addition, the female genitalia were not dissected. See generic discussion for the explanation of the nomenclatural confusion in literature.

Felisacus glabratus is closely related to F. albus, $F$. indicus, and F. insularis. They share a similar structure of the right paramere, which is broad medially, twice as long as the basal part (figs. $11 \mathrm{~A}, \mathrm{AF}, 12 \mathrm{~A}, \mathrm{C})$. All of them also have similar vesical spicules, but differ in their shape and/or number (cf. fig. 8J with fig. 8A, $\mathrm{K}$ and L).
Material EXAMINed: Lectotype: SRI LANKA: Des Montagnes de Nuwara Eliya [Nura-Ellia] et Patannas., $6.9738^{\circ} \mathrm{N} 80.8265^{\circ} \mathrm{E}$, 1700, Motschulsky, 1 † (00017876) (NHRS). Paralectotype: SRI LANKA: Des Montagnes de Nuwara Eliya [Nura-Ellia] et Patannas., $6.9738^{\circ} \mathrm{N}$ $80.8265^{\circ} \mathrm{E}, 1700$, Motschulsky, paralectotype, 1 ㅇ (00017871) (NHRS).

\section{Felisacus gressitti Miyamoto}

Figures 5, 18

Felisacus gressitti Miyamoto, 1965: 162 (original description).

Diagnosis: Recognized by the following combination of characters: head and anterior part of pronotum mostly yellow, clypeus mostly dark brown; posterior part of pronotum dark brown with yellow stripe medially; antennal segment I yellow, reddish apically; marking along inner margin of corium brown, narrow, not extending toward $\mathrm{R}+\mathrm{M}$ anteriorly and posteriorly (fig. 5); antennal segment I slightly widened (as in Namyatova et al., 2016: fig. 6E); labium reaching abdominal segment II; antennal segment II ca. $1.6 \times$ as long as head width; right paramere sickle shaped (Miyamoto, 1965: figs. 35, 36; Lin, 2000: fig. 2B) and left paramere widened with outgrowth posteriorly (Lin, 2000: fig. 2B).

Redescription: Male. Not examined, see Miyamoto (1965) and Lin (2000). Female. Total length 3.2. COLORATION (fig. 5): Mostly yellow with reddish tinge posteriorly; tubercle around antennal fossa whitish yellow; clypeus dark brown, red basally. Eye dark brown, reddish laterally. Labium: Segments I-II whitish yellow, segments III-IV yellow. Antenna: Segment I yellow with reddish tinge; segment II reddish brown; segments III-IV dark brown. Thorax: Anterior part of pronotum yellow; posterior part of pronotum dark brown with yellow stripe medially; scutellum, mesoscutum, and thoracic pleura yellow; scent gland evaporative area yellow basally and red apically. Hemelytron: Mainly translucent and colorless; inner part of corium opaque, yellow, brown basally and along 
inner margin; area along inner margin of corium brown; embolium with yellow margins, brown apically; cuneus yellow; membrane with brown tinge; membrane cell brown. Legs: Coxae whitish yellow; femora with whitish yellow basal half and yellow apical half; tibiae yellow; tarsal segment I whitish yellow, segments II-III pale brown to brown. Abdomen: Yellow, segment IX reddish yellow with red lateral stripe. SURFACE AND VESTITURE: Corium with shallow punctures. Dorsum and femora with setae longer than antennal segment II diameter; segment II clothed with suberect setae mostly shorter than antennal segment II diameter; abdomen with setae of different length, mostly longer than antennal segment II diameter. STRUCTURE AND MEASUREMENTS: Body ca. $4.1 \times$ as long as pronotum width. Head: Depression delimiting occipital region very shallow, present only dorsally; distance between depression and pronotum distinctly shorter than eye diameter; longitudinal sulcus on dorsal surface of head slightly shorter than eye diameter; distance from eye to pronotum shorter than eye diameter, not swollen laterally; vertex ca. $1.7 \times$ as wide as eye; vertex upraised; buccula ca. $0.2-0.25 \times$ as long as clypeus. Labium: Reaching abdominal segment II; segments I and II reduced, combined longer than half of segment III; segment I shorter than wide; segment II longer than wide, its dorsal surface elongate posteriorly (as in Namyatova et al., 2016: fig. 6E); segment IV twice as long as segment III. Antenna: Segment I slightly widened medially, ca. $1.3 \times$ as long as head width, ca. $0.8 \times$ as long as pronotum width; segment II ca. $1.6 \times$ as long as head width, ca. $1.0 \times$ as long as pronotum width; segment III subequal to segment II. Thorax: Anterior part of pronotum subequal to half of posterior part; posterior part slightly upraised; posterior margin straight; pronotum ca. $1.3 \times$ as wide as long and ca. $1.6 \times$ as wide as head; mesoscutum exposed. Hemelytron: Area along inner margin of corium almost flat; inner margin of cuneus convex (as in Namyatova et al., 2016: fig. 13E), outer margin of cuneus ca.
$3 \times$ as long as base. Female genitalia were not investigated.

Distribution: South Japan (fig. 18).

Host plants: Collected from ferns (Miyamoto, 1965).

Discussion: Characters of the male as given in the diagnosis and discussion were adapted from Miyamoto (1965) and Lin (2000). Miyamoto (1965) described Felisacus gressitti from two males and two females. According to his description, the holotype and two paratypes are preserved in the Entomological Laboratory, Kyushu University, and a single paratype is preserved in BPBM. We did not locate the paratype in BPBM and we were unsuccessful in acquiring information from the Kyushu University on the types.

We examined a single female from the Tomohide Yasunaga collection and it fits the description of $F$. gressitti. We did not dissect its genitalia: Felisacus gressitti is similar to F. vitilevu externally (fig. 7) and they have a very similar paramere structure (cf. Miyamoto, 1965: figs. 34-38, Lin, 2000: fig. 2B; fig. 13V, W). However, F. vitilevu differs by the clypeus being mostly yellow to pale brown, but is also sometimes red, antennal segment II in males is ca. $1.9-2.1 \times$ long as wide, and in female, it is ca. $1.9-2.0 \times$ as long as wide. Although these two species are consistently different, differences are minor their status is still in question, as we only examined a single female of $F$. gressitti. Nonetheless, they are broadly disjunct (F. gressitti is known from Japan and Taiwan and F. vitilevu inhabits Fiji Islands), and pending further evidence, we treat them as distinct.

Felisacus gressitti is also similar to F. madagascariensis in structure and coloration (fig. 5 ), but the latter species differs by the pronotum being brown posteriorly, the marking along the inner margin of corium is yellow, and the labium reaches the posterior margin of the mesosternum.

MATERIAL EXAMINED: JAPAN: Okinawa: Ohshittai, Nago, $26.59336^{\circ} \mathrm{N} 127.97844^{\circ} \mathrm{E}, 02$ Dec 2001, T. Yasunaga, 1 우 (00201839) (TYCN). 
Felisacus indicus, sp. nov.

Figures 5, 8K, 12A, B, 14O, 18

Diagnosis: Recognized by the following set of characters: coloration of dorsum mostly whitish yellow, pronotum with brown humeral angles; cuneus opaque, whitish yellow with yellow apex and margins (fig. 5), cylindrical antennal segment I (as in Namyatova et al., 2016: fig. 8A), transverse depression on head delimiting occipital region extending laterally, vertex in males ca. $1.2 \times$ as wide as eye, upraised (as in Namyatova et al., 2016: fig. 6D); labium reaching middle of metasternum; cuneus ca. $2-2.5 \times$ as long as its width at base; genital capsule almost as long as wide (fig. 14O); medial part of right paramere twice as wide as basal part, and shorter than apical and basal parts combined; its outer margin straight and inner margin widened (fig. 12A); vesica with five spicules, including spicules $B$ and F, without serrate spicules (fig. 8K).

Description: Male. Total length 4.0. COLORATION (fig. 5): Head: Mostly whitish yellow with reddish markings. Eye whitish yellow. Labium: Segments I-III whitish yellow, segment IV yellow. Antenna: Segments I-II whitish yellow with reddish tinge, segments III-IV pale brown. Thorax: Pronotum whitish yellow with brown anterior margin and posterior angles; punctures between anterior and posterior parts pale brown; mesoscutum and scutellum whitish yellow with pale brown punctures between them; thoracic pleura whitish yellow; scent gland evaporative area whitish basally and pale brown apically. Hemelytron: Inner part of clavus opaque, whitish yellow, with brown margins; outer part of clavus whitish and translucent; corium translucent, area along inner margin of corium pale brown anteriorly and whitish yellow posteriorly; embolium opaque, whitish yellow, with apex and margins pale brown; cuneus opaque, whitish yellow, with yellow apex and margins; membrane translucent, colorless; membrane cell mostly whitish yellow, pale brown anteriorly. Legs: Coxae whitish; femora and tibiae mostly whitish yellow, hind femur red apically; hind tibia whitish with reddish tinge; tarsi whitish, pale brown dorsally. Abdomen: Uniformly whitish yellow. SURFACE AND VESTITURE: Corium smooth, often with scarce shallow punctures. Dorsum with suberect setae most often slightly longer than diameter of antennal segment II; antennal segment I and femora with suberect setae shorter than diameter of antennal segment II; abdomen clothed with suberect short simple setae. STRUCTURE AND MEASUREMENTS: Body ca. $4.3 \times$ as long as pronotum width. Head: Depression delimiting occipital region present dorsally and laterally (as in Namyatova et al., 2016: fig. 4E); distance between depression and pronotum distinctly shorter than eye diameter; longitudinal sulcus on dorsal surface longer than eye diameter; distance from eye to pronotum slightly longer than eye diameter, not swollen laterally (as in Namyatova et al., 2016: fig. 4E); vertex ca. $1.2 \times$ as wide as eye; vertex upraised; buccula ca. $0.2-0.25 \times$ as long as clypeus. Labium: Reaching middle of metasternum; segments I and II strongly reduced, combined length shorter than segment III; segment I slightly shorter than wide (as in Namyatova et al., 2016: figs. 6D, 9C), segment II slightly longer than wide, elongate dorsally, segment IV ca. $1.5 \times$ as long as segment III. Antenna: Segment I cylindrical (as in Namyatova et al., 2016: fig. $8 \mathrm{~A}$ ), ca. $1.3 \times$ as long as head width, ca. $0.9 \times$ as long as pronotum width; segment II ca. $1.7 \times$ as long as head width, ca. $1.1 \times$ as long as pronotum width. Thorax: Anterior part of pronotum only slightly shorter than posterior part; collar delimited; posterior part upraised; posterior margin concave; pronotum ca. $1.2 \times$ as wide as long and ca. $1.5 \times$ as wide as head; mesoscutum exposed. Hemelytron: Area along inner margin on corium almost flat; inner margin of cuneus convex, costal margin ca. $2-2.5 \times$ as long as base. Abdomen: Genital capsule weakly rotated to left-hand side. Genitalia: Genital capsule (fig. 14O) almost as long as wide; ventral wall twice as long as dorsal wall, its posterior margin smooth, semioval, without outgrowth, not curved; left side of genital cap- 
sule not widened; right paramere socket slightly acute and left paramere socket rounded; distance between paramere sockets subequal to half of genital capsule with at base. Right paramere (fig. 12A) distinctly curved in apical half; apex almost straight posteriorly; medial part twice as wide as basal part, bearing setae, with outer margin straight and inner margin convex; outer angle distinct; inner angle rounded, without setae; basal part of right paramere ca. $0.15-$ $0.2 \times$ as long as rest of paramere; apical part of right paramere lost. Left paramere (fig. 12B) L-shaped; apical part not flattened, with toothlike outgrowth on posterior side medially (as in fig. 11G) and without outgrowth on dorsal surface; middle part widened, without swelling or outgrowth; setae only on middle part near outer margin. Aedeagus conjunctiva weakly sclerotized; secondary gonopore placed at base of vesica in repose; sclerotization of ductus seminis around secondary gonopore of shorter than wide; vesica with five spicules including spicules $\mathrm{B}$ and $\mathrm{F}$ (fig. 8K).

Female. Unknown.

Distribution: India (fig. 18).

Host Plants: Unknown.

Discussion: Felisacus indicus is similar to $F$. albus in external morphology (figs. 4, 5), and the structure of the genital capsule (fig. 14A, O) and parameres (cf. fig. 11A, B with fig. 12A, B). Felisacus albus differs from $F$. indicus by the humeral angles of the pronotum whitish yellow, the cuneus is whitish yellow to yellow with a reddish tinge and the presence of seven vesical spicules (fig. 8A). Felisacus indicus is also similar to F. insularis in color patterning (fig. 5), the shape of the right paramere (cf. fig. 21A with 12C) and the presence of spicules B and F (cf. fig. $8 \mathrm{~K}$ with $8 \mathrm{~L}$ ). The latter species differs by the head and the humeral angles yellow, the ventral wall of the genital capsule ca. $1.7 \times$ as long as the dorsal wall (fig. 14P), and the vesica has a serrate spicule (fig. $8 \mathrm{~L}$ ).

Material Examined: Holotype: INDIA: Kerala: Kerala Prov, $10^{\circ} \mathrm{N} 76.5^{\circ} \mathrm{E}, 1991$, P.K. Sumodan, $1 \delta^{\star}$ (00017872) (NML).

\section{Felisacus insularis Miyamoto}

Figures 5, 8L, 12C, D, 14P, 18

Felisacus insularis Miyamoto, 1965: 159 (original description).

Diagnosis: Recognized by the following combination of characters: mostly yellow coloration of head and pronotum, head, collar, and inner part of clavus without brown markings; cuneus often at least partly yellow or red (fig. 5), cylindrical antennal segment I (as in Namyatova et al., 2016: fig. 8A), transverse depression delimiting occipital region on head extending laterally, vertex upraised (as in Namyatova et al., 2016: fig. 6D); body length in male 3.7-4.2 and in female 3.8-4.3; vertex in male ca. $1.5-1.9 \times$ as long as eye diameter; labium reaching middle of mesosternum; ventral wall of genital capsule ca. $1.7 \times$ as long as dorsal wall (fig. 14P); medial part of right paramere twice as wide as basal part, shorter than basal and apical parts combined, its outer margin straight (fig. 12C); vesica with five spicules, including spicules $\mathrm{B}$ and $\mathrm{F}$ and large serrate spicule (fig. 8K).

Redescription: Male. Total length 3.7-4.2. COLORATION (fig. 5): Head: Mostly whitish yellow to yellow; frons, mandibular plate and tubercle around antennal fossa often with reddish tinge or small markings. Eye dark brown, often reddish at margins. Labium: Yellow, segments I-II sometimes whitish yellow, segment II with pale brown or reddish stripe ventrally. Antenna: Segment I yellow to pale brown, whitish yellow basally, sometimes with reddish tinge; segment II reddish brown, darker than segment I, segment III-IV brown to dark brown, darker than segment II. Thorax: Pronotum whitish yellow to yellow, sometimes with reddish stripe laterally, anterior margin often pale brown, sometimes humeral angle pale brown; thoracic pleura whitish yellow to yellow, scent gland evaporative area whitish yellow often yellow apically, sometimes yellow with pale brown apex; mesoscutum and scutellum whitish yellow to yellow, punctures between them often pale 
brown. Hemelytron: Mostly translucent, colorless; inner part of clavus whitish yellow to yellow, with yellow or pale brown margins, sometimes opaque; corium with marking along inner margin yellow to pale brown, narrow and short; embolium sometimes yellow, with brown margins, often reddish or reddish brown apically; cuneus yellow to reddish yellow, sometimes only apex yellow or reddish or cuneus with yellow tinge only; membrane cell yellow. Legs: Coxae whitish yellow to yellow; femora whitish yellow basally and yellow apically, rarely mostly pale brown, often with reddish tinge apically; tibiae yellow to pale brown, often reddish basally, rarely mostly reddish; tarsi yellow to pale brown. Abdomen: Ventral and lateral sides yellow, segment IX pale brown, dorsal surface reddish, rarely abdomen uniformly yellow. SURFACE AND VESTITURE: Corium smooth, with shallow and scarce punctures. Dorsum with suberect setae slightly longer than antennal segment II diameter; antennal segment I and femora with suberect setae subequal to or shorter than antennal segment II diameter; abdomen clothed with suberect mostly short simple setae. STRUCTURE AND MEASUREMENTS: Body ca. $3.8-4.3 \times$ as long as pronotum width. Head: Depression delimiting occipital region present dorsally and laterally (as in Namyatova et al., 2016: fig. 4E); distance between depression and pronotum distinctly shorter than eye diameter; longitudinal sulcus on dorsal surface longer than eye diameter; distance from eye to pronotum slightly longer than eye diameter, not swollen at sides (Namyatova et al., 2016: fig. 4E); vertex ca. 1.5-1.9× as wide as eye, upraised (as in Namyatova et al., 2016: fig. 6D). Labium: Reaching middle of mesosternum; segments I and II strongly reduced, combined subequal to half of segment III; segment I slightly shorter than wide (as in Namyatova et al., 2016: figs. 6D, 9C); segment II slightly longer than wide, elongate dorsally; segment III as long as ventral side of head length; segment IV ca. 1.5x as long as segment III. Antenna: Segment I cylindrical (as in Namyatova et al., 2016: fig. 8A), ca. $1.2-1.8 \times$ as long as head width, ca. $0.8-1.1 \times$ as long as pronotum width; segment II ca. 1.5-2.2× as long as head width, ca. $0.9-1.4 \times$ as long as pronotum width; segments III slightly longer than segment II; segment IV ca. $0.3 \times$ as long as segment III. Thorax: Posterior part slightly upraised; collar delimited posterior margin slightly concave; pronotum ca. $1.2-1.4 \times$ as wide as long and ca. $1.5-1.7 \times$ as wide as head; mesoscutum exposed. Hemelytron: Area along inner margin of corium flat; inner margin of cuneus convex, outer margin of cuneus ca. $2.5-3 \times$ as long as base. Abdomen: Genital capsule rotated left at right angle relative to rest of abdomen. Genitalia: Genital capsule (fig. 14P) twice as long as wide, ventral wall ca. $1.5 \times$ as long as dorsal wall, its posterior margin smooth, semioval, without outgrowth(s), not curved; sides of genital capsule not modified; paramere socket more or less rounded; distance between paramere sockets ca. $0.7 \times$ as long as genital capsule width at base; right angle of left paramere socket not projecting. Right paramere (fig. 12C) distinctly curved in apical half; apex straight posteriorly; medial part almost twice as wide as basal part, bearing setae, with outer margin straight and inner margin widened; outer angle distinct, inner angle rounded, without setae; basal part of paramere ca. $0.15-0.2 \times$ as long as rest of paramere. Left paramere (fig. 12D) L-shaped; apical part not flattened, with toothlike outgrowth on posterior side medially (as in fig. $11 \mathrm{G}$ ) and without outgrowth on dorsal surface; middle part widened, without swelling or outgrowth; setae only on middle part near outer margin. Aedeagus conjunctiva weakly sclerotized; secondary gonopore placed at base of vesica in repose; sclerotization of ductus seminis around secondary gonopore shorter than wide; vesica with five spicules, including spicules $\mathrm{B}$ and $\mathrm{F}$ and large serrate spicule (fig. 8L).

Female. Total length 3.8-4.3. COLORATION (fig. 5): Similar to male, abdomen: uniformly yellow, sometimes with dorsal surface pale brown. SURFACE AND VESTITURE: As in male. STRUCTURE AND MEASUREMENTS: Structure as in male; body ca. $4.0-4.6 \times$ as long as pro- 
notum width; vertex ca. $1.5-1.9 \times$ as wide as eye; antennal segment I ca. 1.3-1.4× as long as head width, ca. $0.7-0.9 \times$ as long as pronotum width; segment II ca. $1.7-1.9 \times$ as long as head width, ca. $1.0-1.2 \times$ as long as pronotum width; pronotum ca. $1.1-1.5 \times$ as wide as long and ca. $1.5-1.8 \times$ as wide as head. Genitalia (as in Namyatova et al., 2016: fig. 23F, G): Dorsal labiate plate wider than distance between apodemes of second valvula; mostly smooth, without distinct striations or longitudinal membranous ridge, with semicircular sclerites and distinct sclerotized rings laterally; lateral oviducts placed almost medially, very close to each other, spermathecal gland placed between lateral oviducts; dorsal labiate plate with distinct tubercles, without membranous lobe medially.

Distribution: China, Japan, Thailand, Vietnam (fig. 18).

Host Plants: Sweeping from Pteridium sp. (Miyamoto, 1965).

Discussion: Miyamoto (1965) described F. insularis based on the basis of a male holotype and a number of male and female paratypes. According to information given in his description, the holotype and some paratypes are preserved in the Entomological Laboratory, Kyushu University, and two paratypes are preserved in the BPBM. We did not find the paratypes of $F$. insularis in BPBM, and we did not acquire information about the types of this species from Kyushu University.

We have examined a number of specimens from southeast Asia belonging to a single species and more or less fitting the description of Miyamoto, aside from minor variation in coloration. These specimens also have a similar right paramere, with a broad medial region, as depicted in Miyamoto (1965: fig. 30), and we consider them as conspecific to $F$. insularis.

Felisacus insularis is similar to F. albus and F. indicus (figs. 4,5 ) in external view and the medial part of the right paramere, which is twice as wide as the basal part (cf. fig. 12C with figs. 11A, 12A). Felisacus albus differs by the mostly whitish yellow head and collar, the genital capsule is almost as long as wide (fig. 14A), and the presence of seven vesical spicules (fig. 8A). Felisacus indicus can be separated by the vertex in males being ca. $1.2 \times$ as wide as the eye diameter, the genital capsule is almost as long as wide (fig. 14O), the humeral angles of the pronotum are brown, and the vesica is without serrate spicules (fig. 8L).

Material eXAmined: CHINA: Guangdong: Yao'anxiang, Lianzhou, Qingyuan, $25.01826^{\circ} \mathrm{N}$ $112.40858^{\circ} \mathrm{E}, 20$ Oct 1962 , Hanhua Cheng and Leyi Zheng, $10^{\top}$ (00018484) (NKMU). Hainan Prov.: Jianfeng $\mathrm{Mt}, 18.72^{\circ} \mathrm{N} 108.88^{\circ} \mathrm{E}, 08$ May 1964, Unknown, $10^{\star}$ (00018482) (NKMU); Apr 1980, Unknown, 1 đo (00017887), 2 우 (00018480, 00018481) (NKMU). Yunnan: [Man Xue], 06 Jun 1958, Unknown, $1+$ (00018483) (IOZ). JAPAN: Kyushu (Island): Okinawa Pref.: Ishigaki I., Kara-yama, 14 Mar 1964, C.M. Yoshimoto and J. Harrell, $2 q$ (00018486, 00018479) (BPBM). Okinawa: Ishigaki Is., Ryukyu Islands, $24.4^{\circ} \mathrm{N} 124.2^{\circ} \mathrm{E}$, Oct 1951 , R.M. Bohart, $10^{\star}$ (00018477) (AM); 13 Oct 1999, Belokobylskij, 3 ㅇ (00271508, 00271507), 2 ㅎ (00271509, 00271508) (ZISP). THAILAND: Chiang Mai Province: Doi Suthep, $18.81277^{\circ} \mathrm{N} 98.89361^{\circ} \mathrm{E}$, 900 m, 14 Nov 1957, J.L. Gressitt, 10 (00017875) (AM). VIETNAM: Gia Lai: $20 \mathrm{~km}$ N of Pleiku, $14.15162^{\circ} \mathrm{N} 107.94731^{\circ} \mathrm{E}, 650 \mathrm{~m}, 09$ May 1960 , L.W. Quate, 1 sex unknown (00017866), 10 (00017874) (AM). Ha Noi: 70 km NWW Ha Noi $\mathrm{BaVi}, 21.087^{\circ} \mathrm{N} 105.302^{\circ} \mathrm{E}, 22$ Nov 1990, Belokobylskij, 1 đิ (00018478) (AM).

\section{Felisacus jacobsoni Poppius}

Figures 5, 8M, 12E, F, 18

Felisacus jacobsoni Poppius, 1914: 149 (original description).

Diagnosis: Recognized by the following combination of characters: dorsal surface of head brown anteriorly; pronotum brown along posterior margin; inner part of clavus opaque, brown; scent gland evaporative area brown; cuneus red with outer margin brown; marking along inner margin of corium brown, not reaching $\mathrm{R}+\mathrm{M}$ anteriorly and posteriorly (fig. 5), cylindrical antennal segment I (as in Namyatova et al., 2016: 
fig. 8A), transverse depression on head extending laterally, vertex upraised (as in Namyatova et al., 2016: fig. 6D); labium reaching posterior margin of metasternum; vesica with five spicules, including spicules $A$ and $B$, spicule A elongate and widened, spicule B small and not swollen (fig. 8M).

Redescription: Male. Total length 4.4-4.7. COLORATION (fig. 5): Head: Mostly yellow, brown dorsally, labrum brown. Eye dark brown. Labium: Uniformly yellow. Antenna: Segment I brown with yellow base, segments II-IV dark brown. Thorax: Pronotum yellow with brown collar and markings on anterior part of pronotum laterally, posterior part of pronotum with paired brown markings near margin; scutellum yellow; pleura yellow, scent gland evaporative area brown, with whitish yellow apex and base. Hemelytron: Mostly translucent and colorless; inner part of clavus opaque, brown; marking along inner margin of corium brown, cuneus mostly red with outer margin translucent with yellow tinge and margins pale brown; membrane with grayish tinge and pale brown veins. Legs: Coxae whitish yellow; femora whitish yellow basally and yellow apically; tibiae yellow to pale brown, brown basally; tarsi brown. SURFACE AND VESTITURE: Corium smooth with shallow and scarce punctures. Dorsum and femora with suberect setae mostly subequal to antennal segment II diameter; antennal segment I with scarce suberect setae mostly shorter than antennal segment II diameter. STRUCTURE AND MEASUREMENTS: Body ca. $4.4-4.6 \times$ as long as pronotum width. Head: Depression, delimiting occipital region, present dorsally and laterally (as in Namyatova et al., 2016: fig. 4E); distance between depression and pronotum distinctly shorter than eye diameter; longitudinal sulcus on dorsal surface longer than eye diameter; distance from eye to pronotum slightly longer than eye diameter, not swollen laterally (as in Namyatova et al., 2016: fig. 4E); vertex ca. $1.4-1.7 \times$ as wide as eye upraised. Labium (as in Namyatova et al., 2016: figs. 6D, 9C): Almost reaching posterior margin of metasternum; segments I and II strongly shortened, combined length subequal to half of segment III; segment I shorter than wide; segment II slightly longer than wide, its dorsal surface elongate posteriorly; segment III slightly shorter than ventral side of head; segment IV twice as long as segment III. Antenna: Segment I cylindrical (as in Namyatova et al., 2016: fig. 8A), ca. $1.6 \times$ as long as head width, ca. $1.0-1.1 \times$ as long as pronotum width; segment II ca. $2.1-2.3 \times$ as long as head width, ca. $1.4 \times$ as long as pronotum width; segments III slightly longer than segment II; segment IV ca. $0.3 \times$ as long as segment IV. Thorax: Anterior part of pronotum slightly shorter than posterior part; posterior part of pronotum slightly upraised; posterior margin of pronotum concave, pronotum ca. $1.2-1.3 \times$ as wide as long and ca. $1.6 \times$ as wide as head; mesoscutum exposed. Hemelytron: Area behind clavus almost flat; inner margin of cuneus convex (as in Namyatova et al., 2016: fig. 13E), outer margin of cuneus almost ca. $3 \times$ as long as base. Genitalia: Right paramere (fig. 12E) apical part distinct; apex slightly concave; medial part less than twice as wide as basal part, bearing setae, with outer margin straight and inner margin convex; outer angle distinct, not widened; inner angle rounded, without setae; basal part ca. $0.2-$ $0.25 \times$ as long as rest of paramere. Left paramere (fig. 12F) L-shaped; apical part not flattened, with toothlike outgrowth on posterior side medially (as in fig. 11G) and without outgrowth on dorsal surface; middle part widened, without swelling or outgrowth(s); setae only on middle part near outer margin. Aedeagus conjunctiva weakly sclerotized; secondary gonopore placed at base of vesica in repose; sclerotization of ductus seminis around secondary gonopore shorter than wide; vesica with five spicules: spicule $A$ is long and wide, spicule B short; three additional spicules present on left-hand side, all narrow and acute (fig. 8M).

Female. Total length 4.6-4.8. COLORATION (fig. 5): Similar to male, head often dark brown dorsally, sometimes with reddish-brown marking between eyes; pronotum yellow sometimes with brown stripe along posterior margin; tho- 
racic pleura sometimes with brown markings or mostly pale brown; tibiae sometimes uniformly yellow to pale brown; tarsal segments I-II sometimes whitish yellow. SURFACE AND VESTITURE: As in male. STRUCTURE AND MEASUREMENTS: Similar to male. body ca. 4.3-5.1 $\times$ as long as pronotum width; vertex ca. $1.7-1.8 \times$ as wide as eye; antennal segment I ca. $1.5-1.7 \times$ as long as head width, ca. $0.9-1.1 \times$ as long as pronotum width; segment II ca. $2.1-2.2 \times$ as long as head width, ca. $1.3-1.4 \times$ as long as pronotum width; pronotum ca. $1.1-1.2 \times$ as wide as long and ca. $1.4-1.6 \times$ as wide as head. Genitalia (as in fig. 23F, G): Dorsal labiate plate wider than distance between apodemes of second valvula; mostly smooth, without distinct striations, with semicircular sclerite and distinct sclerotized rings laterally; lateral oviducts placed almost medially, very close to each other, spermathecal gland placed between lateral oviducts; dorsal labiate plate with distinct tubercles, without membranous lobe medially.

Distribution: Java and Lombok Is. (Indonesia) (fig. 18).

Host Plants: Pteris sp.

Discussion: Poppius (1914) described Felisacus jacobsoni from a single female, collected in Java and preserved in the FMNH. Some specimens in the collection of ZISP are from Lombok are very similar to the type specimen, and we assigned them to this species.

Felisacus jacobsoni is most similar to F. bellus, F. bau, and F. signis in coloration (fig. 4): Felisacus bau and $F$. signis differ in body size, which is less than $4 \mathrm{~mm}$ in both sexes. All these species differ in the shape of the vesical spicules (cf. fig. $8 \mathrm{M}$ with figs. $8 \mathrm{D}, \mathrm{E}, 9 \mathrm{~K})$.

Felisacus jacobsoni can be confused with $F$. javanus (fig. 5), which is widely distributed in Indonesia, as the latter also has a bright red cuneus and brown markings. However, F. javanus is paler and its head and pronotum have brown markings, it is smaller, body length, which is $3.0-3.7 \mathrm{~mm}$ in males and $3.5-4.1 \mathrm{~mm}$ in females, and has distinct vesical spicules with spicule B elongate and broad (fig. $8 \mathrm{~N}$ ).
Material eXAmined: Lectotype: INDONESIA: East Java: Nongkojajar [Nongkodjadjar], $7.8965^{\circ} \mathrm{S} 112.8213^{\circ} \mathrm{E}, 1095 \mathrm{~m}$, Jan 1911, E. Jacobson, 1 ㅇ (00017877) (MZH). Additional material: West Nusa Tenggara: Lombok Island, nr Senaru, $8.31956^{\circ} \mathrm{S} 116.405^{\circ} \mathrm{E}, 01 \mathrm{Sep} 2012$, F. Konstantinov, Pteris sp. (Pteridaceae), det. Michael Lovave (LAE herbarium, PNG), $2 \widehat{0}$ (00386513, 00386514), 4 우 (00386515-00386518) (ZISP).

\section{Felisacus javanus (Reuter)}

Figures 5, 8N, 12G, H, 14Q, 19

Hyaloscytus elegantulus var. javanus Reuter, 1908: 187 (original description), stat. nov. Felisacus carpenterae Hsiao, 1944: 385, new synonymy.

Diagnosis: Recognized by the following combination of characters: main coloration of head and pronotum yellow to pale brown, without brown markings, cuneus with inner part red and outer part whitish yellow, margins red (fig. 5), cylindrical antennal segment I (as in Namyatova et al., 2016: fig. 8A), transverse depression on head delimiting occipital region extending laterally, vertex upraised (as in Namyatova et al., 2016: fig. 6D) body length in male 3-3.7, in female 3.5-4.1; labium reaching posterior margin of mesosternum or slightly surpassing it; cuneus ca. $2.5 \times$ as long as base; ventral wall of genital capsule ca. $1.5 \times$ as long as dorsal wall (fig. 14Q); medial part of right paramere slightly wider than basal part, shorter than basal and apical parts combined, its outer margin concave (fig. 12G); vesica with five spicules, including spicules $A, B$, and $C$; spicule A longer than spicule $\mathrm{B}$, spicule $\mathrm{B}$ long and swollen, spicule $\mathrm{C}$ long and distinctly convolute (fig. $8 \mathrm{~N}$ ).

Redescription: Male. Total length 3.0-3.7. COLORATION (fig. 5): Head: Yellow to pale brown, dorsal surface and clypeus sometimes with reddish tinge. Eye dark brown to black, sometimes with pale brown spots or reddish tinge. Labium: Whitish yellow to pale brown, segment III sometimes with reddish tinge ventrally. Antenna: Segment I pale brown, some- 
times with reddish tinge, segment II reddish brown, segments III dark brown. Thorax: Pronotum yellow with anterior margin brown, sometimes whitish yellow posteriorly, sometimes with reddish tinge laterally; humeral angle or marking nearby often yellow to pale brown; mesoscutum and scutellum whitish yellow to pale brown, punctures between them pale brown, scutellum with longitudinal brownish stripe; thoracic pleura yellow to pale brown, sometimes with reddish tinge; scent gland evaporative area yellow, sometimes red apically. Hemelytron: Mostly translucent; clavus sometimes opaque, inner part of clavus whitish yellow to yellow, sometimes brown apically, with yellow, reddish or pale brown margins; outer part of clavus colorless or whitish yellow, with apex yellow to brown; corium whitish yellow to yellow, area along inner margin of corium yellow to pale brown at middle part and reddish posteriorly; embolium yellow with pale brown margins and often with reddish margin; cuneus with inner part red and outer part whitish yellow, margins and often its inner part red; membrane with yellow or grayish tinge, cell red. Legs: Coxa whitish yellow to yellow; femora whitish yellow to yellow basally and yellow to pale brown apically, sometimes with reddish tinge; tibia yellow to pale brown, sometimes somewhat paler basally, sometimes with reddish tinge basally; tarsi pale brown, segment I often whitish yellow to yellow. SURFACE AND VESTITURE: Corium smooth, with shallow and scarce punctures. Dorsum with setae shorter or subequal to antennal segment II diameter; antennal segment I and femora clothed with suberect setae mostly shorter than width of antennal segment II diameter. STRUCTURE AND MEASUREMENTS: Body ca. $4.0-4.4 \times$ as long as pronotum width. Head: Depression delimiting occipital region present dorsally and laterally (as in Namyatova et al., 2016: fig. 4E); distance between depression and pronotum distinctly shorter than eye diameter; longitudinal sulcus on dorsal surface of head longer than eye diameter; distance from eye to pronotum longer than eye diameter, not swollen laterally (as in Namyatova et al., 2016: fig. 4E); vertex ca. 1.3-1.9× as wide as eye, upraised (as in Namyatova et al., 2016: fig. 6D). Labium (as in Namyatova et al., 2016: figs. $6 \mathrm{D}, 9 \mathrm{C}$ ): Reaching posterior margin of mesosternum or slightly surpassing it; segments I and II strongly reduced, combined subequal to half of segment III; segment I shorter than wide; segment II slightly longer than wide, its dorsal surface elongate posteriorly; segment III as long as ventral side of head; segment IV ca. $1.5 \times$ as long as segment III. Antenna: Segment I cylindrical (as in Namyatova et al., 2016: fig. 8A), ca. 1.4$1.6 \times$ as long as head width, ca. $1.0-1.2 \times$ as long as pronotum width; segment III slightly longer than segment II. Thorax: Anterior part of pronotum only slightly shorter than posterior part; collar delimited; posterior part slightly upraised; posterior margin concave, pronotum ca. 1.1$1.2 \times$ as wide as long and ca. $1.4-1.5 \times$ as wide as head; mesoscutum exposed. Hemelytron: Vein along behind clavus almost flat; inner margin of cuneus convex (as in Namyatova et al., 2016: fig. $13 \mathrm{E}$ ), outer margin of cuneus ca. $2.5 \times$ as long as base. Genitalia: Genital capsule (fig. 14Q) ventral wall ca. $1.5 \times$ as long as dorsal wall, with posterior margin of ventral wall semioval, smooth, without outgrowth(s), its apex inclined leftward, not curved; sides of genital capsule not modified; right paramere socket slightly acute, left paramere socket rounded; distance between paramere sockets subequal to half of genital capsule width at base. Right paramere (fig. 12G) distinctly curved in apical half; apex almost straight; medial part only slighter wider than basal part, with row of setae, with outer margin slightly concave and inner margin widened; outer angle distinct, slightly swollen; inner angle rounded, not bearing setae; basal part of paramere ca. 0.15$0.2 \times$ as long as rest of paramere. Left paramere (fig. 12H) L-shaped; apical part flattened, with tooth on posterior side medially (as in fig. 11G) and without outgrowth on dorsal surface; middle part widened, without swelling or outgrowth; setae only on middle part near outer margin. Aedeagus (general view as in Namyatova et al., 2016: fig. 22I) conjunctiva weakly sclerotized, 

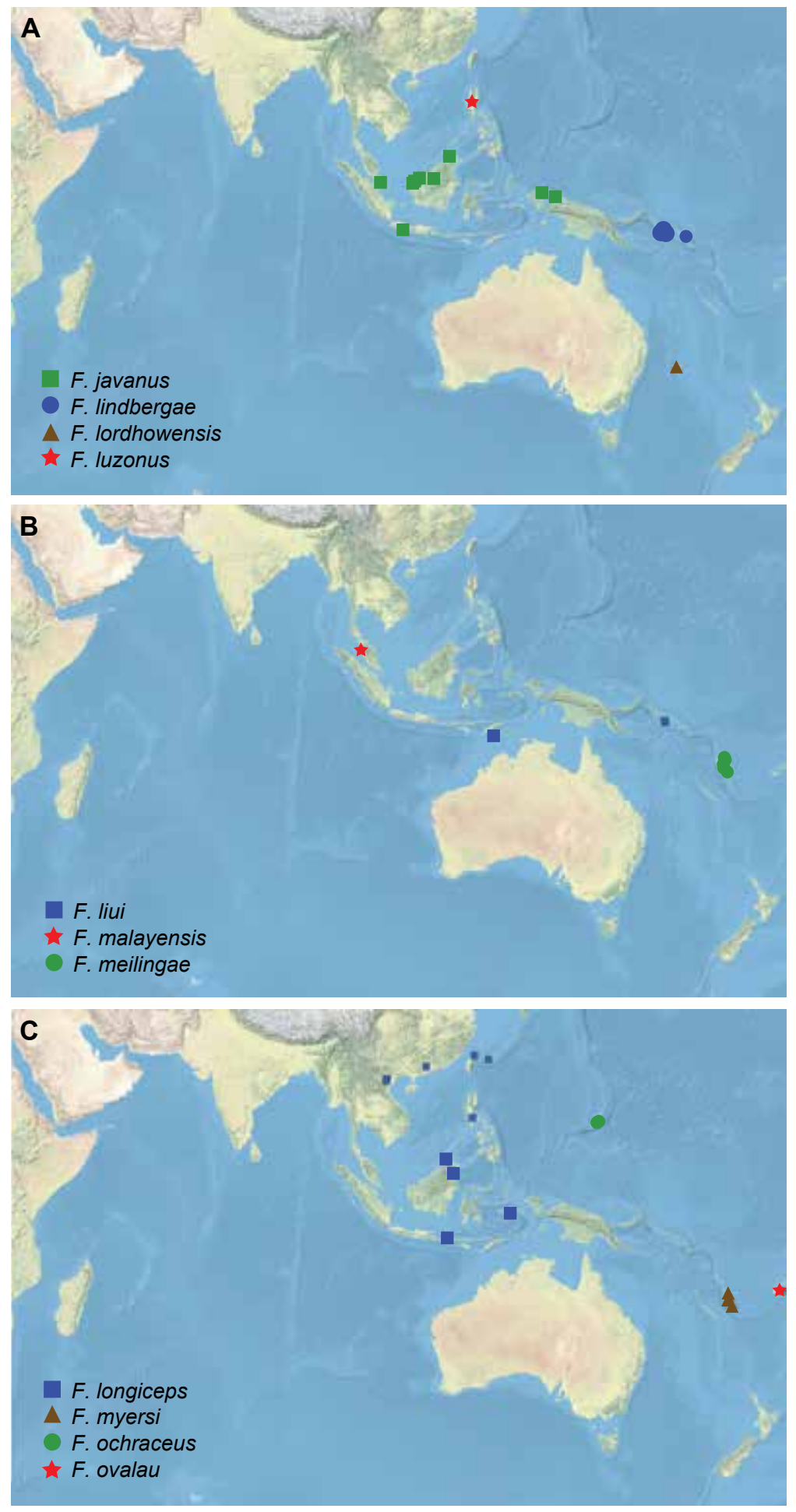

FIGURE 19. Distribution of Felisacus species. 
secondary gonopore placed at base of vesica in repose; sclerotization of ductus seminis around secondary gonopore shorter than wide; vesica with five long spicules, vesica with five spicules, including spicules $\mathrm{A}, \mathrm{B}$, and $\mathrm{C}$; spicule $\mathrm{A}$ long and wide, spicule $B$ long and swollen, spicule $C$ long and distinctly convolute (fig. $8 \mathrm{~N}$ ).

Female. Total length 3.5-4.1. COLORATION (fig. 5): Head: Similar to male, but sometimes with stripe above antennal fossae, markings between antennal fossae and stripe or marking behind eye red. Labium and antenna: As in male. Thorax: Similar to male, sometimes pale brown with brown anterior margin, scent gland evaporative area sometimes yellow with pale brown margin. Hemelytron: Similar to male, embolium rarely pale brown. Legs: Similar to male, rarely uniformly pale brown. Abdomen: Whitish yellow with reddish dorsum. SURFACE AND VESTITURE: As in male. STRUCTURE AND MEASUREMENTS: Structure as in male; body ca. $4.0-4.4 \times$ as long as width of pronotum; vertex ca. $1.3-2.0 \times$ as wide as eye; antennal segment I ca. 1.3-1.5x as long as head width, ca. $0.9-1.0 \times$ as long as pronotum width; antennal segment II ca. $1.7-1.9 \times$ as long as head width, ca. $1.1-1.3 \times$ as long as pronotum width; pronotum ca. $1.2-1.4 \times$ as wide as long and ca. 1.5-1.6× as wide as head. Genitalia (as in Namyatova et al., 2016: fig. 23F, G): Dorsal labiate plate wider than distance between apodemes of second valvula; mostly smooth, without distinct striations, with semicircular sclerite and distinct sclerotized rings laterally; lateral oviducts placed almost medially, very close to each other, spermathecal gland placed between lateral oviducts; dorsal labiate plate with distinct tubercles, without membranous lobe medially.

Distribution: Indonesia (Java, West Papua), Malaysian Borneo (Sabah, Sarawak), Singapore (fig. 19).

Host PLANTs: Nephrolepis biserrata (Davalliaceae).

Discussion: Felisacus javanus was described from a series of specimens from Java (Reuter, 1908), and are preserved in the MZH. We examined the male and female of the type series. Feli- sacus carpenterae was described from Singapore (Hsiao, 1944) and its type specimens are preserved in the USNM, and we examined male and female paratypes. On the basis of very similar external morphology and identical male genitalia, we synonymize $F$. carpenterae with $F$. javanus. In contrast, F. carpenterae signis Hsiao, 1944, differs from the nominotypical subspecies and represents a separate species (see the discussion of F. signis). See generic discussion for the explanation of the nomenclatural confusion concerning F. javanus in literature.

Felisacus javanus is most similar to F. amboinae, F. filicicola, F. ochraceus, and F. solomonicus in coloration and structure. Felisacus amboinae, F. filicicola, and F. solomonicus can be separated by the right paramere with the outer margin straight (cf. fig. $12 \mathrm{G}$ with figs. $11 \mathrm{C}, \mathrm{AD}, 13 \mathrm{R}$ ) and the shape of the vesical spicules (cf. fig. $8 \mathrm{~N}$ with figs. 8B, I, 9L). Felisacus ochraceus is similar to $F$. javanus in the shape of the right paramere and the configuration of the spicules (figs. 9F, 13C). In contrast, $F$. ochraceus has spicule B longer than spicule A.

Felisacus javanus and F. lambkinae are near identical in the shape and configuration of the vesical spicules (cf. fig. $8 \mathrm{~N}$ with $8 \mathrm{O}$ ), body size and structure of the right paramere, with both having the medial region elongate, and the outer margin is concave (cf. fig. 12G with 12I). Felisacus lambkinae differs from $F$. javanus by the anterior part of the pronotum being brown, the inner part of the clavus is pale brown to brown (fig. 5), and the labium reaches or slightly surpasses the posterior margin of the metasternum.

Felisacus javanus can be confused with $F$. jacobsoni as the two species can be collected together and are similar to each other in coloration, including the pale brown ground color, presence of brown markings, with the cuneus at least partly red. However, in contrast to F. java$n u s$, specimens of $F$. jacobsoni have a longer body, with males $4.4-4.7 \mathrm{~mm}$ and females $4.6-$ $4.8 \mathrm{~mm}$ in length and, the labium reaches the posterior margin of the mesosternum. Felisacus jacobsoni differs slightly in coloration, having the 
inner part of the clavus, scent gland evaporative area, and anterior part of the head brown and in vesical spicules (fig. 8M).

MATERIAL EXAMINED: Lectotype (F. javanus): INDONESIA: Java: collector unknown, 1902, O.M. Schmiedeknecht, Lectotype, 10 (00018430) (MZH). Paralectotypes (F. javanus). INDONESIA: Java: collector unknown, 1902, O.M. Schmiedeknecht, paralectotype, 10 (00018435), 4 잉 (00018431-00018434) (MZH). Paratypes ( $F$. carpenterae). SINGAPORE: Singapore: Singapore, $1.291^{\circ} \mathrm{N} 103.848^{\circ} \mathrm{E}$, no date provided, C.F. Baker, 1 ㅎ (00338826), 1 (00338825) (USNM). Additional material: INDONESIA: West Papua: Biak Island, $\mathrm{W}$ of Airport, $1.3425^{\circ} \mathrm{S} 136.1875^{\circ} \mathrm{E}$, 12 Aug 2012, F. Konstantinov, 2 ㅇ (00271384, 00271385) (ZISP). Biak Island nr Taman Burung, $1.17603^{\circ} \mathrm{S} 136.18756^{\circ} \mathrm{E}, 10$ Aug 2012, F. Konstantinov, Nephrolepis biserrata (Sw.) Schott (Davalliaceae), det. Michael Lovave (LAE herbarium, PNG), 11 के (00271364-00271374), 3 juvenile (00271375-00271377), $69 \quad$ (0027137800271383) (ZISP). Manokwari, nr Taman Gunung, Meja, $0.84497^{\circ} \mathrm{S} 134.07342^{\circ} \mathrm{E}, 21 \mathrm{Aug}$ 2012, F. Konstantinov, 5 후 (00271389-00271393), 3 ㅇ (00271395-00271397), 1 sex unknown (00271394) (ZISP). Owi Island nr Biak Island, $1.23817^{\circ} \mathrm{S} 136.20294^{\circ} \mathrm{E}, 12$ Aug 2012, F. Konstantinov, Nephrolepis biserrata (Sw.) Schott (Davalliaceae), det. Michael Lovave (LAE herbarium, PNG), 3 으 (00271386-00271388), 1 우 (00271432) (ZISP). MALAYSIA: Sabah: West Coast Residency, Ranau, $8 \mathrm{mi} \mathrm{N}$ Poring Hot Springs, $6.11407^{\circ} \mathrm{N} 116.72104^{\circ} \mathrm{E}, 500 \mathrm{~m}, 08$ Oct $1958-11$ Oct 1958, T.C. Maa, 19 (00042310) (BPBM). Sarawak: Bau, $1.4167^{\circ} \mathrm{N} 110.15^{\circ} \mathrm{E}, 29$ Aug $1958-$ 30 Aug 1958, T.C. Maa, 10 (00042341), 1 ㅇ (00042311) (BPBM). Merirai Valley nr. Kapit, $1.91009^{\circ} \mathrm{N} 113.63583^{\circ} \mathrm{E}, 01$ Jul 1958-06 Jul 1958, T.C. Maa, $10^{\widehat{0}}$ (00021523) (BPBM). Rajang (Rejang) Delta, Sarikei Dist., $2.42873^{\circ} \mathrm{N}$ $111.44251^{\circ} \mathrm{E}, 15 \mathrm{Jul} 1958-26$ Jul 1958, T.C. Maa, 1 주 (00021526), 1 ㅇ (00021526) (BPBM); $15 \mathrm{Jul}$ 1958-25 Jul 1958, T.C. Maa, 4 đิ (00042337, 00021519-00021521), 2 ㅇ (00021524, 00021525) (BPBM). Sadong, Kampong Tapuh, $1.50361^{\circ} \mathrm{N}$ $110.74222^{\circ} \mathrm{E}, 04$ Jul 1958-09 Jul 1958, T.C. Maa, 1 우 (00021535) (ANIC), $30^{\widehat{0}}$ (00021522, 00021533, 00021534) (BPBM).

\section{Felisacus lambkinae, sp. nov.}

Figures 5, 8O, 12I, J, 14R, 18

Diagnosis: Recognized by anterior part of pronotum brown; inner part of clavus brown to pale brown; marking along inner margin of corium brown, not reaching $\mathrm{R}+\mathrm{M}$; cuneus reddish with colorless and translucent outer part and brown outer margin; cylindrical antennal segment I (as in Namyatova et al., 2016: fig. 8A), transverse depression on head extending laterally, vertex upraised; small size, body length in male 3.1-3.2 and in female 3.2-3.5; labium reaching posterior margin of metasternum or slightly surpassing it; vertex in male ca. 1.2-1.3x as long as eye diameter; cuneus ca. $2.5 \times$ as long wide; medial part of right paramere almost as wide as basal part, its length subequal to basal and apical parts combined; its outer margin concave and inner margin convex (fig. 12I); vesica with five spicules, including spicules $\mathrm{A}, \mathrm{B}$, and $\mathrm{C}$ (fig. 8O).

Description: Male. Total length 3.1-3.2. COLORATION (fig. 5): Head: Dorsal surface brown medially, yellow to pale brown laterally, sometimes with reddish tinge, longitudinal stripe dark brown; anterior side yellow to brown; frons brown, areas below antennal fossae whitish yellow, clypeus yellow to pale brown, brown basally, sometimes with reddish tinge; tubercle around antennal fossa whitish yellow with pale brown markings; lateral side whitish yellow to pale brown, buccula, mandibular and maxillary plates whitish yellow; ventral side whitish yellow to pale brown, sometimes brown anteriorly. Eye pale brown. Labium: Segments I-II whitish yellow, segment III whitish yellow, yellow ventrally, segment IV yellow. Antenna: Segment I yellow to pale brown; segment II pale brown to brown, sometimes with reddish tinge, segments III-IV brown to dark brown. Thorax: Anterior part of pronotum and punctures between anterior and 
posterior parts brown, anterior margin dark brown, posterior part of pronotum whitish yellow with brown marking near posterior angle; scutellum and mesoscutum whitish yellow to pale brown; mesoscutum sometimes somewhat darker than scutellum; punctures between scutellum and mesoscutum pale brown; thoracic pleura brown to dark brown; scent gland evaporative area uniformly whitish yellow. Hemelytron: Clavus translucent, its inner part pale brown to brown with margins brown, sometimes with reddish tinge, outer part of clavus colorless, pale brown to brown apically; corium translucent with marking along inner margin of corium brown, narrow, not reaching $\mathrm{R}+\mathrm{M}$; embolium opaque, whitish yellow, pale brown or reddish apically, with brown margins, opaque; cuneus mostly opaque, reddish with colorless and translucent outer part and brown outer margin; membrane translucent with grayish tinge; membrane cell pale brown veins. Legs: Coxae whitish yellow; femora whitish yellow basally, yellow apically, tibiae mostly yellow or pale brown, often whitish yellow apically, fore- and middle tarsi whitish yellow to pale brown, hind tarsus whitish yellow to yellow. Abdomen: Whitish yellow ventrally and pale brown with reddish tinge dorsally. SURFACE AND VESTITURE: Corium smooth, with shallow and scarce punctures. Dorsum, antennal segment I and femora with suberect setae shorter than antennal segment II diameter; abdomen clothed with suberect setae of different length. STRUCTURE AND MEASUREMENTS: Body ca. $4.4-4.6 \times$ as long as pronotum width. Head: Depression, delimiting occipital region distinct dorsally and laterally (as in Namyatova et al., 2016: fig. 4E); distance between depression and pronotum distinctly shorter than eye diameter; longitudinal sulcus on dorsal surface longer than eye diameter; distance from eye to pronotum slightly longer than eye diameter, not swollen laterally (as in Namyatova et al., 2016: fig. $4 \mathrm{E}$ ); vertex ca. $1.2-1.3 \times$ as wide as eye, upraised (as in Namyatova et al., 2016: fig. 6D). Labium (as in Namyatova et al., 2016: figs. 6D, 9C): Reaching posterior margin of metasternum or slightly surpassing it; segments I and II strongly reduced; combined subequal to half of segment III; segment I as long as wide; segment II slightly longer than wide, its dorsal surface elongate posteriorly; segment III slightly longer than ventral side of head; segment IV twice as long as segment III. Antenna: Segment I cylindrical (as in Namyatova et al., 2016: fig. 8A), ca. $1.2-1.6 \times$ as long as head width, ca. $0.9-1.1 \times$ as long as pronotum width; segment II ca. $1.9 \times$ as long as head width, ca. $1.3 \times$ as long as pronotum width; segment III slightly longer than segment II; segment IV ca. $0.25 \times$ as long as segment IV. Thorax: Anterior and posterior parts of pronotum subequal in length; collar delimited; posterior part slightly upraised; posterior margin straight or slightly concave, pronotum ca. $1.2-1.3 \times$ as wide as long and ca. $1.4-1.5 \times$ as wide as head; mesoscutum exposed. Hemelytron: Marking along inner margin of corium almost flat; inner margin of cuneus convex (as in Namyatova et al., 2016: fig. 13E), outer margin of cuneus almost ca. $2.5 \times$ as long as base. Abdomen: Genital capsule rotated left at right angle relative to the rest of abdomen. Genitalia: Genital capsule (fig. 14R) ca. $1.5 \times$ as long as wide; ventral wall ca. $1.5 \times$ as long as dorsal wall, its posterior margin smooth, semioval, without outgrowth, not curved, its apex inclined leftward; sides of genital capsule not modified; right paramere socket slightly angulate and left socket rounded; distance between paramere sockets ca. $0.7 \times$ as long as genital capsule width at base. Right paramere (fig. 12I) distinctly curved in apical half; apex slightly concave; medial part slightly wider than basal part, bearing setae, with outer margin concave and inner margin convex; outer angle distinct; inner angle rounded, without setae; basal part of paramere ca. $0.15-2 \times$ as long as rest of paramere. Left paramere (fig. 12J) widened, only slightly curved; apical part straight, with toothlike outgrowth on posterior side medially (as in fig. 11G) and without outgrowth on dorsal surface; middle part of paramere widened, without swelling or outgrowth; setae only on middle part near outer margin. Aedeagus (general view as in Namyatova 
et al., 2016: fig. 22I) conjunctiva weakly sclerotized; secondary gonopore placed at base of vesica in repose; sclerotization of ductus seminis around secondary gonopore shorter than wide; vesica with five spicules, including spicules $A, B$, and $\mathrm{C}$ (fig. 8O).

Female. Total length 3.2-3.5. COLORATION (fig. 5): Head: Similar to male, but dorsal surface sometimes yellow to pale brown with reddish tinge, brown anteriorly; frons yellow to brown, sometimes with reddish tinge; clypeus yellow sometimes with reddish tinge, sometimes brown basally; ventral side whitish yellow to pale brown. Labium and antenna: As in male. Thorax: Similar to male, but anterior part of pronotum sometimes pale brown with reddish tinge and brown anterior margin; thoracic pleura yellow to brown, embolium translucent. Abdomen: Whitish yellow with segment $\mathrm{X}$ and dorsal surface red. SURFACE AND VESTITURE: As in male. STRUCTURE AND MEASUREMENTS: Structure as in male; body ca. $4.1-4.4 \times$ as long as pronotum width; vertex ca. $1.8-1.9 \times$ as wide as eye diameter; antennal segment I ca. $1.4-1.6 \times$ as long as head width, ca. $0.9-1.0 \times$ as long as pronotum width; segment II ca. $1.7-1.9 \times$ as long as head width, ca. 1.1-1.3 $\times$ as long as pronotum width; pronotum ca. $1.2-1.3 \times$ as wide as long and ca. $1.5-1.7 \times$ as wide as head. Genitalia (as in Namyatova et al., 2016: fig. 23F, G): Dorsal labiate plate wider than distance between apodemes of second valvula; mostly smooth, without distinct striations, with semicircular sclerite and distinct sclerotized rings laterally; lateral oviducts placed almost medially, very close to each other, spermathecal gland placed between lateral oviducts; dorsal labiate plate with distinct tubercles, without membranous lobe medially.

Distribution: Christmas Is. (fig. 18).

Host Plants: Unknown.

Eтумоlogy: The species is named after Christine Lambkin, curator of the Entomology in Queensland Museum (Brisbane), who has assisted us in this work including the loan of material.

Discussion: Felisacus lambkinae is not very similar in coloration to any other Felisacus. How- ever, it has near identical vesical spicules, with $F$. javanus (cf. fig. $8 \mathrm{~N}$ with $8 \mathrm{O}$ ), sharing spicules $\mathrm{A}$, $\mathrm{B}$, and $\mathrm{C}$, with all of them similar in shape. These species also have similar body size and a red cuneus, but $F$. javanus differs by the anterior part of the pronotum being yellow to pale brown, the inner part of the clavus is mostly whitish yellow to yellow, with reddish or pale brown margins, and the labium reaches the posterior margin of the mesosternum or slightly surpasses it.

Material examined: Holotype: AUSTRALIA: Territory of Christmas Island: Grants Well. Christmas Is., $10.48333^{\circ} \mathrm{S} 105.65^{\circ} \mathrm{E}, 27 \mathrm{Apr}$ 1989, J.C. Cardale, $1 \delta^{\pi}$ (00033781) (ANIC). Paratypes: AUSTRALIA: Territory of Christmas Island: Grants Well. Christmas Is., $10.48333^{\circ} \mathrm{S} 105.65^{\circ} \mathrm{E}, 15$ Apr 1989, J.C. Cardale, $2 \delta^{\top} \quad(00033781,00033783), 19 \quad(00033784)$ (ANIC); 27 Apr 1989, J.C. Cardale, 4 ㅇ (00033785-00033788) (ANIC).

Felisacus linae, sp. nov.

Figures 5, 8P, 12K, L, 14S, 18

Diagnosis: Recognized by the following combination of characters: dorsal surface of head whitish yellow to pale brown; pronotum mostly yellow to pale brown with markings posteriorly and with collar darker than remainder of pronotum; cuneus with yellow tinge or with yellow to pale brown inner margin; cylindrical antennal segment I (as in Namyatova et al., 2016: fig. 8A), transverse depression on head extending laterally; vertex upraised; labium reaching posterior margin of mesosternum; antennal segment I ca. $1.7-1.9 \times$ as long as head width; cuneus ca. $3 \times$ as long as its base; apical part of right paramere only slightly concave, medial part of right paramere distinctly wider than basal part, shorter than basal and apical part combined (fig. 12K); vesica with six spicules, including spicules $A, B$, and $\mathrm{C}$, spicule B shortened (fig. 8P).

Description: Male. Total length 3.7-3.9. COLORATION (fig. 5): Head: Mostly whitish yellow to pale brown, often with brown or red 
markings; clypeus sometimes brown. Eye dark brown to black, often with reddish tinge. Labium: Whitish yellow to yellow, segment III with pale brown or reddish stripe ventrally. Antenna: Segment I yellow to paler brown, sometimes with reddish tinge, somewhat paler basally; segment II pale brown to dark brown, often with reddish tinge; segments III-IV brown to dark brown. Thorax: Pronotum mostly whitish yellow to pale brown, rarely with reddish longitudinal stripe laterally; collar often pale brown with anterior margin dark brown or uniformly dark brown; punctures between anterior and posterior parts pale brown; posterior margin of pronotum with pair of brown to dark brown making near humeral angles, sometimes posterior margin pale brown to brown between markings; scutellum and mesoscutum whitish yellow to pale brown; scutellum sometimes with pale brown to brown marking or stripe medially or apically, punctures between mesoscutum and scutellum often pale brown; thoracic pleura whitish yellow to pale brown; scent gland evaporative area whitish yellow, paler than pleura, often reddish apically. Hemelytron: Mostly translucent, colorless; inner part of clavus sometimes opaque, yellow to brown with brown margins; outer part of clavus often with pale brown to brown apex; area along inner margin of corium brown, often somewhat darker anteriorly; embolium yellow to pale brown apically with brown margins; cuneus with colorless outer part and yellow to pale brown inner part with pale brown or brown margins, sometimes with yellow tinge and pale brown margins; membrane with yellow cell. Legs: Coxae whitish yellow; femora whitish yellow basally and yellow to pale brown apically, sometimes with red stripe at least apically; tibiae yellow to pale brown, often paler apically, sometimes with red stripe at least apically; tarsi yellow to brown, sometimes segments I and II yellowish and segment II brown. Abdomen: Ventral and lateral sides whitish yellow to yellow with genital segment yellow or red, dorsal surface red. SURFACE AND VESTITURE: Corium smooth, with shallow, scarce punctures. Body clothed with pale simple setae; dorsum, antennal segment I clothed with setae subequal to antennal segment II diameter; femora clothed with suberect setae shorter than antennal segment II diameter; abdomen clothed with short suberect setae. STRUCTURE AND MEASUREMENTS: Body ca. $4.3-5.1 \times$ as long as pronotum width. Head: Depression delimiting occipital region present dorsally and laterally (as in Namyatova et al., 2016: fig. 4E); distance between depression and pronotum distinctly shorter than eye diameter; longitudinal sulcus on dorsal surface of head as long as eye diameter; distance from eye to pronotum distinctly longer than eye diameter, not swollen laterally (as in Namyatova et al., 2016: fig. 4E); vertex ca. 1.3-1.8× as wide as eye, upraised (as in Namyatova et al., 2016: fig. 6D). Labium (as in Namyatova et al., 2016: figs. 6D, 9C): Reaching posterior margin of mesosternum or slightly surpassing it; segments I and II strongly reduced, combined shorter than half of segment III; segment I shorter than wide; segment II as long as wide, elongate dorsally; segment III as long as ventral side of head; segment IV ca. $1.5 \times$ as long as segment III. Antenna: Segment I cylindrical (as in Namyatova et al., 2016: fig. $8 \mathrm{~A}$ ), ca. $1.7-1.9 \times$ as long as head width, ca. $1.1-1.2 \times$ as long as pronotum width; segment II ca. $2.1-2.4 \times$ as long as head width, ca. $1.4-1.5 \times$ as long as pronotum width; segment III slightly longer than segment II; segment IV ca. $0.3 \times$ as long as segment III. Thorax: Anterior part of pronotum distinctly shorter than posterior part, collar delimited; posterior part slightly upraised; posterior margin of pronotum straight or slightly concave; pronotum ca. $1.2-1.3 \times$ as wide as long and ca. 1.5-1.7x as wide as head; mesoscutum exposed or not exposed. Hemelytron: Area along inner margin of corium not swollen; inner margin of cuneus convex (as in Namyatova et al., 2016: fig. 13E), outer margin of cuneus ca. $3 \times$ as long as base. Abdomen: Genital capsule rotated left at right angle relative to rest of abdomen. Genitalia: Genital capsule (fig. 14S) ca. $1.5 \times$ as long as 
wide; ventral wall almost twice as long as dorsal wall, with posterior margin of ventral wall semioval, smooth, without outgrowth(s), its apex inclined rightward; sides of genital capsule not modified; right paramere socket slightly acute, left one rounded; distance between paramere sockets subequal to half of genital capsule width at base. Right paramere (fig. 12K) distinctly curved in apical half; apex concave posteriorly; medial part only slighter wider than basal part, bearing setae, with outer margin straight and inner margin convex; outer angle distinct, only slightly widened; inner angle indistinct, not bearing setae; basal part of paramere ca. $0.15-0.2 \times$ as long as rest of paramere. Left paramere (fig. 12L) L-shaped; apical part not flattened, with toothlike outgrowth on posterior side medially (as in fig. 11G) and without outgrowth on dorsal surface; middle part widened, without swelling or outgrowth; setae only on middle part near outer margin. Aedeagus (general view as in Namyatova et al., in press: fig. 22I) conjunctiva weakly sclerotized; secondary gonopore placed at base of vesica; sclerotization of ductus seminis at secondary gonopore shorter than wide; vesica with six spicules, including spicules A, B, and C. Spicule A long and wide, spicule $B$ shortened, swollen medially, spicule $\mathrm{C}$ distinctly moved posteriorly, long and convolute basally (fig. 8P).

Female. Total length 3.8-4.2. COLORATION (fig. 5): Mostly as similar to male, but scutellum sometimes mostly pale brown with yellow margins or uniformly pale brown. Abdomen: Ventral side whitish yellow to yellow, lateral and dorsal surfaces reddish. SURFACE AND VESTITURE: As in male. STRUCTURE AND MEASUREMENTS: Structure as in male; body ca. 4.0-4.4× as long as pronotum width; vertex ca. 1.6-1.9x as wide as eye; antennal segment I ca. 1.4-1.8 $\times$ as long as head width, ca. $0.9-1.0 \times$ as long as pronotum width; segment II ca. $1.8-2.1 \times$ as long as head width, ca. $1.1-1.4 \times$ as long as pronotum width; pronotum ca. $1.2-1.4 \times$ as wide as long and ca. $1.4-1.8 \times$ as wide as head. Genitalia (figs. 23F, G in Namyatova et al., 2016): Dorsal labiate plate wider than distance between apodemes of second valvula; mostly smooth, without distinct striations, with semicircular sclerite and distinct sclerotized rings laterally; lateral oviducts placed almost medially, very close to each other, spermathecal gland placed between lateral oviducts; dorsal labiate plate with distinct tubercles, without membranous lobe medially.

Distribution: Portuguese Timor (fig. 18).

Host Plants: Unknown.

Eтyмology: The species is named after Meiying Lin (Institute of Zoology, Chinese Academy of Sciences), who helped us with a loan of Felisacus specimens.

Discussion: Felisacus linae is externally similar to F. filicicola, F. ochraceus, and F. solomonicus (figs. 5, 6). These three species differ from $F$. linae in the collar the same color as the rest of the pronotum. Felisacus filicicola also differs in having seven vesical spicules (fig. 8I). Felisacus ochraceus also can be separated by the following characters in the male genitalia, with the right paramere narrow medially, only slightly wider than the basal part, almost as long as basal and apical parts combined (fig. 13C), and it has five vesical spicules, with spicule B elongate (fig. 9F). Felisacus solomonicus is also similar to F. linae in coloration, but differs in smaller size, with the body length of males $3.1-3.4 \mathrm{~mm}$ and females 3.3-3.4 $\mathrm{mm}$. It also has the right paramere distinctly concave apically (fig. 13R) and has five vesical spicules, lacking spicules $B$ and $C$ (fig. 9L).

Material examined: Holotype: EAST TIMOR: Estação Zootecnica and foot of Mundo Perdido nr Ossu, Timor Portugues, $8.73423^{\circ} \mathrm{S}$ $126.35914^{\circ} \mathrm{E}, 15$ Mar 1961, G.F. Gross, $10^{\star}$ (00017820) (SAMA). Paratypes: EAST TIMOR: Esçãao Zootecnica and foot of Mundo Perdido $\mathrm{nr}$ Ossu, Timor Portugues, $8.73423^{\circ} \mathrm{S}$ $126.35914^{\circ} \mathrm{E}, 14 \mathrm{Mar} 1961$, G.F. Gross, $6{ }^{\star}$ (00017813-00017818), 1 sex unknown (00017823) (AM); 15 Mar 1961, G.F. Gross, $2 \widehat{ }$ (00017819, 00017821), 1 sex unknown 00017822), 1 juvenile $(00017811), \quad 7$ 우 (00017824-00017830) (SAMA). 


\section{Felisacus lindbergae, sp. nov.}

Figures 5, 10F, 12M, N, 14T, 16E, 19

Diagnosis: Recognized by the following combination of characters: antennal segment II brown, cuneus colorless, sometimes with brown tinge apically; femora with marking in apical half brown to dark brown; marking on corium dark brown, C-shaped, its anterior part reaching or almost reaching $\mathrm{R}+\mathrm{M}$ and only slightly inclined; antennal segment I widened (as in Namyatova and Cassis, in press: fig. 8B), ventral wall of genital capsule with tooth posteriorly (fig. 14T); right paramere sickle shaped with inner angle bearing straight outgrowth (fig. 12M); left paramere with tooth apically and outgrowth on dorsal surface, but without outgrowth on inner margin (fig. $12 \mathrm{~N}$ ); half of ductus seminis sclerotized, sickle shaped apically; vesica without sclerite (fig. 10F).

Description: Male. Total length 3.4-4.1. COLORATION (fig. 5): Head: Mostly yellow to pale brown, dorsal surface sometimes with brown marking near eye, longitudinal sulcus sometimes brown, darker than dorsal surface, anterior side and clypeus basally sometimes yellow, paler than other sides, clypeus apically and buccula brown. Eye dark brown with reddish tinge. Labium: Segments I-II dark brown, segment III-IV yellow to brown, paler than segment II, segment IV sometimes darker than segment III. Antenna: Segments I-II brown, segments III-IV yellow to pale brown. Thorax: Anterior part of pronotum mostly yellow to pale brown, often brown medially, anterior margin brown, posterior part of pronotum uniformly brown; scutellum and mesoscutum brown to dark brown; thoracic pleura brown to dark brown; scent gland evaporative area uniformly whitish yellow. Hemelytron: Clavus opaque brown to dark brown; corium and embolium translucent, colorless; corium with C-shaped dark brown marking, its anterior part of this marking reaching or almost reaching $\mathrm{R}+\mathrm{M}$ vein; posterior part of C-shaped marking reaching costal margin; embolium with brown outer margin and colorless inner margin and dark brown apex; cuneus translucent, colorless, with brown margins and apex sometimes with brown tinge; membrane translucent, gradually changing color from brown anteriorly and pale brown posteriorly, sometimes membrane pale brown anteriorly and colorless posteriorly; cell brown. Legs: Coxae whitish yellow, femora whitish yellow basally and yellow apically with apex and marking in apical half brown to dark brown, sometimes marking in apical half very pale; foretibia mostly brown, whitish yellow to yellow apically, sometimes brown apically and yellow apically; middle and hind tibiae brown basally and whitish yellow apically; tarsi mostly whitish yellow, sometimes segments II and III of fore- and middle tarsi pale brown to brown. Abdomen: Whitish yellow to yellow with brown dorsum. SURFACE AND VESTITURE: Corium smooth, with shallow and scarce punctation. Dorsum and forefemora with setae subequal to or longer than antennal segment II diameter; antennal segment I, middle and hind femora clothed with suberect setae mostly shorter than antennal segment II diameter; abdomen clothed with short erect setae. STRUCTURE AND MEASUREMENTS: Body ca. $4.1-4.5 \times$ as long as pronotum width. Head: Depression, delimiting occipital region, present only dorsally; distance between depression and pronotum distinctly longer than eye diameter; longitudinal sulcus on dorsal surface of head shorter than eye diameter; distance from eye to pronotum distinctly longer than eye diameter, not swollen laterally; vertex ca. 1.4-1.6x as wide as eye, flat (Namyatova et al., 2016: fig. 6E). Labium: Almost reaching posterior margin of prosternum, but not surpassing it; segments I and II longer than wide, each of them subequal to half of segment III; dorsal surface of segment II not elongate posteriorly (as in Namyatova et al., 2016: fig. 6E); segment III distinctly shorter than ventral side of head; segment IV ca. $1.5 \times$ as long as segment III. Antenna: Segment I swollen in basal portion (as in Namyatova et al., 2016: fig. $8 \mathrm{~B}$ ), ca. $1.2-1.3 \times$ as long as head width, ca. $0.8-0.9 \times$ as long as pronotum width; segment II ca. $1.5-1.8 \times$ as long as head width, ca. 1.1-1.3× 
as long as pronotum width; segment III slightly longer than segment II and twice as long as segment IV. Thorax: Anterior part of pronotum shorter than posterior part; collar delimited; posterior part slightly upraised; posterior margin of pronotum straight or concave; pronotum ca. $1.0-1.3 \times$ as wide as long and ca. $1.3-1.5 \times$ as wide as head; mesoscutum usually exposed, sometimes not exposed. Hemelytron: Area along inner margin of corium swollen; inner margin of cuneus straight (as in Namyatova et al., 2016: fig. $13 \mathrm{~F}$ ), outer margin of cuneus twice as long as its width at base. Abdomen: Genital capsule rotated left at small angle relative to rest of abdomen. Genitalia: Genital capsule (fig. $14 \mathrm{~T}$ ) ca. $1.5 \times$ as long as wide; ventral wall ca. $1.5 \times$ as long as dorsal wall, with posterior margin of ventral wall truncate, not curved dorsally, with small toothlike outgrowth from left side and with right side folded; left side of genital capsule not widened; paramere sockets distinctly angulate; distance between paramere sockets subequal to half of width of genital capsule base at base. Right paramere (fig. 12M) sickle shaped; apex straight posteriorly; medial part narrower than basal part, without setae, outer margin of medial part convex and inner margin concave, without swelling; outer angle absent; inner angle present, with straight outgrowth, bearing setae; basal part of paramere ca. $0.7 \times$ as long as rest of paramere. Left paramere (fig. $12 \mathrm{~N}$ ) curved medially; apical part not flattened, with toothlike outgrowth on posterior side apically and with outgrowth on dorsal surface; inner margin of paramere slightly swollen dorsally, bearing setae. Aedeagus (general view as in Namyatova et al., 2016: fig. 22M) vesica without spicules; apical half of ductus seminis sclerotized, secondary gonopore placed near phallotheca mouth in repose; ductus seminis hooked apically (fig. 10F).

Female. Total length 3.7-4.4. COLORATION (fig. 5): Similar to male, antennal segments IIIIV yellow, paler than segment II, sometimes segment IV pale brown, darker than segment III. SURFACE AND VESTITURE: As in male. STRUCTURE AND MEASUREMENTS: Struc- ture as in male; body ca. $4.1-4.3 \times$ as long as pronotum width; vertex ca. $1.5-1.8 \times$ as wide as eye diameter; antennal segment I ca. $1.1-1.2 \times$ as long as head width, ca. $0.7-0.8 \times$ as long as pronotum width; segment II ca. $1.5-1.8 \times$ as long as head width, ca. $1.0-1.1 \times$ as long as pronotum width; pronotum ca. $1.1-1.2 \times$ as wide as long and ca. $1.5-1.7 \times$ as wide as head. Genitalia: Dorsal labiate plate very small and transparent, as wide as distance with apodemes of second valvulae, without striations or membranous ridge medially; semicircular sclerite and sclerotized rings absent; lateral oviducts placed in near posterior margin very close to each; spermathecal gland attached near anterior margin (fig. 16E); dorsal labiate plate without distinct tubercles, without membranous lobe posteriorly (as in fig. 16B).

Distribution: Solomon Is. (fig. 19)

Host Plants: Freycinetia sp. (Pandanaceae).

Eтymology: The species is named after Gunvi Lindberg, the curatorial assistant in Swedish Museum of Natural History (Stockholm) for the loan of type specimens.

Discussion: Felisacus lindbergae is most similar to F. longiceps, F. magnificus, and F. zuparkoi in coloration and structure (figs. 5-7). These three species differ by the labium reaching the posterior margin of the mesosternum, the outgrowth on the inner angle of the right paramere is curved (figs. 12M, 12Q, W, 13AD), and the medial part of the left paramere has an outgrowth (cf. figs. 12N, 12R, X, 13AE). Felisacus magnificus can also be separated by the right paramere straight (fig. 12W) and the apical part of the left paramere broad (fig. 12X). Felisacus zuparkoi differs from the above species by the femora without markings apically and the presence of a vesical spicule (fig. 10P).

Material eXamined: Holotype: SOLOMON ISLANDS: New Georgia Islands: Gizo, Gizo Is., $8.1^{\circ} \mathrm{S} 156.85^{\circ} \mathrm{E}, 100 \mathrm{~m}$, Nov 1975, N.L.H. Krauss, $10^{\text {t }}$ (00043172) (BPBM). Paratypes: SOLOMON ISLANDS: Malaita: Auki, $8.767^{\circ} \mathrm{S} 160.7^{\circ} \mathrm{E}, 100 \mathrm{~m}$, Feb 1985, N.L.H. Krauss, $2 \overbrace{}^{\dagger}$ (00043164, 00043165) (BPBM). New Georgia Islands: Gizo, Gizo Is., 
$8.1^{\circ} \mathrm{S} 156.85^{\circ} \mathrm{E}, 100 \mathrm{~m}$, Nov 1975, N.L.H. Krauss, 8ठ (00043166-00043171, 00043173, 00043174), 2 우 $(00043175,00043176)(B P B M)$. Western Province: New Georgia Islands: Munda, New Georgia Is., $8.31666^{\circ} \mathrm{S} 157.25^{\circ} \mathrm{E}, 50 \mathrm{~m}$, Nov 1980, N.L.H. Krauss, 1 ( 90043178$)$ (BPBM). New Georgia Island, Munda, $8.31666^{\circ} \mathrm{S} 157.25^{\circ} \mathrm{E}, 20 \mathrm{Jul}$ 1959, J.L. Gressitt, Freycinetia sp. (Pandaceae), 1 đ (00043163) (BPBM). Gizo, Kolombangara Is., Gizo, $7.93799^{\circ} \mathrm{S}$ $157.09339^{\circ} \mathrm{E}, 70 \mathrm{~m}$, Dec 1980, N.L.H. Krauss, 2 ㅇ (00043177-00043179) (BPBM).

Felisacus liui, sp. nov.

Figures 5, 8Q, 12O, P, 14U, 19

Diagnosis: Recognized by the following combination of characters: small body, length in male 2.6-2.8, in female 2.9; dark coloration with dorsal surface of head and anterior part of pronotum mostly brown, posterior part of pronotum pale brown with brown marking posteriorly, marking along inner margin of corium brown, not reaching $\mathrm{R}+\mathrm{M}$; and cuneus with narrow red stripe along inner margin; cylindrical antennal segment I (as in Namyatova et al., 2016: fig. 8A), transverse depression on head extending laterally, vertex upraised (as in Namyatova et al., 2016: fig. 6D); antennal segment I ca. $1.2-1.5 \times$ as long as head width; labium reaching posterior margin of mesosternum or slightly surpassing it; middle part of right paramere almost as wide as basal part, shorter than basal and apical parts combined (fig. 12O); vesica with six spicules, none of which can be homologized with the spicules of other species (fig. 8Q)

Description: Male. Total length 2.6-2.8. COLORATION (fig. 5): Head: Varying from dark brown to pale brown; buccula, clypeus, and tubercle around antennal fossa yellow, mandibular and maxillary plates yellow to pale brown. Eye brown with reddish tinge. Labium: Yellow to pale brown, segment III often brown or reddish ventrally and basally. Antenna: Segment I reddish with yellow base, segment II reddish brown or brown, segments III-IV brown. Thorax: Anterior part or pronotum brown with collar pale brown and anterior margin dark brown; posterior part of pronotum whitish yellow to yellow, with small brown marking at posterior margin medially and brown marking near posterior angle; scutellum and mesoscutum whitish yellow, with brown longitudinal stripe medially, rarely uniformly whitish yellow; thoracic pleura pale brown to dark brown; scent gland evaporative area pale brown to brown with reddish apex. Hemelytron: Mostly colorless, translucent; inner part of clavus with orange, reddish, or pale brown margins; brown marking along inner margin of corium narrow, not reaching $\mathrm{R}+\mathrm{M}$; embolium with pale brown margins; cuneus with pale brown, orange, or reddish marking along inner margin and pale brown margins, rarely cuneus colorless with yellow margins. Legs: Coxae whitish yellow; femora whitish yellow to yellow with reddish apices; tibiae reddish basally and whitish yellow to yellowish apically; foretibia sometimes uniformly reddish; tarsi whitish yellow to yellow. Abdomen: Yellow with red or brown lateral sides, apex and dorsal surface sometimes uniformly yellow with reddish tinge. SURFACE AND VESTITURE: Corium smooth, often with shallow scarce punctures. Dorsum with suberect setae mostly shorter than or subequal to antennal segment II diameter; antennal segment I and femora with suberect setae shorter than antennal segment II diameter; abdomen clothed with suberect mostly short simple setae. STRUCTURE AND MEASUREMENTS: Body ca. $4.5-4.8 \times$ as long as pronotum width. Head: Transverse depression delimiting occipital region present dorsally and laterally (as in Namyatova et al., 2016: fig. 4E); distance between depression and pronotum distinctly shorter than eye diameter; longitudinal sulcus on dorsal surface longer than eye diameter; distance from eye to pronotum slightly longer than eye diameter, not swollen laterally (as in Namyatova et al., 2016: fig. 4E); vertex ca. 2.0-2.3× as wide as eye, upraised (as in Namyatova et al., 2016: fig. 6D). Labium (as in Namyatova et al., 2016: figs. 6D, 9C): Reaching posterior margin 
of mesosternum or slightly surpassing it; segments I and II strongly shortened, combined shorter than half of segment III; segment II slightly longer than wide, its dorsal surface elongate posteriorly; segment III slightly longer than ventral side of head; segment IV twice as long as segment III. Antenna: Segment I cylindrical (as in Namyatova et al., 2016: fig. 8A), ca. $1.2-1.4 \times$ as long as head width, ca. $0.9-1.1 \times$ as long as pronotum width; segment II ca. 1.6$1.8 \times$ as long as head width, ca. $1.2-1.4 \times$ as long as pronotum width; segment III subequal to segment II. Thorax: Anterior part of pronotum only slightly shorter than posterior part; collar delimited; posterior part slightly upraised; posterior angles of pronotum not delimited with depression; posterior margin concave, pronotum ca. $1.1-1.2 \times$ as wide as long and ca. 1.2$1.4 \times$ as wide as head; mesoscutum exposed. Hemelytron: Area along inner margin of corium almost flat; inner margin of cuneus convex (as in Namyatova et al., 2016: fig. 13E), outer margin of cuneus almost ca. $3 \times$ as long as base. Abdomen: Genital capsule rotated left at right angle relative to the rest of abdomen. Genitalia: Genital capsule (fig. $14 \mathrm{U}$ ) ca. $1.5 \times$ as long as wide; ventral wall ca. $1.5 \times$ as long as dorsal wall, its posterior margin smooth, semioval, without outgrowth, not curved dorsally; its apex inclined leftward; sides of genital capsule not modified; margins of paramere sockets rounded; distance between paramere sockets subequal to half of genital capsule base. Right paramere (fig. 12O) distinctly curved in apical half; apex straight; medial part slightly wider than basal part, bearing setae, with outer margin concave and inner margin convex; outer angle distinct, slightly swollen; inner angle indistinct, without setae; basal part of paramere ca. $0.2-0.25 \times$ as long as rest of paramere. Left paramere (fig. 12P) L-shaped; apical part not flattened, with tooth on posterior side medially (as in fig. 11G) and without outgrowth on dorsal surface; middle part widened, without swelling or outgrowth; setae only on middle part near outer margin. Aedeagus (as in Namyatova et al., 2016: fig. 22I) conjunctiva weakly sclerotized; secondary gonopore placed at base of vesica in repose; sclerotization of ductus seminis around secondary gonopore shorter than wide; vesica with six spicules, none of which can be homologized with the spicules of other species (fig. 8Q).

Female. Total length 2.9. COLORATION (fig. 5): Similar to male, but scutellum and mesoscutum whitish yellow with brown longitudinal stripe, scent gland evaporative area brownish with reddish apex; clavus sometimes yellowish and opaque, cuneus whitish and translucent with reddish inner part and pale brown margins. SURFACE AND VESTITURE: As in male. STRUCTURE AND MEASUREMENTS: Structure as in male; body ca. $4.5-4.8 \times$ as long as pronotum width; vertex ca. 1.7-2.0x as wide as eye; antennal segment I ca. 1.4-1.5 $\times$ as long as head width, ca. $0.9-1.1 \times$ as long as pronotum width; segment II ca. $1.8 \times$ as long as head width, ca. $1.2-1.3 \times$ as long as pronotum width; pronotum ca. $1.1-1.2 \times$ as wide as long and ca. $1.4-1.5 \times$ as wide as head. Genitalia (as in Namyatova et al., 2016: fig. 23F, G): Dorsal labiate plate wider than distance between apodemes of second valvula; mostly smooth, without distinct striations, with semicircular sclerite and distinct sclerotized rings laterally; lateral oviducts placed almost medially, very close to each other, spermathecal gland placed between lateral oviducts; dorsal labiate plate with distinct tubercles, without membranous lobe medially.

Distribution: Solomon Islands (Kolombangara Is., Gizo Is., New Georgia Is.) (fig. 19).

Host PLANTS: Unknown.

ЕтумоLogy: The species is named after GuoQing Liu, who loaned us the material from the collection of Nankai University (China).

Discussion: Feliscaus liui is most similar externally and in dark coloration to F. lambkinae and F. minutus. However, F. lambkinae and F. minutus have a larger red marking on the cuneus (figs. 5, 6). Felisacus minutus is also recognized by the posterior part of the pronotum being 
brown laterally. Felisacus lambkinae and F. minutus also differ from F. liui in the shape of vesical spicules (cf. figs. 8Q, O, 9D).

MATERIAl eXAmined: Holotype: SOLOMON ISLANDS: Western Province: Gizo, Kolombangara Is., Gizo, $7.93799^{\circ} \mathrm{S} 157.09339^{\circ} \mathrm{E}, 70 \mathrm{~m}$, Dec 1980, N.L.H. Krauss, 10 (00043238) (BPBM). Paratypes: SOLOMON ISLANDS: Western Province: New Georgia Islands: Munda, New Georgia Is., $8.31666^{\circ} \mathrm{S} 157.25^{\circ} \mathrm{E}, 50 \mathrm{~m}$, Nov 1980, N.L.H. Krauss, 1 ㅇ (00043240) (BPBM). Gizo, Kolombangara Is., Gizo, $7.93799^{\circ} \mathrm{S} 157.09339^{\circ} \mathrm{E}$, 70 m, Dec 1980, N.L.H. Krauss, 4 ơ (0004323400043237), 1 ㅇ (00043239) (BPBM).

\section{Felisacus longiceps Poppius, 1915}

Figures 5, 10H, 12Q, R, 14V, 19

Felisacus longiceps Poppius, 1915b: 55 (original description).

Felisacus okinawanus Miyamoto, 1965: 166; new synonymy.

Diagnosis: Recognized among congeners by the following combination of characters: presence of dark brown C-shaped marking on corium, with anterior part reaching $\mathrm{R}+\mathrm{M}$ and not inclined posteriorly (fig. 5); antennal segment I widened (as in Namyatova and Cassis, in press: fig. 8B), red, reddish brown, or brown; antennal segment II often mostly yellow; vertex flat and not widened laterally; labium reaching posterior margin of mesosternum; dark band in apical part of fore- and middle femora usually absent; right paramere sickle shaped with outgrowth on inner angle slightly curved (fig. 12Q); apical part of left paramere narrow, with toothlike outgrowth apically and outgrowth on dorsal surface; medial part of left paramere with narrow outgrowth (fig. 12R); apical half of ductus seminis sclerotized, hooked; vesica without sclerite (fig. 10H).

Redescription: Male. Total length 3.0-3.4. COLORATION (fig. 5): Head: Mainly pale brown, sometimes with reddish markings; anterior side, clypeus, mandibular and maxillary plates, and tubercle around antennal fossa yellow, often buccula and apex of clypeus and rarely lateral side behind eye brown. Eye brown with reddish tinge. Labium: Segment I yellow to pale brown; segment II pale brown; segment III yellow to pale brown; segment IV yellow, rarely labium uniformly yellow to pale brown. Antenna: Segment I brown or reddish brown; segment II yellow to dark brown, segments III-IV pale brown. Thorax: Anterior part of pronotum yellow to pale brown, sometimes with brown anterior margin; posterior part of pronotum brown, rarely yellow or pale brown; scutellum and mesoscutum pale brown to brown; thoracic pleura pale brown to brown, rarely yellow, scent gland evaporative area whitish yellow. Hemelytron: Clavus opaque, uniformly brown to dark brown, rarely pale brown; corium, embolium, cuneus, and membrane mostly translucent, colorless; corium with pale brown anterior angles and C-shaped dark brown marking, reaching $\mathrm{R}+\mathrm{M}$ anteriorly and posteriorly, its anterior part not inclined posteriorly; embolium pale brown basally and brown apically, with pale brown or yellow margins; cuneus yellow, red, or brown apically, with reddish brown or yellow outer margin and colorless inner margin; membrane gradually changing color from pale brown to brownish basally and grayish apically; membrane cell pale brown to brown. Legs: Coxae whitish yellow; femora whitish yellow basally and brown apically, often with reddish tinge apically, sometimes with brown marking at apical part, rarely fore- and middle femora whitish yellow to yellow, with reddish markings apically, sometimes with brown band on apical half of hind femur; basal part of tibiae yellow to brown, often with reddish tinge, apical part whitish yellow, rarely tibiae uniformly whitish yellow; tarsi uniformly whitish yellow. Abdomen: Whitish yellow to pale brown ventrally and laterally, reddish apically and brown dorsally. SURFACE AND VESTITURE: Corium smooth, with shallow and scarce punctation. Dorsum and femora clothed with setae subequal to or longer than antennal segment II diameter; antennal segment I clothed with suberect setae shorter than antennal segment II diameter; abdomen clothed 
with short erect setae. STRUCTURE AND MEASUREMENTS: Body ca. $3.9-4.2 \times$ as long as pronotum width. Head: Transverse depression delimiting occipital region present only dorsally; distance between depression and pronotum slightly longer than eye diameter; longitudinal sulcus on dorsal surface of head shorter than eye diameter; distance from eye to pronotum longer than eye diameter, not swollen; vertex ca. 1.9-2.5x as wide as eye, flat (Namyatova et al., 2016: fig. $6 \mathrm{E})$. Labium: Reaching posterior margin of mesosternum or slightly surpassing it; segments I and II shorter than wide, combined subequal to half of segment III; dorsal surface of segment II not elongate (as in Namyatova et al., 2016: fig. 6E); segment III shorter than ventral side of head; segment IV ca. $1.5 \times$ as long as segment III. Antenna: Segment I slightly longer than head width, swollen basally (as in Namyatova et al., 2016: fig. 8B), ca. $1.0-1.3 \times$ as long as head width, ca. $0.6-0.7 \times$ as long as pronotum width; segment II ca. 1.6-1.7× as long as head width, ca. $0.8-1.0 \times$ as long as pronotum width; segment III slightly longer than segment II and twice as long as segment IV. Thorax: Anterior part of pronotum shorter than posterior part; collar delimited, posterior part slightly upraised; posterior angles not delimited with depression; posterior margin of pronotum concave; pronotum ca. $1.3 \times$ as wide as long and ca. $1.7-2.0 \times$ as wide as head; mesoscutum usually exposed, sometimes not exposed. Hemelytron: Area along inner margin of corium swollen; inner margin of cuneus straight (as in Namyatova et al., 2016: fig. 13F), outer margin of cuneus twice as long as base. Abdomen: Angle between genital capsule and rest of abdomen varying from very small to almost right. Genitalia: Genital capsule (fig. 14V) twice as long as wide; ventral wall ca. $1.5 \times$ as long as dorsal wall, with posterior margin of ventral wall not curved, with small toothlike outgrowth; right side of genital capsule folded, left side of genital capsule not widened; paramere sockets distinctly acute; distance between paramere sockets ca. $0.3 \times$ as long as genital capsule width at base. Right paramere (fig. 12Q) sickle shaped; apex slightly concave; medial part nar- rower than basal part, without setae, outer margin of medial part convex, inner margin concave, without swelling; outer angle absent; inner angle present with curved outgrowth bearing setae; basal part of paramere slightly shorter than rest of paramere. Left paramere (fig. 12R) apical part not flattened, with toothlike outgrowth apically and with outgrowth on dorsal surface; inner margin with narrow outgrowth, with setae near outgrowth. Aedeagus (general view as in Namyatova et al., 2016: fig. 22M) vesica without spicules; apical half of ductus seminis sclerotized, hooked apically, secondary gonopore placed near phallotheca mouth in repose (fig. 10H).

Female. Total length 3.5. COLORATION (fig. 5): Head: Similar to male, often with reddish markings on dorsal surface, frons, mandibular and maxillary plates, and clypeus; antennal segment II often yellow, rarely pale brown apically or uniformly pale brown. Thorax: Similar to male, but posterior part of pronotum sometimes pale brown with brown posterior margin. Abdomen: As in male. SURFACE AND VESTITURE: As in male. STRUCTURE AND MEASUREMENTS: Structure as in male; body ca. $3.8-4.0 \times$ as long as pronotum width; vertex ca. $1.8-2.2 \times$ as wide as eye; antennal segment I ca. $1.1-1.2 \times$ as long as head width, ca. $0.6 \times$ as long as pronotum width; segment II ca. $1.2-1.6 \times$ as long as head width, ca. $0.7-0.8 \times$ as long as pronotum width; pronotum ca. $1.2-1.4 \times$ as wide as long and ca. $1.8-2.0 \times$ as wide as head. Genitalia (as in figs. 16A, B): Dorsal labiate plate very small and transparent, as wide as distance with apodemes of second valvulae, without striations or membranous ridge medially; semicircular sclerite and sclerotized rings absent; lateral oviducts placed in anterior part; spermathecal gland attached near anterior margin; dorsal labiate plate without distinct tubercles, without membranous lobe posteriorly.

Distribution: Borneo, Japan (Ryukyu Is.), Vietnam (fig. 19).

Host PLANTs: Many specimens were collected from Nephrolepis biserrata (Davalliaceae) and Plesioneuron sp. (Thelypteridaceae) on Ambon and Sulawesi islands. 
Discussion: Felisacus capitatus, F. longiceps, F. magnificus, F. okinawanus, and F. pulchellus are very similar externally (see discussion for F. magnificus for details). The identification of the material belonging to this group of species was not straightforward, as the types of $F$. longiceps, $F$. magnificus, and $F$. pulchellus are either females or had lost genitalia, and we could not examine the types of $F$. capitatus and F. okinawanus from Kyushu University, where they are preserved according to the initial description (Miyamoto, 1965).

We divided all the material examined for the above five taxa into three species, based on the structure of the male genitalia, particularly for that of the parameres. We identified one of them as Felisacus magnificus (see its discussion for details). The second species is paler, often having a pale brown pronotum; in this species if the posterior part of the pronotum is dark brown, then antennal segment I and the legs are almost uniformly yellow. This pattern of coloration is similar to F. longiceps. The parameres and coloration of this species are also similar to F. okinawanus (figs 12Q, R; Miyamoto, 1965: figs. 43-46). On the basis of these observations, we synonymized $F$. okinawanus with $F$. longiceps. The third species was unlike any other among the described taxa, and we describe it as a new species, F. zuparkoi.

Felisacus magnificus and F. zuparkoi differ from F. longiceps externally by the antennal segment II, and the posterior part of pronotum dark brown, whereas both species have dark bands on the fore- and middle femora. Felisacus magnificus also differs from $F$. longiceps by the straight right paramere (fig. 12W) and the broad left paramere (fig. 12X). F. zuparkoi differs in the broad outgrowth on the inner margin of the left paramere (fig. 13AE) and the presence of a vesical spicule (fig. 10P).

Felisacus longiceps is also similar to F. ceylonicus and F. lindbergae. Felisacus ceylonicus differs from $F$. longiceps by its vertex broad laterally behind the eye and the outgrowth on the medial part of the left paramere distinctly curved (fig.
11R). Felisacus lindbergae can be separated from F. longiceps by the labium almost reaching the posterior margin of the prosternum, the brown antennal segment II, the presence of dark bands on the fore- and middle femora and the straight outgrowth on the inner angle of the right paramere (fig. 12M).

Material eXAmined: Holotype (Felisacus longiceps). TAIWAN: Chip-Chip, no date provided, unknown collector, 19 (00018972) (HNHM). Additional material: CHINA: Guandong: Mt Dinghu [Dinghu Shan, Dinhushan], $23.1751^{\circ} \mathrm{N} 112.5533^{\circ} \mathrm{E}, 28$ Nov 1959 , Rodendorf, $10^{\dagger}$ (00271521) (ZISP). INDONESIA: Maluku: Ambon Island $\mathrm{nr}$ Ambon City, 3.60706 $\mathrm{S}$ $128.28328^{\circ} \mathrm{E}, 23$ Aug 2012, F. Konstantinov, Nephrolepis biserrata (Sw.) Schott (Davalliaceae), det. Michael Lovave (LAE herbarium, PNG), 50 (00271434-00271438), 2 ㅇ (00271439, 00271440) (ZISP). West Nusa Tenggara: Lombok Island, Senaru, Panorama track to Sendang Gila Waterfall, $8.30111^{\circ} \mathrm{S} 116.40833^{\circ} \mathrm{E}, 28$ Aug 2012, F. Konstantinov, 13 o (00271441-00271453), 1 sex unknown (00271351), 8 우 (00271454-00271461) (ZISP); 30 Aug 2012, F. Konstantinov, Nephrolepis biserrata (Sw.) Schott (Davalliaceae), det. Michael Lovave (LAE herbarium, PNG), 9 $\widehat{ }$ (00271462-00271470), 2 sex unknown (00271471, 00271472), 9 ㅇ (00271473-00271481) (ZISP). Lombok Island, Senaru, track to Tiu Kelep Waterfall, $8.30111^{\circ} \mathrm{S} 116.40833^{\circ} \mathrm{E}, 31$ Aug 2012, F. Konstantinov, Nephrolepis biserrata (Sw.) Schott (Davalliaceae), 4 đ (00271482-00271484, 00271424) Plesioneuron sp. (Thelypteridaceae), $10^{\top}$ (00386467) (ZISP). Lombok Island, $\mathrm{nr}$ Senaru, $8.31689^{\circ} \mathrm{S} 116.40381^{\circ} \mathrm{E}, 29$ Aug 2012, F. Konstantinov, 11 ㅎ (00271485-00271495), 8 우 (00271496-00271499, 00271501-00271504), 1 sex unknown (00271350) (ZISP). Lombok Island, nr Senaru, $8.31956^{\circ} \mathrm{S} 116.405^{\circ} \mathrm{E}, 31$ Aug 2012, F. Konstantinov, Nephrolepis biserrata (Sw.) Schott (Davalliaceae), 1 ㅇ 00271500) Plesioneuron sp. (Thelypteridaceae), det. Michael Lovave (LAE herbarium, PNG), 5 đ (00386617-00386621), $3+$ (00271515-00271517) (ZISP). JAPAN: Okinawa: Ishigaki Is., Ryukyu Islands, $24.4^{\circ} \mathrm{N}$ 
$124.2^{\circ} \mathrm{E}, 01$ Nov 1952, G.E. Bohart, 2 ๙ (00043262, 00043263) (BPBM); 10 Nov 1952-15 Nov 1952, G.E. Bohart, 1 đ (00043261) (BPBM); 14 Oct 1999, Belokobylskij, 1 đ (00271505) (ZISP). MALAYSIA: Sabah: Kalabakan, $4.4167^{\circ} \mathrm{N} 117.4833^{\circ} \mathrm{E}, 08$ Nov $1958-15$ Nov 1958 ,

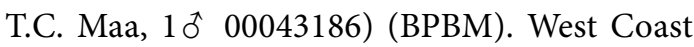
Residency [Coast Residency], Ranau, $6.08333^{\circ} \mathrm{N}$ $116.5^{\circ} \mathrm{E}, 500 \mathrm{~m}, 08$ Oct $1958-11$ Oct 1958 , T.C. Maa, 2 đิ (00043344, 00043345) (BPBM). PHILIPPINES: Laguna: Los Banos, $14.17086^{\circ} \mathrm{N}$ $121.24334^{\circ} \mathrm{E}$, no date provided, Baker [no date], 1 ( $(00018446)(\mathrm{MZH})$. TAIWAN: N Taiwan, $\mathrm{Nei}-\mathrm{Hu}$, Taipei, $25.09074^{\circ} \mathrm{N} 121.55972^{\circ} \mathrm{E}, 28 \mathrm{Aug}$ 1963, Hsien, 1 ㅇ (00005965) (BPBM). VIETNAM: Ha Noi: $70 \mathrm{~km}$ NWW Ha Noi BaVi, $21.087^{\circ} \mathrm{N} 105.302^{\circ} \mathrm{E}, 22$ Nov 1990 , Belokobylskij, 1 ( 00018444$)$ (ZISP). Hòa Bình: Hoa Binh: Near Mai Chau [Mai Chon, Mai Chou], $20.667^{\circ} \mathrm{N}$ $105.084^{\circ} \mathrm{E}, 31$ Oct 1990, Belokobylskij, 3 ㅇ (00018436, 00018442), 5 ठ (00018437, 00018439, 00018440, 00271520) (ZISP); 01 Nov 1990, Belokobylskij, 1 đิ (00018438) (ZISP); 02 Nov 1990, Belokobylskij, 1 ㅇ (00018443) (ZISP); 03 Nov 1990, Belokobylskij, 2 đ (00386603) (ZISP); 04 Nov 1990, Belokobylskij, 2 đิ (00018441) (ZISP).

\section{Felisacus lordhowensis, sp. nov.}

Figures 5, 8R, 12S, T, 14W, 19

Diagnosis: Recognized by the following combination of characters: cylindrical antennal segment I (as in Namyatova et al., 2016: fig. 8A), vertex upraised (as in Namyatova et al., 2016: fig. 6D); head, clavus, and pronotum whitish yellow to yellow, head without dark marking dorsally, pronotum sometimes with narrow pale brown to brown marking along posterior margin, clavus uniformly colored; cuneus mostly colorless; labium reaching or surpassing posterior margin of metasternum; antennal segment II ca. 1.6-1.9× as long as head width; cuneus $3 \times$ as long as wide; medial part of right paramere shorter than apical and basal parts combined (fig. 12S); apical part of left paramere ca. $3 \times$ as long as wide (fig. 12T), vesica with six spicules, including spicules $B$ and $\mathrm{E}$, spicule B short and widened (fig. 8R).

Description: Male. Total length 3.5-4.0. COLORATION (fig. 5): Head: Mostly whitish yellow to yellow, often with reddish tinge or red markings; clypeus often pale brown or red apically. Eye brown with reddish tinge or red. Labium: Whitish yellow to yellow, segment II often reddish ventrally. Antenna: Segment I yellow with reddish tinge; segment II yellow with pale brown or reddish apex; segment III yellow basally and pale brown to brown apically; segment IV pale brown to brown. Thorax: Pronotum whitish yellow to yellow, often pale brown or brown posteriorly, punctures between anterior and posterior parts yellow to pale brown; scutellum and mesoscutum whitish yellow to yellow, often with reddish stripe between them; thoracic pleura yellow; scent gland evaporative area whitish yellow, rarely green apically. Hemelytron: Mostly translucent, colorless; inner part of clavus whitish yellow to yellow, sometimes opaque, often brown basally, with pale brown, brown, or red margins; area along inner margin of corium brown; embolium with yellow to pale brown margins; cuneus with pale brown outer margin; membrane with grayish tinge; membrane cell red. Legs: Coxae whitish yellow; femora whitish yellow, often yellow apically, sometimes with reddish tinge; tibiae yellow, often whitish yellow apically, sometimes with reddish tinge basally, rarely uniformly whitish yellow or yellow; tarsi pale brown. Abdomen: Whitish yellow, often yellow or red dorsally, rarely greenish basally. SURFACE AND VESTITURE: Corium smooth, with shallow scarce punctures. Dorsum; antennal segment I and femora with suberect setae shorter than antennal segment II diameter; abdomen clothed with suberect mostly short simple setae. STRUCTURE AND MEASUREMENTS: Body ca. 4.6-4.7× as long as pronotum width. Head: Depression delimiting occipital region present dorsally and laterally (as in Namyatova et al., 2016: fig. 4E); distance between depression and pronotum distinctly shorter than eye diameter; longitudinal sulcus on dorsal surface longer than eye diameter; distance from eye to pronotum eye 
longer than eye diameter, not swollen laterally (as in Namyatova et al., 2016: fig. 4E); vertex ca. 2.0$2.4 \times$ as wide as eye, upraised (Namyatova et al., 2016: fig. 6D). Labium: Reaching or slightly surpassing posterior margin of metasternum; segments I and II strongly reduced, combined shorter than half of segment III; segment I shorter than wide (as in Namyatova et al., 2016: figs. 6D, 9C); dorsal surface of segment II elongate posteriorly, elongate dorsally; segment III slightly longer than ventral side of head; segment IV ca. $1.5 \times$ as long as segment III. Antenna: Segment I cylindrical (as in Namyatova et al., 2016: fig. 8A), ca. 1.6-1.9× as long as head width, ca. $1.0-1.1 \times$ as long as pronotum width; segment II ca. $2.0-2.3 \times$ as long as head width, ca. $1.3-1.4 \times$ as long as pronotum width; segment III subequal to or slightly longer than segment II; segment IV ca. $0.25-0.3 \times$ as long as segment IV. Thorax: Anterior part of pronotum slightly shorter than posterior part; collar delimited; posterior part slightly upraised; posterior margin concave; pronotum ca. $1.1-1.2 \times$ as wide as long and ca. $1.5-1.8 \times$ as wide as head; mesoscutum exposed. Hemelytron: Area along inner margin of corium almost flat; inner margin of cuneus convex (as in Namyatova et al., 2016: fig. 13E), outer margin of cuneus ca. $3 \times$ as long as base. Abdomen: Genital capsule rotated left at right angle relative to rest of abdomen. Genitalia: Genital capsule (fig. 14V) twice as long as wide; ventral wall ca. $1.5 \times$ as long as dorsal wall, its posterior margin smooth, semioval, without outgrowth, rounded, not curved; sides of genital capsule not modified; right paramere socket slightly acute, left paramere socket rounded; distance between paramere sockets subequal to half of genital capsule width at base. Right paramere (fig. 12S) distinctly curved in apical half; apex slightly concave posteriorly; medial part only slighter wider than basal part, bearing setae, with outer margin slightly concave and inner margin convex; outer angle distinct, widened; inner angle rounded, without setae; basal part of paramere ca. $0.15-0.2 \times$ as long as rest of paramere. Left paramere (fig. 12T) L-shaped; apical part not flattened, with toothlike outgrowth on posterior side medially (as in fig.
$11 \mathrm{G})$ and without outgrowth on dorsal surface; middle part widened, without swelling or outgrowth(s); setae only on middle part near outer margin. Aedeagus (general view as in Namyatova et al., 2016: fig. 22I) conjunctiva weakly sclerotized, secondary gonopore placed at base of vesica in repose; sclerotization of ductus seminis around secondary gonopore shorter than wide; vesica with six spicules, including spicules B and E (fig. 8R), spicule B short and widened.

Female. Total length 3.9-4.5. COLORATION (fig. 5): Similar to male, scent gland evaporative area always whitish yellow; abdomen uniformly yellow, often red dorsally, sometimes only apical part of dorsal surface red. SURFACE AND VESTITURE: As in male. STRUCTURE AND MEASUREMENTS: Structure as in male; body ca. $4.2-4.8 \times$ as long as pronotum width; vertex ca. $1.8-2.1 \times$ as wide as eye diameter; antennal segment I ca. $1.6-2.1 \times$ as long as head width, ca. $1.0-1.1 \times$ as long as pronotum width; segment II ca. $2.0-2.3 \times$ as long as head width, ca. $1.2-1.5 \times$ as long as pronotum width; pronotum ca. $1.2 \times$ as wide as long and ca. $1.5-1.8 \times$ as wide as head. Genitalia (as in Namyatova et al., 2016: fig. 23F, G): Dorsal labiate plate wider than distance between apodemes of second valvula; mostly smooth, without distinct striations, with semicircular sclerite and distinct sclerotized rings laterally; lateral oviducts placed almost medially, very close to each other, spermathecal gland placed between lateral oviducts; dorsal labiate plate with distinct tubercles, without membranous lobe medially.

Distribution: Lord Howe Is. (fig. 19).

Host PLANTS: Unknown.

Eтymology: The species is named after Lord Howe Island, where it was collected.

Discussion: Felisacus lordhowensis is similar to F. caledonicus, F. elegantulus, F. schuhi, and F. tanna in pale coloration (figs. 5,6 ). In contrast to F. lordhowensis, F. caledonicus has the labium reaching the middle of the mesosternum, the collar often pale brown to brown laterally (fig. 4), the apical part of the left paramere is broad, twice as long as wide (fig. 11Q) and four vesical spicules, including spicules A and B are present 
(fig. 8F). Felisacus elegantulus differs from $F$. lordhowensis by the labium reaching the posterior margin of the metasternum, the humeral angles of the pronotum are pale brown to dark brown, and the presence of five vesical spicules, including spicule B (fig. 8H). Felisacus schuhi can be separated from $F$. lordhowensis by the inner part of the clavus mostly brown, the labium slightly surpasses the middle of the mesosternum, and the vesica has five spicules, including spicules A, B, and C (fig. 9J). Felisacus tanna is most similar to F. lordhowensis, and differs from it by having five vesical spicules, including spicules A, B, and E. (fig. 9M)

Material examined: Holotype: AUSTRALIA: New South Wales: On SW spur of Mt Lidgebird, Lord Howe Island, $31.56666^{\circ} \mathrm{S}$ $159.08333^{\circ} \mathrm{E}, 122 \mathrm{~m}, 12$ Sep 1975 , Lambkin, $10^{\text {त }}$ (00017833) (AM). Paratypes: AUSTRALIA: New

South Wales: Lord Howe Is., Old Settlement, $31.519^{\circ} \mathrm{S} 159.05083^{\circ} \mathrm{E}, 21 \mathrm{Feb} 1971$, D.K. McAlpine, $2 \sigma^{\text {( }}$ (00017836, 00017837) (AM). Lord Howe Island, $31.552^{\circ} \mathrm{S} 159.081^{\circ} \mathrm{E}$, A.M. Lea, $30^{\circ}$ (00038900), 6 ㅇ (00038900) (SAMA). On SW spur of Mt Lidgebird, Lord Howe Island, $31.56666^{\circ} \mathrm{S} 159.08333^{\circ} \mathrm{E}, 122 \mathrm{~m}, 12$ Sep 1975 , Lambkin, 3 ơ (00017832, 00017834, 00017835), 6 웅 (00017838-00017843) (AM).

\section{Felisacus luzonus, sp. nov.}

Figures 5, 10I, 12U, V, 14X, 16F, 19

Diagnosis: Recognized by the following combination of characters: marking along inner margin of corium brown, narrow, reaching $\mathrm{R}+\mathrm{M}$ posteriorly and not extending toward $\mathrm{R}+\mathrm{M}$ anteriorly; antennal segment I swollen medially (as in Namyatova et al., 2016: fig. 8B), red; transverse depression delimiting occipital region present only dorsally; dorsal surface of labial segment I not elongate posteriorly (as in Namyatova et al., 2016: fig. 6E); labium reaching middle of mesosternum; ventral wall of genital capsule curved apically; genital capsule not swollen from lefthand side (fig. 14X); right paramere with outer and inner angles distinct, without outgrowths (fig. 12U); inner margin of medial part of left paramere with triangular-shaped swelling (fig. $12 \mathrm{~V}$ ); apical half of ductus seminis sclerotized, straight apically (fig. 10I).

Description: Male. Total length 3.8. COLORATION (fig. 5): Head: Dorsal and lateral sides mostly pale brown, anterior and ventral surfaces mostly yellow; dorsal surface posteriorly and marking on frons reddish, buccula pale brown anteriorly, mandibular and maxillary plates yellow; clypeus yellow, with reddish tinge basally and brown apically; eye reddish brown. Labium: Segments I, III, and IV yellow, segment II pale brown. Antenna: Segments I-II reddish brown, segments III-IV brown. Thorax: Pronotum pale brown, brown posteriorly; mesoscutum and scutellum pale brown; thoracic pleura mostly pale brown, mesopleura with brown marking; scent gland evaporative area whitish yellow. Hemelytron: Mostly translucent; clavus opaque, brown; corium colorless, marking along inner margin of corium brown, reaching $\mathrm{R}+\mathrm{M}$ posteriorly and not extending toward $\mathrm{R}+\mathrm{M}$ anteriorly; embolium colorless with brown margins; cuneus with yellow tinge, with outer margin brown and inner margin whitish yellow; membrane with brownish tinge; membrane cell brown. Legs: Coxae whitish yellow, femora whitish basally and yellow apically; tibiae and tarsi yellow, foretibia and tarsus somewhat darker than middle and hind tibiae and tarsi. SURFACE AND VESTITURE: Corium smooth, with shallow and scarce punctation. Dorsum with setae subequal to or longer than antennal segment II diameter; antennal segment I clothed with suberect setae shorter than antennal segment II diameter; forefemur clothed with suberect setae longer than antennal segment II diameter. STRUCTURE AND MEASUREMENTS: Body ca. $4.0 \times$ as long as pronotum width. Head: Depression delimiting occipital region present only dorsally (Namyatova et al., 2016: fig. 6E); distance between depression and pronotum shorter than eye diameter; longitudinal sulcus on dorsal surface of head shorter than eye diameter; distance from eye to pronotum distinctly longer than eye diameter, not swollen 
laterally; vertex ca. $1.5 \times$ as wide as eye, flat (as in Namyatova et al. 2016: fig. 6E). Labium: Reaching middle of mesosternum; segments I and II slightly longer than wide, combined longer than half of segment III; dorsal surface of segment II not elongate posteriorly (as in Namyatova et al., 2016: fig. 6E); segment III shorter than ventral side of head, segment IV ca. $1.5 \times$ as long as segment III. Antenna: Segment I slightly longer than head width, widened medially (as in Namyatova et al., 2016: fig. 8B), ca. $1.4 \times$ as long as head width, ca. $0.8 \times$ as long as pronotum width; segment II ca. $1.7 \times$ as long as head width, ca. $0.9 \times$ as long as pronotum width; segment III slightly longer than segment II; segment IV subequal to half of segment III. Thorax: Anterior part shorter than posterior part; collar delimited; posterior part slightly upraised; posterior margin of pronotum slightly concave; pronotum ca. $1.4 \times$ as wide as long and ca. $1.9 \times$ as wide as head; mesoscutum slightly exposed. Hemelytron: Area along inner margin of corium swollen; inner margin of cuneus straight (Namyatova et al., 2016: fig. 13F), outer margin of cuneus twice as long as base. Genitalia: Genital capsule (fig. 14X) twice as long as wide; ventral wall ca. $1.5 \times$ as long as dorsal wall, with posterior margin acute, apex placed almost medially, slightly curved dorsally, without toothlike outgrowth; left side of genital capsule not widened, margins of paramere sockets distinctly angulate; distance between paramere sockets ca. $0.25 \times$ as long as genital capsule width at base. Right paramere (fig. 12U) distinctly curved; apex concave posteriorly, medial part almost as wide as basal part, without setae, with straight outer margin and curved inner margin bearing triangular outgrowth; outer angle distinct; inner angle distinct, without swellings or outgrowth(s), bearing setae; basal part of paramere slightly shorter than rest of paramere. Left paramere (fig. 12V) irregularly shaped; apical part flattened, with subrectangular outgrowth, removed from apex; middle side widened, with two outgrowths, one of them bearing setae. Aedeagus (general view as in Namyatova et al., 2016: fig. 22M) conjunctiva membranous; vesica without spicules; half of ductus seminis sclerotized apically, secondary gonopore placed near theca mouth in repose; ductus seminis straight apically (fig. 10I).

Female. Total length 4.1. COLORATION: Head: Mostly as in male, abdomen whitish with brown dorsum. SURFACE AND VESTITURE: As in male. STRUCTURE AND MEASUREMENTS: Structure as in male; body ca. $4.1 \times$ as long as pronotum width; vertex ca. $1.4 \times$ as wide as eye; pronotum ca. $1.2 \times$ as wide as long and $1.9 \times$ as wide as head. Genitalia: Dorsal labiate plate very small and transparent, as wide as distance between apodemes of second valvulae, without striations or membranous ridge medially; semicircular sclerite and sclerotized rings absent; lateral oviducts placed in posterior part, removed from each other, spermathecal gland attached near anterior margin (as in fig. 16G); dorsal labiate plate without distinct tubercles, without membranous lobe posteriorly (fig. 16F).

Distribution: Philippines (fig. 19).

Host Plants: Unknown.

REMARKs: Antennal segments and legs except all coxae and middle and hind femora are lost in females. Abdomen of males was dissected before description.

Eтrmology: The species is named after Luzon Island, where the holotype was collected.

Discussion: Felisacus luzonus is similar to $F$. philippinensis externally (cf. fig. 5 with 6 ), but the latter species differs in the markings along the inner margin of the corium where it is short, and does not extend anteriorly nor posteriorly (fig. 6 ), the labium only slightly surpasses the posterior margin of the mesosternum, the genital capsule is broad on the left-hand side (fig. 15G), and the ductus seminis is hooked apically (fig. 10K).

Material examined: Holotype: PHILIPPINES: Luzon: Dalton Pass, Nueva Vizcaya Prov., $16.11722^{\circ} \mathrm{N} 120.96^{\circ} \mathrm{E}, 915 \mathrm{~m}, 09 \mathrm{Apr}$ 1968-10 Apr 1968, D.E. Hardy, $1 \delta^{\star}$ (00017865) (BPBM). Paratype: PHILIPPINES: Luzon: Imugan [Imugin], Nueva Vizcaya [N. Viscaya] Prov., $16.1589^{\circ} \mathrm{N} 120.9036^{\circ} \mathrm{E}, 949 \mathrm{~m}, 1700$, Baker, $1+$ (00017867) (MZH). 

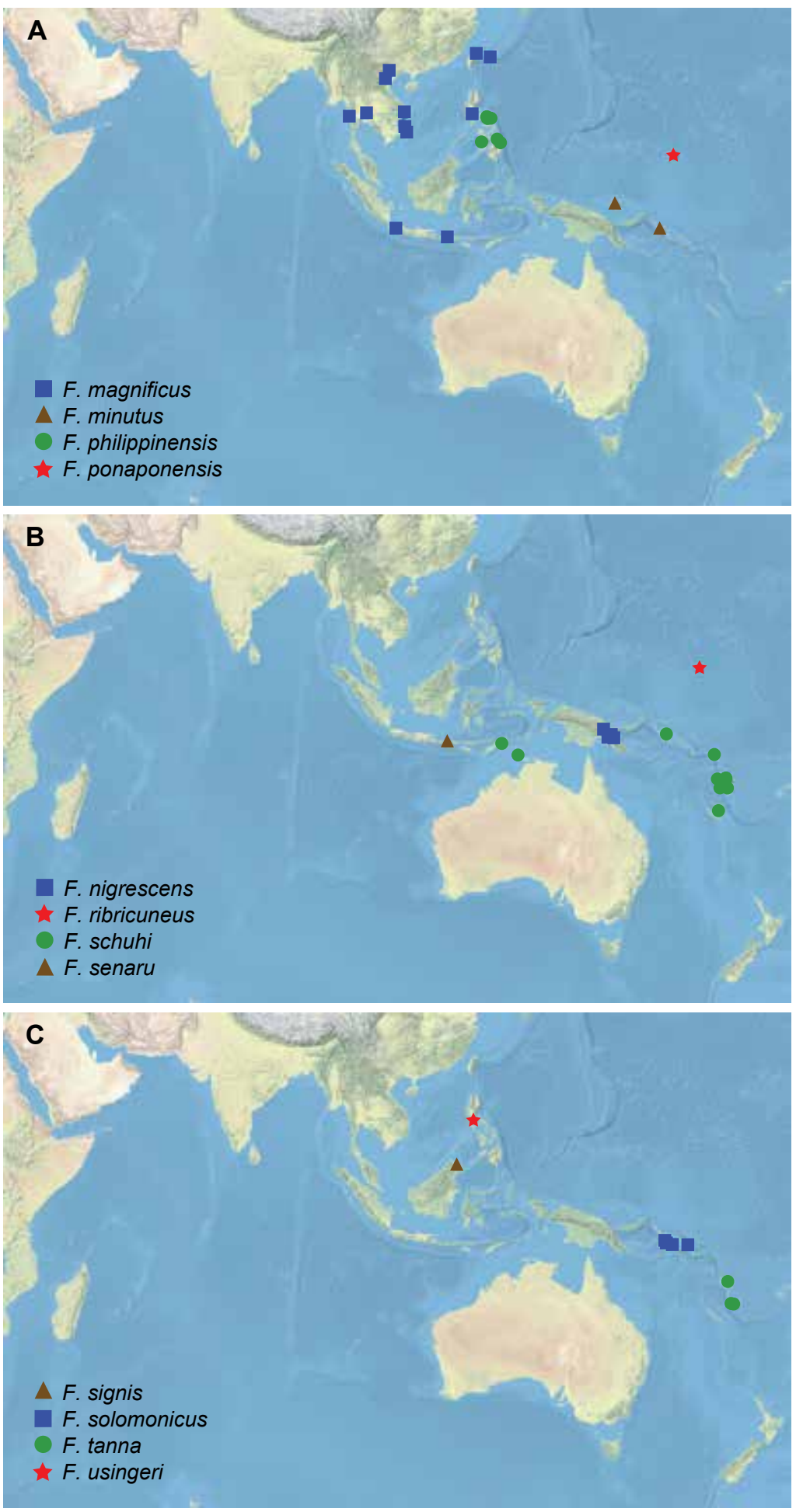

FIGURE 20. Distribution of Felisacus species. 

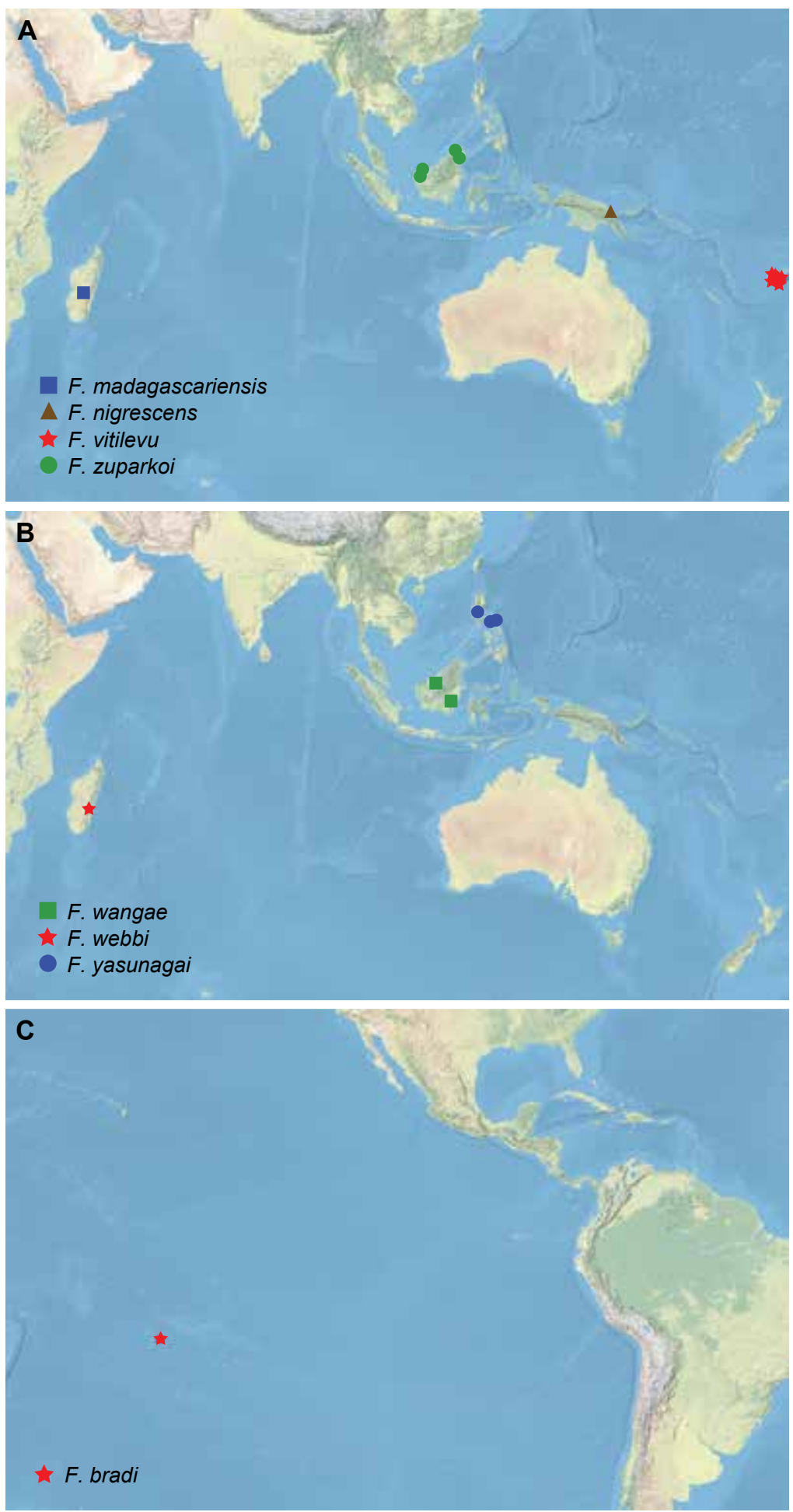

FIGURE 21. Distribution of F. bradi. 


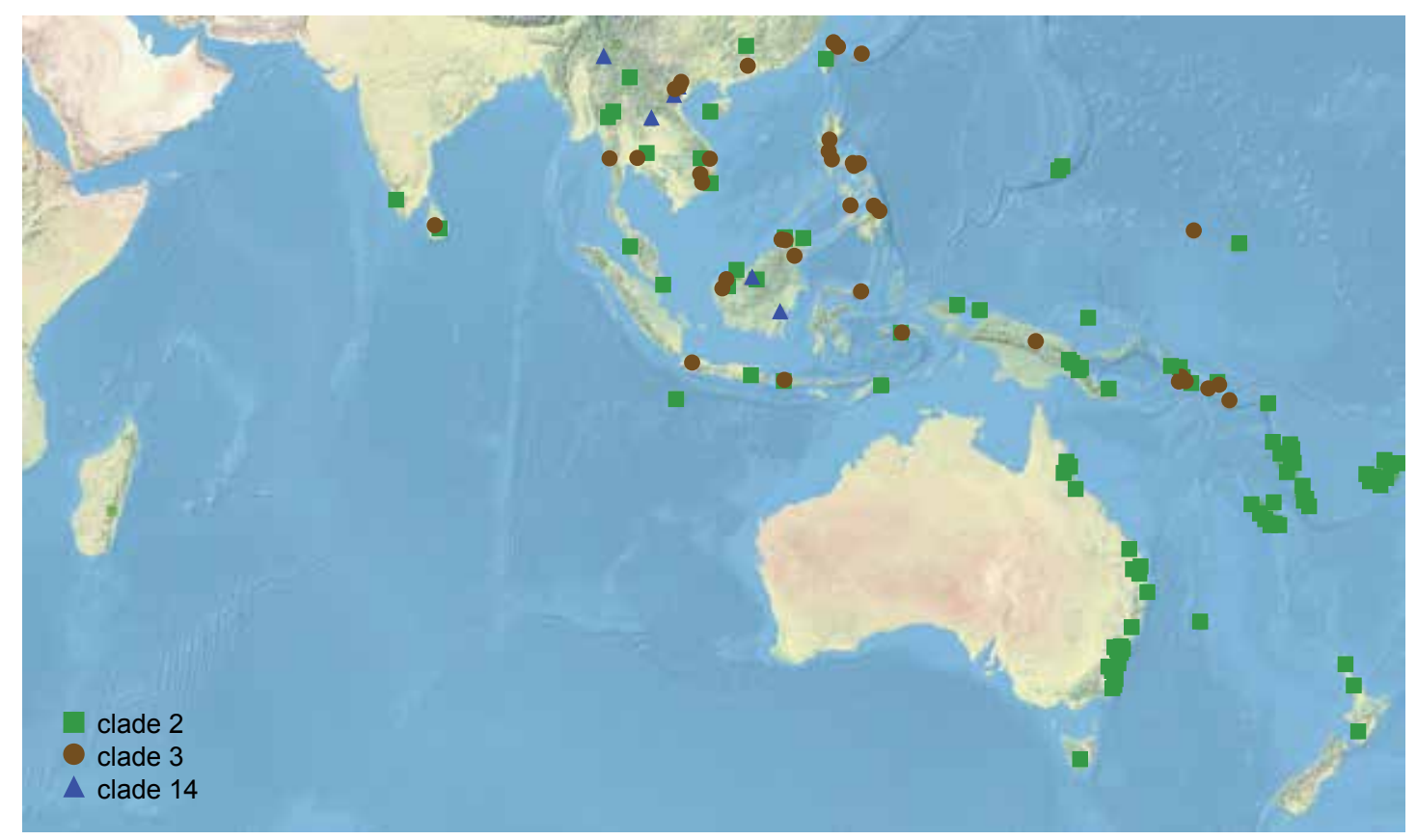

FIGURE 22. Distribution of clades 2, 3, and 14.

\section{Felisacus madagascariensis Poppius}

Figures 5, 21

Felisacus madagascariensis Poppius, 1912: 182 (original description).

Diagnosis: Recognized by the following combination of characters: marking along inner margin of corium yellow, not reaching $\mathrm{R}+\mathrm{M}$ anteriorly and posteriorly (fig. 5); transverse depression delimiting occipital region present only dorsally; antennal segment I cylindrical (as in Namyatova et al., 2016: fig. 8A), ca. $1.7 \times$ as long as head width, reddish brown; pronotum mostly brown to dark brown with yellow longitudinal stripe medially on posterior part; labium reaching posterior margin of mesosternum; dorsal surface of labial segment II elongate posteriorly (as in Namyatova et al., 2016: fig. 6D).

Redescription: Male. Unknown. Female. Total length 4.0. COLORATION (fig. 5): Head: Pale brown dorsally and anteriorly with reddish tinge, lateral and ventral surfaces yellow; longi- tudinal sulcus on dorsal surface of head pale brown; buccula, mandibular and maxillary plates yellow; clypeus pale brown, brown apically; tubercle around antennal fossa yellow with red markings. Eyes white. Labium: Whitish yellow, segment IV slightly darker than other segments. Antenna: Segments I-II reddish brown. Thorax: Anterior part of pronotum brown anteriorly, and yellow with reddish tinge posteriorly, posterior part of pronotum dark brown with yellow longitudinal stripe medially; mesoscutum pale brown, scutellum yellow with anterior angles pale brown; thoracic pleura and scent gland evaporative area yellow. Hemelytron: Mostly opaque; inner part of clavus pale brown with reddish tinge, outer part of clavus whitish yellow, pale brown apically; corium whitish yellow, marking along inner margin of corium yellow, short and narrow, not reaching $\mathrm{R}+\mathrm{M}$; embolium whitish yellow, with reddish margins; cuneus whitish yellow, with reddish outer and posterior margins; membrane translucent, pale brown with pale brown tinge. Legs: Coxa whitish yellow. SURFACE AND VESTITURE: 
Corium smooth, with very shallow punctures. STRUCTURE AND MEASUREMENTS: Body $4.2 \times$ as long as pronotum width. Head: Depression delimiting occipital region present only dorsally; distance from depression to pronotum distinctly shorter than eye diameter; longitudinal sulcus on dorsal surface longer than eye diameter; distance from eye to pronotum slightly longer than eye diameter, not swollen laterally; vertex ca. $2.1 \times$ as wide as eye, upraised (as in Namyatova et al., 2016: fig. 6D). Labium: Reaching posterior margin of mesosternum; segments I and II strongly reduced, combined length subequal to half of segment III; segment I shorter than wide; segment II slightly longer than width, its dorsal surface elongate posteriorly; segment IV ca. $1.5 \times$ as long as segment III. Antenna: Segment I cylindrical (as in Namyatova et al., 2016: fig. 8A), 1.7× as long as head width, $1.0 \times$ as long as pronotum width. Thorax: Anterior part shorter than posterior part; collar not delimited; posterior part slightly upraised; posterior margin concave, pronotum ca. $1.4 \times$ as wide as long and ca. $1.7 \times$ as wide as head; mesoscutum exposed. Hemelytron: Area along inner margin of corium almost flat; inner margin of corium convex (as in Namyatova et al., 2016: fig. $13 \mathrm{E}$ ), outer margin of corium almost ca. $3 \times$ as long as base. Genitalia: Dorsal labiate plate wider than distance between apodemes of second valvulae; with semicircular sclerite and distinct sclerotized rings laterally (similar to Namyatova et al., 2016: fig. 23F); dorsal labiate plate with distinct tubercles (similar to Namyatova et al., 2016: fig. 23G).

Distribution: Madagascar (fig. 21).

Host Plants: Unknown.

Discussion: Antennal segments III-IV, femora, tibiae, and tarsi are lost. The abdomen is in a vial attached to the specimen. Vestiture of the holotype has been lost. Some characters of the female genitalia were not recorded, including striation of the dorsal labiate plate, position of the lateral oviducts, spermathecal gland, and presence of the membranous lobe of the posterior wall.
Poppius (1912) described Felisacus madagascariensis from a single specimen, and he noted that it was a male. We examined the type species, housed in the MZH, which is a female, suggesting that Poppius' recording on the sex of the specimen was incorrect. Felisacus madagascariensis is similar to $F$. vitilevu and F. gressitti in coloration and structure (figs. 5, 7). Felisacus vitilevu can be separated from F. madagascarensis by the labium reaching the posterior margin of the metasternum, the anterior part of the pronotum is yellow, antennal segment $\mathrm{I}$ is mostly pale brown or reddish, ca. $1.3-1.6 \times$ as long as the head width. Felisacus gressitti differs from $F$. madagascariensis in the anterior part of the pronotum is yellow and the labium reaches abdominal segment II.

MATERIAl EXAmined: Holotype: MADAGASCAR: [Madagascar], 1700, A.E. Hildebrand, 19 (00018976) (MZH).

\section{Felisacus magnificus Distant, 1904}

Figures 6, 10J, 12W, X, 14Y, 16A, B, 20

Felisacus magnificus Distant, 1904: 439 (original description).

Felisacus pulchellus Poppius, 1915a: 80 (synonymized by Carvalho, 1981: 62).

Felisacus capitatus Miyamoto, 1965: 164; new synonymy.

Diagnosis: Recognized by the following combination of characters: presence of distinct C-shaped dark brown marking on corium, with anterior and posterior parts reaching $\mathrm{R}+\mathrm{M}$, anterior part not inclined posteriorly (fig. 6); antennal segment I widened (as in Namyatova and Cassis, in press: fig. 8B), red; antennal segment II often brown; dorsal surface of head flat (as in Namyatova et al., 2016: fig. 6E), vertex flat; labium reaching posterior margin of mesosternum; apex of cuneus red; femora often with brown or red markings in apical half; ventral wall of genital capsule with tooth posteriorly (fig. $14 \mathrm{Y})$; right paramere straight, its inner angle with slightly curved outgrowth (fig. 12W); apical 
part of left paramere widened, with tooth apically and without outgrowth on dorsal surface; medial part of left paramere with narrow outgrowth (fig. 12X); apical half of ductus seminis sclerotized, hooked apically; vesica without sclerites (fig. 10J).

Redescription: Male. Total length 3.4-4.0. COLORATION (fig. 6): Head: Mostly yellow to pale brown, sometimes with reddish markings; buccula and apex of clypeus often brown. Eye dark brown with reddish tinge, sometimes uniformly red. Labium: Segment I-II brown, segments III yellow to pale brown, rarely brown, segment IV yellow. Antenna: Segment I red, reddish brown or brown, segment II brown, often yellow at base, rarely yellow and brown apically, segments III-IV pale brown to brown, often darker than segment II, sometimes segment IV somewhat paler than segment III. Thorax: Anterior part of pronotum yellow to pale brown, brown near forecoxae, posterior part of pronotum uniformly brown to dark brown; scutellum and mesoscutum brown to dark brown; thoracic pleura mostly brown to dark brown, metapleuron often whitish yellow posteriorly, scent gland evaporative area whitish yellow. Hemelytron: Mostly translucent; clavus opaque, uniformly brown to dark brown; corium, embolium, and cuneus translucent; corium with yellow tinge, with brown anterior angles and C-shaped dark brown marking, anterior part of this marking reaching $\mathrm{R}+\mathrm{M}$, posterior part reaching costal margin; embolium colorless, with dark brown apex and sometimes pale brown to dark brown marking medially, margins of embolium yellow to pale brown, outer margin sometimes somewhat darker than inner margin; cuneus colorless with red apex, yellow outer margin and colorless inner margin; membrane gradually changing color from pale brown to brown anteriorly and yellow posteriorly, membrane cell pale brown to brown. Legs: Coxae whitish yellow to yellow; femora yellow, often whitish yellow basally, often hind femur and rarely fore- and middle femora with pale brown to brown or reddish apex and marking on apical part, sometimes that marking very pale; tibiae often yellow basally and whitish yellow apically, sometimes pale brown, brown, or reddish basally and yellow apically, rarely uniformly yellow; foretarsus whitish or yellow, middle and hind tarsi yellow. Abdomen: Yellow with brown segment IX and dorsum, sometimes reddish apically. SURFACE AND VESTITURE: Corium smooth, with shallow punctation. Dorsum clothed with setae longer than antennal segment II diameter; antennal segment I clothed with suberect setae shorter than antennal segment II diameter; femora clothed with suberect setae subequal to or longer than antennal segment II diameter; abdomen clothed with suberect setae of different length. STRUCTURE AND MEASUREMENTS: Body ca. 3.9-4.2 $\times$ as long as pronotum width. Head: Transverse depression delimiting occipital region present only dorsally; distance between depression and pronotum slightly longer than eye diameter; longitudinal sulcus on dorsal surface of head shorter than eye diameter; eye diameter distinctly shorter than distance from head to pronotum; vertex ca. 1.9-2.3 $\times$ as wide as eye, flat (Namyatova et al., 2016: fig. 6E). Labium: Reaching posterior margin of mesosternum or slightly surpassing it; segments I and II as long as wide, combined ca. $1.5 \times$ as long as segment III; dorsal surface of segment II not elongate posteriorly (as in Namyatova et al., 2016: fig. 6E); segment III shorter than ventral side of head; segment IV subequal to half of segment III. Antenna: Segment I widened medially (as in Namyatova et al., 2016: fig. 8 B), ca. $1.1-1.2 \times$ as long as head width, ca. $0.6-0.7 \times$ as long as pronotum width; segment II ca. 1.4-1.6× as long as head width, ca. $0.7-0.8 \times$ as long as pronotum width; segment III slightly longer than segment II and ca. twice as long as segment IV. Thorax: Anterior part of pronotum distinctly shorter than posterior part; collar distinct; posterior part slightly upraised; posterior margin of pronotum usually straight, sometimes slightly concave; pronotum ca. $1.2-1.4 \times$ as wide as long and ca. $1.8-2.9 \times$ as wide as head; mesoscutum usually slightly exposed, sometimes not exposed. Hemelytron: 
Area along inner margin of corium; inner margin of cuneus straight (as in Namyatova et al., 2016: fig. 13F), outer margin of cuneus twice as long as base. Abdomen: Genital capsule rotated $45^{\circ}$. Genitalia: Genital capsule (fig. 14Y) twice as long as wide; ventral wall ca. $1.5 \times$ as long as dorsal wall, with posterior margin of ventral wall nor curved, with toothlike outgrowth; right side of genital capsule folded, left side of genital capsule not widened; paramere sockets angulate; distance between paramere sockets ca. $0.3 \times$ as long as genital capsule width at base. Right paramere (fig. 12W) almost straight; apex slightly concave; medial part narrower than basal part, without setae, outer margin convex and inner margin concave, without swelling; outer angle absent; inner angle distinct with curved outgrowth, bearing setae; basal part ca. $0.7 \times$ as long as rest of paramere. Left paramere (fig. 12X) distinctly curved medially; apical part flattened, with toothlike outgrowth apically, posterior surface without other outgrowth; middle part widened dorsally, with narrow outgrowth at inner side, bearing setae. Aedeagus (general view as in Namyatova et al.: fig. 22M) conjunctiva membranous; vesica without spicules; apical half of ductus seminis sclerotized, secondary gonopore placed near phallotheca mouth in repose; ductus seminis hooked apically (fig. 10J).

Female. Total length 3.6-4.0. COLORATION, SURFACE, AND VESTITURE (fig. 6): As in male. STRUCTURE AND MEASUREMENTS: Structure as in male; body ca. $4.0-4.2 \times$ as long as pronotum width; vertex ca. $1.9-2.1 \times$ as wide as eye; antennal segment I ca. $1.1-1.2 \times$ as long as head width, ca. $0.6 \times$ as long as pronotum width; segment II ca. $1.5-1.7 \times$ as long as head width, ca. $0.8-0.9 \times$ as long as pronotum width; pronotum ca. $1.2-1.4 \times$ as wide as long and ca. $1.9-2.1 \times$ as wide as head. Genitalia (figs. 16A, B): Dorsal labiate plate very small and transparent, as wide as distance with apodemes of second valvulae, without striations or membranous ridge medially; semicircular sclerite and sclerotized rings absent; lateral oviducts placed in anterior part; spermathecal gland attached near anterior mar- gin; dorsal labiate plate without distinct tubercles, without membranous lobe posteriorly.

Distribution: Japan, Java, Taiwan, Vietnam, (fig. 20).

Host PLANTS: Some specimens from Lombok Is. were collected from Plesioneuron sp. (Thelypteridaceae) and Diplazium esculentum (Woodsiaceae).

Discussion: Distant (1904) described F. magnificus from Burma. Poppius (1915a) described F. pulchellus from the Philippines, noting that it differs from F. magnificus by its different coloration, antennal structure, and smooth basal part of the pronotum. Poppius (1915b) described F. longiceps from Taiwan and compared it with F. pulchellus. According to him, F. longiceps differs from the latter by the longer head and antennal segments, and different leg coloration. Carvalho (1981) synonymized Felisacus pulchellus with F. magnificus.

We examined the holotypes of $F$. longiceps (female), and F. pulchellus (female) and lectotype of F. magnificus (sex unknown) and regard them as very similar to each other. As all the types are females or had lost genitalia, it is problematic to determine which specimens belong to these three species. We also examined many specimens similar to these species from Southeast Asia. We were able to split the specimens into three species, based on male genitalia. They also slightly differ in coloration. The larger specimens with the dark brown to black antennal segment II and bands on the hind femora most likely belong to F. magnificus, and are very similar to the type specimen, preserved in $\mathrm{BMNH}$, and to the type of its synonym $F$. pulchellus, preserved in the HNHM. The rest of the specimens with yellow antennal segment II and the femora without banding represent two species, with one of them having an identical vesica compared with $F$. magnificus, and the other species has a unique claw-shaped spicule, which has not been previously found in any Felisacus species. Felisacus longiceps is without claw-shaped spicules and is also broadly distributed in Southeast Asia. Specimens with 
claw-shaped spicules were collected from the Philippines and Borneo only. We regard the Taiwanese specimens as conspecific and we treat the species with a yellow antennal segment II and without bands on hind femora as F. longiceps, and the species with similar color pattern but with claw-shaped spicule as the new species F. zuparkoi (see below).

Felisacus longiceps is also very similar to F. capitatus externally and the male genitalia are depicted by Miyamoto (1965: figs. 39-41), and they are likely conspecific. According to this author, the types were preserved in the Entomological Laboratory, Kyushu University, but we could not get any information on them from this university. Although, according to Miyamoto's (1965) description of $F$. capitatus, antennal segment II is yellow, we consider this difference as minor and synonymize F. capitatus with F. magnificus.

Based on the structure of the parameres as depicted in Carvalho (1981), the specimens he examined for the description of F. magnificus are most likely $F$. longiceps. However, the external view of this species is most similar to F. magnificus. It is also possible that Carvalho had representatives of both species in his series, as those species can be collected together (see Material Examined sections) The identification of $F$. magnificus in Woodward (1954) is correct.

Felisacus magnificus is also similar to F. ceylonicus and F. lindbergae, and comparisons are provided in the discussion sections for those two species.

MATERIAL EXAMINed: Lectotype (Felisacus magnificus): MYANMAR: Myitta, Tenasserim Valley, $14.1667^{\circ} \mathrm{N} 98.5167^{\circ} \mathrm{E}, 183 \mathrm{~m}$, Doherty, Lectotype, 1 sex unknown (BMNH). Holotype (F. pulchellus): Laguna: Los Banos, 1700, Baker, 1 (00018445) (MZH). Additional material: INDONESIA: Java: Bogor, $6.58916^{\circ} \mathrm{S}$ $106.79305^{\circ} \mathrm{E}, 240 \mathrm{~m}, 23$ Apr 1955, J. v. d. Vecht, 2 o $(00018971,00018968), 1$ sex unknown (00018970), 1 웅 (00018969) (NML).West Nusa Tenggara: Lombok Island, Senaru, Panorama track to Sendang Gila Waterfall, $8.30111^{\circ} \mathrm{S}$ $116.40833^{\circ} \mathrm{E}, 30$ Aug 2012, F. Konstantinov,
Diplazium esculentum Swartz (Woodsiaceae), det. Michael Lovave (LAE herbarium, PNG), $10^{\Uparrow}$ (00386604) (ZISP). Lombok Island, Senaru, track to Tiu Kelep Waterfall, $8.30111^{\circ} \mathrm{S}$ $116.40833^{\circ} \mathrm{E}, 31 \mathrm{Aug} 2012$, F. Konstantinov, Plesioneuron sp. (Thelypteridaceae), det. Michael Lovave (LAE herbarium, PNG), 3 o (0038663600386638) (ZISP). Lombok Island, nr Senaru, $8.31956^{\circ} \mathrm{S} 116.405^{\circ} \mathrm{E}, 31$ Aug 2012, F. Konstantinov, Diplazium esculentum Swartz (Woodsiaceae), det. Michael Lovave (LAE herbarium, PNG), 3 o (00386623, 00386624, 00386622), 2 sex unknown (00386625, 00271349) (ZISP). JAPAN: Okinawa: Ishigaki Is., Ryukyu Islands, $24.4^{\circ} \mathrm{N} 124.2^{\circ} \mathrm{E}, 13$ Oct 1999 , Belokobylskij, $10^{\star}$ (00271512) (ZISP); 14 Oct 1999, Belokobylskij, 10 (00271511) (ZISP); 20 Oct 1999, Belokobylskij, 1 tै (00271510) (ZISP); 21 Oct 1999, Belokobylskij, $1 \delta^{\Uparrow}$ (00271513), 19 (00271506) (ZISP). TAIWAN: Pihu, $49 \mathrm{~km}$ E of Taipei on Hwy 9 to Yilan, $24.79194^{\circ} \mathrm{N} 121.78166^{\circ} \mathrm{E}, 380$ m, 18 Feb 1972, T.C. Maa, $30^{\star}$ (00043195, 00043197, 00043198), 7 우 (00043199-00043202, 00043204-00043206) (BPBM). Wulai nr Taipei, 400 m, 12 Apr 1960, T.C. Maa, 1 đ (00043196) (BPBM). THAILAND: Nakhon Nayok:Sarika Waterfall, $14.30489^{\circ} \mathrm{N} 101.25506^{\circ} \mathrm{E}, 17$ Jun 2009-18 Jun 2009, T. Yasunaga, 500 (0002159400021598), 1 우 (00021599) (TYCN). VIETNAM: Dak Lak: Buon Ma Thuot [BanMeThuot], $12.6733^{\circ} \mathrm{N} 108.04459^{\circ} \mathrm{E}, 500 \mathrm{~m}, 20 \mathrm{Dec} 1960-24$ Dec 1960, C.M. Yoshimoto, 10 (00043193) (BPBM). Gia Lai: 20 km N Kan Nak [ZalayKontum Prov., Buon-Luoi Dist., 20 km N Kannack], $14.18252^{\circ} \mathrm{N} 108.58748^{\circ} \mathrm{E}, 20$ Oct 1988 , Sharkov, 19 (00271526) (ZISP). Hòa Bình: Hoa Binh: Near Mai Chau [Mai Chon, Mai Chou], $20.667^{\circ} \mathrm{N} 105.084^{\circ} \mathrm{E}, 31$ Oct 1990 , Belokobylskij, 40 (00271522-00271525) (ZISP). Lam Dong: Fyan [Ngoc Son], $11.88333^{\circ} \mathrm{N}$ 108.2 $2^{\circ}$ E, $1200 \mathrm{~m}, 11 \mathrm{Jul}$ 1961-09 Aug 1961, N.R. Spencer, 10 (00043194) (BPBM). Vinh Phuc: Tam Dao, $100 \mathrm{~km}$ NW Ha Noi [Hanoi], $21.47607^{\circ} \mathrm{N} 105.56339^{\circ} \mathrm{E}, 1000 \mathrm{~m}, 16$ Feb 1990 , Belokobylskij, 4 우 (00045813, 00045812, 00045811, 00045810), 6 § (00045814, 00045812, 
00045810) (ZISP); 12 Nov 1990, Belokobylskij, 1 ㅇ (00045815), 1 우 (00045815) (ZISP); $14 \mathrm{Nov}$ 1990, Belokobylskij, 11 đิ (00038596-00038598, 00386602, 00386601, 00038599), 6 ㅇ (00038597, 00038598, 00386602, 00038599) (ZISP).

\section{Felisacus malayensis, sp. nov.}

Figures 6, 9A, 12Y, Z, 15A, 19

Diagnosis: Recognized by the following combination of characters: head and pronotum mostly yellow to pale brown with posterior part of pronotum mostly brown, cuneus red; marking along inner margin of corium brown, not reaching $\mathrm{R}+\mathrm{M}$ anteriorly; cylindrical antennal segment I (as in Namyatova et al., 2016: fig. 8A), transverse depression on head extending laterally, vertex upraised (as in Namyatova et al., 2016: fig. 6D), body length in male 3.2-3.7, in female 3.8; labium reaching posterior margin of metasternum or slightly surpassing it; cuneus ca. $3 \times$ as long as base; medial part of right paramere only slightly wider than basal part, shorter than basal and apical parts combined (fig. 12Y); vesica with five spicules, including spicules $A, B$, and C (fig. 9A).

Description: Male. Total length 3.2-3.7. COLORATION (fig. 6): Head: Mainly pale brown, anterior part of head and frons with reddish tinge. Eye dark brown, reddish at sides. Labium: Uniformly yellow. Antenna: Segment I yellow, darker apically; segment II pale brown, brown apically; segments III-IV brown to dark brown. Thorax: Anterior part of pronotum pale brown with collar brown; posterior part of pronotum mostly brown, pale brown anteriorly; mesoscutum and scutellum pale brown, scutellum brown apically; thoracic pleura brown; scent gland evaporative area yellow, pale brown apically. Hemelytron: Mostly translucent; inner part of clavus opaque, pale brown; outer part of clavus colorless, yellow to pale brown apically; corium colorless, whitish with marking along inner margin of corium brown; embolium mostly colorless, with yellow apical part and reddish apex, margins pale brown; cuneus sometimes opaque, red; membrane colorless with pale brown cell. Legs: Mostly yellow, with tarsal segments II and III often yellow to pale brown. Abdomen: Whitish yellow to yellow with brown dorsal surface and segment IX. SURFACE AND VESTITURE: Corium smooth, with shallow and scarce punctures. Dorsum with suberect setae subequal to or shorter than antennal segment II diameter; antennal segment I and femora with suberect setae shorter than antennal segment II diameter; abdomen clothed with suberect, mostly short simple setae. STRUCTURE AND MEASUREMENTS: Body 4.0-4.4× as long as pronotum width. Head: Depression delimiting occipital region present dorsally and laterally (as in Namyatova et al., 2016: fig. 4E); distance between depression and pronotum distinctly shorter than eye diameter; longitudinal sulcus on dorsal surface longer than eye diameter distance from eye to pronotum eye slightly longer than eye diameter, not swollen laterally (as in Namyatova et al., 2016: fig. $4 \mathrm{E}$ ); vertex ca. $1.6-1.9 \times$ as wide as eye; upraised (as in Namyatova et al., 2016: fig. 6D); buccula ca. $0.2-0.25 \times$ as long as clypeus. Labium: Reaching posterior margin of mesosternum or slightly surpassing it; segments I and II strongly reduced, combined shorter than half of segment III; segment I shorter than wide (as in Namyatova et al., 2016: figs. 6D, 9C); segment II longer than wide, its dorsal surface elongate posteriorly; segment III slightly longer than ventral side of head; segment IV ca. $1.5 \times$ as long as segment III. Antenna: Segment I cylindrical (as in Namyatova et al., 2016: fig. 8A), ca. 1.6$1.7 \times$ as long as head width, ca. $1.1 \times$ as long as pronotum width; segment II ca. $1.8-2.0 \times$ as long as head width, ca. $1.2-1.3 \times$ as long as pronotum width; segment III slightly longer than segment II; segment IV ca. $0.4-0.5 \times$ as long as segment IV. Thorax: Anterior part of pronotum slightly shorter than posterior part; collar delimited; posterior part slightly upraised; posterior margin of pronotum slightly concave; pronotum ca. 1.2$1.3 \times$ as wide as long and ca. $1.5 \times$ as wide as head; mesoscutum exposed. Hemelytron: Area along inner margin of corium almost flat; inner margin 
of cuneus convex (as in Namyatova et al., 2016: fig. $13 \mathrm{E}$ ), outer margin ca. $3 \times$ as long as base. Abdomen: Genital capsule rotated at right angle relative to rest of abdomen. Genitalia: Genital capsule (fig. 15A) twice as long as wide; ventral wall ca. $1.5 \times$ as long as dorsal wall, its posterior margin smooth, semioval, without outgrowth(s), not curved dorsally; its apex inclined rightward; sides of genital capsule not modified; margins of paramere sockets more or less rounded; distance between paramere sockets ca. $0.7 \times$ as long as genital capsule base. Right paramere (fig. 12Y) distinctly curved in apical half; apex slightly concave; medial part slightly wider than basal part, bearing setae, with outer margin concave and inner margin widened; outer angle distinct, widened; inner angle rounded, without setae; basal part of paramere ca. $0.15-0.2 \times$ as long as rest of paramere. Left paramere (fig. 12Z) L-shaped; apical part flattened, with tooth on posterior side medially and without outgrowth on dorsal surface; middle part widened, without swelling or outgrowth; setae only on middle part near outer margin. Aedeagus (general view as in Namyatova et al., 2016: fig. 22I) conjunctiva weakly sclerotized, secondary gonopore placed at base of vesica in repose; sclerotization of ductus seminis around secondary gonopore shorter than wide; vesica with five spicules, including spicules $A, B$, and C (fig. 9A).

Female. Total length 3.8. COLORATION (fig. 6): Mostly pale brown, dorsal surface, frons, and areas below antennal fossa with reddish tinge, antennal segment I with reddish tinge, antennal segment II brown to dark brown, inner part of clavus yellow. Thorax and legs: As in male. Hemelytron: Similar to male, but outer part of clavus pale brown, brown apically; cuneus red with brown outer margin and paler outer part; membrane with pale brown tinge, membrane cell brown. Abdomen: Yellow with segments VIII-IX and dorsal surface red. SURFACE AND VESTITURE: As in male. STRUCTURE AND MEASUREMENTS: Structure as in male; body ca. $4.0 \times$ as long as pronotum width; vertex ca. $2.2 \times$ as wide as eye; antennal segment
I ca. $1.4 \times$ as long as head width, ca. $0.9 \times$ as long as pronotum width; segment II ca. $1.9 \times$ as long as head width, ca. $1.2 \times$ as long as pronotum width; pronotum ca. $1.3 \times$ as wide as long and ca. $1.6 \times$ as wide as head. Genitalia (as in Namyatova et al., 2016: fig. 23F, G): Dorsal labiate plate wider than distance between apodemes of second valvula; mostly smooth, without distinct striations, with semicircular sclerite and distinct sclerotized rings laterally; lateral oviducts placed almost medially, very close to each other, spermathecal gland placed between lateral oviducts; dorsal labiate plate with distinct tubercles, without membranous lobe medially. Antennae are lost in females.

Distribution: Malaya (Penang) (fig. 19).

Host PLANTS: Unknown.

Eтymology: The species is named after the Malaya Peninsula, where it was collected.

Discussion: Felisacus malayensis is similar to F. bau, F. bellus, and F. jacobsoni in coloration (cf. figs. 4, 5, 6) and shape of the right paramere having a long apical process (cf. fig. $12 \mathrm{Y}$ with figs. $11 \mathrm{H}, \mathrm{J}, 12 \mathrm{E}$ ). Felisacus jacobsoni differs from F. malayensis in the larger size, the body length is $4.4-4.7 \mathrm{~mm}$ in males and $4.6-4.8 \mathrm{~mm}$ in females, and in the shape and configuration of the spicules (fig. 8M). Felisacus bellus can be separated from $F$. malayensis in the presence of six vesical spicules, including spicules $A, B$, and G (fig. 8E). Felisacus. bau differs from F. malayensis in the cuneus twice as long as its base and the presence of six vesical spicules, including spicules $A$ and $C$ (fig. 8D).

Material eXAmined: MALAYSIA: Pulau Pinang [Penang], $5.26553^{\circ} \mathrm{N} 100.48428^{\circ} \mathrm{E}, 12$ Jan 1959-14 Jan 1959, L.W. Quate, $2 \delta^{\top}$ (00017857, 00017858), 1 (

\section{Felisacus meilingae, sp. nov.}

Figures 6, 9B, 12AA, AB, 15B, 19

Diagnosis: Recognized by the following combination of characters: dorsal surface of head and pronotum mostly yellow, lateral margins of collar not dark; inner part of clavus often pale 
brown to brown, sometimes yellow with brown margins; posterior margin of pronotum with brown marking laterally; cuneus mostly translucent, colorless (fig. 6); cylindrical antennal segment I (as in Namyatova et al., 2016: fig. 8A), transverse depression on head extending laterally, vertex upraised, labium reaching middle of mesosternum or slightly surpassing it; antennal segment I ca. $1.5-1.7 \times$ as long as wide; labium reaching middle of mesosternum; cuneus ca. $3 \times$ as long as base; medial part of right paramere slightly wider than basal part, shorter than basal and apical parts combined (fig. 12AA); apical part of left paramere not widened, ca. $3 \times$ as long as wide (fig. 12AB); vesica with six spicules, including spicules A, C, D, G, and I (fig. 9B).

Description: Male. Total length 4.0-4.5. COLORATION (fig. 6): Head: Whitish yellow to yellow, dorsal surface often somewhat darker than other sides; head sometimes with stripe above eye and marking between eyes reddish and clypeus with darker apex. Eye dark brown to black, often with reddish tinge. Labium: Yellow, segment III often brown or reddish ventrally. Antenna: Segment I yellow to brown with paler base, segment II pale brown to brown, usually darker than segment I, segments III-IV brown to dark brown. Thorax: Pronotum mostly yellow, with anterior margin pale brown or brown and posterior margin with pair brown to dark brown marking near humeral angle, sometimes pale brown between markings; scutellum and mesoscutum whitish yellow to pale brown, scutellum with brown apex; thoracic pleura yellow to pale brown, scent gland evaporative area whitish yellow to yellow, often darker apically, paler than thoracic pleura. Hemelytron: Mostly colorless and translucent; inner part of clavus yellow to brown with small markings and margins pale brown to brown; outer part of clavus sometimes with pale brown to brown apex; corium with marking long, inner margin of corium yellow to dark brown, often paler medially; embolium sometimes yellow with brownish margins; cuneus with brown outer and posterior margins and whitish inner margin; membrane with yellowish to pale brown cell, rarely cell colorless. Legs: Coxae whitish or yellow, femora whitish yellow to yellow basally and darker, yellow to pale brown or reddish apically; tibia yellow to pale brown, often paler apically, sometimes with reddish tinge; tarsi pale brown to brown, sometimes segment I yellow and segments II-III pale brown or brown. Abdomen: Whitish yellow to yellow, often with dorsal surface pale brown, brown, or red. SURFACE AND VESTITURE: Corium smooth, with shallow and scarce punctures. Dorsum, antennal segment I and femora with setae subequal to or slightly longer than antennal segment II diameter; abdomen clothed with short erect setae, distinctly mostly shorter than antennal segment II diameter. STRUCTURE AND MEASUREMENTS: Body ca. $4.2-4.4 \times$ as long as pronotum width. Head: Depression delimiting occipital region distinct dorsally and laterally (as in Namyatova et al., 2016: fig. 4E); distance between depression and pronotum distinctly shorter than eye diameter; longitudinal sulcus on dorsal surface of head longer than eye diameter; distance from eye to pronotum longer than eye diameter, not swollen laterally (as in Namyatova et al., 2016: fig. 4E); vertex ca. 1.6-2.0× as wide as eye, upraised (as in Namyatova et al., 2016: fig. 6D). Labium (as in Namyatova et al., 2016: figs. 6D, 9C): Reaching middle of mesosternum; segments I and II strongly reduced, combined shorter than half of segment III; segment I shorter than wide; segment II as long as wide, its dorsal surface elongate posteriorly; segment III longer than ventral side of head; segment IV ca. $1.5 \times$ as long as segment III. Antenna: Segment I cylindrical (as in Namyatova et al., 2016: fig. 8A), ca. 1.5$1.7 \times$ as long as head width, ca. $0.9-1.2 \times$ as long as pronotum width; segment II ca. $1.6-2.5 \times$ as long as head width, ca. $1.1-1.5 \times$ as long as pronotum width; segment III slightly longer than segment II; segment IV ca. $0.3 \times$ as long as segment III. Thorax: Anterior and posterior parts of pronotum subequal in length, collar delimited; posterior part slightly upraised; posterior margin of pronotum concave, pronotum ca. $1.1-1.4 \times$ as wide as long and ca. $1.4-1.8 \times$ as wide as head; 
mesoscutum exposed. Hemelytron: Area along inner margin of corium almost flat; inner margin of cuneus convex (as in Namyatova et al., 2016: fig. 13E), outer margin of cuneus ca. $3 \times$ as long as base. Abdomen: Genital capsule rotated leftward at right angle relative to rest of abdomen. Genitalia: Genital capsule (fig. 15B) ca. $1.5 \times$ as long as wide; ventral wall ca. $1.5 \times$ as long as dorsal wall, with posterior margin of ventral wall semioval, smooth, without outgrowth(s), its apex inclined to left-hand side, not curved; left side of genital capsule not widened; right paramere socket slightly acute, left one rounded; distance between paramere sockets subequal to half of genital capsule width at base. Right paramere (fig. 12AA) distinctly curved in apical half; apex slightly concave; medial part slightly wider than basal part, bearing setae, with outer margin slightly concave and inner margin convex; outer angle distinct; inner angle indistinct, not bearing setae; basal part of paramere ca. $0.15-0.2 \times$ as long as rest of paramere. Left paramere (fig. $12 \mathrm{AB}) \mathrm{L}$-shaped; apical part not flattened, with tooth on posterior side medially (as in fig. 11G) and without outgrowth on dorsal surface; middle part widened, without swelling or outgrowth; setae only on middle part near outer margin. Aedeagus (general view as in Namyatova et al., 2016: fig. 22I) conjunctiva weakly sclerotized; secondary gonopore placed at base of vesica in repose; sclerotization of ductus seminis around secondary gonopore shorter than wide; vesica with six spicules, including spicules A, C, D, G, I (fig. 9B).

Female. Total length 4.2-4.6. COLORATION (fig. 6): Head: Similar to male, but coloration varying from whitish yellow to pale brown. Labium: As in male. Antenna: Segments I-II often as in males, but rarely reddish. Thorax: Similar to male, but posterior part of pronotum, mesoscutum, and scutellum sometimes with reddish tinge; thoracic pleura yellow to pale brown. Hemelytron: Similar to male, but inner part of clavus sometimes uniformly brown. Legs: As in male. Abdomen: Yellow to pale brown with reddish dorsal surface. SURFACE AND VESTITURE: As in male. STRUCTURE AND MEASUREMENTS: Structure as in male; body ca. $4.2-4.4 \times$ as long as pronotum width; vertex ca. $1.6-2.0 \times$ as wide as eye; antennal segment I ca. $1.4-1.7 \times$ as long as head width, ca. $0.8-1.1 \times$ as long as pronotum width; segment II ca. $1.8-2.1 \times$ as long as head width, ca. $1.1-1.3 \times$ as long as pronotum width; pronotum ca. $1.2-1.3 \times$ as wide as long and ca. $1.5-1.7 \times$ as wide as head. Genitalia (as in Namyatova et al., 2016: fig. 23F, G): Dorsal labiate plate wider than distance between apodemes of second valvula; mostly smooth, without distinct striations, with semicircular sclerite and distinct sclerotized rings laterally; lateral oviducts placed almost medially, very close to each other, spermathecal gland placed between lateral oviducts; dorsal labiate plate with distinct tubercles, without membranous lobe medially.

Distribution: Vanuatu (Ambrym Is., Pentecost Is., Shepherd Is., and Maewo Is.) (fig. 19).

Host PLANTS: Unknown.

Eтyмology: This species is named after MeiLing Chan (National Museum of Natural Sciences, Taichung, Taiwan), who loaned us the paratype of Felisacus bellus Lin, 2000.

Discussion: Felisacus meilingae is similar to F. schuhi in coloration and structure (fig. 6), but the latter species can be separated by the pronotum uniformly yellow to pale brown and the presence of five vesical spicules (fig. 9J).

Felisacus meilingae is also similar to F. myersi in external morphology (fig. 6) and the shape of vesical spicules (cf. fig. 9B with 9C); F. myersi differs from it by the dorsal surface of the head brown to dark brown, the inner part of the clavus mostly colorless or yellow and it has four vesical spicules.

Material eXAmined: Holotype: VANUATU: Malampa: Ambrym Is.: Ranon to Mount Toyo, $16.15949^{\circ} \mathrm{S} 168.13365^{\circ} \mathrm{E}, 400 \mathrm{~m}, 02$ Sep 1979, W.C. Gagne, 1 o (00043085) (BPBM). Paratypes: VANUATU: Malampa: Ambrym Is.: Ambrym Is., $16.24546^{\circ} \mathrm{S} 168.12298^{\circ} \mathrm{E}$, Dec 1984 , N.L.H. Krauss, $1 \delta^{\text {T }}$ (00043095) (BPBM). Ranon to Mount Toyo, $16.15949^{\circ} \mathrm{S} 168.13365^{\circ} \mathrm{E}, 400 \mathrm{~m}, 02$ Sep 1979, W.C. Gagne, 50 (00043084, 0004308611H, J, 00043089), $1+$ (00043090), 1 
sex unknown (00043091) (BPBM). S Ambrym [Ambrim] Is., $16.35815^{\circ} \mathrm{S} 168.14838^{\circ} \mathrm{E}, 22 \mathrm{Aug}$ 1967-04 Sep 1967, J. and M. Sedlacek, 19 (00043092) (BPBM). Penama: Maewo Is.: Sounwari, $15.38^{\circ} \mathrm{S} 168.12989^{\circ} \mathrm{E}, 180 \mathrm{~m}, 04$ Sep $1979-$ 05 Sep 1979, G.A. Samuelson, 2 (00043064, 00043065) (BPBM). Sounwari, $15.38^{\circ} \mathrm{S}$ $168.12989^{\circ}$ E, 20 m, 04 Sep 1979, B.H. Gagne, 4 ๙ (00043048-00043051), 6 우 (00043005500043060), 1 sex unknown (00045806) (BPBM). Pentecost Is.: Wall Bay, $15.76364^{\circ} \mathrm{S} 168.19233^{\circ} \mathrm{E}$, 50 m, Dec 1984, N.L.H. Krauss, 19 (00043096) (BPBM). Shefa: Shephard Group: Tongariki Island, $16.8^{\circ} \mathrm{S} 168.5^{\circ} \mathrm{E}, 300 \mathrm{~m}, 29$ Aug 1979, G.M. Nishida, 4 ㅇ (00042274, 00044635, 00043094, 00043093) (BPBM).

\section{Felisacus minutus Carvalho}

Figures 6, 9D, 12AC, AD, 20

Felisacus minutus Carvalho, 1981: 6 (original description).

Diagnosis: Recognized by the following combination of characters: short body, $2.6 \mathrm{~mm}$ in male; posterior margin of pronotum brown with yellow wide stripe medially; cuneus red, with yellow outer part and brown margins; marking along inner margin of corium pale brown, not reaching $\mathrm{R}+\mathrm{M}$ anteriorly antennal segment I cylindrical (as in Namyatova et al., 2016: fig. 8A); transverse depression on head extending laterally, vertex upraised (as in Namyatova et al., 2016: fig. 6D); vertex ca. $1.3 \times$ as wide as eye diameter; cuneus $3 \times$ as wide as base; medial part of right paramere distinctly wider than basal part, its outer and inner parts straight (fig. 12AC); vesica with six spicules, including spicule $\mathrm{A}$.

REDESCRIPTION: Male. Total length 2.6. COLORATION (fig. 6): Head: Pale brown with reddish tinge. Eye brown, reddish laterally. Labium: Yellow. Antenna: Segment I pale brown with reddish tinge, whitish yellow basally; segment II reddish brown. Thorax: Anterior part of pronotum yellow with reddish tinge and brown anterior margin; posterior part of pronotum brown with wide yellow stripe medially; mesoscutum and scutellum yellow; thoracic pleura yellow; scent gland evaporative area yellow with reddish tinge apically. Hemelytron: Mostly translucent; inner part of clavus opaque, yellow with reddish tinge and with red margins; corium colorless; marking along inner margin of corium pale brown; cuneus red, with yellow outer part and brown margins; membrane and membrane cell with grayish tinge. Legs: Mostly yellow with red markings in femora and tibiae; tarsal segments II-III pale brown. SURFACE AND VESTITURE: Corium with shallow scarce punctures. Setae on body shorter or as long as antennal segment II diameter. STRUCTURE AND MEASUREMENTS: Body ca. $4.3 \times$ as long as pronotum width. Head: Depression delimiting occipital region distinct dorsally and laterally (as in Namyatova et al., 2016: fig. 4E); distance between depression and pronotum distinctly shorter than eye diameter; longitudinal sulcus on dorsal surface of head longer than eye diameter; distance from eye to pronotum subequal to eye diameter, not swollen laterally (as in Namyatova et al., 2016: fig. 4E); vertex ca. $1.3 \times$ as wide as eye, upraised (as in Namyatova et al., 2016: fig. 6D). Labium (as in Namyatova et al., 2016: figs. 6D, 9C): Segments I and II strongly reduced, combined length shorter than half of segment III; segment I shorter than wide; segment II slightly longer than wide, its dorsal surface elongate posteriorly; segment III subequal to ventral side of head. Antenna: Segment I cylindrical (as in Namyatova et al., 2016: fig. 8A), ca. 1.6× as long as head width, ca. $1.1 \times$ as long as pronotum width; segment II ca. $2.0 \times$ as long as head width, ca. $1.4 \times$ as long as pronotum width. Thorax: Anterior part of pronotum slightly shorter than posterior part; collar delimited; posterior part slightly upraised; posterior margin of pronotum concave; pronotum ca. $1.2 \times$ as wide as long and ca. $1.4 \times$ as wide as head; mesoscutum exposed. Hemelytron: Area along inner margin of corium flat; inner margin of cuneus convex (as in Namyatova et al., 2016: fig. 13E), outer margin of cuneus ca. $3 \times$ as long as base. Genitalia: Right 
paramere (fig. 12AC) distinctly curved in apical part; apex straight dorsally; medial part distinctly wider than basal part, bearing setae, with margins almost straight; outer angle distinct, inner angle rounded, without setae; basal part of paramere ca. $0.3 \times$ as long as rest of paramere. Left paramere (fig. 12AD) L-shaped; apical part not flattened, with tooth on posterior side medially (as in fig. 34G) and without outgrowth on dorsal surface; middle part widened, without swelling or outgrowth; setae only on middle part near outer margin. Aedeagus (general view as in Namyatova and Cassis, in press: fig. 22I) conjunctiva weakly sclerotized, sclerite around secondary gonopore short, bowl shaped, secondary gonopore placed at base of vesica in repose; vesica with six spicules, including long spicule $\mathrm{A}$ and five additional spicules of different shape and size (fig. 9D).

Female. Not seen.

Distribution: Papua New Guinea (fig. 20).

Host Plants: Unknown.

Discussion: Carvalho (1981) described F. minutus from two males. We examined the holotype and an additional male specimen of the species. This species is unlike its congeners on the basis of coloration of the pronotum, size of the vesical spicules.

Material examined: Holotype: PAPUA NEW GUINEA: Manus: Bismarck Arch., Momote, $2.06168^{\circ} \mathrm{S} 147.4245^{\circ} \mathrm{E}, 24$ Dec 1959, T.C. Maa, $10^{\Uparrow}$ (BPBM_TCN 00002956) (BPBM). Additional material: PAPUA NEW GUINEA: Bougainville Province: Buin, $6.81361^{\circ} \mathrm{S}$ $155.73194^{\circ} \mathrm{E}, 29 \mathrm{~m}, 31$ May 1956, J.L. Gressitt, 10 (00045805) (BPBM).

\section{Felisacus myersi, sp. nov.}

Figures 6, 9C, 12AE, AF, 15C, 19

Diagnosis: Recognized by the following combination of characters: antennal segment I ca. $1.5-1.8 \times$ as long as head width; pronotum mostly yellow; dorsal surface of head brown to dark brown; inner part of clavus often whitish yellow to yellow; cuneus mostly colorless with $\mathrm{p}$ ale brown to brown margins; cylindrical antennal segment I (as in Namyatova et al., 2016: fig. 8A), transverse depression on head extending laterally, vertex upraised (as in Namyatova et al., 2016: fig. 6D). setae on femora mostly longer than antennal segment II width; labium reaching middle of mesosternum or slightly surpassing it; cuneus ca. $3 \times$ as long as base; medial part of right paramere slightly wider than basal part, shorter than basal and apical parts combined (fig. 12AE); apical part of left paramere not widened, ca. $3 \times$ as long as wide (fig. 12AF); vesica with five spicules, including spicules A, C, D, G, I (fig. 9C).

Description: Male. Total length 3.4-4.2. COLORATION (fig. 6): Head: Dorsal surface of head brown to dark brown, yellow posteriorly, anterior side of head pale brown to brown, sometimes with yellow markings below inferior margin of antennal fossa; clypeus pale brown to dark brown, darkened apically; tubercles around antennal fossa yellow to pale brown, sometimes brown dorsally; mandibular plate often yellow to brown; maxillary plate whitish yellow to pale brown; buccula whitish yellow to yellow; ventral side of head yellow. Eye whitish yellow to brown, sometimes with reddish tinge. Labium: Often uniformly whitish yellow to yellow, sometimes segment I yellow to pale brown, rarely segment II brownish basally or labium uniformly pale brown. Antenna: Segment I often pale brown or brown, paler at base and darkened apically, rarely yellow with pale brown apex; segment II brown to dark brown, often paler basally; segments IIIIV dark brown. Thorax: Pronotum often yellow with pale brown or brownish anterior margin and brown posteriorly, sometimes posterior part of pronotum yellow with pale brown humeral angles; mesoscutum yellow; scutellum yellow, often pale brown to dark brown apically, sometimes depression and punctures between mesoscutum and scutellum pale brown; thoracic pleura yellow to pale brown, scent gland evaporative area uniformly whitish yellow to yellow, sometimes with reddish or pale brown apex. Hemelytron: Mostly translucent; inner part of clavus 
sometimes opaque, whitish yellow to yellow, often with pale brown or brown apex and lateral margins, rarely inner part of clavus pale brown with brown to dark brown lateral margins; outer part of clavus whitish yellow, rarely brown apically; corium mostly colorless, vein from apical part of clavus to cuneus pale brown to brown, often marking along inner margin on corium pale brown to brown; embolium colorless, sometimes whitish yellow to yellow with pale brown to brown margins; cuneus mostly colorless with pale brown to brownish margins; membrane colorless with yellow to brown veins. Legs: Coxae whitish yellow to yellow; femora whitish yellow to yellow basally and yellow to pale brown apically, sometimes also with small reddish markings apically; tibiae yellow, often darkened basally and paler apically, sometimes uniformly whitish yellow to pale brown, sometimes with reddish stripe basally; tarsi uniformly pale brown to brown or with segment I yellow. Abdomen: Ventral and lateral sides of pregenital segments whitish yellow, sometimes third and fourth segments pale brown, dorsal surface of pregenital segments reddish, pale brown or brown, genital capsule whitish yellow to pale brown. SURFACE AND VESTITURE: Corium smooth, with shallow and small punctures. Dorsum clothed with suberect setae slightly longer than antennal segment II diameter; antennal segment I with rare suberect setae subequal to or slightly longer than antennal segment II diameter; femora with suberect setae longer than antennal segment II diameter, abdomen clothed with suberect mostly short simple setae. STRUCTURE AND MEASUREMENTS: Body ca. $4.5-4.6 \times$ as long as pronotum width. Head: Transverse depression delimiting occipital region present dorsally and laterally (as in Namyatova et al., 2016: fig. 4E); distance between depression and pronotum distinctly shorter than eye diameter; longitudinal sulcus on dorsal surface longer than eye diameter; distance from eye to pronotum slightly longer than eye diameter, not swollen laterally (as in Namyatova et al., 2016: fig. 4E); vertex ca. 1.6-1.9x as wide as eye, vertex upraised (as in Namyatova et al., 2016: fig.
6D). Labium (as in Namyatova et al., 2016: figs. 6D, 9C): Reaching middle of mesosternum or slightly surpassing it; segments I and II greatly reduced, combined subequal to half of segment III; segment I shorter than wide; segment II slightly longer than wide, its dorsal surface elongate posteriorly; segment III slightly longer than ventral side of head; segment IV ca. $1.5 \times$ as long as segment III. Antenna: Segment I straight (as in Namyatova et al., 2016: fig. 8A), ca. 1.8-2.0x as long as head width, ca. $1.2-1.3 \times$ as long as pronotum width; segment II ca. 1.9-2.3x as long as head width, ca. $1.3-1.5 \times$ as long as pronotum width; segments III slightly longer than segment II; segment IV ca. $0.3 \times$ as long as segment III. Thorax: Anterior part of pronotum slightly shorter than posterior part; collar delimited; posterior part slightly upraised; posterior margin of pronotum concave; pronotum ca. $1.2-1.3 \times$ as wide as long and ca. $1.4-1.6 \times$ as wide as head; mesoscutum exposed. Hemelytron: Area along inner margin of corium almost flat; inner margin of cuneus convex (as in Namyatova et al., 2016: fig. 13E), outer margin of cuneus ca. $3 \times$ as long as base. Abdomen: Genital capsule rotated left at right angle relative to rest of abdomen. Genitalia: Genital capsule (fig. 15C) ventral wall ca. $1.7 \times$ as long as dorsal wall, posterior margin smooth, semioval, without outgrowth(s), its apex inclined leftward, not curved; sides of genital capsule on modified; right paramere socket slightly acute, left paramere socket rounded; distance between paramere sockets ca. $0.4 \times$ as long as genital capsule width at base. Right paramere (fig. 12AE) distinctly curved in apical half; apex slightly concave, medial part only slighter wider than basal part, bearing setae, with outer margin straight and inner margin convex; outer angle distinct, slightly swollen; inner angle indistinct, not bearing setae; basal part of paramere ca. $0.15-0.2 \times$ as long as rest of paramere. Left paramere (fig. $12 \mathrm{AF}) \mathrm{L}$-shaped; apical part flattened, with tooth on posterior side medially and without outgrowth on dorsal surface; middle part widened, without swelling or outgrowth; setae only on middle part near outer margin. Aedeagus (gen- 
eral view as in Namyatova and Cassis, in press: fig. 22I) conjunctiva weakly sclerotized, secondary gonopore placed at base of vesica in repose; sclerotization around secondary gonopore shorter than wide; vesica with four spicules, including spicules A, C, D, G, I (fig. 9C).

Female. Total length 3.7-4.2. COLORATION (fig. 6): Head: Color pattern similar to male, but anterior side of head pale brown to brown, sometimes with yellow markings along inferior margin of antennal fossa of head; lateral side yellow to pale brown, with brown stripe along eye margin or with brown making below eye, mandibular plate pale brown or brown. Labium: Whitish yellow or yellow often with segment I somewhat darker, yellow, brownish yellow or pale brown, segment II rarely brownish at base, segment III rarely with reddish tinge. Antenna: As in male. Thorax: Additionally to coloration of pronotum described in males, collar rarely brownish dorsally, posterior part of pronotum rarely almost uniformly brownish, yellow only anteriorly with dark brown markings near posterior angles; scutellum and mesoscutum as in male, but sometimes scutellum pale brown or brown; thoracic pleura yellow to pale brown, scent gland evaporative area whitish yellow to yellow with yellow or pale brown apex. Hemelytron: Similar to male, but inner part of clavus sometimes yellow to pale brown basally and brown to dark brown apically or uniformly brown to dark brown; cuneus sometimes with yellow tinge. Legs: As in male. Abdomen: Ventral and lateral sides of segments whitish yellow to brown; dorsal surface pale brown to brown. SURFACE AND VESTITURE: As in male. STRUCTURE AND MEASUREMENTS: Structure as in males; body ca. $4.3-4.6 \times$ as long as width of pronotum; vertex ca. $1.8-2.1 \times$ as wide as eye; antennal segment I ca. 1.6-2.0× as long as head width, ca. 1.0-1.3× as long as pronotum width; segment II ca. $2.0-2.1 \times$ as long as width of head, ca. $1.2-1.4 \times$ as long as width of pronotum; pronotum ca. $1.2-1.3 \times$ as wide as long and ca. $1.5-1.7 \times$ as wide as head. Genitalia (as in Namyatova et al., 2016: fig. 23F, G): Dorsal labiate plate wider than distance between apodemes of second valvula; mostly smooth, without distinct striations, with semicircular sclerite and distinct sclerotized rings laterally; lateral oviducts placed almost medially, very close to each other, spermathecal gland placed between lateral oviducts; dorsal labiate plate with distinct tubercles, without membranous lobe medially.

Distribution: Vanuatu (Aneityum, Tanna, and Erromanga islands) (fig. 19).

Host Plants: Unknown.

Eтүмоlogy: Species is names after Shepherd Myers, former curator of the BPBM insect collection, who kindly helped us during a visit (by A.A.N.) to that museum and loaned specimens.

Discussion: Felisacus myersi is similar to $F$. meilingae in the external structure (fig. 6) and the shape of vesical spicules (cf. fig. 9B with 9C), but the latter species differs by the yellow dorsal surface of the head, the inner part of the cuneus is mostly pale brown to brown and the presence of additional small vesical spicule distally (fig. 9B).

Material eXAmined: Holotype: VANUATU: Taeffa: Aneityum Is.: vicinity of Anelghowhat [Analgahaut], Aneityum Island, New Hebrides, $20.22505^{\circ} \mathrm{S} 169.76858^{\circ} \mathrm{E}, 18$ Jul 1971, G.F. Gross, 19 (00017546) (SAMA). Paratypes: VANUATU: Taeffa: Aneityum Is.: Anelghowhat [Anelgaohat], Aneityum [Aneytioum] Is., New Hebrides, $20.22505^{\circ} \mathrm{S} 169.76858^{\circ} \mathrm{E}, 100 \mathrm{~m}$, Nov 1978, N.L.H. Krauss Coll., 1 (00042212) (BPBM). vicinity of Anelghowhat [Analgahaut], Aneityum Island, New Hebrides, $20.22505^{\circ} \mathrm{S} 169.76858^{\circ} \mathrm{E}$, 18 Jul 1971, G.F. Gross, 4 ㅇ (00017547-00017550) (SAMA); 19 Jul 1971, G.F. Gross, 19 (00017551), 1 조 (00017661) (SAMA); 20 Jul 1971, G.F. Gross, 1 †ิ (00017662) (SAMA); 22 Jul 1971, G.F. Gross, 4 우 (00017542-00017545), 6 주 (0001765500017660) (SAMA). Erromango Is.: Port Narvin [Narevin], Erromango [Erromanga] Is., New Hebrides, $18.74923^{\circ} \mathrm{S} 169.20622^{\circ} \mathrm{E}, 25$ Aug 1979, N.L.H. Krauss Coll., 1 우 (00042213) (BPBM).

Tanna Is.: Lenakel, 0-200 m, $19.51921^{\circ} \mathrm{S}$ $169.28217^{\circ} \mathrm{E}, 150 \mathrm{~m}$, Mar 1980, N.L.H. Krauss, 1 sex unknown (00042219) (BPBM); Jan 1981, N.L.H. Krauss, 1 ㅇ (00042214) (BPBM). Lenakel, Tanna Is., New Hebrides, $19.52733^{\circ} \mathrm{S}$ $169.26935^{\circ} \mathrm{E}, 50 \mathrm{~m}$, Nov 1978, N.L.H. Krauss 
Coll., 3 đิ (00042215-00042217) (BPBM). West Coast, Tanna Is., New Hebrides, $19.54157^{\circ} \mathrm{S}$ $169.26939^{\circ} \mathrm{E}, 12$ Mar 1964, R. Straatman, $1 \delta^{\star}$ (00042218) (BPBM).

\section{Felisacus nigrescens Carvalho}

Figures 6, 9E, 13A, B, 15D, 20

Felisacus nigrescens Carvalho, 1981: 63 (original description).

Diagnosis: Recognized by the following combination of characters: cylindrical antennal segment I (as in Namyatova et al., 2016: fig. 8A), transverse depression on head extending laterally, dorsal surface of head mostly brown; pronotum brown to dark brown; marking along inner margin of corium brown, widened, not reaching $\mathrm{R}+\mathrm{M}$; inner part of clavus brown; cuneus colorless or whitish with brown marking along inner margin; body length in male 4.4-4.7, in female 4.4-4.8; cuneus ca. $3 \times$ as long as base; medial part of right paramere as wide as basal part, as long as basal and apical parts combined, and with margins straight (fig. 13A); vesica with six spicules, including spicule A (fig. 9E).

Redescription: Male. Total length 4.4-4.7. COLORATION (fig. 6): Head: Pale brown to brown, longitudinal sulcus dark brown; anterior side yellow to pale brown, sometimes with reddish tinge; clypeus yellow to pale brown basally and brown apically, sometimes with reddish marking, tubercles around antennal fossa pale brown; lateral sides and buccula pale brown, mandibular and maxillary plates whitish yellow to yellow. Eye brown with reddish tinge or dark brown. Labium: Uniformly yellow. Antenna: Segments I dark brown; segment II brown to dark brown, sometimes pale brown apically, segments III-IV brown, segment III darkened basally. Thorax: Pronotum brown to dark brown, somewhat paler medially; scutellum and mesoscutum yellow to pale brown, sometimes mesoscutum yellow and scutellum pale brown; thoracic pleura brown; scent gland evaporative area yellow with brown margins. Hemelytron: Mostly translucent, colorless; inner part of clavus opaque, brown; outer part of clavus brown apically; marking along inner margin of corium brown widened, not reaching $\mathrm{R}+\mathrm{M}$; embolium sometimes opaque, with brown margins; cuneus sometimes opaque, with brown inner part and margins; membrane sometimes with grayish tinge, with brown membrane cell. Legs: Coxa whitish yellow; femora whitish yellow basally and pale brown to brown apically; tibiae pale brown to brown, often paler apically; tarsi yellow to pale brown. Abdomen: Whitish ventrally and laterally and brown dorsally. SURFACE AND VESTITURE: Corium smooth, with shallow and scarce punctures. Dorsum and femora clothed with suberect setae subequal to or shorter than antennal segment II diameter; antennal segment I with scarce suberect setae shorter than antennal segment II diameter; abdomen clothed with suberect short simple setae. STRUCTURE AND MEASUREMENTS: Body ca. $4.4-4.7 \times$ as long as pronotum width. Head: Depression, delimiting occipital region, present dorsally and laterally (as in Namyatova et al., 2016: fig. 4E); distance between depression and pronotum distinctly shorter than eye diameter; longitudinal sulcus on dorsal surface longer than eye diameter; distance from eye to pronotum slightly longer than eye diameter, not swollen laterally (as in Namyatova et al., 2016: fig. $4 \mathrm{E}$ ); vertex ca. $1.5-1.7 \times$ as wide as eye, upraised (as in Namyatova et al., 2016: fig. 6D). Labium (as in Namyatova et al., 2016: figs. 6D, 9C): Almost reaching posterior margin of mesosternum; segments I and II combined shorter than half of segment III; strongly reduced; segment I shorter than wide; segment II slightly longer than wide, its dorsal surface elongate posteriorly; segment III slightly longer than ventral side of head; segment IV ca. $1.5 \times$ as long as segment III. Antenna: Segment I cylindrical (as in Namyatova et al., 2016: fig. $8 \mathrm{~A})$, ca. $1.3-1.6 \times$ as long as head width, ca. $0.9-1.0 \times$ as long as pronotum width; segment II ca. $1.6-1.9 \times$ as long as head width, ca. $1.0-1.2 \times$ 
as long as pronotum width; segment III slightly longer than segment II. Thorax: Anterior part of pronotum shorter than posterior part; collar delimited; posterior part slightly upraised; posterior margin of pronotum concave; pronotum ca. $1.3-1.4 \times$ as wide as long and ca. $1.4-1.7 \times$ as wide as head; mesoscutum exposed. Hemelytron: Area along inner margin of corium flat; inner margin of corium concave (as in Namyatova et al., 2016: fig. 13E), outer margin ca. $3 \times$ as long as base. Abdomen: Genital capsule rotated left at right angle relative to rest of abdomen. Genitalia: Genital capsule (fig. 15D) ca. $1.5 \times$ as long as wide; ventral wall ca. $1.5 \times$ as long as dorsal wall, its posterior margin smooth, semioval, without outgrowth(s), not curved; its apex inclined rightward; sides of genital capsule not modified; margins of paramere sockets more or less rounded; distance between paramere sockets ca. $0.7 \times$ as long as genital capsule width at base. Right paramere (fig. 13A) distinctly curved in apical half; apex distinctly concave posteriorly; medial part only slighter wider than basal part, bearing setae; outer and inner margins of middle part almost straight; outer angle distinct; inner angle rounded, without setae; basal part of paramere ca. $0.15-0.2 \times$ as long as rest of paramere. Left paramere (fig. 13B) L-shaped; apical part not flattened, with tooth on posterior side medially (as in fig. 11G) and without outgrowth on dorsal surface; middle part widened, without swelling or outgrowth; setae only on middle part near outer margin. Aedeagus (general view as in Namyatova and Cassis, in press: fig. 22I) conjunctiva weakly sclerotized; secondary gonopore placed at base of vesica in repose; sclerotization of ductus seminis around secondary gonopore shorter than wide; vesica with six spicules; including spicule A (fig. 9E).

Female. Total length 4.4-4.8. COLORATION (fig. 6): Similar to male, but mesoscutum sometimes reddish, legs rarely with reddish tinge; abdomen whitish yellow laterally and ventrally, with reddish segment $\mathrm{X}$, brown dorsally. SURFACE AND VESTITURE: As in male. STRUC-
TURE AND MEASUREMENTS: Structure as in male; body ca. $4.3-4.9 \times$ as long as pronotum width; vertex ca. $1.9-2.1 \times$ as wide as eye; antennal segment I ca. $1.4-1.5 \times$ as long as head width, ca. $0.8-0.9 \times$ as long as pronotum width; segment II ca. $1.7-1.9 \times$ as long as head width, ca. 1.0$1.1 \times$ as long as pronotum width; segment IV ca. $0.3 \times$ as long as segment III; pronotum ca. $1.3 \times$ as wide as long and ca. $1.7 \times$ as wide as head. Genitalia (as in Namyatova et al., 2016: fig. 23F, G): Dorsal labiate plate wider than distance between apodemes of second valvula; mostly smooth, without distinct striations, with semicircular sclerite and distinct sclerotized rings laterally; lateral oviducts placed almost medially, very close to each other, spermathecal gland placed between lateral oviducts; dorsal labiate plate with distinct tubercles, without membranous lobe medially.

Distribution: Papua New Guinea (fig. 20).

Host Plants: Pteris gardneri (Pteridaceaelarge number of specimens; Ptelea sp. (Rutaceae)-single specimen; beating ferns (Carvalho, 1981).

Discussion: Segment IV is lost in male specimens that we examined. Carvalho (1981) described F. nigrescens on the basis of male and female specimens. We examined the paratypes of both sexes. Based on the coloration and the vesical spicules, Felisacus nigrescens is not similar to any other species of the genus.

Material eXAmined: Paratypes: PAPUA NEW GUINEA: Eastern Highlands: NE Okapa, $6.56475^{\circ} \mathrm{S} 145.60089^{\circ} \mathrm{E}, 1900 \mathrm{~m}, 24$ Jun $1967-25$ Jun 1967, G.A. Samuelson, 19 (00043247) (BPBM), 2 우 (00018981, 00018982) (TAMU). Morobe Province: Wau, $7.3333^{\circ} \mathrm{S} 146.71667^{\circ} \mathrm{E}, 1750 \mathrm{~m}, 06 \mathrm{Sep}$ 1965, J. and M. Sedlacek, 1 đo (00043244) (BPBM). Additional material: PAPUA NEW GUINEA: Morobe Province: Edie Creek, NE Wau, $7.31666^{\circ} \mathrm{S}$ $146.68333^{\circ} \mathrm{E}, 1100 \mathrm{~m}, 08$ Sep 1971, W.C. Gagne, $10^{\text {t }}$ (00043245) (BPBM). Mt. Missim, $7.1167^{\circ} \mathrm{S}$ $146.9167^{\circ} \mathrm{E}, 1600 \mathrm{~m}, 23$ Mar 1978, W.C. Gagne, 1 ㅇ (00045819) Pteris gardneri (Pteridaceae), 10 (00043246), 2 ㅇ (00043248, 00043249), 2 sex unknown (00043250, 00043251) (BPBM). Namie 
Creek, $7.31666^{\circ} \mathrm{N} 146.7^{\circ} \mathrm{E}, 25$ May 1982, P. Grootaert, Ptelea sp. (Rutaceae), 1 đิ (00018973) (ISNB).

\section{Felisacus nigricornis Poppius}

Figure 21

Felisacus nigricornis Poppius, 1912: 2 (original description).

Diagnosis: Recognized by the following characters: head, pronotum, scutellum, base of clavus red; main part of clavus, claval commissure apically, inner margin of corium and antennal segments I-II black; outer and inner parts of cuneus brown; body length 4.0.

Description (from Poppius (1912), translated from German):

Head, pronotum, scutellum, as well as base of clavus, red; apex of clypeus, collar, rest of clavus, claval commissure apically, inner margin of corium, narrow outer margin of embolium, as well as antennal segments I-II (segments III-IV lost) black; narrow inner margin of embolium, corium apically, outer and inner parts of cuneus, as well as membrane cell, brown; rest of hemelytron transparent, colorless; ventral side of body red, posterior part of body with yellow marking medially; antennal segment I basally red; labium and legs yellow; femora basally whitish yellow, somewhat reddish apically. Head from anterior view slightly longer than wide, tapering; occipital region delimited with depression; from lateral view slightly longer than basal height; frons slightly less than twice as long as eye diameter; eye rather large, distinctly protruding, very finely granulate; labium reaching mesofemora, with segment I not reaching posterior margin of head; segment II slightly longer, slightly narrower than segment I. Antennae long, clothed with suberect setae; segment I almost longer than pronotum, segment II slightly longer, slightly narrower than segment I. Pronotum distinctly longer than wide, posterior margin almost twice as long as anterior margin; calli delimited with depression; calli large, merged with each other, collar narrow; pronotal disc distinctly convex and declivous. Hemelytron in female longer than posterior part of body. Legs with pale setae. Length 4 , width $1 \mathrm{~mm}$.
Distribution: New Guinea (fig. 21).

Host Plants: Unknown.

Discussion: The type of Felisacus nigricornis is preserved in the Hungarian Museum of Natural Sciences, but is mutilated (Carvalho, 1980); this was also confirmed by the curators of this collection (András Orosz and Dávid Rédei, personal commun.). We did not find any additional specimens which could be assigned to this species. Poppius (1911) compared F. nigricornis with F. elegantulus. Based on Poppius' description, the affinities of this species are not clear. Carvalho (1981) also redescribed F. nigricornis based on additional material.

There are six Felisacus species known from New Guinea: F. dauloi, F. javanus, F. nigrescens. F. longiceps, F. magnificus, and F. minutus. They all differ from $F$. nigricornis in coloration. Felisacus dauloi can be separated from $F$. nigricornis in the head, pronotum, scutellum, and inner part of the clavus mostly yellow, the outer part of the clavus colorless, antennal segment I-II reddish brown, the cuneus mostly colorless, translucent with its margins and often apex yellow, red or mostly yellow. Felisacus javanus differs from F. nigricornis by the head yellow to brown, antennal segment I pale brown, sometimes with a reddish tinge, segment II reddish brown, the pronotum mostly yellow, the scutellum whitish yellow to pale brown, sometimes with a reddish tinge laterally, the inner part of the clavus mostly whitish yellow to yellow, the outer part of the clavus colorless; the cuneus with its inner part red and the outer part whitish yellow. Felisacus nigrescens differs from $F$. nigricornis by the head mostly pale brown, brown dorsally, the pronotum brown to dark brown, the scutellum yellow to pale brown, the inner part of the clavus brown, the outer part of the clavus colorless, brown apically, the cuneus colorless with the inner part and margins brown. Felisacus minutus is separated from $F$. nigricornis in the head and the anterior part of the pronotum mostly pale brown with a reddish tinge, the posterior part 
of the pronotum brown with a wide yellow stripe medially, the cuneus red with the outer part yellow and the margins brown. Felisacus magnificus and $F$. longiceps differ from $F$. nigricornis by the head and the anterior part of the pronotum yellow to pale brown, the posterior part of the pronotum dark brown to black, the C-shaped marking on the corium reaching $\mathrm{R}+\mathrm{M}$ anteriorly and posteriorly, and the cuneus mostly colorless and red apically. No other Felisacus species have the head, pronotum, and scutellum red.

\section{Felisacus ochraceus Usinger}

Figures 6, 9F, 13C, D, 15E, 19

Felisacus ochraceus Usinger, 1946: 69 (original description).

Diagnosis: Recognized by the following combination of characters: cylindrical antennal segment I (as in Namyatova et al., 2016: fig. 8A), transverse depression on head extending laterally, vertex upraised (as in Namyatova et al., 2016: fig. 6D); main coloration of head and pronotum yellow to pale brown, humeral angles not darkened; inner part of clavus whitish yellow, with pale brown or brown margins; cuneus with whitish and translucent outer part and yellow or reddish inner part; labium reaching posterior margin of mesosternum; cuneus $3 \times$ as long as wide; medial part of right paramere as wide as basal part, subequal to basal and apical parts combined, its outer margin concave and inner margin convex (fig. 13C); vesica with five spicules, including spicules $\mathrm{A}, \mathrm{B}, \mathrm{C}$, and $\mathrm{H}$, spicule $\mathrm{B}$ with long distal arm (fig. 9F).

Redescription: Male. Total length 3.6-4.0. COLORATION (fig. 6): Head: Mostly yellow, sometimes with marking near antennal fossa and stripe behind eye reddish, dorsal surface often with reddish tinge, longitudinal sulcus sometimes pale brown. Eye dark brown with reddish tinge. Labium: Uniformly whitish yellow to yellow. Antenna: Segment I yellow basally and pale brown apically, sometimes reddish yellow; segments II-III pale brown to brown, sometimes reddish brown. Thorax: Pronotum whitish yellow to yellow, anterior margin and punctures between anterior and posterior parts pale brown; scutellum and mesoscutum whitish yellow to yellow, depression between them pale brown; thoracic pleura yellow, scent gland evaporative area whitish yellow, paler than thoracic pleura, or whitish basally and yellow or reddish apically. Hemelytron: Mostly translucent and colorless; inner part of clavus whitish yellow, with pale brown or brown margins; corium with marking along apical part of clavus pale brown, marking along inner margin of corium yellow, sometimes red posteriorly; embolium with yellow or red apex and yellow or pale brown margins; cuneus with yellow or reddish inner part, margins yellow to pale brown; sometimes cuneus uniformly reddish yellow; membrane cell yellow. Legs: Mostly whitish yellow, femora apically and tibiae basally yellow, sometimes femora apically and entire tarsi reddish yellow, tarsi yellow to pale brown. Abdomen: Yellow with red markings dorsally and laterally or uniformly yellow. SURFACE AND VESTITURE: Corium smooth, shallow and scarce punctures. Dorsum, antennal segment I and femora clothed with setae shorter than antennal segment II diameter; abdomen clothed with short erect setae. STRUCTURE AND MEASUREMENTS: Body ca. 4.3-4.7× as long as pronotum width. Head: Depression delimiting occipital region distinct dorsally and laterally (as in Namyatova et al., 2016: fig. 4E), distance between depression and pronotum distinctly shorter than eye diameter; longitudinal sulcus on dorsal surface of head as long as eye diameter; distance from eye to pronotum longer than eye diameter, not swollen laterally (as in Namyatova et al., 2016: fig. $4 \mathrm{E}$ ); vertex ca. $1.4-1.7 \times$ as wide as eye, upraised (as in Namyatova et al., 2016: fig. 6D). Labium: Reaching posterior margin of mesosternum or slightly surpassing it; segments I and II strongly reduced, combined shorter than half of segment III; segments I as long as wide (as in Namyatova et al., 2016: figs. 6D, 9C); segment II slightly longer than wide, its dorsal surface elongate posteriorly; segment III longer than 
ventral side of head; segment IV ca. $1.5 \times$ as long as segment III. Antenna: Segment I cylindrical (as in Namyatova et al., 2016: fig. 8A), ca. 1.5$1.6 \times$ as long as head width, ca. $1.0-1.1 \times$ as long as pronotum width; segment II twice as long as head width, ca. $1.4-1.5 \times$ as long as pronotum width; segment III slightly longer than segment II. Thorax: Anterior and posterior parts subequal in length, collar delimited; posterior part slightly upraised; posterior margin concave, pronotum ca. $1.2-1.3 \times$ as wide as long and ca. $1.4-1.5 \times$ as wide as head; mesoscutum exposed; Hemelytron: Area along inner margin of corium flat; inner margin of cuneus convex (as in Namyatova et al., 2016: fig. 13E), outer margin ca. $3 \times$ as long as base. Abdomen: Genital capsule rotated left at right angle relative to rest of abdomen. Genitalia: Genital capsule (fig. 15E) ca. 1.5× as long as wide; ventral wall ca. $1.5 \times$ as long as dorsal wall, with posterior margin of ventral wall semioval, smooth, without outgrowth(s), its apex inclined leftward, not curved dorsally; sides of genital capsule not modified; right paramere socket slightly angulate and left socket rounded; distance between paramere sockets subequal to half of genital capsule width at base; right angle of left paramere socket not projecting. Right paramere (fig. 13C) distinctly curved in apical half; apex slightly concave; medial part as wide as basal part, bearing setae, with outer margin concave and inner margin convex; outer angle distinct; inner angle indistinct, without setae; basal part very short, basal part of paramere ca. $0.15-0.2 \times$ as long as rest of paramere. Left paramere (fig. 13D) L-shaped, apical part flattened, with toothlike outgrowth on posterior side medially (as in fig. $11 \mathrm{G}$ ) and without outgrowth on dorsal surface; middle part widened, without swelling or outgrowth; setae only on middle part near outer margin. Aedeagus (general view as in Namyatova et al., 2016: fig. 22I) conjunctiva weakly sclerotized, sclerotized part of ductus seminis very short, secondary gonopore placed at base of vesica in repose; vesica with five spicules, including spicules $\mathrm{A}, \mathrm{B}, \mathrm{C}$, and $\mathrm{H}$, spicule $\mathrm{B}$ with long apical arm (fig. 9F).
Female. Total length 3.8-3.9. COLORATION (fig. 6): Head: Similar to male, but dorsal surface slightly darker than other sides. Labium: As in male. Antenna: Similar to male, segment II uniformly reddish brown. Thorax and legs: As in male. Hemelytron: Similar to male, but cuneus with outer part colorless and with inner part reddish or pale brown, rarely mostly yellow with pale brown inner part. Abdomen: Pale brown with reddish dorsal surface. SURFACE AND VESTITURE: As in male. STRUCTURE AND MEASUREMENTS: Structure as in male; body ca. $4.2-4.4 \times$ as long as pronotum width; $\mathrm{ca}$. vertex 1.3-1.6x as wide as eye; antennal segment I ca. $1.2-1.5 \times$ as long as head width, ca. $0.9-1.0 \times$ as long as pronotum width; segment II ca. 1.9$2.0 \times$ as long as head width, ca. $1.3-1.4 \times$ as long as pronotum width; pronotum ca. $1.1-1.3 \times$ as wide as long and ca. $1.4-1.6 \times$ as wide as head. Genitalia (as in Namyatova et al., 2016: fig. 23F, G): Dorsal labiate plate wider than distance between apodemes of second valvula; mostly smooth, without distinct striations, with semicircular sclerite and distinct sclerotized rings laterally; lateral oviducts placed almost medially, very close to each other, spermathecal gland placed between lateral oviducts; dorsal labiate plate with distinct tubercles, without membranous lobe medially.

Distribution: Guam (fig. 19).

Host Plants: Ferns (Usinger, 1946).

Discussion: Antennal segment IV is lost in males and segment III-IV are lost in females. Usinger (1946) described F. ochraceus from a number of specimens. We examined the paratypes of both sexes. Based on the structure of the parameres, the specimens described by Carvalho (1981) as F. ochraceus belongs to another species, whose identity we were not able to establish; however, the shape of parameres in figures 115 and 116 of Carvalho (1981) is similar to those of $F$. nigrescens and F. solomonicus (figs. 13A, R), but coloration differs from both of these species.

Felisacus ochraceus is almost identical with $F$. australicus in structure, including the parameres (cf. fig. 11E, F with fig. 13C, D) and vesical spic- 
ules (cf. fig. 8C with 9F), but the latter species differs in coloration, with the head, antennal segment I, and the pronotum mostly yellow to pale brown, the inner part of clavus pale brown to brown, and the scent gland evaporative area pale brown.

Felisacus ochraceus is also similar in coloration to F. amboinae, F. filicicola, F. dauloi, F. insularis, and F. linae (figs. 4,5). All these species can be separated from $F$. ochraceus by the medial part of right paramere wider than the basal part and distinctly shorter than the basal and apical parts combined, with the outer margin straight or slightly concave (figs. $11 \mathrm{C}, \mathrm{X}, \mathrm{AD}, 12 \mathrm{C}, \mathrm{K}$ ), as well as in the number and shape of the vesical spicules (fig. 8B, G, I, L, P ). Felisacus dauloi also differs from F. ochraceus by the cuneus colorless or yellow basallyand reddish apically. Felisacus linae differs from $F$. ochraceus by the cuneus mostly translucent with the inner part pale brown.

Material examined: Paratypes: GUAM: Piti, $13.46^{\circ} \mathrm{N} 144.69166^{\circ} \mathrm{E}, 5 \mathrm{~m}, 24$ Aug 1936, O.H. Swezey, $10^{\text {tै }}$ 00399747), $3 q$ (00399751, 00399749, 00399750) (CAS). Additional material: GUAM: Mariana Is: Guam, Mt. Lamlam, Oct 1957, N.L.H. Krauss, $20^{\star}$ (00043157, 00043159) (BPBM). Mt. Alifan, $13.38055^{\circ} \mathrm{N} 144.67138^{\circ} \mathrm{E}$, Oct 1957, N.L.H. Krauss, 19 (00043161) (BPBM). Yigo, $13.53194^{\circ} \mathrm{N} 144.88027^{\circ} \mathrm{E}, 126 \mathrm{~m}$, Oct 1957, N.L.H. Krauss, $1 \delta^{\top}$ (00043158), 2 ㅇ (00043160, 00043162) (BPBM).

\section{Felisacus ovalau, sp. nov.}

Figures 6, 9G, 13E, F, 15F, 19

Diagnosis: Recognized by the following combination of characters: transverse depression on head present only dorsally; head and pronotum mostly yellow; antennal segment I yellow with reddish tinge; posterior part of pronotum yellow with pair of brown marking near humeral angles; labium reaching abdominal segment V; inner margin of corium convex (as in Namyatova et al., 2016: fig. 13E); apex of ventral wall of genital capsule slightly curved dorsally (fig. 15F); right paramere sickle shaped (fig. 13E); left paramere wide, with three rounded outgrowths (fig. 13F); sclerotization around ductus seminis distinctly elongate, secondary gonopore placed at base of vesica in repose; vesica with a number of small toothlike spinules and two large sclerites (fig. 9G).

Description: Male. Total length 3.2. COLORATION (fig. 6): Head: Mostly yellow with reddish tinge, mandibular and maxillary plates whitish yellow. Eye dark brown with reddish tinge. Labium: Uniformly yellow. Antenna: Segment I yellow with reddish tinge, whitish yellow basally and reddish apically; segment II uniformly reddish. Thorax: Pronotum yellow with brown marking near humeral angle; scutellum and mesoscutum yellow with reddish tinge; thoracic pleura yellow; scent gland evaporative area whitish yellow, with reddish marking apically. Hemelytron: Mainly whitish yellow, translucent; clavus yellow, outer part paler than inner part; marking along inner margin of corium yellow to pale brown, narrow, not reaching $\mathrm{R}+\mathrm{M}$; embolium whitish yellow, yellow apically; cuneus whitish with yellow tinge; membrane translucent with brown tinge, membrane cell pale brown. Legs: Mostly whitish yellow; apical parts of femora yellow with reddish tinge, tibiae yellow with reddish tinge basally and apically; tarsi brown. SURFACE AND VESTITURE: Corium with distinct punctation. Dorsum with setae subequal to or slightly longer than antennal segment II diameter; antennal segment I with suberect setae shorter than antennal segment II diameter; femora with suberect setae longer than antennal segment II diameter; abdomen clothed with short erect setae. STRUCTURE AND MEASUREMENTS: Body ca. $4.6 \times$ as long as pronotum width. Head: Depression delimiting occipital region present only dorsally; distance between depression and pronotum distinctly shorter than eye diameter; longitudinal sulcus on dorsal surface of head shorter than eye diameter; distance from eye to pronotum longer than eye diameter, not swollen laterally; vertex ca. $2.0 \times$ as wide as eye, upraised. Labium (as in Namyatova et al., 2016: figs. 6D, 9C): Reaching abdominal sternum V; segments I and II combined longer than half of segment III; segment I 
shorter than width; segment II twice as long as wide, its dorsal surface elongate posteriorly; segment III longer than ventral side of head; segment IV ca. $0.3 \times$ as long as segment III. Antenna: Segment I distinctly longer than head width, slightly widened, ca. $1.4 \times$ as long as head width, $0.9 \times$ as long as pronotum width; segment II ca. $1.8 \times$ as long as head width, $1.3 \times$ as long as pronotum width; antennal segments III-IV lost. Thorax: Anterior part of pronotum somewhat shorter than posterior part, collar delimited; posterior part of pronotum slightly upraised; posterior margin concave, pronotum ca. $1.1 \times$ as wide as long and ca. $1.5 \times$ as wide as head; mesoscutum exposed. Hemelytron: Area along inner margin of corium flat; inner margin of corium convex (as in Namyatova et al., 2016: fig. 13E), its outer margin ca. $3 \times$ as long as base. Abdomen: Genital capsule rotated left at right angle relative to rest of abdomen. Genitalia: Genital capsule (fig. 15F) ca. $1.5 \times$ as long as wide; ventral wall ca. $1.5 \times$ as long as dorsal wall, with posterior margin of ventral wall acute apically, smooth, without outgrowth, its apex placed almost medially, curved dorsally; right side of genital capsule not curved, left side not widened; right paramere socket acute, left one angulate; distance between paramere sockets ca. $0.3 \times$ as long as genital capsule width at base. Right paramere (fig. 13E) distinctly curved in apical half; apex concave posteriorly; medial part narrower than basal part with setae near inner margin, its outer margin convex and inner margin concave; paramere slightly swollen dorsally; outer and inner angles rounded, not bearing setae; basal part of paramere ca. $0.4 \times$ as long as rest of paramere. Left paramere (fig. 13F) irregularly shaped; apical part curved, flattened, without outgrowth posteriorly; middle part with three rounded swellings, setae placed on middle part near outer margin. Aedeagus conjunctiva sclerotized basally and with sclerotized teeth apically; secondary gonopore place at base of vesica in repose, sclerotization of ductus seminis around secondary gonopore as long as wide, its dorsal wall distinctly longer than ventral part; vesica with teeth apically and two spicules (fig. 9G).
Female. Unknown.

Distribution: Tahiti (fig. 19).

Host Plants: Unknown.

EтумоLоgy: The species is named after Ovalau Is. (Fiji), where it was collected.

Discussion: Felisacus ovalau is similar to $F$. bradi, F. usingeri, and F. webbi in coloration and structure (figs. 4, 7). Felisacus bradi can be separated from $F$. ovalau in the antennal segment I mostly brown, the pronotum without brown markings, the left paramere with a single outgrowth posteriorly (fig. 110), the sclerite around the ductus seminis distinctly longer than wide (fig. 10B). Felisacus webbi differs by from F. ovalau by the ventral wall of the genital capsule not curved apically, and with an outgrowth dorsally and to the right-hand side (fig. $15 \mathrm{~N}$ ), the left paramere sickle shaped, without outgrowths (fig. 13AA), and the vesica has a long curved spicule, and without toothlike spinules (fig. 10N). Felisacus usingeri differs from $F$. ovalau by antennal segment I yellow, brown apically, the pronotum without brown markings, and the labium reaches the middle of the mesosternum.

Felisacus vitilevu also inhabits Fiji and is closely related to F. ovalau. However, F. vitilevu differs in the pronotum mostly dark brown with a yellow stripe medially (fig. 7), the left paramere without a rounded outgrowth, only with a single outgrowth posteriorly (fig. 13W), and sclerotization of the ductus seminis around the secondary gonopore longer than wide (fig. $9 \mathrm{~N}$ ).

Material examined: Holotype: FIJI: Central Division: Levuka, Ovalau Is., $17.68039^{\circ} \mathrm{S}$ $178.82994^{\circ} \mathrm{E}, 100 \mathrm{~m}$, Dec 1978, N.L.H. Krauss, 1 đิ (00042352) (BPBM).

\section{Felisacus philippinensis Hsiao}

Figures 6, 10K, 13G, H, 15G, 16G. H, 20

Felisacus philippinensis Hsiao, 1944: 386 (original description).

Diagnosis: Recognized by the following combination of characters: dorsal side of head and 
pronotum mostly yellow; marking along inner margin of corium yellow to dark brown, not continuing toward $\mathrm{R}+\mathrm{M}$ (fig. 6); transverse depression on head not continuing laterally; antennal segment I widened (as in Namyatova and Cassis, in press: fig. 8B), red; labium slightly surpassing posterior margin of prosternum; inner margin of cuneus straight (as in Namyatova et al., 2016: fig. 13F); genital capsule widened from left-hand side dorsally, its ventral wall not curved apically (fig. $15 \mathrm{G})$; right paramere sickle shaped, with outer angle indistinct and inner angle distinct (fig. 13G); apical half of ductus seminis sclerotized, hooked apically (fig. 15G).

Redescription: Male. Total length 3.9-4.1. COLORATION (fig. 6): Head: Mostly yellow, often with pale brown or red markings; tubercles around antennal fossa whitish yellow; clypeus reddish to brown with yellow base; mandibular and maxillary plates yellow, buccula often yellow, brown to dark brown anteriorly, rarely uniformly yellow or brown to dark brown. Eye dark brown with reddish tinge. Labium: Segments I-II pale brown to brown, segments III-IV pale brown to brown, segment III often paler than segment IV. Antenna: Segment I reddish, sometimes reddish brown; segment II reddish brown, segments IIIIV brown to dark brown. Thorax: Pronotum mostly yellow, anterior margin often pale brown to brown; collar and calli often with reddish tinge; posterior margin often pale brown with pair of brown to brown markings near humeral angles, sometimes uniformly yellow to brown; scutellum and mesoscutum yellow to pale brown, sometimes with reddish tinge; thoracic pleura usually pale brown, sometimes mostly brown to dark brown; scent gland evaporative area uniformly whitish yellow to yellow. Hemelytron: Mostly translucent; clavus sometimes opaque, its inner part pale brown to dark brown, rarely yellow; outer part mostly pale brown to dark brown, rarely colorless or yellow, often paler than inner part; corium with yellow tinge; marking along inner margin of corium yellow to dark brown; embolium colorless, with yellow tinge and yellow to pale brown margins; cuneus colorless, with yellow tinge, outer margin yellow and inner margin whitish; membrane colorless, sometimes pale brown to brown medially; membrane cell pale brown to dark brown. Legs: Often uniformly yellow, sometimes femora apically and tibiae basally red, sometimes middle tibia and fore- and middle tarsal segments II-III pale brown to brown. Abdomen: Dorsal and lateral sides mostly yellow, often with brown markings and stripe, genital capsule sometimes with reddish tinge, dorsal surface red or brown. SURFACE AND VESTITURE: Corium with shallow punctation. Dorsum and femora with setae subequal to or slightly longer than antennal segment II diameter; antennal segment I clothed with adpressed setae shorter than antennal segment II diameter; abdomen clothed with erect setae of different length. STRUCTURE AND MEASUREMENTS: Body ca. $4.4-4.6 \times$ as long as pronotum width. Head: Depression delimiting occipital region present only dorsally; distance between depression and pronotum as long as eye diameter, not swollen laterally; longitudinal sulcus on dorsal surface of head shorter than eye diameter; distance from eye to pronotum longer than eye diameter, not swollen laterally; vertex ca. 1.4$1.6 \times$ as wide as eye; upraised. Labium: Slightly surpassing prosternum; segments I and II longer than wide, II combined as long as segment III; dorsal surface of segment II not elongate posteriorly (as in Namyatova et al., 2016: fig. 6E); segment III distinctly shorter than ventral side of head; segment IV ca. $1.5 \times$ as long as segment III. Antenna: Segment I widened basally and medially (as in Namyatova et al., 2016: fig. 8B), ca. $1.3-1.6 \times$ as long as head width, ca. $0.9 \times$ as long as pronotum width; segment II ca. $1.8-2.2 \times$ as long as head width, ca. $1.2-1.3 \times$ as long as pronotum width; antennal segment III slightly longer than segment II, segment IV only slightly shorter than segment III. Thorax: Anterior part of pronotum distinctly shorter than posterior part; collar distinct; posterior part slightly upraised; posterior margin of pronotum straight or concave; pronotum ca. 1.1-1.2 $\times$ as wide as long and ca. $1.4-1.9 \times$ as wide as head; mesoscu- 
tum exposed. Hemelytron: Area along inner margin of corium swollen; inner margin of cuneus straight (as in Namyatova et al., 2016: fig. 13F), outer margin of cuneus twice as long as width at base. Abdomen: Genital capsule rotated left at right angle relative to the rest of abdomen. Genitalia: Genital capsule (fig. $15 \mathrm{G}$ ) ca. $1.5 \times$ as long as wide; ventral wall ca. $1.5 \times$ as long as dorsal wall, with posterior margin smooth, without outgrowth(s), not curved; right side of genital capsule not curved, left side widened; paramere sockets angulate; distance between paramere sockets ca. ca. $0.25-0.3$ as long as width of genital capsule at base. Right paramere (fig. 13G) distinctly curved apically; apex concave posteriorly, medial part narrower than basal part, without setae, with outer margin convex and inner margin widened; outer angle indistinct, rounded, inner angle distinct, widened, bearing setae; basal part of paramere subequal to half of rest of paramere. Left paramere (fig. $13 \mathrm{H}$ ) irregularly shaped; apical part of paramere flattened and widened, with four outgrowths medially of different shape and length; setae placed on middle part at inner margin. Aedeagus conjunctiva membranous; vesica without spicules; apical half of ductus seminis sclerotized, hooked apically, secondary gonopore placed near phallotheca mouth in repose (fig. 10K).

Female. Total length 4.3-4.9. COLORATION (fig. 6): Head: Similar to male, but dorsal surface sometimes mostly reddish brown. Labium: Similar to male, segment III sometimes pale brown to brown, of the same color as segments I-II. Antenna: As in male. Thorax: Similar to male, but pronotum yellow to pale brown with brown to dark brown lateral sides, scutellum yellow to brown, sometimes with reddish tinge. Hemelytron: Similar to male. Legs: Similar to male, but sometimes coxae and femora basally whitish yellow and tibiae yellow basally and whitish yellow apically. Abdomen: Ventral and lateral sides mostly yellow, often with brown stripes and markings, segment IX often brown or reddish brown, dorsal surface brown or reddish. SURFACE AND VESTITURE: As in male. STRUCTURE AND MEASURE-
MENTS: Structure as in male; body ca. $4.5-4.7 \times$ as long as pronotum width; vertex ca. $1.4-1.6 \times$ as wide as eye; antennal segment I ca. $1.3-1.5 \times$ as long as head width, ca. $0.8 \times$ as long as pronotum width; segment II ca. $1.9-2.1 \times$ as long as head width, ca. $1.1-1.2 \times$ as long as pronotum width; pronotum ca. $1.1-1.2 \times$ as wide as long and ca. $1.8-1.9 \times$ as head wide. Genitalia (figs. 16G, H): Dorsal labiate plate very small and transparent, as wide as distance with apodemes of second valvulae, without striations or membranous ridge medially; semicircular sclerite and sclerotized rings absent; lateral oviducts placed in posterior part, close to each other, far from lateral margins of dorsal labiate plate; spermathecal gland attached near anterior margin; dorsal labiate plate without distinct tubercles, with triangular membranous lobe posteriorly.

Distribution: Philippines (Luzon, Mindanao, Negros) (fig. 20). Only females are known from Negros.

Host PLANTS: Unknown.

Discussion: Hsiao (1944) described F. philippinensis, and the types are preserved in the USNM and were examined but not dissected. We have specimens which fit the description of Hsiao and we treated them as conspecific with $F$. philippinensis.

Felisacus philippinensis is similar to F. luzonus externally (figs. 5, 6), but the latter species differs by the posterior part of the marking along the corium extends, to $\mathrm{R}+\mathrm{M}$, the labium reaches the middle of the mesosternum, the genital capsule is not broad on the right-hand side (fig. 14X) and the ductus seminis is straight apically (fig. 10I).

Material examined: PHILIPPINES: Camarines Sur: Iriga Mt, $13.45416^{\circ} \mathrm{N} 123.45055^{\circ} \mathrm{E}, 26$ Apr 1962, H.M. Torrevillas, $2 \overbrace{}^{\dagger}$ (00043115, $00043116)(\mathrm{BPBM})$. Iriga $\mathrm{Mt}, 13.45416^{\circ} \mathrm{N}$ $123.45055^{\circ} \mathrm{E}, 550 \mathrm{~m}, 24$ Apr 1962, H.M. Torrevillas, 1 to (00043114), 2 ㅇ $(00043119,00043120)$ (BPBM). Isarog Mt, $20 \mathrm{~km}$ E of Naga, $13.65805^{\circ} \mathrm{N}$ $123.37305^{\circ} \mathrm{E}, 550 \mathrm{~m}, 06 \mathrm{Apr}$ 1963, H.M. Torrevillas, 1 ㅇ (00043112) (BPBM). Isarog Mt, Pili, $13.65805^{\circ} \mathrm{N} 123.37305^{\circ} \mathrm{E}, 850 \mathrm{~m}, 12$ Apr 1965 , L.M. Torrevillas, $8{ }^{\star}$ (00043097-00043104), 2 우 
(00043105, 00043107) (BPBM). Isarog Mt, Pili, $13.65805^{\circ} \mathrm{N} 123.37305^{\circ} \mathrm{E}, 600 \mathrm{~m}, 20$ Sep 1964 , M.D. Delfinado, $2+(00043109,00043110)$ (BPBM). Isarog Mt, Pili, $13.65805^{\circ} \mathrm{N} 123.37305^{\circ} \mathrm{E}$, 500 m, 04 Apr 1963, H.M. Torrevillas, $1 \overbrace{}^{\text {तै }}$ (00043113) (BPBM). Isarog Mt, Pili, $13.65805^{\circ} \mathrm{N}$ $123.37305^{\circ} \mathrm{E}, 100 \mathrm{~m}, 20$ Apr 1965, H.M. Torrevillas, 1 ㅇ (00043108) (BPBM). Mt. Isarog, Pili, $13.70805^{\circ} \mathrm{N} 123.75083^{\circ} \mathrm{E}, 800 \mathrm{~m}, 27$ Apr 1965, H.M. Torrevillas, 19 (00043111) (BPBM). Davao del Sur: Galog Riv., Mt. Apo, Mindanao, 1829 m, 07 Sep 1700, C.S. Clagg, 1 ô (00045807) (BPBM). Mindanao: Matibog Creek, Bayugan, Esperanza, Agusan, $8.91716^{\circ} \mathrm{N} 125.78854^{\circ} \mathrm{E}, 300$ m, 07 Nov 1959, C.M. Yoshimoto, $10^{\Uparrow}$ (00043128) (BPBM). Negros Oriental: Balinsasayao Lake, $9.35305^{\circ} \mathrm{N} 123.17916^{\circ} \mathrm{E}, 01$ Oct $1959-07$ Oct 1959, L.W. Quate, $2+$ (00043123, 00043125) (BPBM); 01 Oct 1959-07 Oct 1959, C.M. Yoshimoto, 3 ㅇ (00043124, 00043126, 00043127), 1 juvenile (00043121) (BPBM). Surigao: Lake Mainit, $9.4333^{\circ} \mathrm{N} 125.5333^{\circ} \mathrm{E}, 24$ Nov $1959-01$ Dec 1959, L.W. Quate, 3 ơ (00043122, 00043117, 00043118) (BPBM).

\section{Felisacus ponaponensis (Carvalho)}

Figures 6, 10L, 13I, J, 15H, 20

Felisacoris ponaponensis Carvalho, 1956: 24

(original description), comb. nov.

DiAgnosis: Recognized by the following combination of characters: collar not delimited; anterior margin of pronotum distinctly raised and covering head, almost reaching eyes; mostly yellow coloration, marking along inner margin of corium yellow to pale brown, narrow, not extending toward $\mathrm{R}+\mathrm{M}$ (fig. 6), widened antennal segment I (as in Namyatova et al., 2016: fig. 8B), dorsal surface of labial segment II not elongate posteriorly (as in Namyatova et al., 2016: fig. 6E), right paramere sickle shaped, without outer angle and with inner angle (fig. 13I), left paramere with flattened apical half, with widened and serrate outgrowth on inner margin (fig. 13J), ductus seminis elongate, straight apically (fig. 10L).
Description: Male. Total length 3.5-3.6. COLORATION (fig. 6): Head: Mostly yellow. Eye dark brown with reddish tinge. Labium: Uniformly yellow. Antenna: Segment I yellow, sometime with reddish tinge, segment II red, segments III-IV reddish brown. Thorax: Often uniformly yellow, pronotum and scutellum sometimes with reddish tinge dorsally. thoracic pleura and scent gland evaporative area whitish yellow to yellow. Hemelytron: Mainly whitish yellow, translucent; clavus yellow, inner part opaque; marking along inner margin of corium yellow to pale brown; embolium whitish yellow, opaque, yellow to pale brown apically; cuneus whitish with yellow tinge, sometimes opaque; membrane with brown tinge, membrane cell yellow to brown. Legs: Whitish yellow to pale brown, tarsi sometimes pale brown. SURFACE AND VESTITURE: Corium smooth without punctation. Dorsum, femora, and abdomen with setae longer than antennal segment II diameter; antennal segment I with suberect setae shorter than antennal segment II diameter. STRUCTURE AND MEASUREMENTS: Body ca. 3.5-3.7× as long as pronotum width. Head: Depression delimiting occipital region present dorsally and laterally; distance between depression and pronotum distinctly shorter than eye diameter; longitudinal sulcus on dorsal surface of head shorter than eye diameter; distance from eye to pronotum shorter than eye diameter, not swollen laterally; vertex ca. 1.5$1.8 \times$ as wide as eye, upraised; head slightly swollen dorsally. Labium: Reaching or almost reaching posterior margin on prosternum; segments I and II combined subequal to segment III; segment I shorter than wide, segment II slightly longer than wide, its dorsal surface not elongate posteriorly (as in Namyatova et al., 2016: fig. 6E); segment III subequal to half of head length ventrally; segment IV ca. $0.3 \times$ as long as segment III. Antenna: Segment widened (as in Namyatova et al., 2016: fig. 8B), ca. 1.4$1.5 \times$ as long as head width, ca. $0.8-0.9 \times$ as long as pronotum width; segment II ca. $1.7-1.8 \times$ as long as head width, ca. $1.0-1.1 \times$ as long as pro- 
notum width; segment III slightly longer than segment II. Thorax: Anterior part of pronotum distinctly shorter than posterior part, distinctly raised above head; collar not delimited; posterior part slightly upraised; posterior margin concave, pronotum ca. $1.0-1.1 \times$ as wide as long and ca. $1.7-1.8 \times$ as wide as head; mesoscutum not exposed; inner margin of cuneus convex (as in Namyatova et al., 2016: fig. 13F), its outer margin ca. $2.5 \times$ as long as base. Abdomen: Genital capsule rotated left $45^{\circ}$ relative to the rest of abdomen. Genitalia: Genital capsule (fig. 15H) slightly longer than wide; ventral wall ca. $1.5 \times$ as long as dorsal wall, posterior margin of genital capsule not curved, right side folded, left side not widened; paramere sockets distinctly acute; distance between paramere sockets ca. $0.3 \times$ as long as genital capsule width at base; paramere sockets distinctly acute; distance between paramere sockets ca. $0.25 \times$ as long as genital capsule width at base. Right paramere (fig. 13I) sickle shaped; apex concave; medial part as wide as basal part, without setae, outer margin of medial part convex, inner margin concave, without swelling; outer angle absent; inner angle present, without outgrowth; basal part of paramere slightly shorter than rest of paramere. Left paramere (fig. 13J) apical part flattened, with toothlike outgrowth apically, without outgrowth on dorsal surface; inner margin with wide, short, serrate outgrowth. Aedeagus (general view as in Namyatova et al.: fig. 22M) vesica without spicules; apical half of ductus seminis sclerotized, hooked apically, secondary gonopore placed near phallotheca mouth in repose (fig. 10L).

Female. Total length 3.6-3.8. COLORATION: As in male. STRUCTURE AND MEASUREMENTS: As in male, segment IV ca. $0.3 \mathrm{x}$ as long as segment III. STRUCTURE AND MEASUREMENTS: Structure as in male; body ca. $3.4-3.5 \times$ as long as pronotum width; vertex ca. $2.8-2.9 \times$ as wide as eye; antennal segment I ca. $1.5 \times$ as long as head width, ca. $0.8 \times$ as long as pronotum width; segment II ca. $1.6-1.7 \times$ as long as head width, ca. $0.9 \times$ as long as pronotum width; pro- notum ca. $1.1 \times$ as wide as long and ca. $1.9 \times$ as wide as head. Genitalia: Not dissected.

Distribution: Ponape Is. (Micronesia) (fig. 20). Host PLANTS: Unknown.

Discussion: Felisacus ponaponensis was originally described in the monotypic genus Felisacoris (Carvalho, 1956). Namyatova and Cassis (2016) tentatively placed this genus into the tribe Felisacini on the basis of the structural similarity. Felisacus ponaponensis has the same structural autapomorphies of Felisacus (see diagnosis of the genus), it also has an aedeagus very similar to other species of Felisacus (cf. fig. 10L with figs. $10 \mathrm{C}, \mathrm{D}, \mathrm{F}-\mathrm{I}, \mathrm{J}, \mathrm{K}, \mathrm{O}$ ) and the parameres are very similar to those of F. bismarckensis (cf. fig. 11L, $\mathrm{M}$ with fig. 13I, J). On this basis we synonymize Felisacoris with Felisacus. Felisacus ponaponensis cannot be confused with any other species of Felisacus and we treat it as a distinct species within it, as a new combination.

Material examined: Paratypes: MICRONESIA: Pohnpei: Mt. Dolennankap, 518 m, 10 Aug 1946, H.K. Townes, $1 \delta^{\top}$ (00341131) (USNM). Ponape Is., Matalanium [Matalanim], $6.87835^{\circ} \mathrm{N}$ $158.22799^{\circ} \mathrm{E}, 11$ Aug 1946, R.G Oakley, $10^{\uparrow}$ (00338820), 2 우 (00341132, 00338821) (USNM).

\section{Felisacus rubricuneus Carvalho}

Figures 6, 9H, 13K, 20

Felisacus rubricuneus Carvalho, 1956: 30 (original description).

Diagnosis: Recognized by the following combination of characters: mostly dark coloration; antennal segment I brown to black, antennal segment II yellow, head reddish brown; pronotum brown to black laterally with reddish brown stripe medially; marking along inner margin of corium brown, wide, not extending toward $\mathrm{R}+\mathrm{M}$ anteriorly; cuneus red, cylindrical antennal segment I (as in Namyatova et al., 2016: fig. 8A), vertex upraised (as in Namyatova et al., 2016: fig. 6D); body length in male 3.6-3.8, inner part of cuneus brownish red; medial part of right paramere as wide as basal part, shorter than basal 
and apical parts combined, its inner margin widened (Carvalho, 1956: fig. 17a), vesica with five spicules, none of which can be homologized with the spicules of other species, one of spicules large and suboval (fig. 9H).

Description: Male. Total length 3.6-3.8. COLORATION (fig. 6): Head: Yellow to pale brown with reddish tinge dorsally and ventrally, yellow anteriorly and brown to reddish brown laterally. Eye dark brown to black sometimes with reddish tinge. Labium: Uniformly yellow or with segment IV pale brown. Antenna: Segment I brown with reddish tinge; segment II yellow, segment III yellow basally gradually darkening apically. Thorax: Pronotum mostly brown, yellow to pale brown medially; scutellum pale brown; pleura including scent gland evaporative area whitish yellow. Hemelytron: Mostly translucent, colorless; clavus and marking along inner margin of corium posteriorly brown; cuneus dark red; membrane with yellow or grayish tinge, cell yellow with reddish tinge. Legs: Mostly yellow, hind tibia and tarsi dark yellow to pale brown. Abdomen: Yellow. SURFACE AND VESTITURE: Dorsum and antennal segments I and II, with scarce setae mostly shorter than antennal segment II diameter; femora covered with setae longer than antennal segment II diameter. STRUCTURE AND MEASUREMENTS: Body ca. $4.3-4.5 \times$ as long as pronotum width. Head: Depression delimiting occipital region present dorsally and laterally (as in Namyatova et al., 2016: fig. 4E); distance between depression and pronotum shorter than eye diameter; longitudinal sulcus on dorsal surface longer than eye diameter; distance from eye to pronotum longer than eye diameter, slightly swollen laterally (as in Namyatova et al., 2016: fig. 4E); vertex 2.0$2.2 \times$ as wide as eye, upraised. Labium (as in Namyatova et al., 2016: figs. 6D, 9C): Reaching middle posterior margin of mesosternum; segments I and II combined longer than half of segment III; segment I shorter than wide; segment II slightly longer than wide, elongate dorsally; segment III slightly shorter than ventral side of head; segment IV more than $2.5-3 \times$ as long as segment III. Antenna: Segment I distinctly longer than head width, cylindrical, ca. $1.5 \times$ as long as head width, ca. $0.9 \times$ as long as pronotum width; segment II ca. $2.0-2.1$ as long as head width, ca. $1.2-1.3 \times$ as long as pronotum width. Thorax: Anterior part of pronotum slightly shorter than posterior part; collar delimited; posterior part slightly upraised; posterior margin of pronotum slightly concave; pronotum ca. $1.1-1.2 \times$ as wide as long and 1.6-1.7 $\times$ as wide as head. Hemelytron: Area along inner margin of corium almost flat; inner margin of corium convex (as in Namyatova et al., 2016: fig. 13E), ca. $3 \times$ as long as base. Abdomen: Genital capsule rotated left at right angle relative to rest of abdomen. Genitalia: Left paramere (fig. 13K) L-shaped, apical part flattened, with toothlike outgrowth on posterior side medially (as in fig. $11 \mathrm{G}$ ) and without outgrowth on dorsal surface; middle part widened, without swelling or outgrowth; setae only on middle part near outer margin. Aedeagus (general view as in Namyatova et al., 2016: fig. 22I) conjunctiva weakly sclerotized, sclerotized part of ductus seminis very short, secondary gonopore placed at base of vesica in repose; vesica with five spicules, none of which can be homologized with the spicules of other species (fig. 9H).

Distribution: Caroline Is. (Kusaie) (fig. 20). Host plants: Unknown.

Discussion: Females were not examined. Due to its coloration $F$. rubricuneus cannot be confused with any other Felisacus species. Superficially it is similar to other dark-colored species with a red cuneus, such as F. bau, F. bellus, F. malayensis, F. senaru, and F. signis. However, all those species differ in the posterior part of pronotum being mostly yellow to pale brown and the antennal segment II has similar coloration or darker than antennal segment I.

Material EXAMINED: Paratypes: MICRONESIA: Kosrae: Mt. Tafeyat, Kusaie Is., $5.3134^{\circ} \mathrm{N}$ 162.977E, 305 m, 21 Aug 1946, H.K. Townes, 10 (00338822) (USNM). Mt. Tafeyat, Kusaie Is., $5.3134^{\circ} \mathrm{N} 162.977^{\circ} \mathrm{E}, 198 \mathrm{~m}, 20$ Aug 1946, H.K. Townes, 1 đิ (00338823) (USNM). 


\section{Felisacus schuhi, sp. nov.}

Figures 6, 9J, 13L, M, 15I, 20

Diagnosis: Recognized by the following combination of characters: dorsal surface of head whitish yellow to pale brown; lateral sides of collar yellow to pale brown; pronotum mostly yellow, sometimes with a pair of pale brown markings near humeral angles; inner part of clavus often brown, sometimes yellow to pale brown; cuneus mostly colorless; cylindrical antennal segment I (as in Namyatova et al., 2016: fig. 8A), vertex upraised (as in Namyatova et al., 2016: fig. 6D); labium slightly surpassing middle of mesosternum; antennal segment I ca. 1.5-1.9× as long as head width; cuneus ca. $3 \times$ as long as base; medial part of right paramere slightly wider than basal part, shorter than basal and apical parts combined; its inner margin convex (fig. $13 \mathrm{~L}$ ); apical part of left paramere not widened, ca. $3 \times$ as long as wide (fig. $13 \mathrm{M}$ ); vesica with five spicules, including spicules A, B, and C (fig. 9J).

Description: Male. Total length 3.8-4.3. COLORATION (fig. 6): Head: Whitish yellow to pale brown, usually with red markings, dorsal surface usually darker than lateral and ventral sides; sometimes head uniformly colored. Eye dark brown with reddish tinge, rarely pale brown. Labium: Whitish yellow to pale brown, segments III-IV usually darker than segments I-II and with reddish tinge, sometimes labium uniformly colored. Antenna: Segment I yellow to pale brown, paler basally and sometimes darkened apically; segment II pale brown, reddish brown or brown, often darker than segment I; segments III-IV brown to dark brown, often darker than segment II. Thorax: Pronotum yellow to pale brown, with brown anterior margin, sometimes marking along posterior margin or at least marking near humeral angles also brown, reddish markings laterally sometimes present; mesoscutum and scutellum whitish yellow to yellow, sometimes depression and punctures between them pale brown; scutellum sometimes pale brown to brown apically; thoracic pleura yellow to pale brown; scent gland evaporative area whitish yellow. Hemelytron: Mostly colorless and translucent; inner part of clavus sometimes opaque, often brown with small markings and margins brown to dark brown, rarely inner part of clavus yellow to pale brown with pale brown to brown margins with or without small brown markings; outer part of clavus often yellow to pale brown apically; marking along inner margin of corium pale brown to brown, sometimes paler posteriorly; embolium with margins pale brown to brown, sometimes embolium yellow apically or uniformly yellow; cuneus with yellow or pale brown margins, sometimes outer margin and apex pale brown; membrane sometimes with grayish tinge, membrane cell yellow. Legs: Coxae whitish yellow; femora whitish yellow basally and pale brown, sometimes with reddish marking, apically; tibiae varying from yellow to pale brown, sometimes whitish yellow apically, sometimes apical part or entire tibia with reddish tinge; tarsi pale brown to brown, often with segment I and rarely segment II whitish yellow to yellow. Abdomen: Whitish yellow or yellow, sometimes with pale brown to brown dorsal surface of pregenital segments and genital capsule. SURFACE AND VESTITURE: Corium smooth, with shallow and scarce punctures. Dorsum clothed with setae subequal to or shorter than antennal segment II diameter; antennal segment I and femora clothed with suberect setae shorter than antennal segment II diameter; abdomen clothed with short, erect setae. STRUCTURE AND MEASUREMENTS: Body ca. $4.2-4.5 \times$ as long as pronotum width. Head: Depression delimiting occipital region distinct dorsally and laterally (as in Namyatova et al., 2016: fig. 4E); distance between depression and pronotum distinctly shorter than eye diameter; longitudinal sulcus on dorsal surface longer than eye diameter; distance from eye to pronotum distinctly longer than eye diameter, not swollen laterally (as in Namyatova et al., 2016: fig. 4E); vertex ca. $1.5-1.9 \times$ as wide as eye, upraised (as in Namyatova et al., 2016: fig. 6D). Labium (as in Namyatova et al., 2016: figs. 6D, 9C): Surpassing middle of mesosternum but distinctly not reaching pos- 
terior margin of mesosternum; segments I and II strongly reduced, combined shorter than half of segment III; segment I shorter than wide; segment II slightly longer than wide, its dorsal surface elongate posteriorly; segment III subequal to ventral side of head; segment IV ca. $1.5 \times$ as long as segment III. Antenna: Segment I cylindrical (as in Namyatova et al., 2016: fig. 8A), ca. $1.5-1.9 \times$ as long as head width, ca. $1.0-1.2 \times$ as long as pronotum width; segment II ca. $1.8-2.2 \times$ as long as head width, ca. $1.3-1.5 \times$ as long as pronotum width; segment III slightly longer than segment II; segment IV ca. $0.3 \times$ as long as antennal segment III. Thorax: Anterior part of pronotum slightly shorter than posterior part; collar delimited; posterior part of pronotum slightly upraised; posterior margin of pronotum concave, pronotum ca. $1.2-1.4 \times$ as wide as long and ca. $1.4-1.5 \times$ as wide as head; mesoscutum exposed. Hemelytron: Area along inner margin of corium almost flat; inner margin of cuneus convex (as in Namyatova et al., 2016: fig. 13E), outer margin of cuneus ca. $3 \times$ as long as base. Abdomen: Genital capsule rotated left at right angle relative to rest of abdomen. Genitalia: Genital capsule (fig. 15I) ca. $1.5 \times$ as long as wide; ventral wall ca. $1.7 \times$ as long as dorsal wall, with posterior margin of ventral wall semioval, smooth, without outgrowth(s), its apex slightly shifted left, not curved; sides of genital capsule not modified; right paramere socket acute, left socket rounded; distance between paramere sockets subequal to half of genital capsule width at base. Right paramere (fig. 13L) distinctly curved in apical half; apex straight; medial part slightly wider than basal part, bearing setae, with outer margin straight or slightly concave and inner margin slightly widened; outer angle distinct, not swollen; inner angle rounded, without setae; basal part ca. $0.15-0.2 \times$ as long as rest of paramere. Left paramere (fig. $13 \mathrm{M}$ ) L-shaped; apical part not flattened, with tooth on posterior side medially and without outgrowth on dorsal surface; middle part widened, without swelling or outgrowth; setae only on middle part near outer margin. Aedeagus (as in Namyatova et al.,
2016: fig. 22I) conjunctiva weakly sclerotized; secondary gonopore placed at base of vesical in repose; sclerotization of ductus seminis around secondary gonopore shorter than wide; vesical with five spicules, including large spicules A, B, and C (fig. 9J).

Female. Total length 4.3-4.6. COLORATION (fig. 6): Head: Similar to male, rarely uniformly pale brown. Labium: Similar to male, sometimes uniformly pale brown. Antenna: Similar to male, antennal segment I rarely uniformly pale brown. Thorax: As in male. Legs and hemelytron: As in male. Abdomen: Yellowish to pale brown, often with reddish apex and brownish dorsal surface. SURFACE AND VESTITURE: As in male. STRUCTURE AND MEASUREMENTS: Structure as in male; body ca. $4.2-4.5 \times$ as long as pronotum width; vertex ca. $1.6-2.1 \times$ as wide as eye; antennal segment I ca. $1.5-1.8 \times$ as long as head width, ca. $1.0-1.1 \times$ as long as pronotum width; segment II ca. $1.8-2.2 \times$ as long as head width, ca. $1.2-1.4 \times$ as long as pronotum width; pronotum ca. $1.2-1.3 \times$ as wide as long and ca. 1.5-1.7× as wide as head. Genitalia (as in Namyatova et al., 2016: figs 23F, G): Dorsal labiate plate wider than distance between apodemes of second valvula; mostly smooth, without distinct striations or longitudinal membranous ridge, with semicircular sclerites and distinct sclerotized rings laterally; lateral oviducts placed almost medially, very close to each other, spermathecal gland placed between lateral oviducts; dorsal labiate plate with distinct tubercles, without membranous lobe medially.

Distribution: Loyalty Is., Solomon Is. (Choiseul Is., Santa Cruz), Vanuatu (Malekula Is., Epi Is., Santo Is.) (fig. 20).

Host PLANTS: Unknown.

ЕтумоLоgy: The species is named after Randall Schuh, emeritus curator of the American Museum of Natural History, who kindly loaned us specimens of Felisacus.

Discussion: Felisacus schuhi is similar to $F$. elegantulus, F. lordhowensis, and F. meilingae in coloration and structure (figs. 5, 6). Felisacus elegantulus differs from $F$. schuhi in the humeral angles often brown to dark brown, the inner part 
of the clavus mostly colorless or yellow and reaching posterior margin of the mesosternum; the vesica has a short spicule $B$ and lacks spicules $A$ and $\mathrm{C}$, but with a large bifurcate spicule (fig. $8 \mathrm{H}$ ). Felisacus lordhowensis is separated from F. schuhi by the inner part of the clavus whitish yellow to yellow, the labium reaching or slightly surpassing the posterior margin of the metasternum, and the vesica has six spicules, with a short spicule $B$ and without spicules A and C (fig. 8R). Felisacus meilingae differs from $F$. schuhi by the posterior margin of the pronotum with a brown marking posteriorly and the presence of six vesical spicules, including spicules A, B, and C (fig. 9J).

MATERIAL EXAMINED: Holotype: VANUATU: Shefa: Epi Island: Lowekewou, $16.6^{\circ} \mathrm{S} 168.1667^{\circ} \mathrm{E}$, 10 m, 31 Aug 1979, B.H. Gagne, 1 đo (00043026) (BPBM). Paratypes: EAST TIMOR: Estacao Zootecnica and foot of Mundo Perdido nr Ossu, Timor Portugues, $8.73423^{\circ} \mathrm{S} 126.35914^{\circ} \mathrm{E}, 09 \mathrm{Mar}$ 1961, G.F. Gross, 10 (00017812) (SAMA). NEW CALEDONIA: Province des Iles Loyauté: Fayaoue, Ouvea Is., $20.65774^{\circ} \mathrm{S} 166.54238^{\circ} \mathrm{E}, 25 \mathrm{~m}$, Dec 1968, N.L.H. Krauss, 20 (00042305, 00042307), 1 우 (00042308) (BPBM). SOLOMON ISLANDS: Isabel: Sasamungga [Sasamonga], $7.03333^{\circ} \mathrm{S} 156.78333^{\circ} \mathrm{E}, 50 \mathrm{~m}$, Feb 1984, N.L.H. Krauss, 10 (00043242) (BPBM). Makira-Ulawa: Graciosa Bay, $10.75^{\circ} \mathrm{S} 165.76666^{\circ} \mathrm{E}, 25 \mathrm{~m}$, Jan 1977, N.L.H. Krauss, $10^{\text {to }}$ (00043241), 1 ㅇ (00043243) (BPBM). VANUATU: Espiritu Santo Is.: Big Bay, $\mathrm{E}$ Jordan River, $15.17443^{\circ} \mathrm{S}$ $166.92759^{\circ} \mathrm{E}, 20 \mathrm{~m}, 12$ Sep 1979, B.H. Gagne, $2{ }^{\widehat{0}}$ (00042314, 00042315), 4 우 (00043043-00043046) (BPBM). Malampa: South West Bay, Malekula Is., $16.4722^{\circ} \mathrm{S} 167.43124^{\circ} \mathrm{E}, 13$ Oct 1971 , P. Cochereau, 10 (00017553), $3+$ (00017554-00017556) (SAMA). Penama: Maewo Is.: Sounwari, $15.38^{\circ} \mathrm{S}$ $168.12989^{\circ} \mathrm{E}, 50 \mathrm{~m}, 04$ Sep 1979-05 Sep 1979, B.H. Gagne, $1+$ (00043062) (BPBM). Shefa: Epi Island: Lowekewou, $16.6^{\circ} \mathrm{S} 168.1667^{\circ} \mathrm{E}, 10 \mathrm{~m}, 31$ Aug 1979, B.H. Gagne, 4 đ (00043023-00043025, 00043027), 15 (00043028-00043042) (BPBM). Vaemali, $16.58959^{\circ} \mathrm{S} 168.16855^{\circ} \mathrm{E}, 125 \mathrm{~m}, 06 \mathrm{Aug}$ 1967-10 Aug 1967, J. and M. Sedlacek, $10^{\text {T }}$ (00042313) (BPBM).

\section{Felisacus senaru, sp. nov.}

Figures 6, 9I, 13N, O, 20

Diagnosis: Recognized by the following combination of characters: relative dark coloration; head yellow to pale brown; posterior part of pronotum yellow to pale brown with wide brown stripe along posterior margin; antennal segment I mostly brown and segment II reddish brown; antennal segment I cylindrical (as in Namyatova et al., 2016: fig. 8A); vertex upraised (Namyatova et al., 2016: fig. 6D); body length in male 3.6-3.8, in female 3.8-4.1; medial part of right paramere slightly wider than basal part, with outer margin concave (fig. $13 \mathrm{~N}$ ), vesical with six spicules, including ling spicules $\mathrm{A}, \mathrm{B}$, and $\mathrm{C}$, spicule $\mathrm{C}$ distinctly moved posteriorly (fig. 9I).

Description: Male. Total length 3.6-3.8. COLORATION (fig. 6): Head: Yellow to pale brown with reddish tinge dorsally. Eye dark brown to black. Labium: Yellow. Antenna: Segment I brown, pale yellow to yellow basally and ventrally; segment II reddish brown; segments III-IV dark brown to black, darker than segment II. Thorax: Pronotum yellow to pale brown, with brown anterior margin and wide brown stripe along posterior margin; mesoscutum pale brown, scutellum brown; thoracic pleura yellow; scent gland evaporative area whitish yellow. Hemelytron: Mostly colorless and translucent; inner part of clavus translucent or opaque, brown; marking along inner margin of corium brown; embolium with margins yellow; cuneus with pale brown margins and inner half red; membrane with greyish tinge. Legs: Coxae whitish yellow; femora, tibiae, and tarsi yellow. Abdomen: Yellow with greenish tinge. SURFACE AND VESTITURE: Corium smooth, impunctate. Dorsum clothed with setae suberect and longer than antennal segment II diameter; antennal segment I and femora clothed with suberect setae shorter than antennal segment II diameter; abdomen clothed with short erect setae. STRUCTURE AND MEASUREMENTS: Body ca. $4.4-4.7 \times$ as long as pronotum width. Head: Depression delimiting occipital region 
present dorsally and laterally (as in Namyatova et al., 2016: fig. 4E); distance between depression and pronotum shorter than eye diameter; longitudinal sulcus on dorsal surface longer than eye diameter; distance from eye to pronotum distinctly longer than eye diameter, not swollen laterally (as in Namyatova et al., 2016: fig. 4E); vertex ca. $1.5-1.9 \times$ as wide as eye; upraised view (Namyatova et al., 2016: fig. 6D). Labium (as in Namyatova et al., 2016: figs. 6D, 9C): Surpassing metasternum, but distinctly not reaching posterior margin of metasternum; segments I and II strongly reduced, combined shorter than half of segment III; segment I shorter than wide; segment II slightly longer than wide, its dorsal surface elongate posteriorly; segment III slightly shorter than ventral side of head; segment IV twice as long as segment III. Antenna: Segment I cylindrical (as in Namyatova et al., 2016: fig. $8 \mathrm{~A})$, ca. $1.7-1.9 \times$ as long as head width, ca. 1.1$1.2 \times$ as long as pronotum width; segment II ca. $2.1-2.3 \times$ as long as head width, ca. $1.3-1.5 \times$ as long as pronotum width; segment III slightly longer than segment II; segment IV ca. $0.2 \times$ as long as antennal segment III. Thorax: Anterior part of pronotum shorter than posterior part; collar delimited; posterior part only slightly upraised; posterior margin of pronotum concave, pronotum ca. $1.2 \times$ as wide as long and ca. $1.6 \times$ as wide as head; mesoscutum slightly exposed. Hemelytron: Area along inner margin of corium flat; inner margin of cuneus concave (as in Namyatova et al., 2016: fig. 13E), outer margin of cuneus ca. $2.5 \times$ as long as base. Abdomen: Genital capsule rotated left at right angle relative to rest of abdomen. Genitalia: Right paramere (fig. 13N) apical part distinctly delimited, only slightly concave posteriorly, medial part slightly wider than basal part, bearing setae, with outer margin straight or slightly concave and inner margin slightly widened; outer angle distinct, not swollen; inner angle rounded, without setae; basal part ca. $0.2 \times$ as long as rest of paramere. Left paramere (fig. 13O) L-shaped; apical part not flattened, ca. $3 \times$ as long as wide, with tooth on posterior side medially and with- out outgrowth on dorsal surface; middle part widened, without swelling or outgrowth; setae present only on middle part near outer margin. Aedeagus (general view as in Namyatova et al., 2016: fig. 22I) conjunctiva weakly sclerotized; secondary gonopore placed at base of vesical in repose; sclerotization of ductus seminis around secondary gonopore shorter than wide; vesica with six spicules, including spicules $\mathrm{A}, \mathrm{B}$, and $\mathrm{C}$, spicule $\mathrm{C}$ convolute basally and distinctly moved posteriorly (fig. 9I).

Female. Total length 3.8-4.1. COLORATION (fig. 6): Similar to male, sometimes dorsal side of head and pronotum with red or brown tinge, antennal segment I sometimes almost uniformly yellow to pale brown or yellow with reddish tinge; cuneus sometimes yellow with reddish brown margins and inner parts, tibiae sometimes brown. SURFACE AND VESTITURE: As in male. STRUCTURE AND MEASUREMENTS: Structure as in male; body ca. $4.4-4.5 \times$ as long as pronotum width; vertex ca. $1.8-2.5 \times$ as wide as eye; antennal segment I ca. $1.6-1.8 \times$ as long as head width, ca. $1.0 \times$ as long as pronotum width; segment II ca. $2.0-2.3 \times$ as long as head width, ca. $1.2-1.4 \times$ as long as pronotum width; pronotum ca. $1.2 \times$ as wide as long and ca. 1.6-1.7 $\times$ as wide as head.

Distribution: Specimens were collected only in Senaru (Lombok Is.) (fig. 20).

Eтymology: The species is named after the place Senaru (Lombok, Indonesia), where it was collected.

Host Plants: Plesioneuron sp. (Thelypteridaceae), many specimens.

Discussion: Felisacus senaru can be confused with other dark specimens of this genus that possess a red or partially red cuneus, such as $F$. bau, F. bellus, F. jacobsoni, F. malayensis, and F. signis. These species differs from $F$. senaru in the cuneus entirely or mostly red and in the shape and/or number of vesical spicules (cf. fig. 9I with figs. 8D, E, M, 9A. K).

Material eXAmined: Holotype: INDONESIA: West Nusa Tenggara: Lombok Island, nr Senaru, $8.31689^{\circ} \mathrm{S} 116.40381^{\circ} \mathrm{E}, 29$ Aug 2012, F. Konstantinov, $1{ }^{\Uparrow}$ (00386472) (ZISP). Paratypes: 
INDONESIA: West Nusa Tenggara: Lombok Island, Senaru, Panorama track to Sendang Gila Waterfall, $8.30111^{\circ} \mathrm{S} 116.40833^{\circ} \mathrm{E}, 28$ Aug 2012, F. Konstantinov, 1 đิ (00386469) (ZISP); 30 Aug 2012, F. Konstantinov, Plesioneuron sp. (Thelypteridaceae), det. Michael Lovave (LAE herbarium, PNG), $120^{\star}$ (00386488-00386499), 1 sex unknown (00386500), 12 ㅇ (0038650100386512) (ZISP). Lombok Island, Senaru, track to Tiu Kelep Waterfall, $8.30111^{\circ} \mathrm{S} 116.40833^{\circ} \mathrm{E}$, 28 Aug 2012, F. Konstantinov, 2 (00386461, 00386462) Plesioneuron sp. (Thelypteridaceae), 4 (00386463-00386466) (ZISP); 31 Aug 2012, F. Konstantinov, Plesioneuron sp. (Thelypteridaceae), 1 sex unknown (00386468) (ZISP). Lombok Island, nr Senaru, $8.31689^{\circ} \mathrm{S} 116.40381^{\circ} \mathrm{E}, 29$ Aug 2012, F. Konstantinov, $13 q$ (0038647400386480, 00386474-00386479), 1 sex unknown (00386480), 2 đ (00386470, 00386471) (ZISP). Lombok Island, $\mathrm{nr}$ Senaru, $8.31956^{\circ} \mathrm{S} 116.405^{\circ} \mathrm{E}$, 31 Aug 2012, F. Konstantinov, Plesioneuron sp. (Thelypteridaceae), det. Michael Lovave (LAE herbarium, PNG), 4o (00386481-00386484), 3 우 (00386485-00386487) (ZISP).

Felisacus signis Hsiao, status nov.

Figures 6, 9K, 13P, Q, 20

Felisacus carpenterae signis Hsiao, 1944: 386.

DIAGNOSIs: Recognized by the following combination of characters: head and pronotum yellow to pale brown; posterior part of pronotum with dark brown to black markings at humeral angles; antennal segment I yellow with reddish tinge; cuneus red; marking along inner margin of corium brown, not extending toward $\mathrm{R}+\mathrm{M}$ anteriorly; cylindrical antennal segment I (as in Namyatova et al., 2016: fig. 8A), vertex upraised (as in Namyatova et al., 2016: fig. 6D); length of body in male 3.3, length in female 3.35; right paramere with medial part shorter than apical part and distinctly wider than basal part (fig. 13P); vesica with five spicules, including spicule B (fig. 9K).

Description: Male. Total length 3.3. COLORATION (fig. 6): Head: Mostly yellow to pale brown, with reddish tinge, ventral side yellow to pale brown. Eye dark brown to black. Labium: Yellow. Antenna: Segment I yellow with reddish tinge, segment II reddish brown; segment III brown. Thorax: Pronotum and scutellum yellow to pale brown; humeral angle with pale brown to brown marking, anterior margin sometimes pale brown; thoracic pleura yellow; scent gland evaporative area whitish yellow. Hemelytron: Mostly translucent, colorless; inner part of clavus with yellow tinge and reddish yellow margins; corium with brown marking along apical part of clavus, area along inner margin of corium pale brown to brown; embolium with pale brown or red margins; cuneus red. Legs: Whitish yellow to yellow, sometimes femora and tibiae with reddish tinge. Abdomen: Yellow to pale brown. SURFACE AND VESTITURE: Dorsum, antennal segment I and II and femora with setae shorter than antennal segment II diameter; abdomen clothed with short setae. STRUCTURE AND MEASUREMENTS: Body ca. $4.3 \times$ as long as pronotum width. Head: Depression delimiting occipital region present dorsally and laterally (as in Namyatova et al., 2016: fig. 4E); distance between depression and pronotum distinctly shorter than eye diameter; longitudinal sulcus on dorsal surface subequal to eye diameter; distance from eye to pronotum subequal to or slightly longer than eye diameter, not swollen laterally (as in Namyatova et al., 2016: fig. $4 \mathrm{E}$ ); vertex ca. $1.4 \times$ as wide as eye, upraised (as in Namyatova et al., 2016: fig. 6D). Labium (as in Namyatova et al., 2016: figs. 6D, 9C): Segments I and II strongly reduced, combined subequal to half of segment III; segment I shorter than wide; segment II almost as long as wide, elongate dorsally; segment III slightly shorter than ventral side of head; segment IV twice as long as segment III. Antenna: Segment I distinctly longer than head width, cylindrical (as in Namyatova et al., 2016: fig. 8A), ca. $1.6 \times$ as long as head width, ca. $1.2 \times$ as long as pronotum width; segment II ca. $2 \times$ as long as head width, ca. $1.4 \times$ as long as pronotum width. Thorax: Anterior part of pronotum distinctly shorter than posterior part; collar distinct; pos- 
terior part only slightly swollen; lateral margins not delimited with depression; posterior margin of pronotum straight; pronotum ca. $1.2 \times$ as wide as long and $1.4 \times$ as wide as head. Hemelytron: Area along inner margin of corium almost flat; inner margin of cuneus convex (as in Namyatova et al., 2016: fig. 13E), outer margin of cuneus ca. $2.5 \times$ as long as base. Abdomen: Genital capsule rotated left at right angle relative rest of abdomen. Genitalia: Right paramere (fig. 13P) apical part distinct; apex slightly concave; medial part distinctly wider than basal part, bearing setae, with outer margin straight slightly concave and inner margin swollen; outer angle distinct, slightly swollen; inner angle absent, without setae; basal part ca. $0.25 \times$ as long as rest of paramere. Left paramere (fig. 13Q) L-shaped; apical part not flattened, ca. $3 \times$ as long as wide, with toothlike outgrowth on posterior side medially and without outgrowth on dorsal surface; middle part widened, without swelling or outgrowth(s); setae only on middle part near outer margin. Aedeagus (general view as fig. 22I in Namyatova et al., 2016) conjunctiva weakly sclerotized; secondary gonopore placed at base of vesical in repose; sclerotization of ductus seminis around secondary gonopore shorter than wide; vesica with five spicules, including elongate spicule $\mathrm{B}$, not swollen medially (fig. 9K).

Female. Total length 3.5. COLORATION (fig. 6): As in male. Abdomen: Yellow, sometimes with reddish markings. SURFACE AND VESTITURE: As in male. STRUCTURE AND MEASUREMENTS: Body ca. $4.2 \times$ as long as pronotum width; vertex ca. $1.4 \times$ as wide as eye; antennal segment I ca. $1.6 \times$ as long as head width, ca. $1.1 \times$ as long as pronotum width; segment II ca. $2.0 \times$ as long as head width, ca. $1.3 \times$ as long as pronotum width; pronotum ca. $1.2 \times$ as wide as long and ca. $1.5 \times$ as wide as head.

Distribution: Singapore (fig. 20).

Host Plants: Unknown.

Discussion: Felisacus signis was originally described as a subspecies of $F$. carpenterae (Hsiao, 1944). Examination of the type material from USNM showed that $F$. carpenterae is a junior synonym of $F$. javanus (see discussion for this species), and F. carpenterae signis differs in coloration and male genitalia. On this basis we decided to raise this taxon to species rank.

Felisacus signis differs from $F$. javanus in having darker coloration, the humeral angles are dark brown to black and the cuneus is or entirely red. Felisacus javanus also differs in the shape of the right paramere, with the medial part longer than the apical part and almost as wide as basal part (cf. fig. $12 \mathrm{G}$ with fig. 13P), and the presence of the vesical spicules $\mathrm{A}, \mathrm{B}$, and $\mathrm{C}$ (cf. fig. $8 \mathrm{~N}$ with fig. $9 \mathrm{~K}$ ). Felisacus signis is similar to other dark species of this genus with a red cuneus, including F. bau, F. bellus, F. jacobsoni, F. malayensis, and F. senaru. However, all those species differ from $F$. signis in shape and/or number of vesical spicules (cf. fig. 9K with figs. 8D, E, M, 9A, I).

Material eXamined: Paratypes: MALAYSIA: Sabah: Sandakan, Borneo, $5.84561^{\circ} \mathrm{N}$ $118.05705^{\circ} \mathrm{E}, 66 \mathrm{~m}$, no date provided, Baker, $1 \delta^{\star}$ (00338827), 1 우 (00338828) (USNM).

\section{Felisacus solomonicus, sp. nov.}

Figures 7, 9L, 13R, S, 15J, 20

Diagnosis: Recognized by the following combination of characters: head yellow to pale brown; pronotum mostly yellow, antennal segment I red or brown; outer part of clavus yellow; cuneus yellow with reddish tinge, sometimes outer part almost colorless; cylindrical antennal segment I (as in Namyatova et al., 2016: fig. 8A), vertex upraised (as in Namyatova et al., 2016: fig. 6D); labium slightly surpassing middle of mesosternum; cuneus ca. $3 \times$ as long as base; medial part of right paramere as wide as basal part, shorter than basal and apical parts combined, its outer and inner margins straight, apical part of right paramere distinctly concave (fig. 13R); vesica with six spicules, including spicule A (fig. 9L).

Description: Male. Total length 3.1-3.4. COLORATION (fig. 7): Head: Mostly yellow to pale brown; tubercle around antennal fossa whitish yellow; longitudinal sulcus and buccula 
sometimes pale brown, slightly darker than rest of head, and clypeus rarely reddish apically. Eyes brown with reddish tinge. Labium: Yellow, segment III reddish ventrally, segments I-III sometimes with reddish tinge. Antenna: Segment I reddish brown to brown with yellow base, segments II-IV brown. Thorax: Yellow with anterior margin pale brown and posterior angles reddish or brown; scutellum whitish yellow to yellow, mesoscutum and scutellum yellow to yellowish brown, punctures between mesoscutum and scutellum pale brown; thoracic pleura yellow, scent gland evaporative area yellow to pale brown often with whitish yellow apex. Hemelytron: Mostly translucent, colorless; inner part of clavus translucent or opaque, yellow to pale brown, margins sometimes somewhat darker; outer part of clavus sometimes yellow; area along inner margin of corium yellow or pale brown; embolium yellow apically and pale brown to brown margins; cuneus yellow with reddish tinge, sometimes outer part almost colorless, margin brown or reddish; membrane sometimes with grayish tinge, membrane call yellow to pale brown. Legs: Coxae whitish yellow, femora whitish yellow basally and yellow apically with red marking on apex; tibiae reddish; tarsi yellow to pale brown. Abdomen: Reddish, yellow apically. SURFACE AND VESTITURE: Corium smooth, often with shallow and scarce punctures. Dorsum with suberect setae subequal to or shorter than antennal segment II diameter; antennal segment II and femora with suberect setae shorter than antennal segment II diameter; abdomen clothed with suberect mostly short simple setae. STRUCTURE AND MEASUREMENTS: Body ca. $4.3-4.8 \times$ as long as pronotum width. Head: Depression delimiting occipital region present dorsally and laterally (as in Namyatova et al., 2016: fig. 4E); distance between depression and pronotum distinctly shorter than eye diameter; longitudinal sulcus on dorsal surface longer than eye diameter; distance from eye to pronotum longer than eye diameter, not swollen laterally (as in Namyatova et al., 2016: fig. 4E); vertex ca. $1.6-1.8 \times$ as wide as eye, upraised (as in Namya- tova et al., 2016: fig. 6D). Labium (as in Namyatova et al., 2016: figs. 6D, 9C): Surpassing middle of mesosternum; segments I and II strongly reduced, combined subequal to half of segment III; segment I shorter than wide; segment II slightly longer than wide, its dorsal surface elongate posteriorly; segment III slightly longer than ventral side of head; segment IV ca. $1.5 \times$ as long as segment III. Antenna: Segment I cylindrical (as in Namyatova et al., 2016: fig. 8A), ca. 1.1$1.4 \times$ as long as head width, ca. $0.9-1.1 \times$ as long as pronotum width; segment II ca. $1.8-1.9 \times$ as long as head width, ca. $1.4 \times$ as long as pronotum width; segment III slightly longer than segment II. Thorax: Anterior and posterior parts subequal in length; calli delimited; posterior part slightly upraised; posterior margin not delimited with depression; posterior margin concave, pronotum

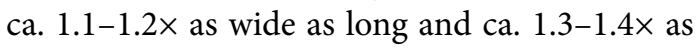
wide as head; mesoscutum exposed. Hemelytron: Area along inner margin of corium almost flat; inner margin of cuneus convex (as in Namyatova et al., 2016: fig. 13E), outer margin ca. $3 \times$ as long as base. Abdomen: Genital capsule rotated $45^{\circ}$ relative to rest of abdomen. Genitalia: Genital capsule (fig. 15J) ca. $1.5 \times$ as long as wide; ventral wall ca. $1.5 \times$ as long as dorsal wall, its posterior margin smooth, semioval, without outgrowth(s), not curved dorsally; its apex slightly shifted right; right side of genital capsule not curved, left side not widened; paramere sockets more or less rounded; distance between paramere sockets ca. $0.7 \times$ as long as genital capsule width at base. Right paramere (fig. 13R) distinctly curved in apical half; apex concave posteriorly; medial part wider than basal part, bearing setae, with outer margin straight and inner margin slightly concave, without swelling; outer angle distinct; inner angle indistinct, without setae; basal part of paramere ca. $0.15-0.2 \times$ as long as rest of paramere. Left paramere (fig. 13S) L-shaped; apical part not flattened, with tooth on posterior side medially (as in fig. 11G) and without outgrowth on dorsal surface; middle part widened, without swelling or outgrowth; setae only on middle part near outer margin. Aedeagus (as in Namyatova et al., 
2016: fig. 22I) conjunctiva weakly sclerotized; secondary gonopore placed at base of vesical in repose; sclerotization of ductus seminis around secondary gonopore shorter than wide; vesica with six spicules, including elongate and narrow spicule A (fig. 9L).

Female. Total length 3.3-3.4. COLORATION (fig. 7): Similar to male, thorax yellow with anterior margin pale brown and posterior angles reddish, evaporatorium uniformly pale brown; abdomen uniformly reddish or pale brown apically. SURFACE AND VESTITURE: As in male. STRUCTURE AND MEASUREMENTS: Structure as in male; body ca. $4.2-4.4 \times$ as long as pronotum width; vertex ca. 1.7-1.9× as wide as eye; antennal segment I ca. 1.3-1.4× as long as head width, ca. $0.9-1.0 \times$ as long as pronotum width; segment II ca. $1.7-1.8 \times$ as long as head width, ca. $1.2-1.3 \times$ as long as pronotum width; pronotum ca. $1.1-1.2 \times$ as wide as long and ca. $1.4 \times$ as wide as head. Genitalia (as in Namyatova et al., 2016: fig. 23F, G): Dorsal labiate plate wider than distance between apodemes of second valvula; mostly smooth, without distinct striations, with semicircular sclerite and distinct sclerotized rings laterally; lateral oviducts placed almost medially, very close to each other, spermathecal gland placed between lateral oviducts; dorsal labiate plate with distinct tubercles, without membranous lobe medially.

Remarks: Antennal segment IV lost in males.

Distribution: Solomon Is. (Gizo Is., Malaito Is., Georgia Is., Auki Is.) (fig. 20).

Host Plants: Unknown.

Eтymology: The species is named after Solomon Islands, where it was collected.

Discussion: Felisacus solomonicus is most similar to F. albus, F. amboinae, F. javanus, and F. linae externally (figs. 4,5). All these species can be separated from each other by the apical part of the right paramere straight or slightly concave (figs. 11A, C, 12G, K) and the shape and/or number of the vesical spicules (figs. 8A, B, N, P).

MATERIAL EXAMINED: Holotype: SOLOMON ISLANDS: Malaita: Auki, $8.767^{\circ} \mathrm{S} 160.7^{\circ} \mathrm{E}, 50 \mathrm{~m}$, Dec 1975, N.L.H. Krauss, $10^{\widehat{T}}$ (00043231)
(BPBM). Paratypes: SOLOMON ISLANDS: Malaita: Auki, $8.767^{\circ} \mathrm{S} 160.7^{\circ} \mathrm{E}, 100 \mathrm{~m}$, Feb 1985, N.L.H. Krauss, $1+$ (00043233) (BPBM). Tagatalau [Tangtalau], $8.73333^{\circ} \mathrm{S} 160.73333^{\circ} \mathrm{E}, 200 \mathrm{~m}$, 25 Sep 1957, J.L. Gressitt, 10 (00043229) (BPBM). New Georgia Islands: Gizo, Gizo Is., $8.1^{\circ} \mathrm{S} 156.85^{\circ} \mathrm{E}, 100 \mathrm{~m}$, Nov 1975 , N.L.H. Krauss, $20^{\text {Tे }}(00043227,00043228)$ (BPBM). Tamaneke, $8.48333^{\circ} \mathrm{S} 158.06667^{\circ} \mathrm{E}, 50 \mathrm{~m}$, Feb 1987, N.L.H. Krauss, 1 웅 (00043232) (BPBM). Western Province: New Georgia Islands: Munda, New Georgia Is., $8.31666^{\circ} \mathrm{S} 157.25^{\circ} \mathrm{E}, 50 \mathrm{~m}$, Feb 1984 , N.L.H. Krauss, 1 tิ (00043230) (BPBM).

Felisacus tanna, sp. nov.

Figures 7, 9M, 13T, U, 15K, 20

Diagnosis: Recognized by the following combination of characters: head yellow to pale brown dorsally; pronotum, including collar and humeral angles, mostly whitish yellow to yellow; inner margin of clavus yellow; scent gland evaporative area whitish basally and yellow or red apically, rarely uniformly red; cuneus colorless, often with yellow tinge, with margins yellow to pale brown; cylindrical antennal segment I (as in Namyatova et al., 2016: fig. 8A), vertex upraised (as in Namyatova et al., 2016: fig. 6D); labium reaching posterior margin of metasternum or slightly surpassing it; setae on femora distinctly shorter than antennal segment II width; medial part of right paramere distinctly wider than basal part; shorter than basal and apical parts combined; its outer margin straight (fig. 13T); apical part of left paramere not widened, ca. $3 \times$ as long as wide (fig. 13U); vesica with six spicules, including spicules $\mathrm{A}, \mathrm{B}$, and $\mathrm{E}$ (fig. 9M).

Description: Male. Total length 3.4-3.6. COLORATION (fig. 7): Head: Mostly whitish yellow to yellow, dorsal surface sometimes with reddish tinge and reddish markings. Eye dark brown, often with reddish tinge. Labium: Whitish yellow to yellow, labial segment III with reddish stripe ventrally, segment IV often somewhat darker than segments I-III. Antenna: Segment I yellow to pale brown often with reddish tinge; 
segment II yellow to brown, sometimes with reddish tinge, often darker than segment I; segments III-IV brown to dark brown often darker than segment II. Thorax: Pronotum whitish yellow to yellow, often with reddish tinge anteriorly or with reddish stripe laterally, collar with brown anterior margin; mesoscutum and scutellum whitish yellow to yellow; thoracic pleura yellow, sometimes with reddish tinge; scent gland evaporative area whitish basally and yellow or red apically, rarely uniformly red. Hemelytron: Mostly translucent and colorless; inner part of clavus opaque or translucent, yellow, with margins yellow to pale brown; marking along inner margin of corium yellow; embolium with pale brown margins and yellow apex; cuneus often with yellow tinge, with margins yellow to pale brown; membrane with yellow tinge, membrane cell yellow. Legs: Coxa whitish yellow; femora whitish yellow basally and yellow to pale brown apically; tibia yellow to pale brown, femora and tibia sometimes with reddish tinge; tarsi often pale brown with segment I paler, yellow to pale brown, sometimes uniformly yellow to pale brown. Abdomen: Ventral and lateral sides whitish yellow to yellow, dorsal surface reddish, genital capsule sometimes darker than pregenital segments, yellow to pale brown, rarely abdomen uniformly red. SURFACE AND VESTITURE: Corium smooth, with shallow and scarce punctures. Dorsum clothed with setae subequal to or shorter than antennal segment II diameter; antennal segment II, femora and abdomen clothed with suberect setae distinctly shorter than antennal segment II diameter. STRUCTURE AND MEASUREMENTS: Body ca. 4.4$4.6 \times$ as long as pronotum width. Head: Depression delimiting occipital region present dorsally and laterally (as in Namyatova et al., 2016: fig. 4E); distance between depression and pronotum distinctly shorter than eye diameter; longitudinal sulcus on dorsal surface of head slightly longer than eye diameter; distance from eye to pronotum longer than eye diameter, not swollen laterally (as in Namyatova et al., 2016: fig. $4 \mathrm{E}$ ); vertex ca. $1.6-2.0 \times$ as wide as eye, upraised (as in Namyatova et al., 2016: fig. 6D). Labium (as in Namyatova et al., 2016: figs. 6D, 9C): Reaching posterior margin of metasternum or slightly surpassing it; segments I and II strongly reduced, combined shorter than half of segment III; segment I shorter than wide; segment II slightly longer than wide, its dorsal surface elongate posteriorly; segment III longer than ventral side of head; segment IV ca. $1.5 \times$ as long as segment III. Antenna: Segment I cylindrical (as in Namyatova et al., 2016: fig. 8A), ca. 1.5$1.8 \times$ as long as head width, ca. $0.9-1.1 \times$ as long as pronotum width; segment II ca. $2.0-2.2 \times$ as long as head width, ca. $1.2-1.4 \times$ as long as pronotum width; antennal segment III slightly longer than segment II; segment IV ca. $0.3 \times$ as long as segment III. Thorax: Anterior part of pronotum slightly shorter than posterior part; collar delimited; posterior part of pronotum slightly upraised; posterior angles of pronotum not delimited with depression; posterior margin of pronotum straight or concave, pronotum ca. $1.3 \times$ as wide as long and ca. $1.5-1.7 \times$ as wide as head; mesoscutum not exposed or exposed. Hemelytron: Area along inner margin of corium flat; inner margin of cuneus convex (as in Namyatova et al., 2016: fig. 13E), outer margin of cuneus ca. $3 \times$ as long as base. Abdomen: Genital capsule rotated left at right angle relative to the rest of abdomen. Genitalia: Genital capsule (fig. $15 \mathrm{~K})$ ca. $1.5 \times$ as long as wide; ventral wall ca. $1.5 \times$ as long as dorsal wall, with posterior margin of ventral wall semioval, smooth, without outgrowth, apex inclined leftward, not curved; sides of genital capsule not modified; paramere socket slightly acute, left paramere socket rounded; distance between paramere sockets subequal to half of genital capsule width at base. Right paramere (fig. 13T) distinctly curved in apical half; apex straight posteriorly; medial part twice as wide as basal part, bearing setae, with outer margin straight and inner margin widened; outer angle distinct, not widened; inner angle rounded, without setae; basal part of paramere ca. $0.15-0.2 \times$ as long as rest of paramere. Left paramere (fig. 13U) L-shaped; apical part not flattened, with tooth- 
like outgrowth on posterior side medially (as in fig. $11 \mathrm{G}$ ) and without outgrowth on dorsal surface; middle part widened, without swelling or outgrowth; setae only on middle part near outer margin. Aedeagus (general view as in Namyatova et al., 2016: fig. 22I) conjunctiva weakly sclerotized, secondary gonopore placed at base of vesical in repose; sclerotization of ductus seminis around secondary gonopore shorter than wide; vesica with six spicules, including spicules $A, B$, and E, spicule A short and spicule B large and serrate apically (fig. 9M).

Female. Total length 3.5-3.8. COLORATION (fig. 7): Head and labium: As in male. Antenna: Similar to male, antennal segment II rarely yellow with reddish tinge. Thorax: Similar to male, but posterior part of pronotum rarely pale brown posteriorly. Abdomen: Whitish yellow to yellow with red dorsal surface. SURFACE AND VESTITURE: As in male. STRUCTURE AND MEASUREMENTS: Structure as in male; body ca. $4.2-4.7 \times$ as long as pronotum width; vertex ca. $1.8-2.2 \times$ as wide as eye; antennal segment I ca. $1.6-1.7 \times$ as long as head width, ca. $1.0-1.1 \times$ as long as pronotum width; segment II ca. 1.9-2.1× as long as head width, ca. $1.1-1.3 \times$ as long as pronotum width; pronotum ca. $1.2-1.4 \times$ as wide as long and ca. $1.5-1.7 \times$ as wide as head. Genitalia (as in Namyatova et al., 2016: fig. 22I): Dorsal labiate plate wider than distance between apodemes of second valvula; mostly smooth, without distinct striations, with semicircular sclerite and distinct sclerotized rings laterally; lateral oviducts placed almost medially, very close to each other, spermathecal gland placed between lateral oviducts; dorsal labiate plate with distinct tubercles, without membranous lobe medially.

Distribution: Vanuatu (Tanna Is., Maewo Is.) (fig. 20).

Host Plants: Unknown.

Eтymology: The species is named after Tanna Is., where most of the examined specimens were collected.

Discussion: Felisacus tanna is similar to $F$. glabratus in coloration (figs. 5,7 ) and the broad medial part of the right paramere (cf. fig. $11 \mathrm{AF}$ with fig. 13T), but the latter species differs by the labium reaching the middle of the mesosternum, the medial part of the right paramere has the outer margin concave (fig. 11AF) and the vesica has five spicules, including spicules B and F (fig. 8J).

Felisacus tanna can also be confused with $F$. filicicola, F. lordhowensis, and F. schuhi (figs. 5, 6), but these latter three species differ in the middle part of the right paramere being only slightly wider than the basal part (figs. 11AD, 12S, 13L) and the shape and/or number of the vesical spicules (figs. 8I, R, 9J).

MATERIAL EXAMINED: Holotype: VANUATU: Taffeta: Tanna Is.: $2 \mathrm{~km} \mathrm{~S}$ Ipeukeul, $19.51511^{\circ} \mathrm{S}$ 169.45466 E, 350 m, 23 Aug 1979, G.A. Samuelson, 1 đิ (00043068) (BPBM). Paratypes: VANUATU: Penama: Maewo Is.: Sounwari, $15.38^{\circ} \mathrm{S}$ $168.12989^{\circ} \mathrm{E}, 50 \mathrm{~m}, 04$ Sep $1979-05$ Sep 1979, B.H. Gagne, $3 \sigma^{\star}$ (00043052-00043054), 2 ㅇ (00043061, 00043063) (BPBM). Taffeta: Tanna Is.: $2 \mathrm{~km} \mathrm{~S}$ Ipeukeul, $19.51511^{\circ} \mathrm{S} 169.45466^{\circ} \mathrm{E}$, 350 m, 23 Aug 1979, G.A. Samuelson, 11 đ (00043069-00043072, 00043077-00043083), 3 juvenile (00043073-00043075), 1 sex unknown (00043066), 1 우 (00043076) (BPBM). Loounapkaukangeus, $19.5^{\circ} \mathrm{S} 169.3^{\circ} \mathrm{E}, 350 \mathrm{~m}, 03 \mathrm{Mar} 1970$, N.L.H. Krauss, 10 (00043067) (BPBM).

\section{Felisacus usingeri Woodward}

Figures 7, 20

Felisacus usingeri Woodward, 1954: 47 (original description).

DiAGNOSIs: Recognized by the following combination of characters: head and pronotum mostly yellow; antennal segment I yellow, brown apically; transverse depression delimiting occipital region present only dorsally; labium reaching middle of mesosternum; distance between eye and pronotum slightly longer than eye diameter.

DesCription: Male. Unknown. Female. Total length 3.7. COLORATION (fig. 7): Head: Mostly yellow. Labium: Uniformly yellow. Antenna: Seg- 
ment I yellow, brown apically, segment II uniformly brown. Eye brown. Thorax: Pronotum and scutellum yellow; thoracic pleura yellow; scent gland evaporative area whitish yellow. Hemelytron: Mostly translucent, colorless; clavus yellow; marking along inner margin of corium brown; embolium with yellow tinge and pale brown margins; cuneus with yellow tinge, its outer margin brown. Legs: Coxae whitish yellow; femora whitish yellow, yellow apically; tibae yellow. Abdomen: Whitish yellow. SURFACE AND VESTITURE: Head, pronotum, scutellum, clavus, and costal vein anteriorly with scarce setae subequal to or shorter than antennal segment II diameter; antennal segments I and II with suberect setae shorter than antennal segment II diameter; femora clothed with suberect setae slightly longer than antennal segment II diameter. STRUCTURE AND MEASUREMENTS: Body ca. $4.7 \times$ as long as pronotum width. Head: Depression delimiting occipital region distinct only dorsally; distance between depression and pronotum almost as long as eye diameter; longitudinal sulcus on dorsal surface shorter than eye diameter; distance from eye to pronotum slightly longer than eye diameter, not swollen; vertex ca. $1.8 \times$ as wide as eye, flat. Labium (as in Namyatova et al., 2016: figs. 6D, 9C): Reaching middle of mesosternum; segment I and II combined subequal to segment III; segments I ca. $1.5 \times$ as long as wide; segment II twice as long as wide, elongate, dorsally; segment III distinctly shorter than ventral side of head; segment IV twice as long as segment III. Antenna: Segment I slightly widened, $1.3 \times$ as long as head width, $0.8 \times$ as long as pronotum width; segment II $2.0 \times$ as long as head width, $1.1 \times$ as long as pronotum width. Thorax: Anterior part of pronotum distinctly shorter than posterior part; collar distinct; posterior part of pronotum slightly raised; posterior margin of pronotum slightly concave; pronotum ca. $1.1 \times$ as wide as long and $1.7 \times$ as wide as head; mesoscutum slightly exposed. Hemelytron: Area along inner margin of corium almost flat; inner margin of cuneus convex (as in Namyatova et al., 2016: fig. 13F), medial margin ca. $3 \times$ as long as base. Female genitalia not examined.
Distribution: Philippines (Luzon) (fig. 20). Host Plants: Unknown.

Discussion: Woodward (1954) described $F$. usingeri from a single female, which we examined, but did not dissect its genitalia. Felisacus usingeri is similar to F. auritulus, F. bradi, and F. ovalau in coloration, broad antennal segment I, and dorsally elongate labial segment II. Felisacus auritulus differs from F. usingeri by the distance from the eye to the pronotum, which is slightly shorter than the eye diameter, and antennal segment I dark brown with a yellow base. Felisacus bradi differs from $F$. usingeri by the antennal segment I brown, whitish yellow basally and the labium reaching abdominal segment VIII. Felisacus ovalau can be separated from F. usingeri by antennal segment I yellow with a reddish tinge, with red apically, and the presence of a pair of brown markings on the posterior part of the pronotum; in addition, the labium reaches abdominal segment $\mathrm{V}$.

Material examined: Holotype: PHILIPPINES: Laguna: Los Banos, $14.16667^{\circ} \mathrm{N}$ $121.18333^{\circ} \mathrm{E}, 17 \mathrm{Jul} 1936, \mathrm{R}$. Usinger, $1 q$ (00400378) (CAS).

\section{Felisacus vitilevu, sp. nov.}

Figures 7, 9N, 13V, W, 15L, 16I, J, 21

Diagnosis: Recognized by the following combination of characters: pronotum mostly pale brown to dark brown with reddish yellow or pale brown stripe medially, or at least humeral angles brown to dark brown; marking along inner margin of corium male to brown, not extending toward $\mathrm{R}+\mathrm{M}$ anteriorly and posteriorly; antennal segment I pale brown or reddish with yellow base, transverse depression on head present only dorsally; marking along inner margin of corium narrow and short (fig. 7); antennal segment I ca. $1.3-1.6 \times$ as long as head width; antennal segment II in male ca. $1.9-2.1 \times$ and in female ca. 1.9-2.0 $\times$ as long as head width; labium reaching posterior margin of metasternum or slightly surpassing it; apex of ventral wall of genital capsule curved dorsally (fig. 15L); right para- 
mere sickle shaped (fig. 13V); left paramere wide, with outgrowth posteriorly (fig. 13W); sclerotization of ductus seminis around secondary gonopore twice as long as wide; vesical with four serrate spicules (fig. 9N).

Description: Male. Total length 3.4-4.3. COLORATION (fig. 7): Head: Mostly yellow, reddish yellow, or pale brown, tubercles around antennal fossa whitish yellow and longitudinal sulcus on dorsal surface reddish, sometimes also with reddish marking dorsally or anteriorly above and between antennal fossa; clypeus often reddish apically or uniformly reddish, buccula sometimes also reddish. Eye dark brown with reddish tinge. Labium: Yellow, reddish yellow, or pale brown, segment III sometimes darker than other segments. Antenna: Segment I pale brown or reddish with yellow base; segment II pale brown to brown, often with reddish tinge, sometimes darker than segment I; segments III-IV brown to dark brown. Thorax: Pronotum mostly yellow, reddish yellow, or pale brown with posterior part often brown to dark brown, with yellow, reddish yellow, or pale brown longitudinal stripe medially, sometimes posterior part mostly reddish yellow to pale brown with brown to dark brown humeral angles; scutellum and mesoscutum reddish yellow to pale brown, often with reddish tinge; thoracic pleura reddish yellow to pale brown; scent gland evaporative area whitish yellow to yellow basally and orange or reddish apically, sometimes uniformly reddish yellow to pale brown. Hemelytron: Mainly translucent and colorless, marking along inner margin of corium yellow to dark brown; embolium with reddish or pale brown apex and margins; cuneus with yellowish tinge, with yellow outer margin and colorless inner margin; membrane grayish or pale brown medially, cell yellow to brown, Legs: Coxae whitish yellow to yellow; femora whitish yellow to yellow basally and darker, yellow, reddish yellow, or pale brown apically; tibiae and tarsus yellow, reddish yellow, or pale brown, sometimes tarsal segments II-III of fore- and middle tarsi brown. Abdomen: Ventral and lateral sides mostly red- dish yellow, sometimes yellow basally, dorsal surfaces red, rarely entire abdomen red. SURFACE AND VESTITURE: Corium smooth, with shallow punctures. Dorsum with setae subequal to or slightly longer than antennal segment II diameter; segment II and femora clothed with suberect setae shorter than antennal segment II diameter; abdomen clothed with short erect setae. STRUCTURE AND MEASUREMENTS: Body ca. $4.3-4.8 \times$ as long as pronotum width. Head: Depression delimiting occipital region present only dorsally; distance between depression and pronotum distinctly shorter than eye diameter; longitudinal sulcus on dorsal surface of head longer than eye diameter; vertex ca. $1.8-2.2 \times$ as wide as eye, upraised (as in Namyatova et al., 2016: fig. 6D). Labium (as in Namyatova et al., 2016: figs. 6D, 9C): Reaching posterior margin of metasternum or slightly surpassing it; segments I and II strongly shortened, combined longer than half of segment III; segment I shorter than wide; segment II slightly longer than wide, elongate dorsally; segment III longer than ventral side of head; segment IV $1.5 \times$ as long as segment III. Antenna: Segment I slightly widened, ca. 1.3$1.4 \times$ as long as head width, ca. $0.9-1.0 \times$ as long as pronotum width; segment II ca. $1.9-2.1 \times$ as long as head width, ca. $1.3-1.4 \times$ as long as pronotum width; segment III slightly longer than segment II and twice as long as segment IV. Thorax: Anterior part of pronotum somewhat shorter than posterior part; collar delimited; posterior part slightly raised; posterior margin of pronotum concave; pronotum ca. $1.1-1.3 \times$ as wide as long and ca. $1.4-1.6 \times$ as wide as head; mesoscutum exposed. Hemelytron: Area along inner margin of corium almost flat; inner margin of cuneus convex (as in Namyatova et al., 2016: fig. 13E), outer margin of cuneus ca. $3 \times$ as long as base. Abdomen: Genital capsule rotated left at right angle relative to rest of abdomen. Genitalia: Genital capsule (fig. 15L) ca. $1.5 \times$ as long as wide; ventral wall twice as long as dorsal wall, with posterior margin of ventral wall distinctly tapering apically, smooth, 
without outgrowth(s), its apex slightly shifted left, curved dorsally; sides of genital capsule not modified; paramere sockets more or less acute; distance between paramere sockets subequal to half of genital capsule width at base. Right paramere (fig. 13V) sickle shaped; apex with small toothlike outgrowth tubercle anteriorly, medial part narrower than basal part, with setae, outer margin convex and inner margin concave, without swelling; outer angle indistinct; inner angle distinct, not bearing setae; basal part only slightly shorter than rest of paramere. Left paramere (fig. 13W) widened; apical part flattened, with rectangular outgrowth on posterior side and without outgrowth on dorsal surface; middle part widened dorsally, without swelling or outgrowth(s); setae placed on outer margin medially. Aedeagus conjunctiva sclerotized only basally, secondary gonopore placed at base of endosoma in repose; sclerotized part of ductus seminis around secondary gonopore elongate, but distinctly not reaching phallotheca mouth; its dorsal wall longer than ventral one; vesica with four serrate spicules.

Female. Total length 4.0-4.3. COLORATION (fig. 7): Head and labium: Similar to male, rarely brown. Antenna: As in male. Thorax: Similar to male, rarely posterior part of pronotum uniformly reddish yellow to pale brown. Legs and hemelytron: As in male. Abdomen: Mostly as in male, sometimes uniformly pale brown. SURFACE AND VESTITURE: As in male. STRUCTURE AND MEASUREMENTS: Structure as in male; body ca. $4.2-4.4 \times$ as long as pronotum width; vertex ca. $1.8-2.2 \times$ as wide as eye; antennal segment I ca. $1.3-1.6 \times$ as long as head width, ca. $0.9-1.0 \times$ as long as pronotum width; segment II ca. 1.9$2.0 \times$ as long as head width, ca. $1.1-1.3 \times$ as long as pronotum width; pronotum ca. $1.2 \times$ as wide as long and ca. $1.6-1.7 \times$ as wide as head. Genitalia (fig. 16I, J): Dorsal labiate plate wider than distance between apodemes of second valvulae, mostly smooth, without distinct striations; with semicircular sclerite, widened posteriorly and distinct sclerotized rings laterally; lateral oviducts placed almost medially, very close to each other, spermathecal gland placed between lateral oviducts; dorsal labiate plate with distinct tubercles, without membranous lobe medially.

Distribution: Fiji Is. (Viti Levu Is.) (fig. 21). Host Plants: Unknown.

Eтymology: The species is name after Viti Levu Island, where all known specimens were collected.

Discussion: Felisacus vitilevu is very similar in coloration to F. madagascariensis and F. gressitti (fig. 5). Felisacus madagascariensis can be separated from $F$. vitilevu by the anterior part of the pronotum brown, the labium reaching the posterior margin of the mesosternum, antennal segment I reddish brown and ca. $1.7 \times$ as long as the head width. Felisacus gressitti differs from $F$. vitilevu by the clypeus mostly dark brown and antennal segment II in both males and females is ca. $1.6 \times$ as long as head width. The Fijian species F. ovalau is also very similar, but differs from $F$. vitilevu in the pronotum mostly yellow, the labium reaching abdominal sternum VIII, the left paramere having three rounded outgrowths (fig. 13F), and the sclerotization of the ductus seminis around the secondary gonopore as long as wide; the shape of the vesical sclerotization also differs (cf. fig. 9G with fig. 9N).

Material eXAmined: Holotype: FIJI: Viti Levu: Korotongo, $18.17575^{\circ} \mathrm{S} 177.55112^{\circ} \mathrm{E}, 50 \mathrm{~m}$, Mar 1981, N.L.H. Krauss, 10 (00043142) (BPBM). Paratype: [[SHOULD THIS BE PLURAL?]]FIJI: Central Division: Bilo nr Lami, Viti Levu Is., $18.11092^{\circ} \mathrm{S} 178.41011^{\circ} \mathrm{E}, 20 \mathrm{~m}, 27 \mathrm{Sep}$ 1979, M.K. Kamath, S.N. Lal, G.A and S.L. Samuelson, 19 (00043155) (BPBM). Additional material: Lami, Viti Levu Is., $18.11092^{\circ} \mathrm{S}$ $178.41011^{\circ} \mathrm{E}$, Feb 1951, N.L.H. Krauss, 1 ㅇ (00043145), 3 ๙ (00043133-00043135) (BPBM); May 1951, N.L.H. Krauss, 20 (00043137, 00043136) (BPBM); Nov 1957, N.L.H. Krauss, 3 주 (00043129-00043131), 1 우 (00043143) (BPBM). Lami, Viti Levu Is., $18.11092^{\circ} \mathrm{S}$ $178.41011^{\circ} \mathrm{E}, 100 \mathrm{~m}$, Dec 1978, N.L.H. Krauss, 1 के (00043132), 1 우 (00043144) (BPBM). Mt Koro', $1 \mathrm{~km} \mathrm{~N}$ South Ridge summit, $17.35^{\circ} \mathrm{S}$ $177.55^{\circ} \mathrm{E}, 1000 \mathrm{~m}, 16$ Nov 2005, C. Reid, $2 \sigma^{\top}$ 
(00018965, 00018966) (AM). Nukurua Forest, Viti Levu Is., $17.91723^{\circ} \mathrm{S} 178.57739^{\circ} \mathrm{E}, 95 \mathrm{~m}, 15$ Oct 1979, M.K. Kamath, G.A and S.L. Samuelson, 2 ㅇ $(00043156,00042268 \mathrm{t})(\mathrm{BPBM})$. [Mt Kobalevu summit area], 432 m, 16 Oct 1979, G.A. Samuelson, 1 우 (00045808) (BPBM). Viti Levu: Korotongo, $18.17575^{\circ} \mathrm{S} 177.55112^{\circ} \mathrm{E}, 50 \mathrm{~m}$, Mar 1981, N.L.H. Krauss, $3 q$ (0004315100043153) (BPBM). Rdg. W of Nandarivatu, $17.61265^{\circ} \mathrm{S} 177.94588^{\circ} \mathrm{E}, 853 \mathrm{~m}, 11$ Sep 1938, E.C. Zimmerman, 1 우 (00043148) (BPBM). Western Division: Nadarivatu, Viti Levu Is., $17.56^{\circ} \mathrm{S} 177.966^{\circ} \mathrm{E}, 850 \mathrm{~m}, 08 \mathrm{Mar} 1963-13 \mathrm{Mar}$ 1963, C.M. Yoshimoto, $1 \delta^{\widehat{0}}$ (00043138), 2 우 (00043149, 00043150) (BPBM). Nadarivatu, Viti Levu Is., $17.56^{\circ} \mathrm{S} 177.966^{\circ} \mathrm{E}$, Jan 1955 , N.L.H. Krauss, 2 ㅇ $(00043146,00043154), 30^{\star}$ (00043139-00043141) (BPBM). Nandarivatu, Viti Levu Is., $17.56^{\circ} \mathrm{S} 177.96^{\circ} \mathrm{E}, 823 \mathrm{~m}, 10 \mathrm{Nov}$ 1964, N. McFarland, 1 đ (00017831) (SAMA).

Felisacus wangae, sp. nov.

Figures 7, 10M, 13X, Y, 15M, 16N, O, 21

DiAgnosis: Recognized by the following combination of characters: pronotum yellow with three brown markings posteriorly; hemelytron with narrow brown marking along inner margin of corium, not extending toward $\mathrm{R}+\mathrm{M}$ anteriorly (fig. 7); antennal segment I slightly widened; occipital region delimited only dorsally; vertex upraised; dorsal surface of labial segment I not elongate posteriorly (as in Namyatova et al., 2016: fig. 6E); right side of ventral wall of genital capsule widened (fig. 15M); right paramere with distinct outer and inner angles (fig. 13X); left paramere sickle shaped (fig. 13Y); sclerotization of ductus seminis around secondary gonopore twice as long as wide; vesica with irregularly shaped sclerite, bearing toothlike outgrowth and with small triangular spicule apically (fig. 10M).

Description: Male. Total length 4.6-4.7. COLORATION (fig. 7): Head: Yellow to pale brown, sometimes with dorsal surface brown; buccula brown anteriorly; clypeus brown apically or uniformly brown. Eye brown with reddish tinge. Labium: Segments I-III yellow, segment IV pale brown. Antenna: Segments I-II pale brown, segments III-IV brown to dark brown. Thorax: Pronotum yellow with pale brown anterior margin; humeral angles and medial longitudinal stripe pale brown or brown, sometimes only posterior part of that stripe distinct; mesoscutum and scutellum yellow, punctures between them pale brown; thoracic pleura yellow to pale brown with scent gland evaporative area yellow. Hemelytron: Mostly translucent; inner part of clavus opaque, yellow to brown; outer part of clavus whitish yellow; corium whitish yellow, with narrow pale brown or brown marking along inner margin of corium and base of cuneus, reaching $\mathrm{R}+\mathrm{M}$ vein posteriorly; embolium whitish yellow, brown apically; cuneus whitish yellow; membrane pale brown anteriorly and whitish apically; membrane cell brown to dark brown. Legs: Coxae yellow; femora yellow, often reddish apically; middle and hind femora with reddish brown or brown marking in apical half; tibiae yellow with brown or dark brown longitudinal stripe at least basally; tarsal segment I yellow to pale brown, tarsal segments II-III brown. Abdomen: Pale brown, brown dorsally. SURFACE AND VESTITURE: Corium smooth with scarce punctures. Dorsum with suberect setae longer than antennal segment II diameter; antennal segment I with scarce suberect setae subequal to or longer than antennal segment II diameter; femora with suberect setae longer than antennal segment II diameter; abdomen clothed with short suberect setae. STRUCTURE AND MEASUREMENTS: Body ca. 3.8-4.0× as long as pronotum width. Head: Depression delimiting occipital region present only dorsally; distance between this depression and pronotum shorter than eye diameter; longitudinal sulcus on dorsal surface shorter than eye diameter; distance from eye to pronotum slightly longer than eye diameter, not swollen laterally; vertex ca. 1.4-1.5x as wide as eye, upraised. Labium: Reaching middle of mesosternum; segments I and II distinctly longer than wide, combined subequal to segment III; segment II not elongate dorsally (as in Namyatova 
et al., 2016: fig. 6E); segment IV as long as segment III. Antenna: Segment I slightly widened, ca. $1.2-1.4 \times$ as long as head width, ca. $0.8-1.0 \times$ as long as pronotum width; segment II ca. 1.6-1.7× as long as head width, ca. $1.1 \times$ as long as pronotum width; segment III slightly longer than segments II and IV. Thorax: Anterior part of pronotum shorter than posterior part; collar delimited; posterior part of pronotum slightly upraised; posterior margin of pronotum slightly concave; pronotum ca. $1.3 \times$ as wide as long and ca. 1.6-1.7 $\times$ as wide as head; mesoscutum slightly exposed. Hemelytron: Area along inner margin of corium swollen; inner margin of cuneus convex (as in Namyatova et al., 2016: fig. 13E), outer margin of cuneus ca. $3 \times$ as long as base. Abdomen: Genital capsule rotated at very small angle relative to rest of abdomen. Genitalia: Genital capsule (fig. $15 \mathrm{M})$ twice as long as wide; ventral wall ca. $1.5 \times$ as long as dorsal wall, its posterior margin smooth, semioval, without outgrowth, its apex placed medially; right side of genital capsule curved, left side not widened; paramere sockets more or less acute; distance between paramere sockets subequal to half of genital capsule width at base. Right paramere (fig. 13X) sickle shaped; apex concave posteriorly; medial part as wide as basal part, without setae, with outer margin convex and inner margin with slightly widened; outer angle distinct, inner angle distinct, without outgrowth(s) or swelling, bearing setae; basal part as long as rest of paramere. Left paramere (fig. 13Y) sickle shaped; apical part not flattened, without tooth or outgrowth on apical part; middle side slightly widened, without swelling or outgrowth(s); setae placed on middle part near outer margin. Aedeagus conjunctiva not sclerotized, secondary gonopore placed at base of vesical in repose; sclerite surrounding secondary gonopore twice as long as wide; vesica with two spicules; one of them very small, smooth; second one large, bearing toothlike outgrowths (fig. 10M).

Female. COLORATION (fig. 7): Head: Pale brown with clypeus and marking on buccula brown. Thorax: Similar to male, but medial stripe on posterior part of pronotum distinct only pos- teriorly, posterior angles brown; thoracic pleura pale brown with scent gland evaporative area yellow basally and brown apically. Hemelytron: Similar to male, clavus brown with brown margins, stripes on hemelytron brown. Legs: Similar to male, tibiae yellow with brown longitudinal stripe. Abdomen: Yellow to pale brown with brown areas. SURFACE AND VESTITURE: As in male. STRUCTURE AND MEASUREMENTS: Structure as in male. Genitalia (figs. 16N, O): Dorsal labiate plate wider than apodemes of second valvulae, with distinct striations, without membranous ridge medially; semicircular sclerite and sclerotized rings absent; lateral oviducts placed in posterior part, at distance from each other; spermathecal gland attached in posterior part, anteriorly to lateral oviducts; dorsal labiate plate with membranous semicircular lobe anteriorly, with tubercles only along posterior margin of posterior wall.

Distribution: Borneo (Sarawak, Kalimantan) (fig. 21).

Host Plants: Unknown.

Eтymology: The species is name after Xiaojing Wang from Guo-Qing Liu's laboratory (Nankai University) who spent the better part of a year at the University of New South Wales and helped us by translating species descriptions from Chinese.

Discussion: The sole female specimen has glue on the dorsum, and segments II-IV are missing. Felisacus wangae is not similar to any species of the genus. It is the sister species of $F$. curvatus, as they both possess similar female genitalia with distinct striations (cf. fig. 16L, N), a broad right side of the genital capsule (cf. figs. $14 \mathrm{~J}, 15 \mathrm{M}$ ), and an apical sclerotized part of the ductus seminis twice as long as wide (cf. fig. 10E, M). Felisacus curvatus differs from F. wangae in the marking on the hemelytron broad (fig. 4), the labium only slightly surpassing the posterior margin of the prosternum, and the presence of two serrate spicules, bearing toothlike outgrowths (fig. 10E).

Material eXAmined: Holotype: INDONESIA: Kalimantan Timur: Pasir Dist.: 4 km W 
Lumut, Gunung Lumut, $1.46305^{\circ} \mathrm{S} 115.99815^{\circ} \mathrm{E}$, 380 m, 15 Nov 2005, E. Gasso Miracle, light trap, 1 đิ (00017870) (NML). Paratypes: INDONESIA: Kalimantan Timur: Pasir Dist.: $4 \mathrm{~km}$ W Lumut, Gunung Lumut, $1.46305^{\circ} \mathrm{S} 115.99815^{\circ} \mathrm{E}$, 380 m, 15 Nov 2005, E. Gasso Miracle, Light Trap, 19 (00017869) (NML). MALAYSIA: Sarawak: Nanga Pelagus, $2.01666^{\circ} \mathrm{N} 112.93305^{\circ} \mathrm{E}$, 07 Aug 1958-14 Aug 1958, T.C. Maa, 1 ๙ (00043874) (BPBM). Nanga Pelagus nr Kapit, $2.01666^{\circ} \mathrm{N} 112.93305^{\circ} \mathrm{E}, 585 \mathrm{~m}, 07$ Aug $1958-14$ Aug 1958, T.C. Maa, 1 ô (00043875) (BPBM).

Felisacus webbi, sp. nov.

Figures 7, 10N, 13Z, AA, 15N, 21

Diagnosis: Recognized by the following combination of characters: head and pronotum yellow, pronotum with pair of brown markings near humeral angles (fig. 7); transverse depression delimiting occipital region present only dorsally; antennal segment I slightly widened; labium reaching abdominal segment $\mathrm{V}$; dorsal surface of labial segment I elongate posteriorly (as in Namyatova et al., 2016: figs. 6D, 9C); ventral wall of genital capsule with outgrowth from right-hand side dorsally, its apex not curved dorsally (fig. $15 \mathrm{~N}$ ); both parameres narrow, sickle shaped, without outgrowths; right paramere swollen medially; outer angle of left paramere present, inner angle rounded (fig. 13Z, AA); vesica with long curved spicule (fig. 10N).

Description: Male. Total length 3.6-3.7. COLORATION (fig. 7): Head: Yellow, frons and clavus with reddish tinge. Labium: Uniformly yellow. Antenna: Segment I yellow with reddish stripe and apex, segments II-IV reddish brown. Thorax: Pronotum yellow with pair of dark brown markings posteriorly; scutellum uniformly yellow; thoracic pleura and scent gland evaporative area uniformly yellow. Hemelytron: Mostly colorless, transparent; clavus whitish yellow to brown; corium with reddish tinge posteriorly, marking along inner margin of corium yellow; embolium with yellow tinge, reddish apically; cuneus yellow along margins; membrane with grayish tinge; membrane cells yellow with reddish tinge. Abdomen: Yellow with reddish tinge. SURFACE AND VESTITURE: Corium smooth, without punctures. STRUCTURE AND MEASUREMENTS: Body ca. $4.2-4.3 \times$ as long as pronotum width. Head: Depression delimiting occipital region present dorsally and laterally; distance between depression and pronotum distinctly shorter than eye diameter; longitudinal sulcus on dorsal surface longer than eye diameter; distance from posterior margin of eye to pronotum as long as eye, not swollen laterally; vertex ca. 2.0 $\times$ as wide as eye, upraised (as in Namyatova et al., 2016: fig. 6D). Labium (as in Namyatova et al., 2016: figs. 6D, 9C ): Reaching abdominal segment V; segments I and II combined subequal to half of segment III; segment I shorter than wide; segment II slightly longer than wide, its dorsal surface elongate posteriorly; segment IV twice as long as segment III. Antenna: Segment I cylindrical (as in Namyatova et al., 2016: fig. 8A), ca. 1.5-1.6× as long as head width, ca. $0.9-1.0 \times$ as long as pronotum width; segment II ca. 1.9-2.1× as long as head width, ca. 1.2$1.3 \times$ as long as pronotum width. Thorax: Anterior part of pronotum shorter than posterior part; collar delimited; posterior part of pronotum slightly upraised; posterior margin of pronotum concave, pronotum ca. $0.8 \times$ as wide as long and ca. 1.6x as wide as head; mesoscutum exposed. Hemelytron: Area along inner margin of corium almost flat; inner margin of cuneus convex (as in Namyatova et al., 2016: fig. 13E), outer margin of cuneus ca. $3 \times$ as long as base. Abdomen: Genital capsule rotated at right angle relative to other segments. Genitalia: Genital capsule (fig. 15N) twice as long as wide; ventral wall ca. $1.3 \times$ as long dorsal wall, with posterior margin of ventral wall rounded, not folded; right side folded, left side not widened; paramere sockets more or less acute; distance between paramere sockets ca. $0.3 \times$ as long as genital capsule base. Right paramere (fig. 13Z) distinctly curved in apical half; anterior part straight posteriorly; medial part slightly wider than basal part, its outer margin concave and inner margin widened; outer angle 
distinct; inner angle rounded; basal part subequal to half of rest of paramere. Left paramere (fig. 13AA) sickle shaped, apical part without outgrowth(s); middle part slightly widened, bearing setae, its inner margin without swelling or outgrowth. Aedeagus (fig. 10N) conjunctiva membranous; with single large curved spicule; secondary gonopore placed at base of vesical in repose; sclerotization of ductus seminis surrounding secondary gonopore shorter than wide; vesica with single large curved spicule.

Female. Unknown.

Distribution: Madagascar (fig. 21).

Host Plants: Unknown.

Eтymology: The species is names after Mick Webb, the curator in the Natural History Museum who helped the first author (A.A.N.) during her visit to the museum and loaned specimens of the genus Felisacus, including two specimens of this new species.

Discussion: Felisacus webbi is most similar to F. ovalau in coloration and structure (figs. 6, 7). The latter species differs from $F$. webbi in the ventral wall of the genital capsule curved apically, without an outgrowth on the right-hand side (fig. 15F), the left paramere having three rounded outgrowths (fig. 13F), and the vesica having a number of small toothlike spinules and two large spicules (fig. 9G).

Material eXAmined: Holotype: MADAGASCAR: Fianarantsoa: Ranomafana National Park, Setam Lodge Hotel, $21.2501^{\circ} \mathrm{S} 47.42678^{\circ} \mathrm{E}, 917$ m, 04 Nov 2005-21 Nov 2005, G. Martin, D.L.J. Quicke and L.P. Holland, $1 \delta$ (00019536) (BMNH). Paratype: MADAGASCAR: Fianarantsoa: Ranomafana National Park, Setam Lodge Hotel, $21.2501^{\circ} \mathrm{S} 47.42678^{\circ} \mathrm{E}, 917 \mathrm{~m}, 04$ Nov 2005-21 Nov 2005, G. Martin, D.L.J. Quicke and L.P. Holland, 1 đิ (00019537) (BMNH).

Felisacus yasunagai, sp. nov.

Figures 7, 10O, 13AB, AC, 15O, 21

Diagnosis: Recognized by the following combination of characters: dark brown marking on corium distinctly $\mathrm{C}$-shaped, reaching $\mathrm{R}+\mathrm{M}$ anteriorly and posteriorly, anterior part of this marking inclined posteriorly (fig. 7); antennal segment II widened (as in Namyatova et al., 2016: fig. 8B), red; vertex flat dorsally (as in Namyatova and Cassis, in press: fig. 6E) and straight laterally; distance between transverse depression on head and pronotum longer than eye diameter; labium reaching posterior margin of metasternum; cuneus uniformly colorless; apical half of femora red; ventral wall of genital capsule with toothlike outgrowth posteriorly (fig. $15 \mathrm{O})$; right paramere sickle shaped, without outgrowth on inner angle (fig. 13AB); apical part of left paramere with toothlike outgrowth apically and outgrowth on dorsal surface; and medial part of left paramere with distinct outgrowth (fig. 13AC); apical half of ductus seminis sclerotized, its apex hooked (fig. 10O).

Description: Male. Total length 3.3-3.5. COLORATION (fig. 7): Head: Mostly yellow with reddish markings. Eye brown with reddish tinge. Labium: Uniformly yellow. Antenna: Segment I red brown apically and often with yellow base; segments II yellow to brown, sometimes yellow, brown apically; segments III-IV yellow. Thorax: Anterior part of pronotum yellow to pale brown with reddish tinge or red; posterior part of pronotum uniformly dark brown; scutellum and mesoscutum uniformly dark brown; thoracic pleura dark brown, metepimeron whitish yellow; scent gland evaporative area whitish yellow. Hemelytron: Clavus opaque, brown anteriorly, whitish posteriorly with brown or reddish margins; corium, embolium, cuneus, and membrane mostly transparent, colorless; corium with brown to dark brown posterior angle and with C-shaped dark brown marking, reaching $\mathrm{R}+\mathrm{M}$ anteriorly and posteriorly, anterior part of this marking inclined posteriorly; embolium brown apically; cuneus with yellow outer margin; membrane cell colorless. Legs: Coxae whitish yellow to yellow; femora whitish yellow to yellow basally and reddish apically, often with brown marking medially; tibiae brown basally and whitish yellow to yellow apically; tarsi whitish yellow to yellow. 
Abdomen: Whitish yellow, sometimes with brown markings. SURFACE AND VESTITURE: Corium with distinct punctation. Dorsum clothed with setae subequal to or shorter than antennal segment II diameter, those setae longer on head and posterior part of pronotum; antennal segment I clothed with suberect setae shorter than antennal segment II diameter; femora clothed with suberect setae longer than antennal segment II diameter; abdomen clothed with setae of different length. STRUCTURE AND MEASUREMENTS: Body ca. 3.9-4.2 $\times$ as long as pronotum width. Head: Transverse depression delimiting occipital region present only dorsally; distance between depression and pronotum longer than eye diameter; longitudinal sulcus on dorsal surface of head shorter than eye diameter; distance between eye and pronotum longer than eye diameter, not swollen; vertex ca. $1.8-2.1 \times$ as wide as eye, flat (as in Namyatova et al., 2016: fig. 6E). Labium: Reaching posterior margin of metasternum or slightly surpassing it, segments I and II shorter than width (as in Namyatova et al., 2016: fig. 6E), combined subequal to half of segment III; dorsal surface of segment II not elongate dorsally (as in Namyatova et al., 2016: fig. 6E), segment III shorter than ventral side of head; segment IV twice as long as segment III. Antenna: Segment I distinctly longer than head width, swollen (as in Namyatova et al., 2016: fig. $8 \mathrm{~B})$, ca. 1.3-1.6× as long as head width, ca. 0.7$0.8 \times$ as long as pronotum width; segment II ca. $1.4-1.5 \times$ as long as head width, ca. $0.8 \times$ as long as pronotum width; segments III almost twice as long as segment II and twice as long as segment IV. Thorax: Anterior part of pronotum distinctly shorter than posterior part; collar distinct; posterior part slightly upraised; posterior margin of pronotum straight or concave; pronotum ca. $1.1-1.2 \times$ as wide as long and ca. $1.8-1.9 \times$ as wide as head; mesoscutum usually exposed. Hemelytron: Area along inner margin of corium swollen; inner margin of cuneus straight (as in Namyatova et al., 2016: fig. 13F), outer margin of cuneus twice as long as base. Abdomen: Genital capsule rotated left at almost right angle relative to the rest of abdomen. Genitalia: Genital capsule (fig. $15 \mathrm{O})$ ca. $1.5 \times$ as long as wide; ventral wall ca. $1.5 \times$ as long as dorsal wall, with posterior margin of ventral not curved dorsally, with small toothlike outgrowth; right side of genital capsule folded, left side widened; paramere sockets distinctly acute; distance between paramere sockets ca. $0.15-0.2 \times$ as long as genital capsule width at base. Right paramere (fig. 13AB) sickle shaped; apex slightly concave; medial part narrower than basal part, without setae, outer margin of medial part convex, inner margin concave, with swelling; outer angle absent, inner margin present, swollen, without setae or outgrowth(s); basal part subequal to rest of paramere. Left paramere (fig. 13AC) apical part not flattened, with toothlike outgrowth apically and with outgrowth on dorsal surface; middle part with outgrowth at inner side, without setae. Aedeagus (general view as Namyatova et al., 2016: fig. 22M) conjunctiva membranous; vesica without spicules; apical half of ductus seminis sclerotized, secondary gonopore placed near phallotheca mouth in repose; ductus seminis hooked apically (Namyatova et al., 2016: fig. 10O).

Female. Total length 3.5-3.8. COLORATION, SURFACE, AND VESTITURE (fig. 7): As in male. STRUCTURE AND MEASUREMENTS: Structure as in male; body ca. $3.8-4.1 \times$ as long as pronotum width; vertex ca. $1.6-1.9 \times$ as wide as eye; antennal segment I ca. $1.2-1.4 \times$ as long as head width, ca. $0.6-0.7 \times$ as long as pronotum width; segment II ca. $1.3-1.5 \times$ as long as head width, ca. $0.6-0.8 \times$ as long as pronotum width; pronotum ca. $1.1-1.2 \times$ as wide as long and ca. $1.8-2.2 \times$ as wide as head. Genitalia: Dorsal labiate plate small and transparent, as wide as distance between apodemes of second valvula, without striations or membranous ridge medially; semicircular sclerite and sclerotized rings absent; lateral oviducts placed medially, close to each other, far from lateral margins of dorsal labiate plate (fig. 16K); dorsal labiate plate without distinct tubercles, with triangular membranous lobe posteriorly (as in fig. 16H).

Distribution: Philippines (Luzon Is.) (fig. 21). 
Host PLANT: Unknown.

Eтymology: Species is named after Tomohide Yasunaga, who loaned us specimens of Felisacus from his collection.

Discussion: Place of attachment of spermathecal gland could not be seen. Felisacus yasunagai is similar to Felisacus species with a developed C-shaped marking on corium, but those species differ in the anterior part of the C-shaped marking not inclined posteriorly; also the labium is shorter, varying from reaching the posterior margin of prosternum to the posterior margin of the mesosternum.

Material examined: Holotype: PHILIPPINES: Camarines Sur: Iriga Mt, $13.45416^{\circ} \mathrm{N}$ $123.45055^{\circ} \mathrm{E}, 26$ Apr 1962, H.M. Torrevillas, $10^{\star}$ (00043225) (BPBM). Paratypes: PHILIPPINES:

Camarines Sur: Iriga Mt, $13.45416^{\circ} \mathrm{N}$ $123.45055^{\circ} \mathrm{E}, 26$ Apr 1962, H.M. Torrevillas, $6 \delta^{\widehat{ }}$ (00043212-00043217), 5 우 (0004322000043224) (BPBM). Isarog Mt, $20 \mathrm{~km} \mathrm{E}$ of Naga, $13.65805^{\circ} \mathrm{N} 123.37305^{\circ} \mathrm{E}, 550 \mathrm{~m}, 06$ Apr 1963 , H.M. Torrevillas, Light Trap, 1 ㅇ (00043341) (BPBM). Isarog Mt, Pili, $13.65805^{\circ} \mathrm{N} 123.37305^{\circ} \mathrm{E}$, 600 m, 05 Apr 1965, H.M. Torrevillas, 10 (00043219), 1 sex unknown (00043226) (BPBM). Mt. Isarog, Pili, $13.70805^{\circ} \mathrm{N} 123.75083^{\circ} \mathrm{E}, 800 \mathrm{~m}$, 27 Apr 1965, H.M. Torrevillas, 1 đo (00043218) (BPBM). Luzon: Salton Pass, Nueva Vizcaya, $15.11666^{\circ} \mathrm{N} 120.95^{\circ} \mathrm{E}, 915 \mathrm{~m}, 09$ Apr $1968-10$ Apr 1968, D.E. Hardy, 19 (00043342) (BPBM). Misamis Oriental: Mt. Kibungol, 09 Apr 196018 Apr 1960, H.M. Torrevillas, light trap, 1 우 (00045817) (BPBM).

\section{Felisacus zuparkoi, sp. nov.}

Figures 7, 10P, 13AD, AE, 15P, 21

Diagnosis: Recognized by the following combination of characters: presence of dark brown $\mathrm{C}$-shaped marking on corium, reaching $\mathrm{R}+\mathrm{M}$ anteriorly and posteriorly, its anterior part not inclined posteriorly (fig. 7); vertex flat (as in Namyatova et al., 2016: fig. 6E), not widened laterally behind eye; distance between transverse depression on head and pronotum longer than eye diameter; antennal segment I red; antennal segment II reddish brown; labium reaching posterior margin of mesosternum; cuneus translucent, red apically; dorsal wall of genital capsule with tooth posteriorly (fig. 15P); right paramere sickle shaped with curved outgrowth on inner angle (fig. 13AD); apical part of left paramere narrow, with tooth apically and outgrowth dorsally; medial part with wide outgrowth (13 AE); half of ductus seminis sclerotized, hooked apically, vesica with small spicule (fig. 10P).

Description: Male. Total length 3.4-4.1. COLORATION (fig. 7): Head: Mostly yellow to pale brown, with reddish tinge or reddish markings, dorsal and lateral sides often darker than frontal and ventral surfaces; clypeus sometimes uniformly reddish; buccula sometimes brown. Eye brown to dark brown with reddish tinge. Labium: Segments I-II brown, segments III-IV yellowish to pale brown, sometimes uniformly yellow to pale brown. Antenna: Segment I red, sometimes brown apically, segment II reddish brown, often apically darkened, segment III pale brown to brown. Thorax: Anterior part of pronotum pale brown, often brown around forecoxa, sometimes with reddish tinge, with brown to dark brown anterior margin; posterior part of pronotum dark brown; scutellum and mesoscutum uniformly brown to dark brown; thoracic pleura brown to dark brown; scent gland evaporative area whitish yellow to pale brown, sometimes brown apically. Hemelytron: Mostly translucent; clavus opaque, uniformly dark brown; corium translucent, colorless with brown anterior angles and C-shaped dark brown marking reaching $\mathrm{R}+\mathrm{M}$ anteriorly and posteriorly, its anterior not inclined posteriorly; embolium with brown outer margin and colorless inner margin, brown apex and sometimes pale brown or reddish marking medially; cuneus colorless with reddish apex and pale brown margins; membrane gradually changing color from pale brown to brown anteriorly and pale brown or whitish posteriorly, cell pale brown to brown. Legs: Coxae whitish yellow to yellow; femora whitish yellow to yellow often with pale brown 
or reddish apices; tibiae yellow, often with pale brown or red bases, rarely also with pale brown apices; tarsi uniformly whitish yellow to yellow. Abdomen: Yellowish with pale brown to brown dorsal surface and segments VIII-IX, sometimes reddish apically, abdomen sometimes uniformly pale brown. SURFACE AND VESTITURE: Corium smooth, with scarce and shallow punctation. Dorsum and femora with setae subequal to or longer than antennal segment II diameter; antennal segment I clothed with suberect setae shorter than antennal segment II diameter; abdomen clothed with short erect setae. STRUCTURE AND MEASUREMENTS: Body ca. 3.9-4.2 $\times$ as long as pronotum width. Head: Depression delimiting occipital region present only dorsally; distance between depression and pronotum as long as eye diameter; longitudinal sulcus on dorsal surface of head shorter than eye diameter; distance from head to pronotum longer than eye diameter, not swollen; vertex ca. $1.6-1.7 \times$ as wide as eye, flat (as in Namyatova et al., 2016: fig. 6E). Labium: Reaching posterior margin of mesosternum or slightly surpassing it; segment I and II combined subequal to half of segment III; segment I as long as wide; segment II slightly longer than width not elongate dorsally (as in Namyatova et al., 2016: fig. 6E); segment III as long as ventral side of head; segment IV ca. $1.5 \times$ as long as segment III. Antenna: Segment I slightly longer than head width, swollen (as in Namyatova et al., 2016: fig. $8 \mathrm{~B}$ ), ca. $1.1-1.2 \times$ as long as head width, ca. $0.6-0.7 \times$ as long as pronotum width; segment II ca. $1.6-1.7 \times$ as long as head width, ca. $0.9-1.0 \times$ as long as pronotum width; segment III slightly longer than segment II. Thorax: Anterior part of pronotum shorter than posterior part; collar delimited; posterior part of pronotum slightly upraised; posterior margin of pronotum straight or slightly concave; pronotum ca. 1.1-1.3x as wide as long and ca. 1.6$1.8 \times$ as wide as head; mesoscutum slightly exposed, sometimes not exposed; Hemelytron: Area along inner margin of corium swollen; inner margin of cuneus straight (as in Namya- tova et al., 2016: fig. 13F), outer margin of cuneus twice as long as base. Abdomen: Genital capsule rotated at small angle relative to rest of abdomen. Genitalia: Genital capsule (fig. 15P) ca. $1.5 \times$ as long as wide; ventral wall ca. $1.5 \times$ as long as dorsal wall, with posterior margin of ventral wall not curved dorsally, with toothlike outgrowth; right side of genital capsule folded, left side not widened; paramere sockets distinctly acute; distance between paramere sockets ca. $0.25 \times$ as long as genital capsule width at base. Right paramere (fig. 13AD) sickle shaped; apex straight posteriorly; medial part narrower than basal part, without setae, outer margin of medial part convex and inner margin concave; outer angle absent; inner angle present, with curved outgrowth bearing setae; basal part slightly shorter than rest of paramere. Left paramere (fig. 13AE) distinctly curved medially; apical part not flattened, with toothlike outgrowth on posterior side apically, without other outgrowths; inner margin of middle part with broad outgrowth with a number of toothlike outgrowths, bearing setae. Aedeagus (general view as in Namyatova et al., in press: fig. 22M) conjunctiva membranous; vesica with single small claw-shaped spicule; apical half of ductus seminis sclerotized, secondary gonopore placed near phallotheca mouth in repose; ductus seminis hooked apically (fig. 10P).

Female. Total length 3.3-3.4. COLORATION (fig. 7): Similar to male, cuneus rarely whitish with pale brown outer margin. SURFACE AND VESTITURE: As in male. STRUCTURE AND MEASUREMENTS: Structure as in male; body ca. 3.7-3.9 $\times$ as long as pronotum width; vertex ca. $2.0-2.2 \times$ as wide as eye; antennal segment I ca. $1.1 \times$ as long as head width, ca. $0.6 \times$ as long as pronotum width; segment II ca. $1.5 \times$ as long as head width, ca. $0.9 \times$ as long as pronotum width; pronotum ca. $1.2-1.4 \times$ as wide as long and ca. $1.8-2.0 \times$ as wide as head. Genitalia: Dorsal labiate plate very small and transparent, as wide as distance between apodemes of second valvulae, without striations or membranous ridge medially; semicircular sclerite and sclerotized rings 
absent; lateral oviducts placed in posterior part; spermathecal gland attached near anterior margin (as in fig. 16G); dorsal labiate plate without distinct tubercles, without membranous lobe posteriorly (as in fig. 16B).

Distribution: Borneo (Sarawak), Philippines (Mindanao Is.) (fig. 21).

Host Plants: Unknown.

Eтymology: The species is named after Robert Zuparko, curatorial assistant at the California Academy of Sciences, for loaning material of Felisacus.

Discussion: Antennal segment IV is lost in both males and females. Felisacus zuparkoi is similar to F. longiceps and F. magnificus externally. Both those species differ from $F$. zuparkoi in the absence of the vesical spicules (fig. $10 \mathrm{H}, \mathrm{J}$ ) and the narrow outgrowth on the left paramere (fig. 12R, X). Felisacus longiceps also can be separated by the antennal segment II often yellow, and F. magnificus differs in the shape of the left paramere, with the apical part flattened (fig. 12X).

Felisacus zuparkoi is also similar to Felisacus ceylonicus and F. lindbergae in coloration (figs. 4, 5). F. ceylonicus differs from F. zuparkoi in having a swollen vertex behind the eyes and the narrow outgrowth on the left paramere (fig. 11S). Felisacus lindbergae can be separated by the labium reaching the posterior margin of the prosternum or slightly surpassing it and the outgrowth on the left paramere is short (fig. 12N).

Material EXAMINED: Holotype: MALAYSIA: Sarawak: Bau District: Bidi, Bau District, $1.38389^{\circ} \mathrm{N} 110.13357^{\circ} \mathrm{E}, 165 \mathrm{~m}, 03$ Sep 1958, T.C. Maa, $1 \delta^{\hat{}}$ (00043182) (BPBM). Paratypes: MALAYSIA: Sabah: Kalabakan, $4.4167^{\circ} \mathrm{N}$ $117.4833^{\circ} \mathrm{E}, 08$ Nov $1958-15$ Nov 1958, T.C. Maa, 1 ㅇ (00043191) (BPBM); 10 Nov 1958-19 Nov 1958, T.C. Maa, $10^{\dagger}$ (00043188) (BPBM). Ranau, $5.9667^{\circ} \mathrm{N} 116.6833^{\circ} \mathrm{E}, 28$ Sep $1958-30$ Sep 1958, T.C. Maa, $10^{\star}$ (00043187) (BPBM). Sarawak: Bau District.: Bidi, Bau District, $1.38389^{\circ} \mathrm{N} 110.13357^{\circ} \mathrm{E}, 03$ Sep 1958, T.C. Maa, 2 कิ $(00043184,00043185)$ (BPBM). Bidi, Bau District, $1.38389^{\circ} \mathrm{N} 110.13357^{\circ} \mathrm{E}, 165 \mathrm{~m}, 03 \mathrm{Sep}$
1958, T.C. Maa, 1 đึ (00043183) (BPBM). Pangkalan Tebang, 350 m, 05 Sep 1958, T.C. Maa, $3 q$ (00043189, 00043190, 00043343) (BPBM). Santubong, Kuching, $1.71666^{\circ} \mathrm{N} 119.3^{\circ} \mathrm{E}, 1150 \mathrm{~m}, 18$ Jun 1958-30 Jun 1958, T.C. Maa, 3 ơ (00043180, 00043181), 1 우 (00043181) (BPBM). PHILIPPINES: Mindanao: [Mt. Empagatao], $1125 \mathrm{~m}$, 19 Apr 1961-30 Apr 1961, H.M. Torrevillas, $10^{\star}$ (00045809) (BPBM).

\section{ACKNOWLEDGMENTS}

This work was part of a Ph.D. project by one of us (A.A.N.), and was supported by a UNSW International Scholarship and a UNSW Ecology and Evolutionary Research Centre Postgraduate Writing and Skills Transfer Award. The project was also sponsored by RFBR research grant no. 15-29-02533 ofi_m. We are also grateful to the Royal Zoological Society (London), Ernst Mayr Travel Grant in Animal Systematics (Harvard University, Museum of Comparative Zoology), International Heteropterists' Society and UNSW School of Biological, Earth and Environmental Sciences who provided travel funds for one of us (A.A.N.) to examine specimens preserved in non-Australian museums. The Australian Biological Resources Study (ABRS) provided a grant to present results on Bryocorinae classification in New Zealand, at the 3rd Combined Australian and New Zealand Entomological Societies Conference. Much of this material was assembled and originally examined by one of us (G.C.) under an ABRS grant to him.

We thank the curators of the following museums for loaning the material: Dave Britton (AM); Randall Schuh (AMNH); Tom Weir and Beth Mantle (ANIC); Shepherd Myers (BPBM); Robert Zuparko (CAS); David Redei and András Orosz (HNHM); Eliane De Coninck and Marc de Meyer (ISNB); Larry Huldén (MZH); Ken Walker (MVMA); Gunvi Lindberg (NHRS); Guoqing Liu (NKMU); Mei-Ling Chan (NMNS); Michael Braby (NTM); Christine Lambkin and Susan Wright (QM); Peter Hudson (SAMA); Katrina Menard and Ed Riley (TAMU); Tomohide Yasu- 
naga (Japan); Brad Balukjian (UCB); Thomas Henry, Jr. (USNM); Terry Houston (WAMP), Dmitry Gapon (ZISP), Ian Millar (PPRI) and various curators from NML. We also thank Mick Webb, Laurence Livermore, and Vladimir Blagoderov (BMNH) for assistance with working in the collection and imaging of the specimens in the Sackler Biodiversity Imaging Lab. We thank Fedor Konstantinov (St. Petersburg State University) for help with access to specimens and use of facilities. We thank all the people from the Cassis' lab (UNSW), especially Celia Symonds for technical support, and Jackie Karras and Anouk Mututantri for assistance with editing plates. Xiaojing Wang is thanked for translating the description of Felisacus curvatus.

\section{REFERENCES}

Bergroth, E. 1922. List of the Ethiopian Bryocorinae (Hem. Miridae) with notes and descriptions. Revue de Zoologie et de Botanique Africaines 10: 51-61.

Bremer, K. 1994. Branch support and tree stability. Cladistics 10: 295-304.

Carvalho, J.C.M. 1952. On the major classification of the Miridae (Hemiptera). Anais da Academia Brasileira de Ciencias 24: 31-110. [with keys to subfamilies and tribes and a catalog of the world genera]

Carvalho, J.C.M. 1955. Keys to the genera of Miridae of the world (Hemiptera). Boletim do Museu Paraense Emilio Goeldi (Série Zoologia) 11: 1-151, 16 pls.

Carvalho, J.C.M. 1956. Insects of Micronesia. Heteroptera: Miridae. Insects of Micronesia 7: 1-100.

Carvalho, J.C.M. 1957. A catalogue of the Miridae of the world. Part I. Arquivos do Museu Nacional 44: 1-158.

Carvalho, J.C.M. 1980. Analecta Miridologica, IV: observations on type specimens in the National Museum of Natural History, Budapest, Hungary (Hemiptera, Miridae). Revista Brasileira de Biologia 40: 649-658.

Carvalho, J.C.M. 1981. The Bryocorinae of Papua New Guinea (Hemiptera, Miridae). Arquivos do Museu Nacional 56: 35-89.

Cassis, G. 2008. The Lattinova Complex of austromirine plant bugs (Hemiptera: Heteroptera: Miridae: Orthotylinae). Proceedings of the Entomological Society of Washington 110: 845-939.

Cassis, G., and G.F. Gross. 1995. Hemiptera: Heteroptera (Coleorrhyncha to Cimicomorpha). Zoological
Catalogue of Australia, vol. 27.3A. Melbourne, Australia: CSIRO.

Cassis, G., and R.T. Schuh. 2012. Systematics, biodiversity, biogeography, and host associations of the Miridae (Insecta: Hemiptera: Heteroptera: Miridae). Annual Review of Entomology 57: 377-404.

China, W.E. 1944. New and little known West African Miridae (Capsidae) (Hemiptera-Heteroptera). Bulletin of Entomological Research 35: 171-191.

Christenhusz, M.J., and Chase M.W. 2014. Trends and concepts in fern classification. Annals of Botany 113: 571-594.

Davis, N.T. 1955. Morphology of the female organs of reproduction in the Miridae (Hemiptera). Annals of the Entomological Society of America 48: $132-150$.

Distant, W.L. 1904. The fauna of British India, including Ceylon and Burma. Rhynchota, vol. 2, part 2. London: Taylor and Francis.

Distant, W.L. 1913. Reports of the Percy Sladen Trust Expedition to the Indian Ocean in 1905. No. IX, Rhynchota. Part I: Suborder Heteroptera. Transactions of the Linnaean Society of London 16: 139-190.

Eyles, A.C., and R.T. Schuh. 2003. Revision of New Zealand Bryocorinae and Phylinae (Insecta: Hemiptera: Miridae). New Zealand Journal of Zoology 30: 263-325.

Felsenstein, J. 1985. Confidence limits on phylogenies: an approach using the bootstrap. Evolution 39: 783-791.

Goloboff, P. 1993. Estimating character weights during tree search. Cladistics 9: 83-91.Goloboff, P., S. Farris, and K. Nixon. 2000. TNT (tree analysis using new technology) (BETA) ver. 1.1. Internet resource (http://www.cladistics.com/aboutTNT.html), accessed August 11, 2015.

Goloboff, P.A., J.S. Farris, and K.C. Nixon. 2008. TNT, a free program or phylogenetic analysis. Cladistics 24: 774-786.

Gorczyca, J. 2000. A revision of the genus Peritropis Uhler 1891 from the Oriental Region (Hemiptera, Miridae, Cylapinae). Denisia 19: 401-422.

Harbach, R.E., I.J. Kitching, C.L., Culverwell, J. Dubois, and Y.-M. Linton. 2012. Phylogeny of mosquitoes of tribe Culicini (Diptera: Culicidae) based on morphological diversity. Zoologica Scripta 41: 499-514.

Hsiao, T.-y. 1944. New genera and species of Oriental and Australian plant bugs in the United States National Museum. Proceedings of the United States National Museum 95: 369-396.

Hu, Q., and L.Y. Zheng. 2001. The Monaloniina from mainland China (Hemiptera: Miridae: Bryocori- 
nae). Acta Zootaxonomica Sinica 26: 414-430. [in Chinese with English summary]

Jensen, A.S., and J. Holman 2000. Macrosiphum on ferns: taxonomy, biology and evolution, including the description of three new species (Hemiptera: Aphididae). Systematic Entomology 25: 339-372.

Kerzhner, I.M., and A. Jansson. 1985. The type-specimens of Heteroptera described by V. Motschulsky. Annales Entomologici Fennici 51: 33-45

Kerzhner, I.M., and F.V. Konstantinov. 1999. Structure of the aedeagus in Miridae (Heteroptera) and its bearing to suprageneric classification. Acta Societatis Zoologicae Bohemicae 63: 117-137.

Kirkaldy, G.W. 1906. List of the genera of the pagiopodous Hemiptera-Heteroptera, with their type species from 1758 to 1904 and also of the aquatic and semi-aquatic Trochalopoda. Transactions of the American Entomological Society 32: 117-156, 156a-156b.

Kirkaldy, G.W. 1908. A catalogue of the Hemiptera of Fiji. Proceedings of the Linnaean Society of New South Wales 33: 345-391, pl. IV.

Knight, H.H. 1935. Hemiptera, Miridae and Anthocoridae insects of Samoa. Part II. British Museum of Natural History 5: 193-228.

Konstantinov, F.V., and A.A. Knyshov. 2015. The tribe Bryocorini (Insecta: Heteroptera: Miridae: Bryocorinae): phylogeny, description of a new genus, and adaptive radiation on ferns. Zoological Journal of the Linnean Society 175: 441-472.

Lin, C.-S. 2000. Genus Felisacus Distant (Hemiptera: Miridae) of Taiwan. Chinese Journal of Entomology 20: 233-241.

Maddison, W.P., and D.R. Maddison. 2010. Mesquite: a modular system for evolutionary analysis. Version 2.73. Internet resource (http://mesquiteproject.org/ mesquite/mesquite.html), accessed accessed August 11, 2015.

Miyamoto, S. 1965. Isometopinae, Deraeocorinae and Bryocorinae of the South-west Islands, lying between Kyushu and Formosa (Hemiptera: Miridae). Kontyu 33: 147-169.

Motschulsky, V. 1863. Essais d'un catalogue des insectes de l'île de Ceylan. Bulletin de la Société des Naturalistes de Moscou 36 (2): 1-153.

Moulds, T., and G. Cassis. 2006. Review of the Australian species of Peritropis (Insecta: Heteroptera: Miridae: Cylapinae). Memoirs of the Queensland Museum 52: 171-190.

Namyatova, A.A., and G. Cassis. 2016. Systematic revision and phylogeny of the plant bug tribe Monaloniini (Insecta: Heteoptera: Miridae: Bryocorinae) of the world. Zoological Journal of the Linnean Society 176 (1): 36-136.

Namyatova, A.A., F.V. Konstantinov, and G. Cassis. 2016. Phylogeny and systematics of the subfamily Bryocorinae based on morphology with emphasis on the tribe Dicyphini sensu Schuh. Systematic Entomology 41 (1): 3-40.

Nixon K. 1999. The parsimony ratchet, a new method for rapid parsimony analysis. Cladistics 15: 407-414.

Penz, C.M., A.V.L. Freitas, L.A. Kaminski, M.M. Casagrande, and P.J. Devries. 2013. Adult and early-stage characters of Brassolini contain conflicting phylogenetic signal (Lepidoptera, Nymphalidae). Systematic Entomology 38: 316-333.

Poppius, B. 1911. Beiträge zur Kenntnis der MiridenFauna von Ceylon. Öfversigt af Finska Vetenskapssocietetens Förhandlingar 53A (2): 1-36.

Poppius, B. 1912. Die Miriden der Äthiopischen Region I Mirina, Cylapina, Bryocorina. Acta Societatis Scientiarum Fennicae 41 (3): 1-203.

Poppius, B. 1914. Zur Kenntnis der Miriden, Anthocoriden und Nabiden Javas und Sumatras. Tijdschrift voor Entomologie (suppl.) 56: 100-187.

Poppius, B. 1915a. Neue orientalische Bryocorinen. Philippine Journal of Science 10: 75-88.

Poppius, B. 1915b. H. Sauter's Formosa-Ausbeute: Nabidae, Anthocoridae, Termatophylidae, Miridae, Isometopidae und Ceratocombidae (Hemiptera). Archiv fur Naturgeschichte, 80A (8): 1-80 (1914).

Reinert, J.F., R.E. Harbach, and I.J. Kitching. 2009. Phylogeny and the calssification of the tribe Aedini (Diptera: Culicidae). Zoological Journal of the Linnean Society 150: 700-794.

Reuter, O.M. 1904. Ad cognitionem Capsidarum Australiae. Öfversigt af Finska Vetenskapssocietetens Förhandlingar 47 (5): 1-16.

Reuter, O.M. 1908. Capsidae Javanicae novae vel minus cognitae. Annalen des Naturhistorisches Hofmuseums Wien 22: 187-189 (1907).

Reuter, O.M. 1910. Neue Beiträge zur Phylogenie und Systematik der Miriden nebst einleitenden Bemerkungen über die Phylogenie der Heteropteren-Familien. Mit einer Stammbaumstafel. Acta Societatis Scientiarum Fennicae 37 (3): iv, 1-167.

Schneider, H. 2016. The ghost of the Cretaceous terrestrial revolution in the evolution of fern-sawfly associations. Journal of Systematics and Evolution 54 (2): 93-103.

Schuh, R.T. 1995. Plant bugs of the World (Heteroptera: Miridae): systematic catalog, distributions, host list, and bibliography. New York: New York Entomological Society. 
Schuh, R.T. 2002-2013. On-line systematic catalog of plant bugs (Insecta: Heteroptera: Miridae) (http:// research.amnh.org/pbi/catalog), accessed August $11,2015$.

Schuh, R.T., and G.M. Stonedahl. 1986. Historical biogeography in the Indo-Pacific: a cladistic approach. Cladistics 2 (4): 337-355.

Schwartz, M.D. 2011. Revision and phylogenetic analysis of the North American genus Slaterocoris Wagner with new synonymy, the description of five new species and a new genus from Mexico, and a review of the genus Scalponotatus Kelton (Heteroptera, Miridae, Orthotylinae). Bulletin of the American Museum of Natural History 354: 1-290.

Stonedahl, G.M. 1991. The Oriental species of Helopeltis (Heteroptera: Miridae): a review of economic literature and guide to identification. Bulletin of Entomological Research 81: 465-490.

Tatarnic, N.J., and G. Cassis. 2010. Sexual coevolution in the traumatically inseminating plant bug genus Coridromius. Journal of Evolutionary Biology 23: 1321-1326.

Usinger, R.L. 1946. Hemiptera Heteroptera of Guam. In Insects of Guam, II. Bulletin of the Bishop Museum 189: 11-103.
Valdez-Mondragón, A. 2013. Morphological phylogenetic analysis of the spider genus "Physocyclus" (Araneae: Pholcidae). Journal of Arachnology 41 (2): 184-196.

Valdez-Mondragón, A. 2014. A reanalysis of the morphological phylogeny of the spider genus Physocyclus Simon (Araneae: Pholcidae) with the description of a new species and description of the female of Physocyclus paredesi Valdez-Mondragon from Mexico. Zootaxa 3866: 202-220.

Weintraub, J.D., J.H. Lawton, and M.J. Scoble. 1995. Lithinine moths on ferns: a phylogenetic study of insect-plant interactions. Biological Journal of the Linnean Society 55: 239-250.

Wheeler, A.G., Jr., G.L. Miller, and T.J. Henry. 1979. Biology and habits of Macrolophus tenuicornis (Hemiptera: Miridae) on hayscented fern (Ptendophyta: Polypodiaceae). Melsheimer Entomololgical Series 27: 11-17.

Woodward, T.E. 1954. On the genus Felisacus Distant (Heteroptera; Miridae; Bryocorinae). Pacific Science 8: 41-50.

Woodward, T.E. 1958. Further notes on Felisacus Distant (Heteroptera; Miridae; Bryocorinae). Pacific Science 12: 236-240. 


\section{APPENDIX 1}

\section{Characters and Character States Used in the Phylogenetic Analysis}

\section{Head}

0 Dorsal side of head posteriorly: $\mathbf{0}$, flat (Namyatova et al., in press: fig. 6E); 1, at least slightly swollen (Namyatova et al., in press: fig. 6D). Most of the Felisacus species have swollen group; in outgroup both states occur.

1 Longitudinal depression on dorsal side of head: $\mathbf{0}$, absent or very shallow; $\mathbf{1}$, distinctly shorter than eye diameter; 2 , as long as or longer than eye diameter (Namyatova et al., in press: fig. 4E). In Felisacus states 1 and 2 are present; in outgroup species states 0 and 1 occur.

2 Transversal depression, delimiting occipital region: $\mathbf{0}$, absent or very shallow; $\mathbf{1}$, distinct only dorsally between eyes; 2, distinct, surrounding neck. In Felisacus states 1 and 2 are present; in outgroup states 0 and 2 occur.

3 Distance between transversal depression and pronotum: $\mathbf{0}$, distinctly shorter than eye diameter; $\mathbf{1}$, as long as or longer than eye diameter. This character was not coded for Stenotus binotatus and Nesidiocoris tenuis, where transversal depression is absent. State 0 is present in most of the Felisacus species as well as in Pachypeltis reuteri.

4 Bucculae shape posteriorly: $\mathbf{0}$, not merged posteriorly (Namyatova et al., in press: fig. 6A, G); 1, merged posteriorly (Namyatova et al., in press: fig. 6D, E). Buccula are merged posteriorly in all species of Felisacus. It is not merged in species included in the outgroup in this analysis, however, within subfamily Bryocorinae it is also merged in the tribe Bryocorini (Namyatova et al., in press: fig. 6F).

5 Antennal segment I shape: $\mathbf{0}$, straight (Namyatova et al., in press: fig. 8A); 1 , widened basally or medially (Namyatova et al., in press: fig. 8B). In Felisacus, as well as in outgroup species, both states occur.

6 Labial segment I length: $\mathbf{0}$, shorter or as long as width (Namyatova et al., in press: fig. 6D, E); 1, elongate, twice as long as wide; 2 , elongate, more than twice as long as wide (Namyatova et al., in press: fig. 9A, E). In most species of Felisacus state 0 is present, except for F. curvatus, F. philippinensis, and $F$. wangae which possess the state 1 . In outgroup only state 2 is present.
7 Labial segment II length: $\mathbf{0}$, shorter than width, as long as wide, or only slightly longer than wide (Namyatova et al., in press: fig. 6D, E); 1, elongate, distinctly longer than wide (Namyatova et al., in press: fig. 9A, E). In most species of Felisacus state 0 is present, except for $F$. curvatus and $F$. wangae, which possess the state 1 . In outgroup only state 1 is present.

8 Dorsal side of labial segment II shape: $\mathbf{0}$, not elongate dorsally (Namyatova et al., in press: fig. 6E); 1, elongate dorsally (Namyatova et al., in press: fig. 6D). In Felisacus species both states are present; in outgroup species only state 0 occurs.

9 Labial segment III relative length: 0, distinctly shorter than ventral side of head; $\mathbf{1}$, subequal or longer to ventral side of head (Namyatova et al., in press: fig. 9C). In Felisacus and outgroup species both states occur.

10 Labial segment IV relative length: $\mathbf{0}$, as long as segment III; 1, distinctly longer than segment III. State 1 is present in Felisacus and Pachypeltis reuteri.

\section{Thorax}

11 Calli position: 0, separate; 1, fused (Namyatova et al., in press: fig. 4A, E). Calli fused in all species of Felisacus. Within outgroup species they are fused only in Pachypeltis reuteri.

12 Callosite region delimitation: $\mathbf{0}$, not delimited; 1, delimited (Namyatova et al., in press: fig. 4A, E). State 1 is present in all species of Felisacus and Pachypeltus reuteri.

13 Punctures on sulcus between mesoscutum and scutellum occurrence: $\mathbf{0}$, absent; $\mathbf{1}$, present. State 1 is present in all species of Felisacus and Pachypeltus reuteri.

14 Posterior part of pronotum coloration: 0, yellow to pale brown, sometimes dark brown with yellow to pale brown stripe; $\mathbf{1}$, mostly yellow to pale brown, with stripe along posterior margin; 2, uniformly brown to black. In Felisacus all states are present, but state 0 is most common. In ougroups species only state 0 is present.

15 Suture between meso- and metapleuron: 0, inferiorly obsolete, mesepimeron and metepisternum fused ventrad to metathoracic spiracle (Namyatova et al., in press: fig. 14A, B); 1, complete (Namyatova et al., in press: fig. 14C). The state 0 is present in Felisacus and Pachypeltis reuteri. In outgroup species state 1 is present. Within Bryocorinae in all Monaloniini the suture between meso- and metapleuron inferiorly obsolete (see Namyatova et al., in press). 
16 Setae on hemelytron density: 0, present only anteriorly; 1, present, covering entire hemelytron. The state 0 is present in all Felisacus species, all outgroup species state 1 occurs.

17 Row of punctures on clavus occurrence: $\mathbf{0}$, absent (Namyatova et al., in press: fig. 12C); 1, present (Namyatova et al., in press: fig. 11A, C). State 1 is present in Felisacus and Pachypeltis reuteri.

18 Inner part of clavus colouration: $\mathbf{0}$, whitish yellow to pale brown, usually transparent; $\mathbf{1}$, brown to black, usually matt. In Felisacus and outgroup species both states are present.

19 Corial fracture length: 0, short, almost indistinct (Namyatova et al., in press: fig. 11A); 1, long, distinct, usually reaching posterior part of corium (as in Namyatova et al., in press: fig. 12A). The state 0 is present in all species of Felisacus and Nesidiocoris tenuis.

20 Inner margin of cuneus shape: $\mathbf{0}$, straight (Namyatova et al., in press: fig. 13A, F); 1, convex (Namyatova et al., in press: fig. 13E, G). In Felisacus and outgroup species both states are present.

21 C-shaped marking on hemelytron occurrence: $\mathbf{0}$, absent; 1 , present. C-shaped marking on hemelytron is present in some Felisacus species.

22 C-shaped marking on corium shape: $\mathbf{0}$, both arms reaching or almost reaching $\mathrm{R}+\mathrm{M} ; \mathbf{1}$, with anterior arm far not reaching $\mathrm{R}+\mathrm{M} ; 2$, without anterior arm. This character was not coded for those species which do not have c-shaped marking (see char. 21). State 1 is present in F. cristobalus and F. fedori, state 2 is present in F. curvatus and F. luzonus.

23 Tarsus shape: 0, straight (Namyatova et al., in press: fig. 19F); 1, incrassate apically (Namyatova et al., in press: fig. 19A, C). State 1 is present in all Felisacus species and Pachypeltis reuteri. This state is present in all Bryocorinae except of Dicyphinae (see Cassis, 1984; Namyatova et al., in press).

24 Parempodia symmetry: 0, symmetrical (Namyatova et al., in press: fig. 20D, F); 1, asymmetrical (Namyatova et al., in press: fig. 20A, C). Among the species in the analysis, parempodia are asymmetric in Felisacus only. They are also asymmetrical in Eccritotarsini and some groups of Cylapainae (see Namyatova et al., in press).

\section{Male genitalia}

25 Right side of genital capsule shape: $\mathbf{0}$, not folded (e.g., fig. 14A, B, E, X); 1, folded (e.g., fig. 14V, Y). State 1 is present in some species of Felisacus.
26 Small tooth on posterior margin of genital capsule occurrence: 0, absent; 1, present (e.g., fig. 14T, V, Y). State 1 is present in some species of Felisacus.

27 Apex of genital capsule direction: 0, directed posteriorly, not curved; 1, directed dorsally, curved (figs. $14 \mathrm{X}, 15 \mathrm{~F}, \mathrm{~L})$. State 1 is present in F. luzonus, F. ovalau, and F. vitilevu.

28 Inner margin of left paramere socket shape: 0, rounded or slightly angulate (e.g., figs. 14A, L, 15K, L0; 1, distinctly angulate (e.g., fig. 14T, V, X). In Felisacus both states are present. In outgroup species only state 0 is present.

29 Relative size of parameres: $\mathbf{0}$, right paramere longer than left one; 1, right paramere shorter than left one. In all Felisacus species state 0 is present; in outgroup species state 1 is present. Within Bryocorinae state 0 is also present in Eccritotarsini.

30 Apex of right paramere shape: $\mathbf{0}$, almost straight or slightly concave; $\mathbf{1}$, distinctly concave (Namyatova et al., in press: fig. $13 \mathrm{~A}, \mathrm{R})$. The 1 is present in $F$. nigrescens and $\mathrm{F}$. solomonicus only.

31 Apical part of right paramere: 0, indistinct (e.g., fig. $11 \mathrm{H}, \mathrm{L}, \mathrm{T}, \mathrm{V})$; 1, distinct (e.g., fig. 11A, C, E, J). In Felisacus both states are present; in outgroup species only state 0 occurs.

32 Apical part of right paramere length: 0, as long as or longer than medial part (e.g., fig. 11A, C, J, P); 1, distinctly shorter than medial part (e.g., figs. 11E, $A B, 12 G, I)$. This character was not coded for those species, where apical part indistinctly delimited (see char. 31). State 1 is present in F. australicus, $F$. fedori, F. javanus, F. lambkinae, F. luzonus, F. ochraceus, and F. senaru.

33 Outer margin of right paramere shape: $\mathbf{0}$, straight, slightly concave or convex (e.g., fig. 11A, C, H); 1, distinctly concave (e.g., figs. 11E, 12G, I); 2, rounded (e.g., figs. $11 \mathrm{~V}, \mathrm{~T}, 12 \mathrm{M}$ ). This character was not coded for Nesidiocoris tenuis and Pachypeltis reuteri, in which right paramere is very small. In Felisacus all states are present; in Stenotus binotatus state 2 is present.

34 Inner margin of middle part of right paramere shape: $\mathbf{0}$, without swelling, straight or concave (e.g., fig. 11R, T, AB); 1, present (e.g., fig. 11A, C, E). This character was not coded for Nesidiocoris tenuis and Pachypeltis reuteri, in which right paramere is very small. In Felisacus all states are present, in Stenotus binotatus state 0 occurs. 
35 Middle part of right paramere width: $\mathbf{0}$, subequal to width of basal part (e.g., fig. 11C, E, H); 1, twice as wide as basal part (e.g., figs. 11A, AF, 12A, C); 2, narrower than basal part (e.g., figs. $11 \mathrm{~L}, \mathrm{AB}, 12 \mathrm{M}$, $\mathrm{W})$. This character was not coded for Nesidiocoris tenuis and Pachypeltis reuteri, in which right paramere is very small. In Felisacus all states are present, in Stenotus binotatus state 1 occurs.

36 Outer angle of right paramere occurrence: $\mathbf{0}$, absent (e.g., figs. 11R, T, AB, 12M); 1, present (e.g., figs. 11A, C, W, 12U).

37 Inner angle of middle part of right paramere occurrence: $\mathbf{0}$, indistinct or rounded (figs. $11 \mathrm{~A}, \mathrm{E}, \mathrm{N}, 12 \mathrm{~A}$, C); 1, present, distinct (e.g., fig. 11R, T, AB). In Felisacus and outgroup species both states occur.

38 Swelling or outgrowth at the inner margin of proximal inflection occurrence: 0, absent (e.g., figs. 11V, $12 \mathrm{U}, 13 \mathrm{G}$ ); 1, present (e.g., figs. 11T, AB, 12M, W). This character was not coded for those species, in which inner angle of middle part of right paramere indistinct or rounded (see char. 38). In Felisacus both states are present.

39 Outgrowth on inner angle of right paramere length: 0, short, in shape of swelling (figs. 11T, $13 \mathrm{AB}) ; 1$, elongate (e.g., figs. $11 \mathrm{AB}, \mathrm{R}, 12 \mathrm{M}$ ). This character was not coded for those species, in which inner angle of middle part of right paramere indistinct or rounded, or present and not swollen (see chars. 37,38 ). State 0 is present in $F$. cristobalus and F. yasunagai.

40 Elongate outgrowth on inner angle of right paramere shape: 0, straight (figs. $11 \mathrm{AB}, 12 \mathrm{M}$ ); 1, curved (figs. $11 \mathrm{R}, 12 \mathrm{Q}, \mathrm{W}, 12 \mathrm{AD})$. This character was coded only for those species, in which outgrowth on inner angle of right paramere elongate (see char. 39). State 0 is present in F. fedori and F. lindbergae.

41 Basal part of right paramere relative length: $\mathbf{0}$, less than $0.3 \times$ as long as rest of paramere (e.g., fig. 11A, $\mathrm{C}, \mathrm{E}) ; \mathbf{1}$, subequal to or longer than half of rest of the paramere (e.g., fig. $11 \mathrm{~N}, \mathrm{R}, \mathrm{T}$ ). This character was not coded for Nesidiocoris tenuis and Pachypeltis reuteri, in which right paramere is very small. In Felisacus both states are present, in Stenotus binotatus state 0 occurs.

42 Setae on right paramere position: $\mathbf{0}$, placed on middle part along inner margin (e.g., fig. 11A, C, E); 1, placed on inner angle (e.g., figs. 11T, AB, 12M, U). This character was not coded for outgroup species, as the position of setae is unclear. In Felisacus both states are present.
43 Outgrowth on posterior side of left paramere apically: 0, absent; 1, present (e.g., fig. 11M, S, U, AC). In Felisacus both states are present; in outgroup species only state 0 is present.

44 Tooth on posterior side of left paramere medially: 0, absent; 1, present (fig. 11G). Within Felisacus both states are present; in outgroup this tooth is always absent.

45 Apical part of left paramere shape: 0, not flattened; $\mathbf{1}$, flattened (figs. $12 \mathrm{~F}, \mathrm{X}, 13 \mathrm{H}, \mathrm{J}$ ). State 1 is present only in F. luzonus, F. magnificus, F. philippinensis, and $F$. ponaponensis.

46 Outer margin of left paramere shape: 0, straight or convex; 1, distinctly concave (figs. 11U, AC, 12R, 13AE). State 1 is present in F. cristobalus, F. fedori, F. longiceps, and F. zuparkoi.

47 Inner margin of left paramere shape: $\mathbf{0}$, without swelling or outgrowth; 1, with single swelling or outgrowth (e.g., figs. 11M, AC, S 13J); 2, with two or three swelling or outgrowths (figs. $12 \mathrm{~V}, 13 \mathrm{H}$ ). In Felisacus all states are presentl in outgroup species only state 0 occurs.

48 Outgrowth on inner margin of left paramere length: 0, short, in shape of rounded swelling (figs. $11 \mathrm{M}, 12 \mathrm{~N}$ ); 1, short, triangular (figs. $11 \mathrm{U}, \mathrm{AC}, 13 \mathrm{AC}, \mathrm{AE}$ ); 2, elongate (figs. 11S, 12R, X). This character was coded only for those species, where single swelling or outgrowth on inner margin of left paramere is present (see char. 47). State 0 occurs in F. bismarckensis and F. lindbergae, state 1 is present in F. cristobalus, $F$. fedori, F. yasunagai, and F. zuparkoi; state 2 is present in F. ceylonicus, F. longiceps, and F. magnificus.

49 Teeth on outgrowth on inner margin of paramere occurrence: 0, absent; 1, present (e.g., figs. 11U, 13J, $\mathrm{AE})$. This character was coded only for those species, where single swelling or outgrowth on inner margin of left paramere is present (see char. 47). State 1 is present only in F. cristobalus, F. ponaponensis, and F. zuparkoi.

50 Outgrowth on dorsal side of apical part of left paramere occurrence: 0, absent; 1, present (e.g., fig. 11S, $\mathrm{U}, \mathrm{AC}$ ). In Felisacus both states are present; in outgroup species this outgrowth absent.

51 Setae on left paramere position: 0, placed mostly near outer margin (e.g., fig. 11B, F, Q); 1, bunch of setae placed on inner margin (fig. 11S, U, AC). This character was not coded for outgroup species, as well as for F. ponaponensis and F. yasunagai, where those setae were not observed. 
52 Distal part of ductus seminis shape and sclerotization: $\mathbf{0}$, entirely membranous; $\mathbf{1}$, only small apical part of ductus seminis sclerotized (e.g., figs. 8-9); 2, at least apical half of ductus seminis sclerotized (e.g., fig. 10C, D, F). In Felisacus states 1 and 2 are present; in outgroup species 0 and 1 occur.

53 Elongate sclerotized part of ductus seminis shape: 0, straight apically (fig. 10A, I, L); 1, curved apically (e.g., fig. 10C, D, F). This character was coded only for those species, in which at least apical half of ductus seminis sclerotized (see char. 52). State 0 is present only in F. bismarckensis, F. luzonus, and F. ponaponensis.

54 Spicule A (convolute, from right-hand side): $\mathbf{0}$, absent; 1, present. In Felisacus both states are present; in outgroup species this spicule is absent.

55 Spicule A shape: 0, curved (e.g., fig. 8C-F); 1, almost straight (fig. 9B, C). This state was coded only for those species, in which spicule A is present (see char. 54). State 1 occurs only in F. meilingae and F. myersi.

56 Spicule $B$ (curved right side): 0, absent; 1, present (e.g., fig. 8A-C). In Felisacus both states are present; in outgroup species this spicule is absent.

57 Apical arm of spicule $B$ shape: 0, almost straight or slightly curved and not very long (e.g., fig. 8A, B, E, $\mathrm{G}$ ); 1, present, long (figs. 8C, F, 9F). This state was coded only for those species, in which spicule B is present (see char. 56). State 1 is present only in $F$. australicus, F. caledonicus, and F. ochraceus.

58 Spicules $C$ (convolute from left-hand side) occurrence: 0, absent; 1, present (e.g., fig. 8B-D). In Felisacus both states are present; in outgroup species this spicule is absent.

59 Spicule C base position: 0, approximately at the same level with other spicules (e.g., fig. 9A-C); 1, distinctly moved distally (figs. 8B, D, P, 9I). This state was coded only for those species, in which spicule B is present (see char. 58). State 1 is present in F. amboinae, F. bau, F. linae, and F. senaru.

60 Spicule D (small, placed at base) occurrence: 0, absent; 1, present (fig. 9B, C). This spicule is present only in F. meilingae and F. myersi.

61 Spicule E (weakly sclerotized, from right-hand side) occurrence: 0, absent; 1, present (figs. 8I, R, 9M). State 1 is present in F. filicicola, F. lorhowensis, and F. tanna.
62 Spicule I (convolute basally, placed close to middle line) occurrence: $\mathbf{0}$, absent; 1, present (fig. 9B, C). This spicule is present only in F. meilingae and F. myersi.

63 Spicule F (long, needle shaped, placed from left-hand side) occurrence: $\mathbf{0}$, absent; $\mathbf{1}$, present (fig. 8A, J, K, L). This spicule is present in F. albus, F. glabratus, F. indicus, and F. insularis.

64 Spicule G (long, wide and concave, placed from lefthand side) occurrence: $\mathbf{0}$, absent; $\mathbf{1}$, present (figs. $8 \mathrm{E}$, I, 9B, C). This spicule is present only in F. bellus, F. filicicola, F. meilingae, and F. myersi.

65 Spicule $H$ (hook shaped, middle-sized[[?]], placed from left-hand side) occurrence: $\mathbf{0}$, absent; $\mathbf{1}$, present (figs. 8C, 9F). This spicule is present only in F. australicus and F. ochraceus.

66 Distinct teeth on spicules or vesica occurrence: $\mathbf{0}$, absent; 1, present (figs. 9G, N, 10B, E, M). State 1 is present in F. bradi, F. ovalau, F. vitilevu, Nesiciodcoris tenuis, and Stenotus binotatus.

\section{Female genitalia}

67 Dorsal labiate plate size: 0 , wider than distance between valvula apodemes (fig. 16C, I, L, N); 1, very small, entirely placed between valvula apodemes (fig. 16A, E, G, K). In Felisacus both states are present; in outgroup species only state 0 is present.

68 Semioval sclerite on dorsal labiate plate occurrence: $\mathbf{0}$, absent; 1, present (fig. 16C, I). In Felisacus both states are present; in outgroup species only state 0 occurs.

69 Sclerotized rings on dorsal labiate plate occurrence: 0, absent (fig. 16A, E, G, K, N); 1, present (fig. 16C, I). In Felisacus both states are present; in outgroup species only state 1 occurs.

70 Striation on dorsal labiate plate occurrence: 0, absent; 1, present (fig. 16C, L, N). State 1 is present only in F. bradi, F. curvatus and F. wangae.

71 Spermathecal gland position: 0, placed medially or posteriorly of dorsal labiate plate (fig. 16I, L, N); 1, placed at the anterior margin of dorsal labiate plate (fig. 16A, E, G). In Felisacus both states are present; in outgroup species only state 0 occurs.

The associated Data Matrix can be viewed at http://dx.doi.org/10.5531/sd.sp.22 as a .nex file, a format currently supported by the Mesquite Project. 


\title{
Scientific Publications of the American Museum of Natural History
}

AMERICAN MUSEUM NOVITATES

Bulletin of the American Museum of Natural history

anthropological Papers of the American Museum of Natural History

\author{
Publications Committee \\ ROBERT S. VOSS, CHAIR \\ BOARD OF EDITORS \\ Jin Meng, Paleontology \\ LORENZO PRENDINI, INVERTEBRATE ZOOLOGY \\ Robert S. Voss, Vertebrate ZoOlogy \\ Peter M. Whiteley, Anthropology \\ MANAGING EDITOR \\ MARY KNIGHT
}

Submission procedures can be found at http://research.amnh.org/scipubs

All issues of Novitates and Bulletin are available on the web (http://digitallibrary.amnh. org/dspace). Order printed copies on the web from:

http://shop.amnh.org/a701/shop-by-category/books/scientific-publications.html

or via standard mail from:

American Museum of Natural History_Scientific Publications

Central Park West at 79th Street

New York, NY 10024

(0) This paper meets the requirements of ANSI/NISO Z39.48-1992 (permanence of paper).

on the cover: Male specimen of felisacus senaru, NEW SPECIES. 